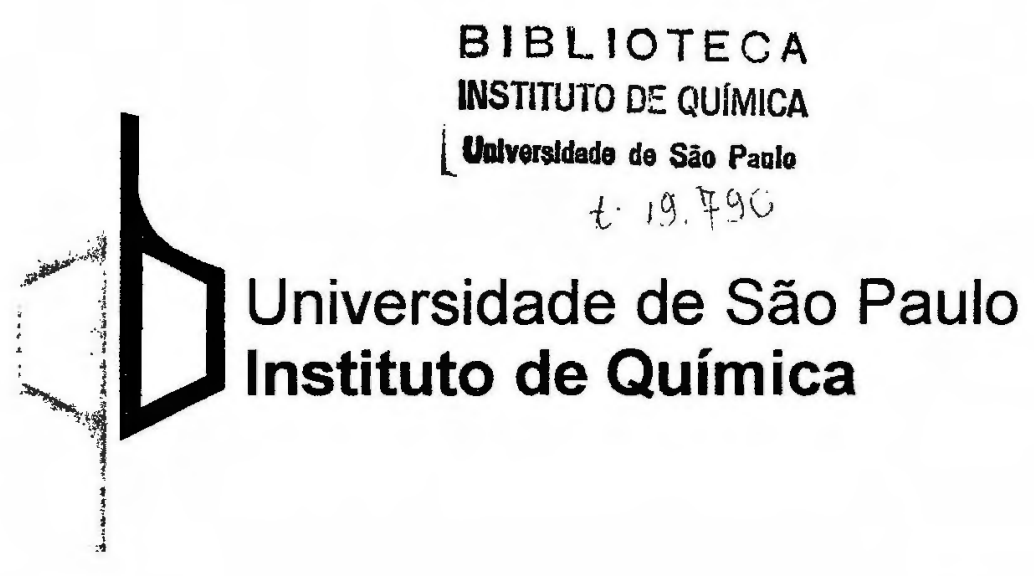

- DisSERTAÇÃo DE MESTRADO -

\title{
Estudo Espectroeletroquímico de Polianilinas Substituídas: Processabilidade dos Materiais Puros e seus Copolímeros
}

Aluna: Andréia Leal Schemid
Orientadora: Profa. Dra. Susana Inés Córdoba de Torresi 


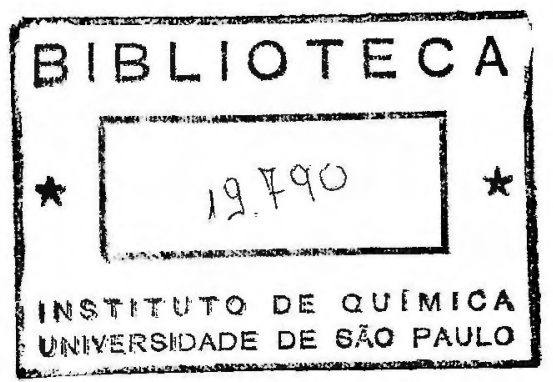

Ficha Catalográfica

Elaborada pela Divisão de Biblioteca e

Documentação do Conjunto das Químicas da USP.

\footnotetext{
Schemid, Andréia Leal

S423e Estudo espectroeletroquímico de polianilinas substituídas: processabilidade dos materiais puros e seus copolímeros / Andréia Leal Schemid. -- São Paulo, 2001. $109 \mathrm{p}$.

Dissertação (mestrado) - Instituto de Química da Universidade de São Paulo. Departamento de Química Fundamental.

Orientador : Córdoba de Torresi, Susana Inés

1. Eletroquímica I. T. II. Córdoba de Torresi, Susana Inés, orientador.
} 


\section{"Estudo Espectroeletroquímico de Polianilinas Substituídas: Processabilidade dos Materiais Puros e seus Copolímeros"}

\section{ANDRÉIA LEALL SCHEMID}

Dissertação de Mestrado submetida ao Instituto de Química da Universidade de São Paulo como parte dos requisitos necessários à obtenção do grau de Mestre em Ciências - Área: Físico-Química.

Aprovado por:

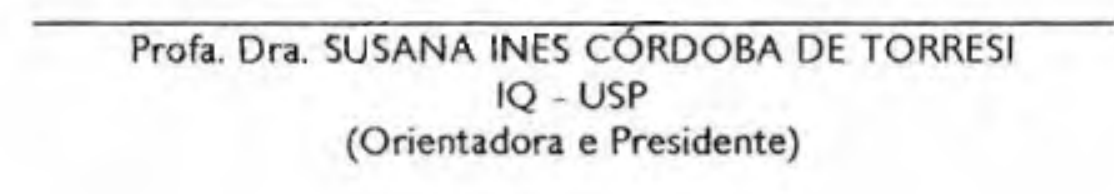

Prof. Dr. ARTUR DE JESUS MOTHEO

IQ SC - USP

Profa. Dra. SILMARA DAS NEVES

USF 
Aos amigos... 


\section{Agradecimentos}

Agradeço a todos aqueles que de alguma maneira contribuiram para o desenvolvimento deste trabalho.

À Profá. Drá. Susana I. Córdoba de Torresi pela paciência e auxilio para comigo durante a realização deste trabalho.

À Profa. Dra. Márcia L. A. Temperini e ao laboratório de Espectroscopia Molecular pela utilização do Renishaw Raman Imaging Microscope, e também de suas instalações, quando nosso laboratório estava em reforma.

Ao Prof. Dr. Roberto Torresi do Instituto de Química da USP - São Carlos pela utilização da microbalança de cristal de quartzo.

Ao Prof. Dr. Yoshio Kawano pelo auxílio na obtenção de curvas DSC.

Aos meus colegas do laboratório de Materiais Eletroativos pela amizade, em particular ao Luiz Marcos pela assistência em algumas medidas, e à Kellie pelo carinho. Aos meus colegas de outros laboratórios pela convivência agradável e enriquecedora.

Aos meus amigos Eliana e Ramon pelo apoio e incentivo.

Ao meu amado companheiro Marcelo pela ajuda e carinho quando eu mais precisei.

Aos meus pais, e familiares que me ajudaram.

Aos funcionários do IQ-USP.

À FAPESP pelo auxilio financeiro para a realização deste trabalho. 


\section{Índice}

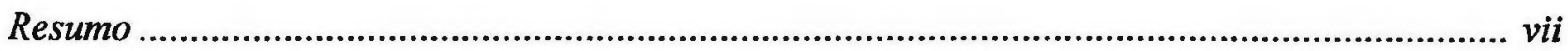

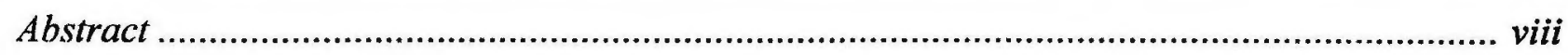

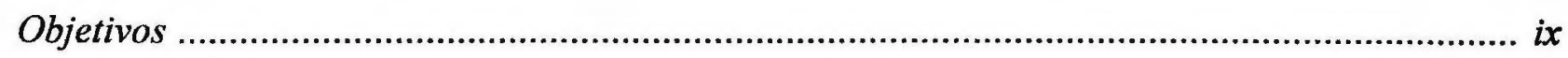

1. Introdução ............................................................................................................ 1

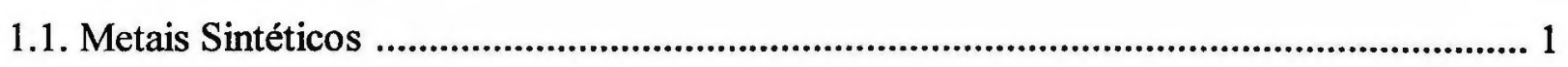

1.1.1. Polímeros Condutores ................................................................................. 3

1.1.1.1. Dopagem Primária .......................................................................... 4

1.1.1.2. Dopagem Secundária ................................................................. 6

1.1.1.3. Condutividade dos Polímeros Condutores ............................................ 6

1.1.1.4. Síntese dos Polímeros Condutores ................................................ 10

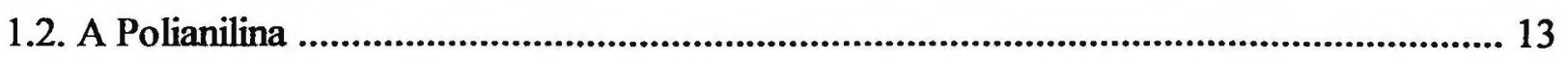

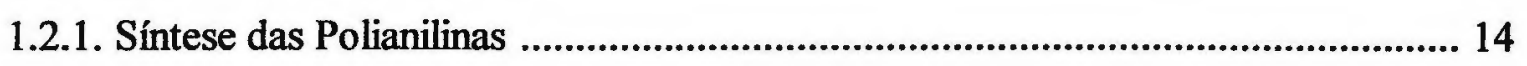

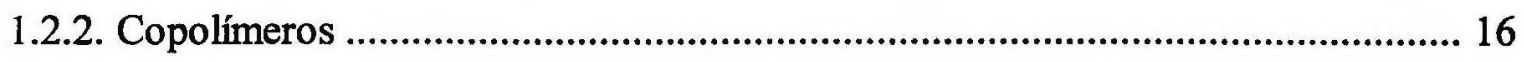




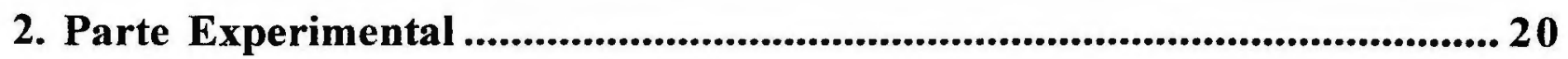

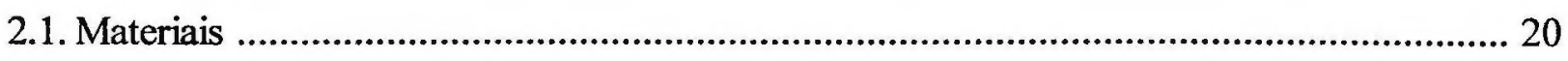

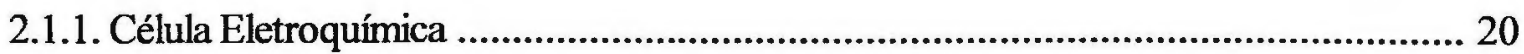

2.1.1.1. Eletrodos de Trabalho ............................................................................ 21

2.1.1.2. Eletrodos de Referência ............................................................................. 22

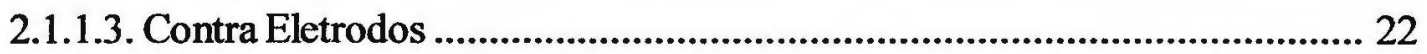

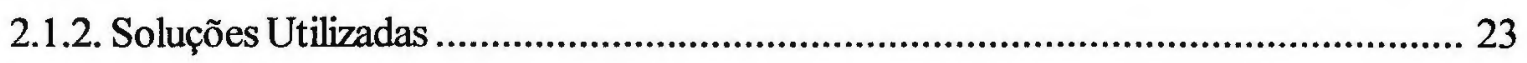

2.1.2.1. Soluções Eletrolíticas ............................................................................... 23

2.1.2.2. Soluções para Síntese Química ................................................................. 24

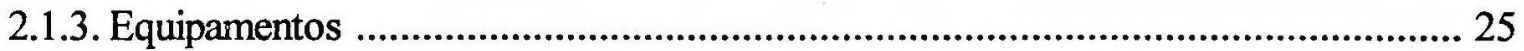

2.2. Metodologias Experimentais ............................................................................................ 25

2.2.1. Eletroquímica ………………………................................................................. 25

2.2.1.1 Estudo Voltamétrico do Substrato …….................................................... 28

2.2.1.2 Síntese Eletroquímica dos Polímeros ............................................................ 28

2.2.2. Espectroeletroquímica e Espectroscopia UV-Vis ................................................ 30

2.2.2.1 Caracterização Espectroeletroquímica dos Polímeros ................................. 32

2.2.3. Medidas Eletrogravimétricas ............................................................................. 33

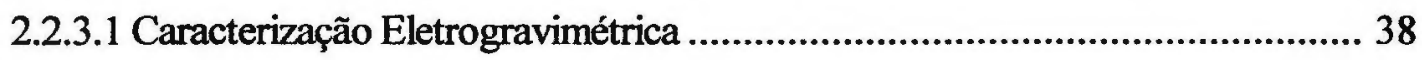

2.2.4. Síntese Química dos Polímeros ............................................................................. 39

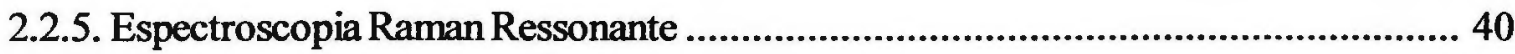

2.2.5.1 Caracterização por Raman Ressonante ....................................................... 43

2.2.6. Medidas de Condutividade Elétrica ....................................................................... 44

2.2.6.1 Medidas de Condutividade AC .............................................................. 47

2.2.7. Solubilidade dos Polímeros ..................................................................................... 48 
3.1. Síntese Eletroquímica e Química ....................................................................... 50

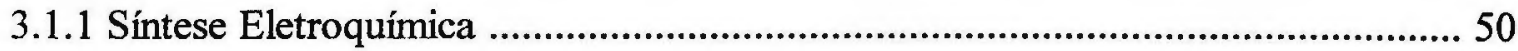

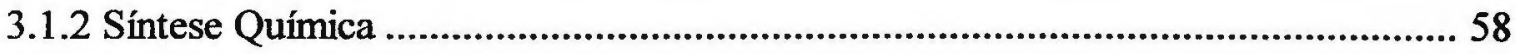

3.2. Caracterização dos Polímeros .......................................................................... 58

3.2.1 Caracterização Eletroquímica ................................................................. 58

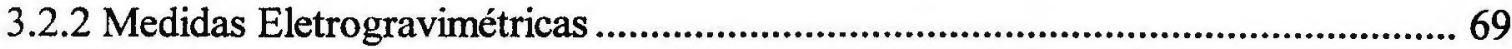

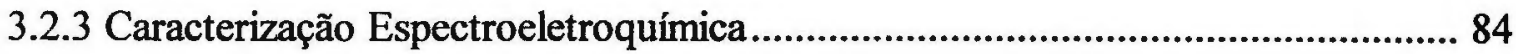

3.2.4 Caracterização por Raman Ressonante .......................................................... 90

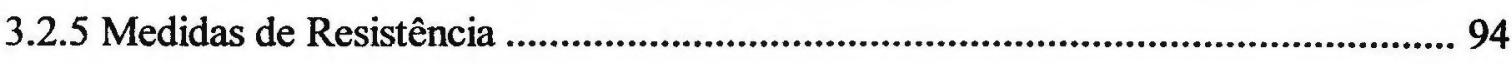

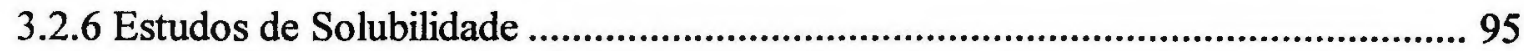

4. Conclusões ........................................................................................................... 97

5. Referências ....................................................................................................... 99

Curriculum Vitae ...................................................................................... 108 


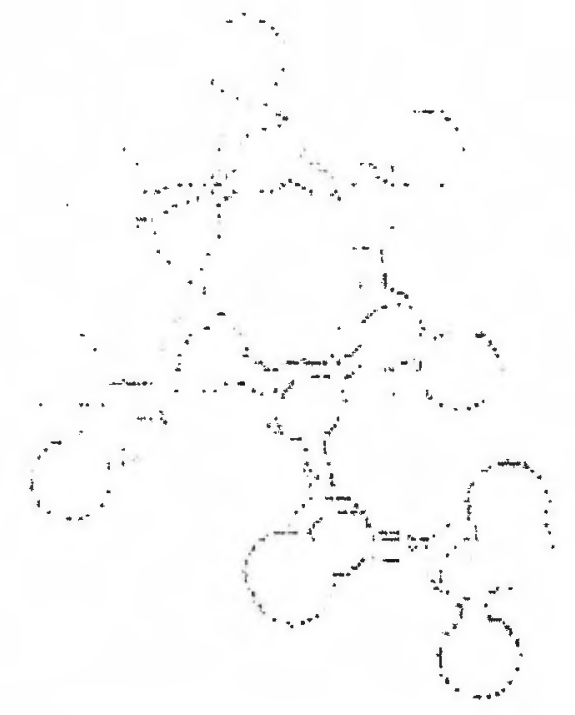

\section{Resumo}

Nos últimos anos a pesquisa em polímeros condutores intensificou-se consideravelmente, particularmente o estudo de polímeros aromáticos. Dentre estes polímeros, a polianilina (PANI) é um dos polímeros condutores mais estudados devido à sua estabilidade química, além de possuir interessantes propriedades ópticas e eletroquímicas. Propriedades estas, que tornam a polianilina um bom material para diversas aplicações tecnológicas, dentre as quais: baterias recarregáveis, proteção contra a corrosão, diodos emissores de luz, sensores moleculares, dispositivos eletrocrômicos, etc.

Porém a processabilidade térmica e a solubilidade da polianilina é limitada, devido à rigidez de sua cadeia polimérica. Consequentemente, qualquer processo pós-síntese torna-se difícil e por isso muitos estudos estão sendo realizados recentemente visando eliminar estes problemas.

A introdução de substituintes alquílicos na cadeia polimérica pode melhorar a solubilidade da polianilina, no entanto sua condutividade elétrica é menor. A condutividade da polianilina, combinada à solubilidade de polianilinas substituídas pode ser conseguida através de copolimerização. Estes copolímeros de anilina e anilinas substituídas são mais solúveis em solventes comuns, enquanto mantêm alta condutividade elétrica. Tanto a solubilidade quanto a condutividade podem ser controladas pela variação da composição do copolímero.

A primeira etapa no estudo dos copolímeros é entender o comportamento de seus homopolímeros. Por isso um estudo comparativo da resposta espectroeletroquímica e eletrogravimétrica dos homopolímeros (polianilina e poli(2-etilanilina)) foi realizado.

Uma série de copolímeros, poli(anilina-co-2-etilanilina), foi preparada tanto por via química, quanto eletroquímica. Estes copolímeros foram caracterizados utilizando métodos eletroquímicos, eletrogravimétricos e espectroscópicos; sendo que medidas de condutividade e testes de solubilidade também foram realizadas. 


\section{Abstract}

The research in electroative polymers in the past few years has received considerable attention, in particular aromatic polymers. Among these polymers, polyaniline (PANI) has been one of the most widely studied conducting polymers because of its optical and electrochemical properties, which can be used in many applications, including rechargeable batteries, corrosion protection, light emitting diodes, molecular sensors, electrochromic devices, etc, and due to its chemical and oxidative stability.

However, as it is common with other conjugated polymers, polyaniline is limited by poor thermal processability and solvent solubility, due to the stiffness of its backbone. Consequently, their post-synthesis processability is quite difficult, and a lot of work has been done recently to overcome this problem.

Improved solubility can be achieved by introducing bulky alkyl substituents into the polyaniline backbone, but limitations are then imposed on the conductivity of the polymer produced. The conductivity of polyaniline and the solubility of substituted polyanilines can be achieved by copolymerization. These copolymers of aniline and substituted anilines show improved solvent solubility, while maintaining high electrical conductivity which can be readily tailored by varying the composition of the copolymer.

The understanding of the behaviour of the homopolymers is a fundamental step to understand the copolymer. For this reason a comparative study of the spectroelectrochemical and electrogravimetric response of the homopolymers (polyaniline and poly(2-ethylaniline)) was performed.

A series of poly(aniline-co-2-ethylaniline) copolymers was prepared by chemical and electrochemical methods. Those copolymers have been characterised by electrochemical, electrogravimetric and spectroscopic methods; conductivity measurements and solubility tests being also reported. 


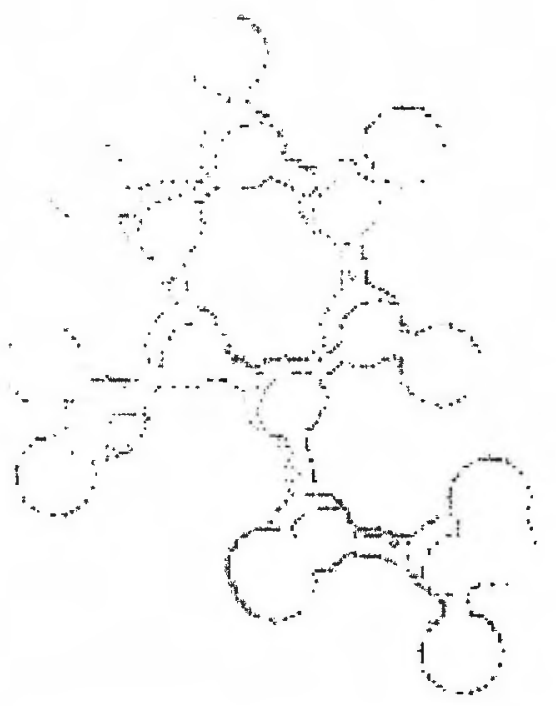

\section{Objetivos}

Síntese química de polianilinas substituídas em diferentes posições, como no anele no nitrogênio.

Síntese eletroquímica de filmes de polianilinas substituídas em diferentes posições, como no anel e no nitrogênio.

Preparação de copolímeros de anilina com anilinas substituídas visando obter melhores propriedades, como melhor processabilidade e condutividade.

Caracterização eletroquímica e espectroeletroquímica em diferentes eletrólitos de filmes de polianilinas substituídas e dos copolímeros obtidos.

Estudos eletrogravimétricos em diferentes eletrólitos de filmes de polianilinas substituídas e dos copolímeros obtidos.

Caracterização espectroeletroquímica por Raman Ressonante "ex-situ" visando o estudo das estruturas presente nos copolímeros sintetizados.

Medidas de condutividade dos copolímeros obtidos em função de sua composição.

Procura de diferentes solventes com o intuito de melhorar a processabilidade dos copolímeros formados. 


\section{Introdução}

\subsection{Metais Sintéticos}

O desenvolvimento de novos materiais que possuem propriedades ópticas, mecânicas e eletrônicas únicas, é de grande interesse para a sociedade. Uma nova química de materiais vem se desenvolvendo de forma à combinar algumas propriedades de materiais poliméricos, metálicos $\mathrm{e}$ cerâmicos.

Durante a década de 60 foram sintetizados os primeiros metais sintéticos, materiais cuja condutividade é maior que $1,0 \mathrm{Scm}^{-1}$. A Figura 1.1 mostra a condutividade de alguns destes materiais.

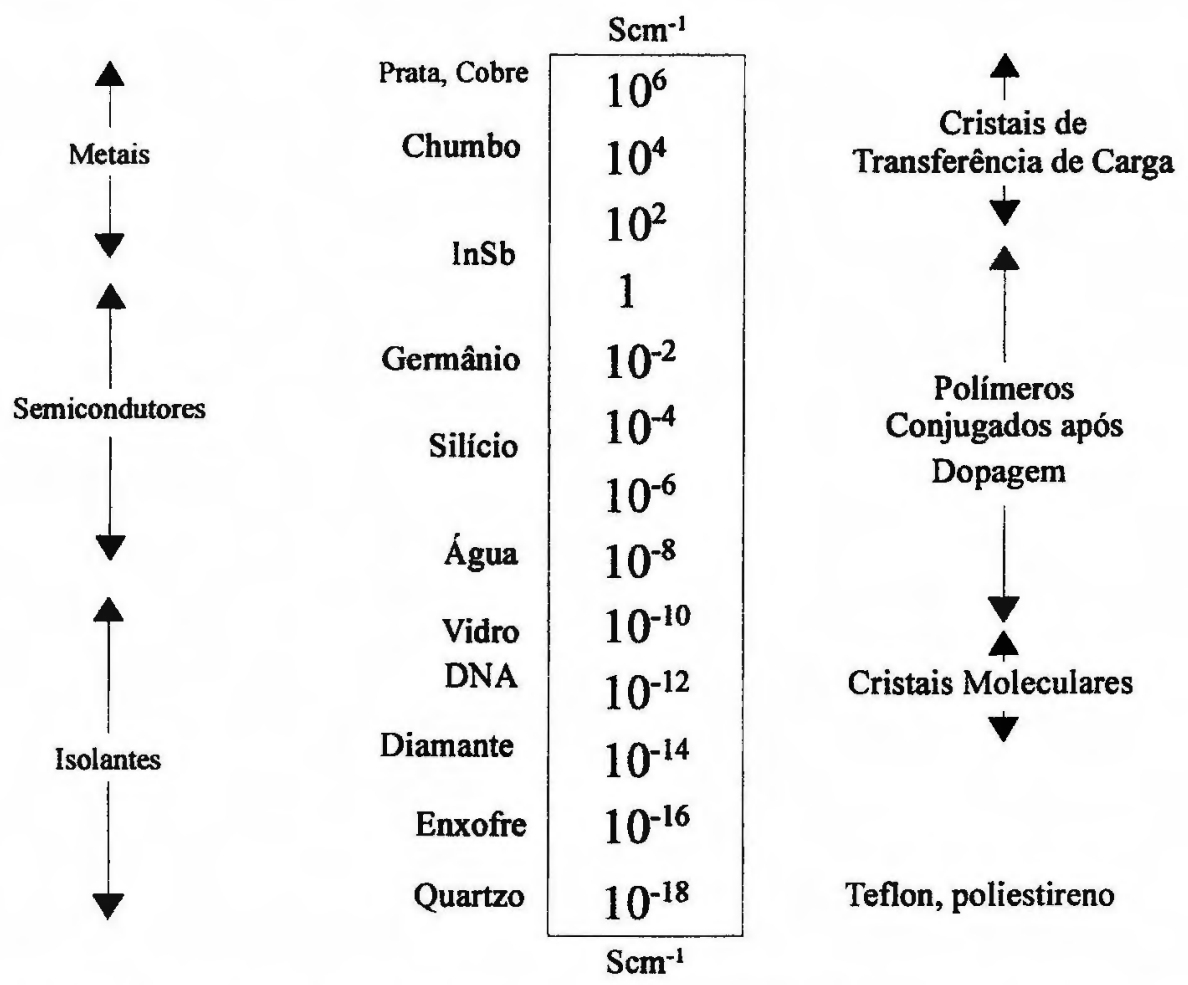

Figura 1.1: Valores de condutividade de alguns polímeros orgânicos, cristais moleculares e sólidos inorgânicos. 
Os primeiros compostos moleculares encontrados que possuíam condutividade próxima à de metais foram os chamados sais de Krogman [1-2]. Estes sais são complexos quadrado planares contendo camadas de unidades $\mathrm{PtX}_{4}$ ou $\mathrm{IrX} \mathrm{X}_{4}\left(\mathrm{X}=\mathrm{CN}\right.$ ou $\left.\mathrm{C}_{2} \mathrm{O}_{4}\right)$ presas por uma cadeia formada por átomos centrais de Pt ou Ir (Figura 1.2). A condutividade destes sais se deve à sobreposição

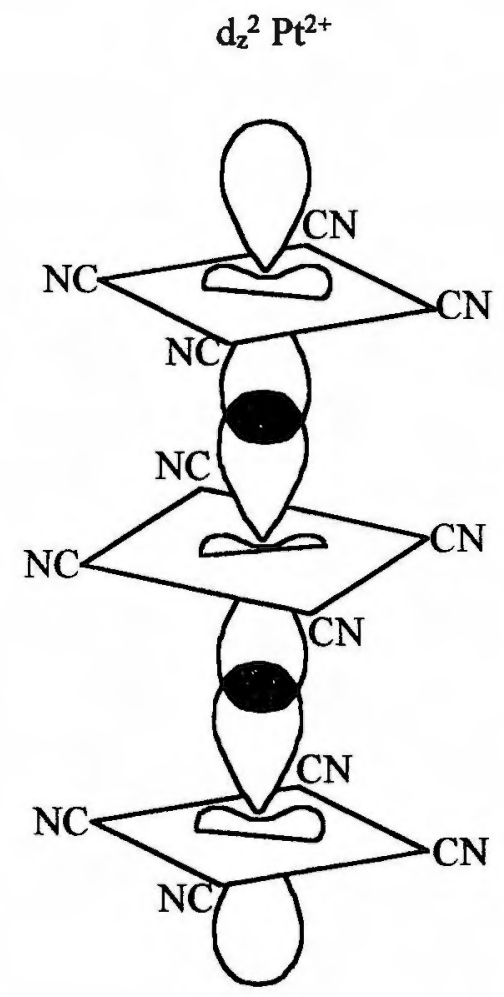

Figura 1.2 : Complexo de platina e cianeto. dos orbitais $d z^{2}$ dos átomos vizinhos de platina ou irídio, formando uma banda de condução. Esta condução pode ser ainda maior quando ocorre a oxidação de parte dos átomos metálicos, passando de semicondutor $\left(10^{-7} \mathrm{Scm}^{-1}\right)$ para condutor $\left(10^{2} \mathrm{Scm}^{-1}\right)$, porém esta condutividade elétrica é altamente anisotrópica, sendo $10^{5} \mathrm{Scm}^{-1}$ maior na direção da cadeia metálica.

A condutividade elétrica destes compostos em cadeia depende de dois fatores. Primeiro, é necessário uma interação ou sobreposição dos orbitais moleculares para que ocorra a formação de orbitais moleculares deslocalizados. Em seguida, é necessário que estes orbitais moleculares deslocalizados estejam parcialmente cheios, desta maneira os elétrons podem se mover quase livremente através da cadeia. $O$ estado eletrônico dos orbitais $p$ e $d$ de hetero-átomos e de elétrons $\pi$ de moléculas orgânicas insaturadas é propício para que haja a devida sobreposição de orbitais, e consequentemente ocorra condutividade elétrica.

Complexos de transferência de carga formam a próxima classe de substâncias moleculares que apresentam condutividade elétrica, como o tetratiofulvaleno (TTF), tetracianoquinodimetano (TCNQ) e seus derivados, que são os complexos deste tipo mais estudados (Figura 1.3).

Doador<smiles>C1=CSC(=C2SC=CS2)S1</smiles>

TTF
Receptor<smiles>N#CC(C#N)=c1ccc(=C(C#N)C#N)cc1</smiles>

TCNQ

Figura 1.3: Tetratiofulvaleno (TTF) e tetracianoquinodimetano (TCNQ). 
Uma camada de moléculas de TTF e TCNQ, com transferência de carga parcial entre eles, possui condutividade maior que $10^{3} \mathrm{Scm}^{-1}$ à $300 \mathrm{~K}$, aumentando com a diminuição de temperatura até $60 \mathrm{~K}[3]$.

Os polímeros condutores formam a terceira maior classe de condutores moleculares. $O$ primeiro exemplar descoberto foi um polímero inorgânico composto de enxofre e nitrogênio (Figura 1.4.) Chapman e cols. [4] mostraram que a compactação deste material policristalino possui uma alta condutividade elétrica, concluindo que este material seria um semicondutor. Nove anos depois foi mostrado que, na forma de cristal, este polímero possui condutividade metálica $\left(1730 \mathrm{Scm}^{-1}\right)$ na direção da cadeia polimérica [5].

Nessa mesma época, o estudo de polímeros orgânicos sofreu um grande avanço. Em 1971 Shirakawa e Ikeda desenvolveram filmes finos de poliacetileno auto suportados para seus estudos espectroscópicos [6], utilizando um catalisador do tipo Ziegler-Natta, sendo que o polímero produzido possuía uma condutividade de $10^{-9} \mathrm{Scm}^{-1}$. O interesse em poliacetileno e seus derivados aumentou em 1977, quando Shirakawa, MacDiarmid e cols. [7] transformaram o filme de poliacetileno de semicondutor para condutor,tratando-o com cloretos, brometos, iodetos, pentafluoreto de arsênio.Obtendo-se assim, filmes com condutividade de até $56 \mathrm{Scm}^{-1}$ para $\mathrm{AsF}_{5}$. A este tratamento, no qual o polímero passa de isolante para condutor, deu-se o nome de "dopagem".

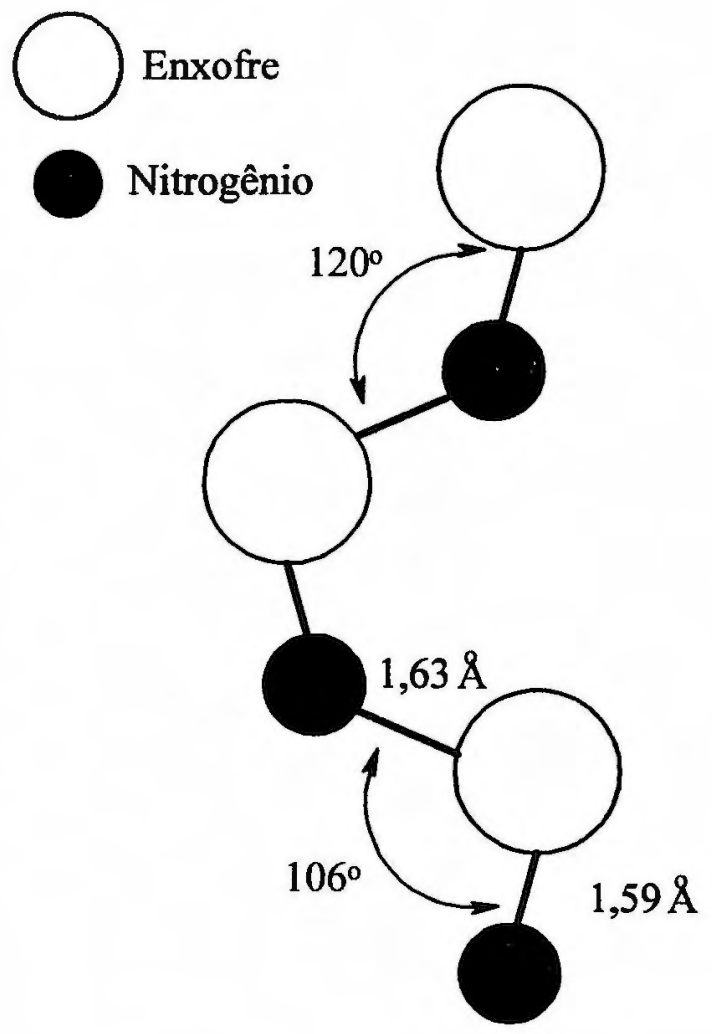

Figura 1.4: Polimero de enxofre e nitrogênio $(S N)_{n}$ [8].

\subsubsection{Polímeros Condutores}

Nos anos que se seguiram à descoberta da condutividade do poliacetileno, imaginou-se que polímeros condutores poderiam ser utilizados em inúmeras novas aplicações. Dentre as quais incluía-se a utilização em linhas de transmissão, em substituição ao cobre, devido à baixa temperatura de processamento e alta flexibilidade apresentadas por estes materiais [9]. Mais tarde, e com uma visão mais realista, as principais funções imaginadas para estes polímeros seriam predominantemente baseadas nas propriedades de filmes finos, como mostradores eletrocrômicos, contato transparente para células fotovoltaicas, eletrodos de bateria, dissipadores de carga eletrostáticas, etc. 
Hoje em dia, conforme o estudo destes materiais desenvolve-se, inúmeras aplicações tecnológicas têm sido propostas e desenvolvidas para polímeros condutores [9-12], dentre elas pode-se citar: diodos emissores de luz [13-19], proteção ativa à corrosão [20-21], filmes para dissipação de carga estática [22-23], blindagem eletromagnética [24-25], dispositivos eletrocrômicos [26-31], capacitores [32], dispositivos para armazenamento de energia [33-37], músculos artificiais [38], componentes para dispositivos para óptica não-linear [39-41], sensores [42-47], biosensores [48-49], catálise [50-51], circuitos poliméricos [52], etc.

Contudo, a maioria destas aplicações tecnológicas é experimental, pois o uso comercial requer boa processabilidade, baixo custo e baixo impacto ambiental. Poucos materiais apresentaram essas características até hoje. Por exemplo, o poliacetileno embora apresente boa condutividade, sua estabilidade térmica e ambiental é baixa, além de ser insolúvel e infusível, inviabilizando seu uso em aplicações comerciais.

Estes polímeros orgânicos condutores possuem uma cadeia $\pi$ conjugada, ou seja, uma alternância de ligações simples e duplas ao longo da cadeia. Esta conjugação é fundamental na condutividade elétrica destes materiais, por outro lado, esta cadeia $\pi$ conjugada confere rigidez à estrutura, dificultando sua processabilidade pós-síntese [9].

Um polímero orgânico que possui as propriedades elétricas, eletrônicas, magnéticas e ópticas de um metal, mantendo características típicas de polímeros chamados convencionais, como propriedades mecânicas e processabilidade, é chamado de polímero intrinsecamente condutor (PIC). As propriedades metálicas existentes são intrínsecas do material “dopado", diferenciando-se dos polímeros extrinsecamente condutores que são meramente misturas físicas de um polímero não condutor e materiais condutores como fibras metálicas ou negro de fumo.

A pesquisa em polímeros intrinsecamente condutores cresceu muito desde a publicação sobre a condutividade do poliacetileno através de "dopagem", levando ao desenvolvimento de novas famílias de polímeros condutores, que com modificações químicas apropriadas podem exibir um intervalo de condutividade desde semicondutor até condutor. Dentre as familias mais estudadas pode-se citar: poliacetileno, polipirrol, polianilina, politiofeno, polifurano, poli( $p$-fenileno), cujas estruturas são mostradas na Figura 1.5.

\subsubsection{Dopagem Primária}

O processo de "dopagem" envolve a inserção de prótons e contra-íons na matriz polimérica, fazendo com que o polímero passe de isolante para condutor. $O$ processo inverso, ou seja, a remoção de prótons e contra-íons da matriz polimérica é chamado de "desdopagem". Este é um processo reversível, onde o polímero original pode ser recuperado com pequeno ou nenhum dano à cadeia polimérica. Através da "dopagem" pode-se obter um aumento de condutividade de até 10 ordens de grandeza. 
Poliacetileno<smiles>C=CC=CC=CC=CC=CC=CC</smiles>

Polipirrol<smiles>Cc1ccc(-c2ccc(-c3ccc(-c4ccc(C)[nH]4)[nH]3)[nH]2)[nH]1</smiles>

Politiofeno

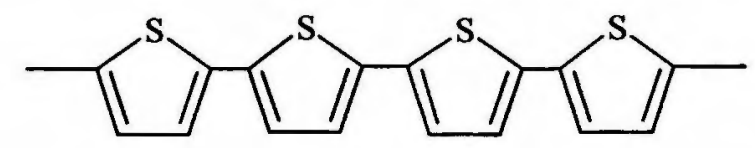

Polifurano

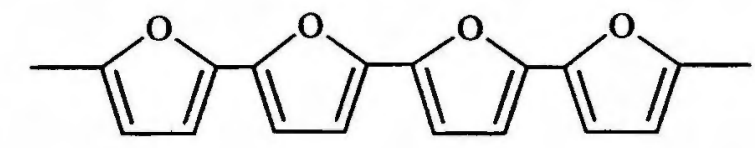

Poli(p-fenileno)

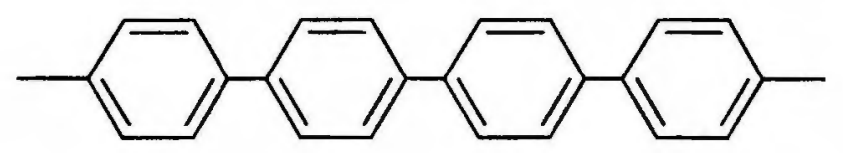

Polianilina<smiles>Cc1cccc(Nc2cccc(Nc3cccc(C)c3)c2)c1</smiles>

Figura 1.5: Estrutura de alguns polimeros condutores intrinsecos.

O termo "dopagem" é utilizado em analogia aos semicondutores inorgânicos cristalinos, sugerindo semelhanças com os polímeros intrinsecamente condutores. Em ambos os casos a dopagem é aleatória e não altera a estrutura do material. No caso de cristais de silício, o processo de dopagem envolve a troca de átomos de silício, que são tetravalentes, por átomos pentavalentes (ex. fósforo, arsênio) ou trivalentes (ex. boro, gálio), resultando em um excesso ou vazio (buracos) de elétrons na rede cristalina, dando origem aos semicondutores inorgânicos extrínsecos.

No entanto, na dopagem de um polímero as impurezas não são introduzidas nas cadeias, mas sim nas suas "vizinhanças". A interação impureza - cadeia gera deformações e "defeitos carregados" localizados, responsáveis pelo aumento de condutividade [53]. Outra diferença significativa está na quantidade de dopante utilizada. Enquanto os semicondutores apresentam "impurezas" que atuam como dopantes, da ordem de ppm, os polímeros intrinsecamente condutores chegam a ter $50 \%$ em massa de dopante.

A maioria dos polímeros condutores conhecidos é dopada por oxidação ou redução do sistema $\pi$ conjugado, já que estes elétrons $\pi$ podem ser facilmente removidos ou adicionados à cadeia, para formar um íon polimérico sem a destruição das ligações necessárias à estabilidade da molécula [54]. Formando assim cargas positivas ou negativas na cadeia polimérica, que são neutralizadas por cátions ou ânions presentes na solução eletrolítica. 


\subsubsection{Dopagem Secundária}

Um dopante secundário é uma substância aparentemente inerte que, quando aplicado ao polímero previamente dopado ("dopagem primária"), induz à mudanças estruturais, aumentando ainda mais sua condutividade. A principal diferença entre dopagem primária e secundária está no fato das propriedades obtidas com a dopagem secundária persistirem, mesmo após a remoção completa do dopante secundário.

Ácidos orgânicos funcionalizados, como ácido canforssulfônico e o ácido dodecil benzeno sulfồnico, são os ácidos orgânicos mais utilizados como dopantes primários [55-57], enquanto que mcresol, xileno e outros solventes, são utilizados como dopantes secundários [58-60]. A presença do solvente provoca alterações conformacionais na cadeia polimérica [61], deixando-a mais distendida [62], aumentando assim a condutividade elétrica em várias ordens de magnitude. Além de provocar mudanças no espectro eletrônico, na viscosidade, e freqüentemente, no estado de cristalinidade.

Outra característica apresentada pelo polímero dopado secundariamente é a intensa absorção no infravermelho próximo atribuída à formação de portadores de carga livres deslocalizados, responsáveis pelo aumento da condutividade.

O fator chave para interação entre solvente e o grupo orgânico do ácido funcionalizado, utilizado como dopante primário, é a polaridade de ambas as espécies. Assim, ácidos contendo grupos funcionais com características apolares, tendem a interagir mais fortemente com solventes também apolares ou menos polares como o tolueno, xileno, clorofôrmio, etc. Enquanto que ácidos contendo grupos funcionais que não possuem uma cadeia alquilica, a interação ocorre mais fortemente com solventes polares como o m-cresol.

\subsubsection{Condutividade dos Polímeros Condutores}

O modelo teórico mais usado para explicar a condutividade elétrica dos polímeros condutores é o de bandas. No estado sólido, os orbitais atômicos de cada átomo estão sobrepostos aos orbitais atômicos do átomo vizinho para formar os orbitais moleculares. Na formação de um composto uma grande quantidade de orbitais moleculares é formada, estes orbitais estão dispostos juntos, em um dado intervalo de energia, formando o que chamamos de bandas (Figura 1.6). A quantidade de elétrons presentes nestas bandas é determinada pelo número de elétrons dos orbitais atômicos envolvidos na sua formação. Os orbitais moleculares ocupados de maior energia constituem a banda de valência (BV) ou banda HOMO e os orbitais moleculares vazios de menor energia, banda de condução (BC) ou banda LUMO. Estas bandas estão separadas por uma faixa proibida de energia chamada de "gap", ou banda proibida.

As propriedades elétricas dos materiais convencionais dependem, portanto, de como estas bandas estão preenchidas. Um material isolante é aquele em que a banda de valência se encontra 


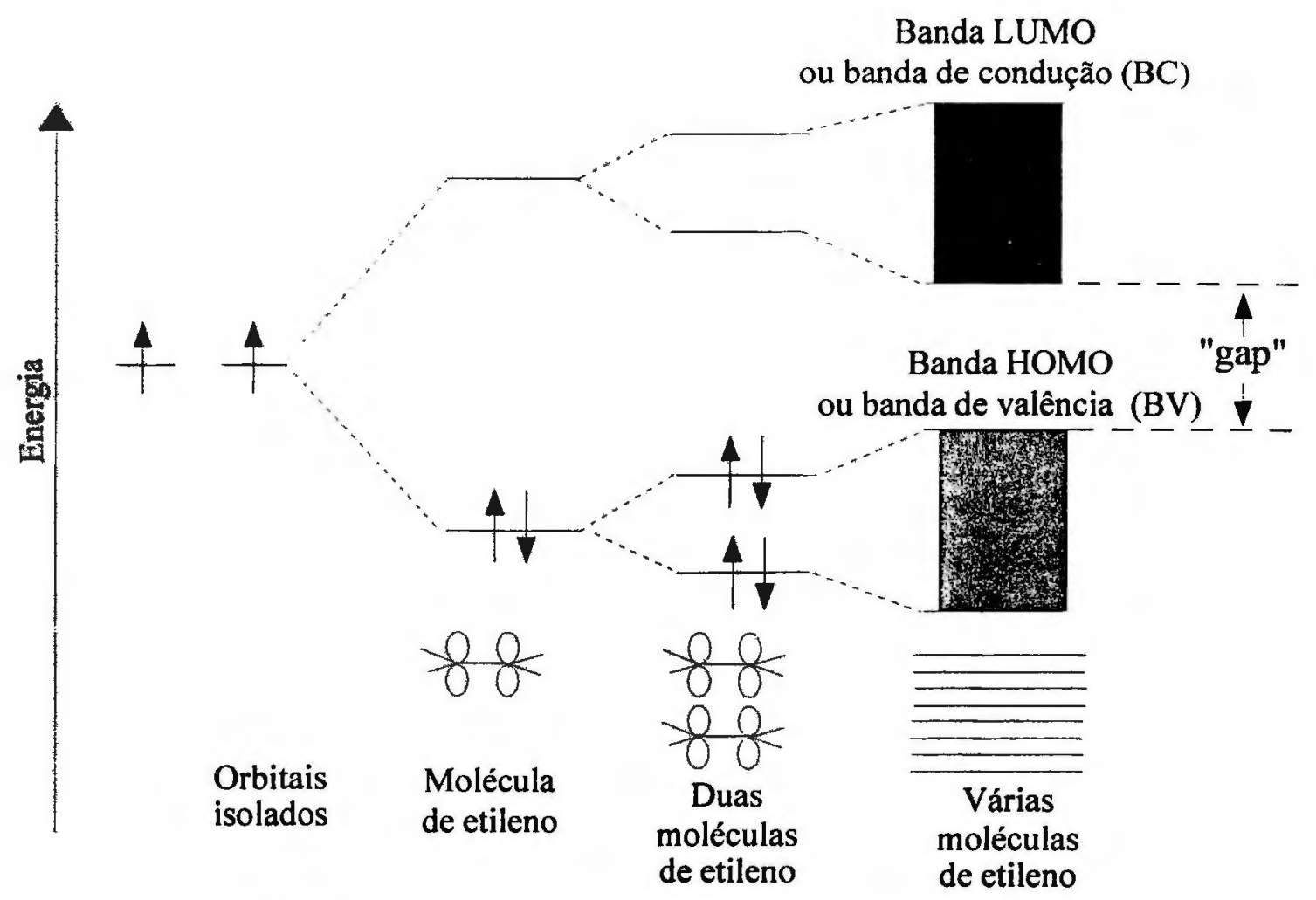

Figura 1.6: Diagrama esquemático mostrando o principio da teoria de bandas.

totalmente preenchida, e a banda de condução totalmente vazia e, como a banda proibida, "gap", possui um grande intervalo de energia, não há passagem de elétrons entre a banda de valência e a banda de condução. Os semicondutores clássicos são aqueles que apresentam um pequeno intervalo de energia entre a banda de valência e a banda de condução, desta maneira, com uma pequena excitação térmica ou luminosa os elétrons da banda de valência são promovidos para a banda de condução, garantindo condutividade elétrica nestes materiais. A alta condutividade dos metais se deve à inexistência dessa banda proibida ou ainda à ocupação parcial das bandas de valência ou condução (Figura 1.7).

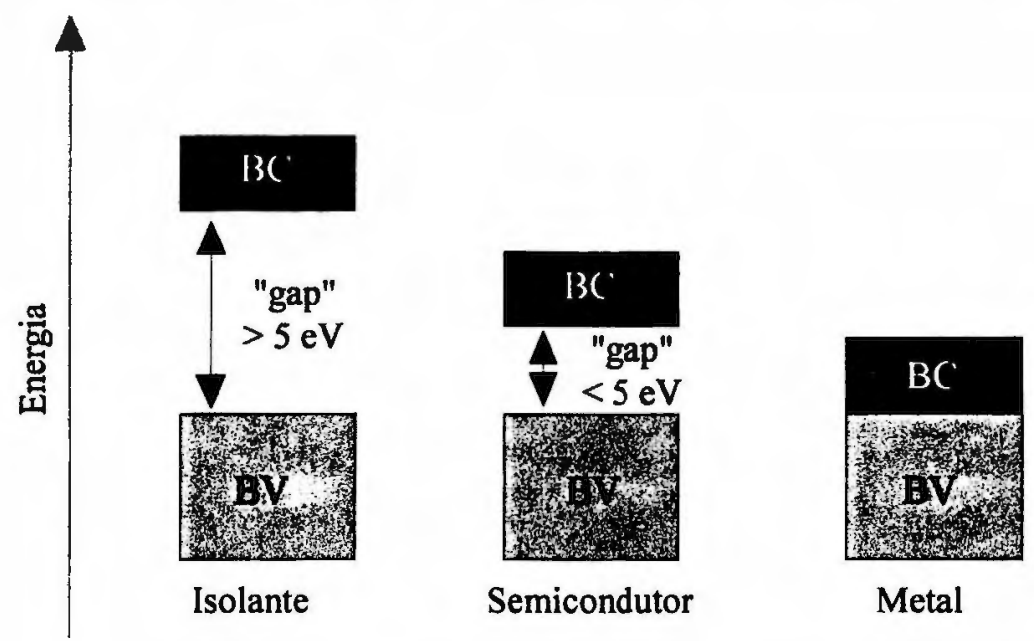

Figura 1.7: Representação esquemática das estruturas de bandas. 
Considerou-se inicialmente que no processo de dopagem dos polímeros condutores os elétrons fossem removidos do topo da banda de valência (dopagem tipo $p$ ), ou adicionados à banda de condução (dopagem tipo $n$ ). Porém este modelo de bandas unidimensional faltha ao tentar explicar o processo de condução em alguns polímeros condutores como o poliacetileno, polipirrol, etc., cuja condutividade não está associada aos elétrons desemparelhados, mas aos portadores de carga com spin zero [63-64].

Para explicar a condutividade do poliacetileno, Su e cols. [65] propuseram um modelo baseado na existência de defeitos estruturais na cadeia originados durante a polimerização, formando um radical no estado não dopado, o "sóliton neutro". Este radical que pode migrar isoenergeticamente ao longo da cadeia conjugada do poliacetileno, já que a estrutura em ambos os lados do radical possui a mesma energia [66], e leva ao aparecimento de um nível eletrônico semipreenchido com energia intermediária entre as bandas de valência e condução. Por oxidação ou redução é possível remover ou adicionar um outro elétron, formando "sólitons" carregados com spin zero, sendo estes os portadores de carga no caso do poliacetileno (Figura 1.8).<smiles>C/C=C/C=C/C=C(I)/C=C/C=C(/C=C(I)/C=C/C=C/C=C/C)C(=O)O</smiles>

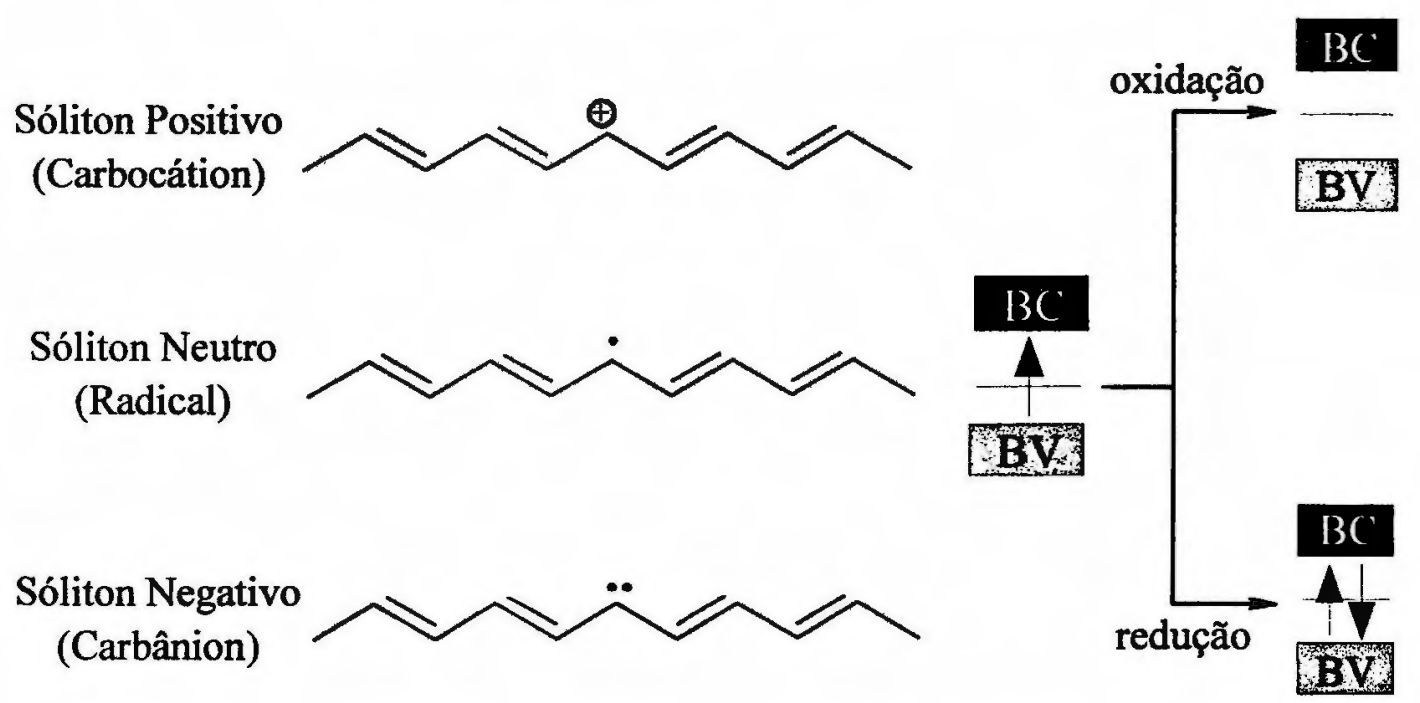

Figura 1.8: Representação esquemática dos sólitons do poliacetileno.

Porém, o modelo baseado em sólitons não explica o comportamento apresentado por polímeros como o polipirrol, politiofeno, polianilina, e poli(p-fenileno), já que nestes polímeros as estruturas em ambos os lados do sóliton carregado seriam diferentes e consequentemente não teriam a mesma energia.

A remoção inicial de um elétron da cadeia polimérica leva à formação de um estado eletrônico denominado "pólaron", ao qual está associado uma distorção da forma aromática para a forma quinônica. Cálculos teóricos [65] previram a formação de pólarons com a ionização do polímero, tanto em 
poliacetileno quanto em polímeros aromáticos [67-68], este pólaron é definido como um íon radical (spin 1/2) associado à uma distorção de rede e a presença de estados eletrônicos localizados no meio da banda proibida. A remoção de um segundo elétron origina um "bipólaron", definido como um par de cargas associadas a uma forte distorção da rede polimérica. Cálculos teóricos mostraram que o bipólaron é termodinamicamente mais estável que dois pólarons separados, devido a repulsão coulômbica de duas cargas confinadas num mesmo sítio [12]. Estes bipólarons podem se movimentar quase independentemente como um sóliton carregado. Desta maneira, os bipólarons transportam a carga movendo-se ao longo da cadeia polimérica ou por saltos entre as cadeias, sendo eles responsáveis pela condutividade sem spin observada nestes polímeros (Figura 1.9).

$$
\begin{gathered}
\text { spin } \\
\text { polímero neutro } \\
\text { instável }
\end{gathered}
$$

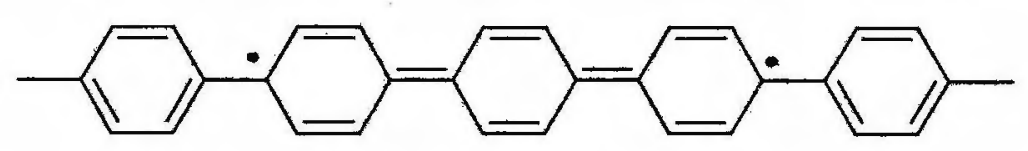

spin

polímero negativo polaron estável "tipo-n"

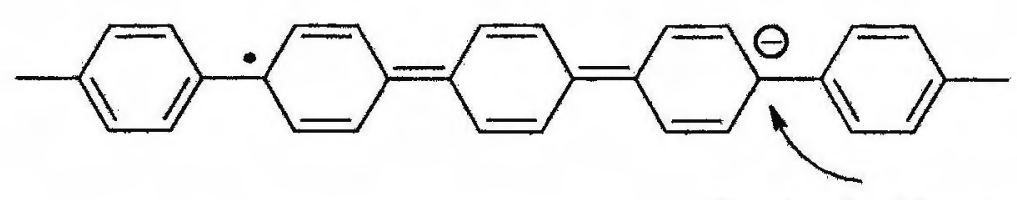

Doador de elétrons

spin

polímero positivo polaron estável "tipo-p"

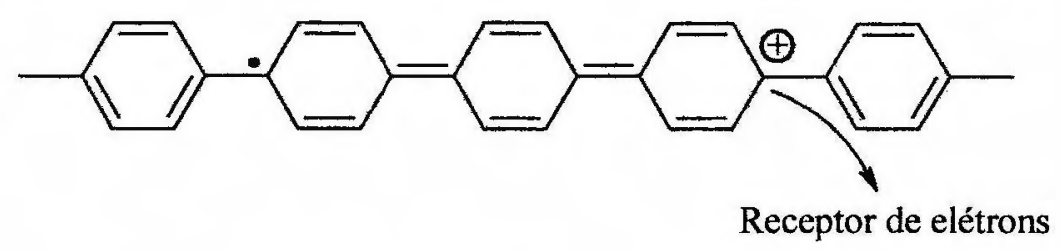

sem spin

polímero negativo bipolaron estável "tipo-n"

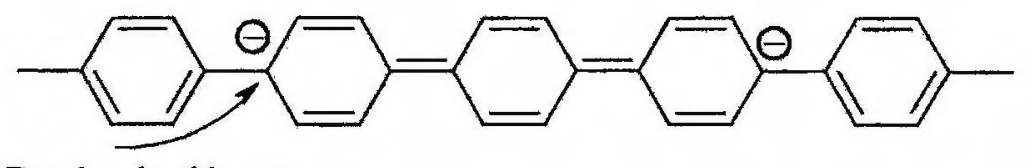

Doador de elétrons

sem spin

polímero positivo bipolaron estável "tipo-p"

\begin{tabular}{|c|c|c|c|}
\hline $\mathrm{BC}^{\circ}$ & $B C^{\circ}$ & $B C^{\circ}$ & $\mathrm{BO}^{\circ}$ \\
\hline$\overline{\text { BV }}$ & $\mathbf{B V}$ & BV & $\overline{\mathbf{B V}}$ \\
\hline $\begin{array}{c}\text { Polímero } \\
\text { neutro }\end{array}$ & $\begin{array}{c}\text { Forma } \\
\text { polarônica }\end{array}$ & $\begin{array}{c}\text { Forma } \\
\text { bipolarônica }\end{array}$ & $\begin{array}{c}\text { Bandas } \\
\text { bipolarônica }\end{array}$ \\
\hline
\end{tabular}

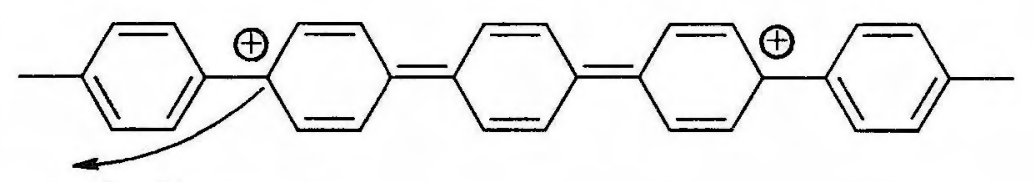

Receptor de elétrons

Figura 1.9: Diagrama das estruturas polarônicas e bipolarônicas do fenileno e as estruturas de bandas para o polímero oxidado. 


\subsubsection{Sintese dos Polímeros Condutores}

As técnicas mais utilizadas para sintetizar polímeros condutores [69] são: a pirólise [70-80], reações de adição utilizando catalisador Ziegler-Natta [89-95], síntese eletroquímica, polimerização por condensação e polimerização radicalar, sendo que a síntese destes polímeros é muito simples.

\section{Pirólise:}

A pirólise é a maneira mais antiga para gerar materiais orgânicos condutores [69]. Este método de preparação de polímeros condutores consiste na eliminação de hetero-átomos (ex. halogênios, oxigênio, nitrogênio) da matriz polimérica por aquecimento, formando uma estrutura aromática extensa [96-100], que eventualmente se aproxima a do grafite [101-103]. Estas estruturas conjugadas aumentam a mobilidade e o número dos carregadores de carga, através da formação de radicais livres, gerando cátions ou ânions [104-106]. O produto da pirólise pode ser na forma de pó, filmes, ou fibras, dependendo da forma e natureza do polímero de partida e das condições de pirólise. Dentre os exemplos de polímeros condutores formados por pirólise podemos citar a poliacrilonitrila, e o Kapton (Figura 1.10).
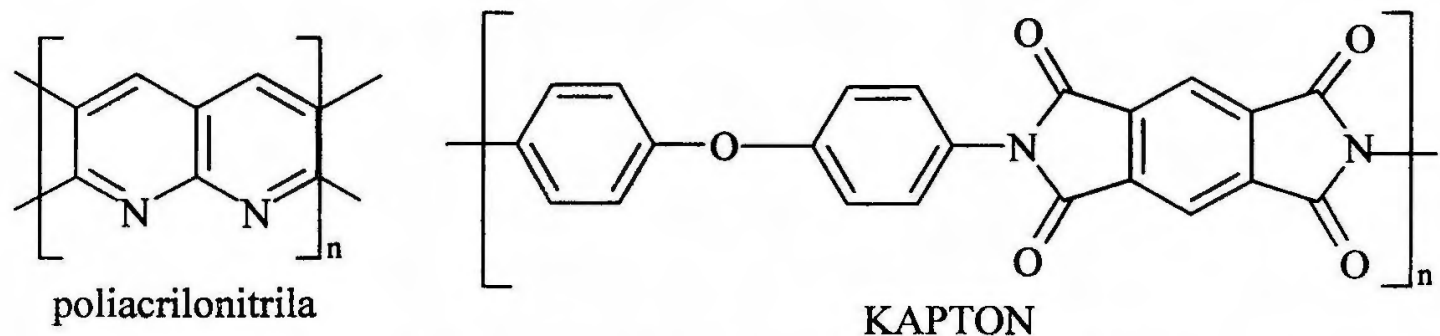

KAPTON

Figura 1.10: Exemplos de polímeros sintetizados por pirólise.

\section{Reações de adição utilizando catalisador de Ziegler-Natta:}

Dos catalisadores utilizados na síntese de polimerização de derivados de acetileno, o catalisador de Ziegler-Natta em suas várias modificações é o mais estudado hoje em dia [81], pois permite a polimerização do acetileno à temperatura ambiente e pressão atmosférica. Ziegler descobriu que esta reação produzia um polímero linear com alta cristalinidade, em oposição aos acetilenos produzidos através de polimerização radicalar, que eram polímeros amorfos e cheios de ramificações, além de exigir altas pressões durante a sintese [82]. $O$ estudo destes catalisadores foi aprimorado por Natta e seus colaboradores, os quais sintetizaram polímeros semi-cristalinos e lineares a partir do propileno, 1-buteno e várias outras $\alpha$-olefinas [82].

O sistema de síntese em todos os casos é heterogêneo, pois apenas em sistemas heterogêneos o catalisador é capaz de produzir poli- $\alpha$-olefinas isotáticas. As várias formas do catalisador são preparadas à partir de uma combinação de compostos organometálicos, onde o metal pertence principalmente aos Grupos I, II ou III, sendo combinado com um haleto ou um metal de 
transição (Grupos IV ao VIII), por exemplo [Ti(O-n- $\left.\mathrm{C}_{4} \mathrm{H}_{9}\right)_{4}-\mathrm{Al}\left(\mathrm{C}_{2} \mathrm{H}_{5}\right)_{3}$ ].

Com este método podem ser sintetizados filmes auto suportados, assim como espumas, filmes parcialmente orientados, compósitos e pós, dependendo do procedimento experimental utilizado [83-88]. Porém a maioria dos materiais produzidos desta maneira é insolúvel e infusível.

\section{Polimerização por Etapas:}

A polimerização por etapas é um método de polimerização bastante extenso e variado, levando à formação de diversos polímeros. Nestas reações, a bifuncionalidade do monômero é de fundamental importância, formando a cadeia polimérica através de reações sucessivas de condensação ou adição entre os grupos funcionais dos monômeros, dímeros, trímeros, etc, que também são bifuncionais. Estas reações são análogas às reações simples envolvendo espécies químicas monofuncionais. Alguns exemplos de polímeros condutores formados através da polimerização em etapas são: poli( $p$-fenileno), poli(sulfeto de $p$-fenileno), poliquinolinas, poliquinoxalinas (Figura 1.11).

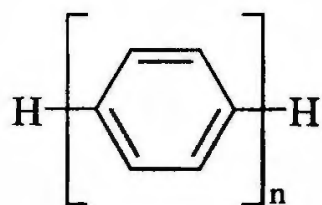

polifenileno

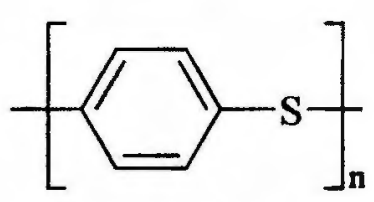

polı(sulfeto de fenileno)

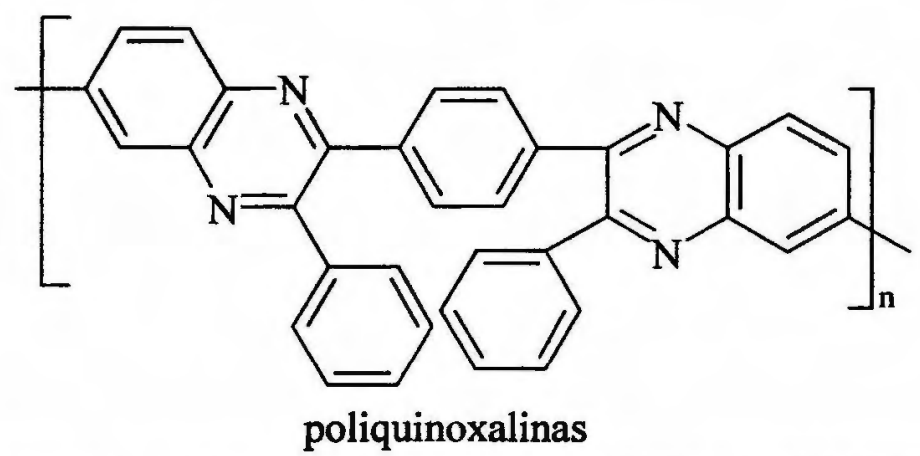<smiles>CCc1cc(-c2ccccc2)c2cc(C)ccc2n1</smiles>

poliquinolina

Figura 1.11: Exemplos de polímeros condutores sintetizados através de polimerização por etapas.

\section{Polimerização de Adição Radicalar:}

Nas reações de polimerização radicalar longas cadeias de polímero são obtidas a partir de monômeros vinílicos cuja estrutura geral é $\mathrm{CH}_{2}=\mathrm{CR}_{1} \mathrm{R}_{2}$. Nestas unidades os elétrons $\pi$ das ligações duplas dos carbonos são susceptíveis a rearranjos quando ativado por iniciadores radicalares ou iônicos. $\mathrm{O}$ centro ativo criado através destas reações se propaga pela cadeia levando à formação de uma única macromolécula cujo crescimento cessa apenas quando este centro ativo é neutralizado por numa reação de terminação. A completa polimerização acorre em três etapas distintas: a iniciação, quando o centro ativo, que funciona como carregador de carga, é criado; a propagação, que envolve o crescimento da cadeia polimérica, e é caracterizada por uma longa seqüên- 
cia de eventos idênticos: a repetida adição de monômero à cadeia polimérica em crescimento; e a terminação, onde o crescimento da cadeia cessa através da neutralização ou transferência do centro ativo.

Geralmente nestas polimerizações radicalares o polímero formado tem a composição química similar ao do monômero, ou seja, cada unidade da cadeia é similar ao monômero completo, e não apenas um resíduo como na maioria das reações por etapas.

Os iniciadores de cadeia podem ser divididos em três categorias: radicais livres, catiônicos, e aniônicos. Um radical livre é uma espécie atômica ou radicalar cujo sistema normal de ligação foi alterado de maneira que elétrons desemparelhados permanecem associados à essa nova estrutura. Um iniciador efetivo é uma molécula que, quando submetido ao calor, radiação eletromagnética ou reação química sofre quebra homolítica (Equação1.1) em radicais com maior reatividade que os monômeros radicalares. Estes radicais precisam ser estáveis o suficiente para reagirem com um monômero e gerarem um centro ativo.

$$
\mathrm{I} \longrightarrow 2 \mathrm{R}
$$

O propagador de cadeia é formado através da reação entre o radical e o monômero (Equação 1.2), e a cadeia se propaga rapidamente, através da adição de monômeros para produzir um polímero linear (Equação 1.3).

$$
\begin{aligned}
& \mathrm{RM}_{1}+\mathrm{M}_{1} \longrightarrow \mathrm{RM}_{2}^{\dot{ }} \\
& \mathrm{RM}_{n}^{\dot{1}}+\mathrm{M}_{1} \longrightarrow \mathrm{RM}_{n+1}^{\dot{1}}
\end{aligned}
$$

Em teoria a cadeia poderia se propagar até que todo o monômero no sistema fosse consumido, mas como os radicais livres são uma espécie particularmente muito reativa, interagindo o mais rápido possivel para formar ligações covalentes inativas. Isto significa que cadeias curtas são produzidas quando a quantidade de radicais no sistema é muito grande, pois a probabilidade deles reagirem entre si é muito alta.

A terminação da cadeia pode ocorrer de várias maneiras: pela interação entre duas cadeias ativas, pela reação entre uma cadeia ativa e um iniciador radicalar, pela transferência de um centro ativo para outra molécula, que pode ser uma molécula de solvente, iniciador ou monômero, ou pela interação entre a cadeia ativa e impurezas ou inibidores presentes na solução.

$$
\sim \mathrm{CH}_{2}-\mathrm{CH}_{2}+\mathrm{CH}_{2}-\mathrm{CH}_{2} \sim \longrightarrow \sim \mathrm{CH}_{2}-\mathrm{CH}_{2}-\mathrm{CH}_{2}-\mathrm{CH}_{2} \sim
$$

\section{Síntese Eletroquímica:}

Polímeros condutores também podem ser sintetizados por métodos eletroquímicos acompanhados da oxidação simultânea do polímero em formação. O filme de polímero aderido ao eletrodo, pode formar-se através de métodos potenciostáticos, galvanostáticos ou potencio-dina- 
micamente. A escolha entre a síntese química ou eletroquímica depende fundamentalmente da aplicação deste material, por exemplo, quando se deseja uma grande quantidade de material a síntese química é a mais indicada pela maior facilidade e baixo custo, por outro lado, com a síntese eletroquímica pode-se formar filmes finos com maior facilidade além de ser um método mais limpo.

Geralmente a eletropolimerização é feita em uma célula eletroquímica de um ou dois compartimentos, onde se encontram os eletrodos e o eletrólito. Três eletrodos são usualmente empregados: um eletrodo de trabalho, que define a interface de estudo, um eletrodo de referência, o qual possui um potencial constante, e um contra eletrodo, o qual fornece corrente ao sistema. Na maioria das vezes a síntese é feita em meio ácido aquoso, embora meios não aquosos também possam ser utilizados.

Um estudo cuidadoso dos vários fatores que envolvem a preparação eletroquímica, permite a otimização das condições de crescimento para que propriedades como condutividade, aderência, morfologia, etc, possam ser controladas.

\subsection{A Polianilina}

A polianilina, provavelmente o mais antigo polímero orgânico sintético conhecido [107], tem sido o polímero mais amplamente estudado por inúmeros grupos de pesquisa no mundo todo, devido sua estabilidade química em condições ambientais, facilidade de polimerização e dopagem, baixo custo e altos níveis de condutividade. As polianilinas representam uma classe de polímeros, cuja composição química na forma base (não dopada) é dada por uma fórmula geral do tipo (Figura 1.12):

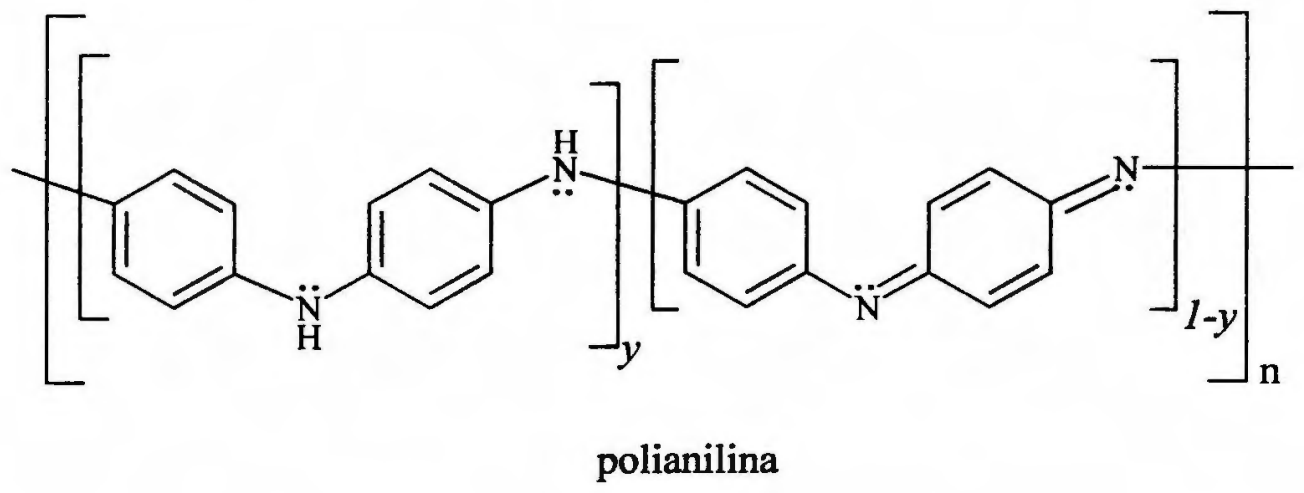

Figura 1.12: Estrutura da polianilina em sua forma básica

A polianilina é composta por y e (1-y) unidades repetitivas de espécies reduzidas e oxidadas respectivamente. $\mathrm{O}$ valor de $y$ pode variar continuamente entre 1 (reduzida, contendo apenas unidades amina) e 0 (oxidada, contendo apenas unidades imina) [108]. Os diferentes estados de oxidação das polianilinas têm as seguintes denominações dependendo do valor de $y$ : leucoesmeraldina $(y=1,00)$, protoesmeraldina $(y=0,75)$, esmeraldina $(y=0,50)$, nigranilina $(y=0,25)$ e pernigranilina $(y=0,00)$ [109]. 
As diferentes composições estão intimamente relacionadas às variações na coloração e nas propriedades elétricas do polímero, sua condutividade pode variar de $10^{-11} \mathrm{Scm}^{-1}$ até $10 \mathrm{Scm}^{-1}$, e sua coloração varia de amarelo até violeta, dependendo do estado de oxidação.

Os filmes de polianilina são obtidos facilmente por oxidação química ou eletroquímica do monômero em solução ácida. De todos os seus estados de oxidação, apenas a esmeraldina $(y=0,5)$, cor esverdeada, apresenta propriedades condutoras quando dopada, sendo que o processo de dopagem, neste caso, envolve a protonação dos nitrogênios imina da cadeia polimérica, diferindo da maioria dos polimeros condutores [110-112].

Quando a polianilina na forma básica é colocada em meio ácido, ocorre a protonação dos nitrogênios imínicos [113] da cadeia polimérica, gerando cargas positivas. Esse polímero sofre uma oxiredução interna [114], que é um rearranjo eletrônico dando origem ao sal de esmeraldina (estrutura polarônica). Neste sal o cátion é a cadeia polimérica e o ânion é o contra-íon do ácido utilizado na protonação do polímero. O grau de protonação da polianilina vai depender, dentre outros fatores, da concentração do ácido utilizado no seu processo de síntese ou dopagem, e do tipo de ânion presente no eletrólito. O polímero pode ser desprotonado, voltando à sua forma básica, com a utilização de uma solução básica, geralmente hidróxido de amônio $(0,1$ à $0,5 \mathrm{~mol} / \mathrm{L})$.

\subsubsection{Síntese das Polianilinas}

A síntese química é normalmente realizada utilizando-se como agentes oxidantes o perssulfato de amônio, o dicromato de potássio, o dióxido de manganês, cloreto férrico, ou mesmo peróxido de hidrogênio. Porém, primeiro é necessário formar o radical livre que será o iniciador da polimerização, no caso do peróxido de hidrogênio ocorre a formação de radicais na presença de íons ferroso, enquanto que o perssulfato decompõe-se em meio aquoso.

$$
\begin{gathered}
\mathrm{H}_{2} \mathrm{O}_{2}+\mathrm{Fe}^{2+} \longrightarrow \mathrm{Fe}^{3+}+\mathrm{OH}^{-}+\mathrm{OH}^{-} \\
\mathrm{S}_{2} \mathrm{O}_{8}{ }^{2-} \longrightarrow 2 \mathrm{SO}_{4}^{-}
\end{gathered}
$$

A solução deve ser ácida, sendo que ácidos inorgânicos, poliácidos, ou ainda ácidos funcionalizados podem ser utilizados. A concentração de monômero pode variar de $0,01 \mathrm{~mol} / \mathrm{L}$ e 2,00 mol/L, sendo que a razão entre as concentrações de agente oxidante e monômero pode variar de 2 à 1 . Através deste método o polímero é obtido na forma de pó de alta massa molecular, desde que a quantidade de agente oxidante seja baixa, para evitar a degradação do polímero [115].

A polianilina pode ser também sintetizada eletroquimicamente na forma de filme sobre eletrodos de diferentes materiais (platina, ouro, carbono vítreo, semicondutores, vidros condutores, etc.), em vários meios ácidos, por métodos potenciostáticos, galvanostáticos, ou potencio-dinâmicos. 
A primeira etapa na síntese da polianilina, e seus derivados, é a formação de radicais cátions do monômero [116-117] (Figura 1.13). A estabilidade deste radical cátion é o fator determinante para a obtenção de um polímero com elevado grau de conjugação. Um cátion radical muito estável pode difundir-se do eletrodo para a solução dando origem a oligômeros solúveis, enquanto que um radical muito reativo, pode sofrer reações paralelas.<smiles>N=C1C=CC(C=C2C=CC=CC2=[NH2+])C=C1</smiles>

Figura 1.13: Esquema das estruturas do radical cátion formado.

Estes radicais cátions se acoplam rapidamente formando dímeros [118]. Devido às suas várias estruturas de ressonância, estes acoplamentos podem ser do tipo cabeça-cauda, cabeçacabeça, ou cauda-cauda (Figuras 1.14-1.16). Estes dímeros se oxidam mais facilmente que o monômero, e, com a oxidação destes dímeros e de mais monômeros, tem-se a formação da cadeia polimérica, que também sofre oxidação.

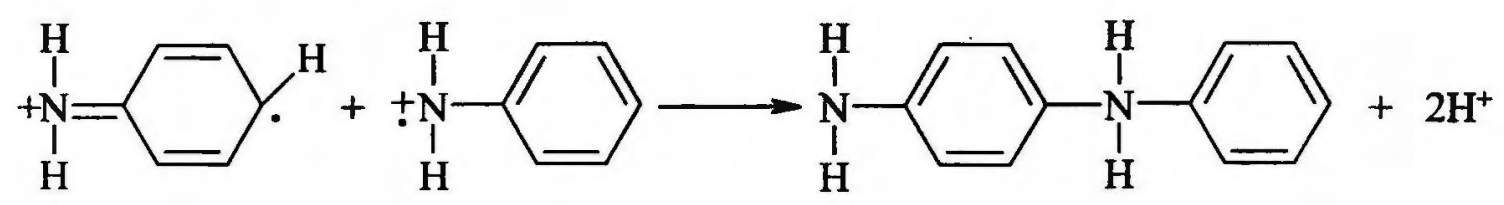

Figura 1.14: Esquema das estruturas do acoplamento cabeça-cauda.

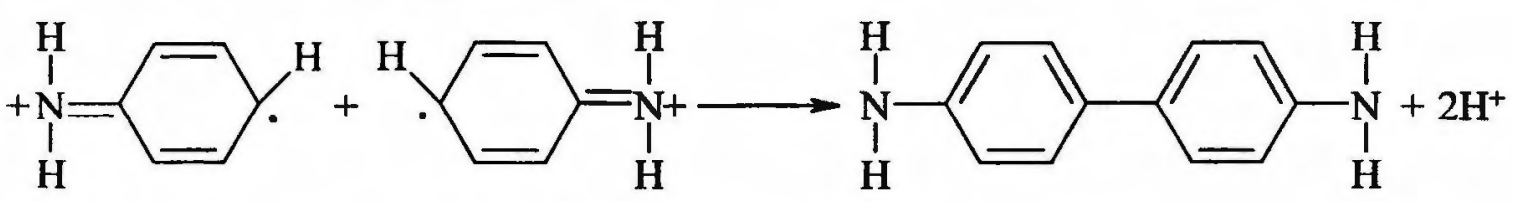

Figura 1.15: Esquema das estruturas do acoplamento cauda-cauda.

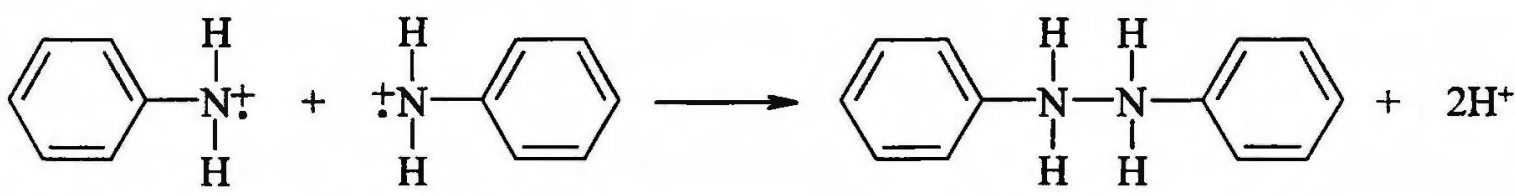

Figura 1.16: Esquema das estruturas do acoplamento cabeça-cabeça.

Existem vantagens e desvantagens na utilização de cada tipo de síntese. Na eletropolimerização não se necessita de agentes oxidantes e a obtenção de filmes finos facilita a caracterização espectroscópica in-situ. No entanto quando se necessita de maior quantidade de material, bem como cadeias poliméricas com massas moleculares maiores, o método químico é o mais recomendado. 
Embora a síntese da polianilina seja simples, há vários parâmetros que alteram profundamente as propriedades elétricas, físico-químicas, morfológicas, etc., do polímero, e o maior desafio no momento é garantir a reprodutibilidade e homogeneidade destes materiais, trabalhando tanto com as condições de síntese, quanto com tratamentos pós-síntese.

\subsubsection{Copolímeros}

Através do estudo de polímeros que apresentam apenas um tipo de unidade monomérica (homopolímeros), observa-se que há uma grande variedade nas propriedades destes materiais, dependendo do tipo de unidade monomérica. Poderia-se imaginar, então, que apenas misturandose fisicamente estes materiais com diferentes propriedades poderia-se obter um único material com as propriedades desejadas. Infelizmente isto não acontece $\mathrm{e}$, muito provavelmente, as qualidades não desejáveis de cada homopolímero apareceriam com maior intensidade na mistura.

Uma alternativa é tentar sintetizar cadeias contendo mais de uma unidade monomérica e examinar o comportamento destes produtos. Escolhendo dois ou mais monômeros apropriados (A e B), a incorporação destes monômeros em uma cadeia polimérica pode ser feito usando-se iniciadores radicalares ou iônicos, e na maioria das vezes o produto exibirá as propriedades desejadas inicialmente, este processo é conhecido como copolimerização.

Mesmo no caso mais simples de copolimerização envolvendo dois monômeros, uma grande variedade de estruturas pode ser obtida.

Copolímeros estatísticos são formados quando ocorre uma propagação irregular da cadeia polimérica, e os dois monômeros entram na cadeia de uma maneira estatística. Esta é a estrutura copolimérica mais encontrada, onde o copolímero formado é representado por poli(A-co-B).

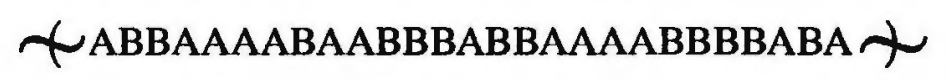

Copolímeros alternados são obtidos quando quantidades eqüimolares das duas unidades monoméricas estão distribuídas de uma maneira alternada regularmente na cadeia polimérica. Estes copolímeros geralmente são polimerizados por etapas, através de reações de condensação.

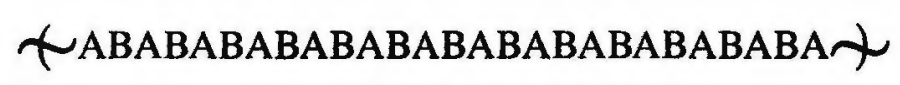

Ao invés de uma distribuição variada das duas unidades ao longo da cadeia, o copolímero pode conter longas seqüências de um monômero conectadas em outra seqüência ou bloco do segundo este copolímero é denominado copolímero de bloco.

$$
\text { భAAAAAAAAAAAAABBBBBBBBBBBBBB } \chi
$$

Copolímero enxertado é um copolímero não linear com ramificações formadas por blocos de uma das unidades monoméricas. Este tipo de copolímero é formado pela inserção de cadeias 
de um monômero em uma cadeia polimérica de outro homopolímero.

Em geral copolímeros de bloco ou enxertados possuem as propriedades de ambos os homopolímeros, enquanto que as estruturas que possuem alternância das unidades monoméricas ao longo da cadeia polimérica possuem características que estão entre os dois extremos.

Torna-se óbvio que os fatores que influenciam uma reação de copolimerização, são muito mais complexos que os fatores envolvidos nas reações de homopolimerização. Foi observado por Staudinger [119], 1930, que quando dois monômeros copolimerizam a tendência de cada um dos monômeros entrar na cadeia polimérica pode diferir muito. Este fenômeno, de diferença de composição, acontece em muitas copolimerizações e tem sido atribuído à maior reatividade relativa de um dos monômeros contidos na mistura de entrar na cadeia do copolímero. Conseqüentemente, em uma copolimerização é necessário distinguir entre a composição do copolímero que está sendo formado durante a reação e a composição da solução de polimerização [120].

Através da proposição de Dostal em 1936 [121], a partir de reações de homopolimerização e heteropolimerização entre dois monômeros $M_{1}$ e $M_{2}$, duas quantidades $\left(r_{1}\right.$ e $\left.r_{2}\right)$ são definidas para prever a composição de um copolímero. As quantidades $r_{1}$ e $r_{2}$ são as razões relativas de reatividade para cada um dos monômeros [122].

$$
\begin{gathered}
\ldots M_{1}^{*}+M_{1} \stackrel{k_{11}}{\longrightarrow} \ldots M_{1} M_{1}^{*} \\
\ldots M_{1}^{*}+M_{2} \stackrel{k_{12}}{\longrightarrow} \ldots M_{1} M_{2}^{*} \\
\ldots M_{2}^{*}+M_{2} \stackrel{k_{22}}{\longrightarrow} \ldots M_{2} M_{2}^{*} \\
\ldots M_{2}^{*}+M_{1} \stackrel{k_{21}}{\longrightarrow} \ldots M_{2} M_{1}^{*} \\
r_{2}=\frac{k_{22}}{k_{21}} \\
r_{1}=\frac{k_{11}}{k_{12}}
\end{gathered}
$$

Onde $k_{l l}$ e $k_{22}$ são as constantes de velocidade de auto-propagação, onde o monômero se propaga em uma cadeia contendo apenas unidades do mesmo monômero, e $k_{12}$ e $k_{21}$ são as constantes de velocidade de propagação cruzada, onde o monômero se propaga em uma cadeia contendo unidades de um monômero diferente. A equação de velocidade de formação da cadeia polimérica é dada por:

$$
\begin{aligned}
& \frac{-d\left[M_{1}\right]}{d t}=k_{11}\left[M_{1}\right]\left[M_{1}^{*}\right]+k_{21}\left[M_{1}\right]\left[M_{2}^{*}\right] \\
& \frac{-d\left[M_{2}\right]}{d t}=k_{22}\left[M_{2}\right]\left[M_{2}^{*}\right]+k_{12}\left[M_{2}\right]\left[M_{1}^{*}\right]
\end{aligned}
$$


Considerando o sistema em estado estacionário:

$$
k_{21}\left[M_{2}^{\bullet}\right]\left[M_{1}\right]=k_{12}\left[M_{1}^{\bullet}\right]\left[M_{2}^{\top}\right]
$$

E assumindo que a reatividade dos monômeros independe do tamanho da cadeia, mas apenas das unidades terminais, pode-se escrever uma equação para o copolímero:

$$
\frac{d\left[M_{1}\right]}{d\left[M_{2}\right]}=\left(\frac{\left[M_{1}\right]}{\left[M_{2}\right]}\right)\left\{\frac{r_{1}\left[M_{1}\right]+\left[M_{2}\right]}{\left[M_{1}\right]+r_{2}\left[M_{2}\right]}\right\}
$$

Com esta equação de copolimerização pode-se calcular a quantidade de cada um dos monômeros que é incorporados na cadeia polimérica para uma dada concentração de solução de síntese, quando a razão de reatividade relativa é conhecida. Conhecendo os valores de $r_{1}$ e $r_{2}$ pode-se definir $F_{1}$ e $F_{2}$, como frações molares dos monômeros $\mathbf{M}_{1}$ e $\mathbf{M}_{2}$ na cadeia copolimérica e $f_{1}$ e $f_{2}$ como a composição correspondente da solução percursora do copolímero:

$$
F_{1}=\frac{\left(r_{1} f_{1}^{2}+f_{1} f_{2}\right)}{\left(r_{1} f_{1}^{2}+2 f_{1} f_{2}+r_{2} f_{2}^{2}\right)}
$$

Através de estudos das reações de copolimerização pode-se entender a relação entre reatividade e a estrutura química dos monômeros, e, consequentemente adquirir um melhor conhecimento do mecanismo de polimerização.

Conklin e cols. [123] mostraram que a composição do copolímero formado quimicamente com anilina e seus alquil derivados é diferente da composição da solução de síntese (Figura 1.17).

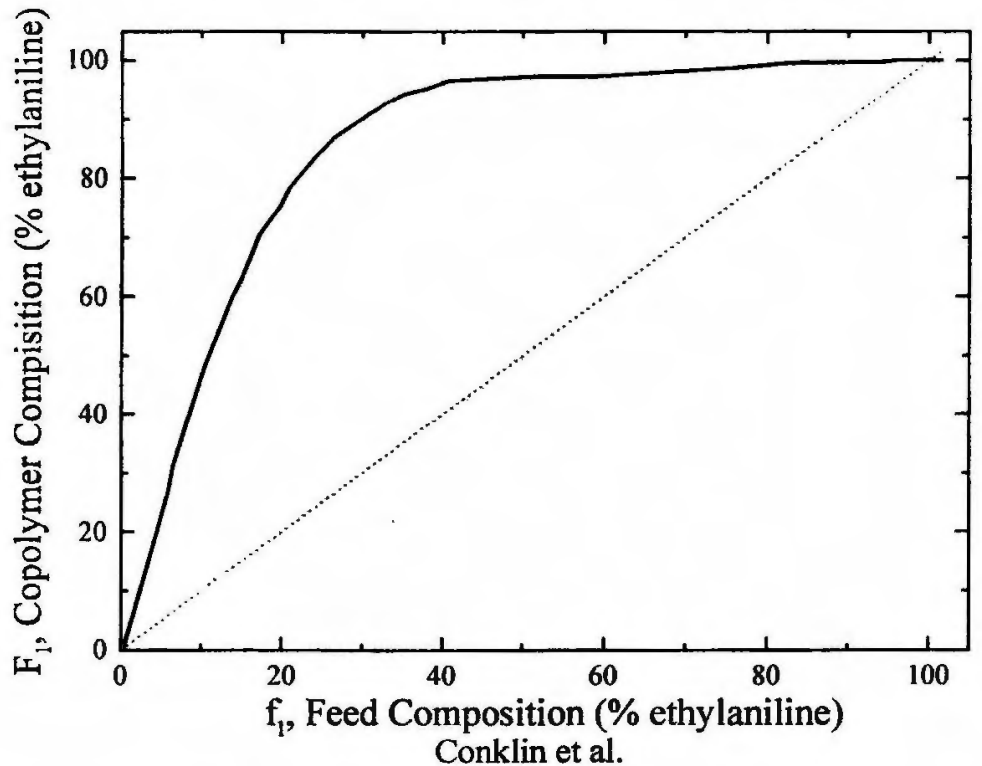

Figura 1.17: Gráfico da composição molar de unidades de 2-etilanilina $(F)$ na cadeia copolimérica em função da composição da solução de síntese $(f)$. [123] 
Isto foi determinado através de medidas de Ressonância Magnética Nuclear de prótons onde a fração de unidades de 2-etilanilina foi calculada da fração da integração das áreas de prótons metílicos e prótons aromáticos. Desta maneira observou-se que as razões de reatividade, é maior para a 2-etilanilina que para a anilina, $r_{1}=11,7 \mathrm{e} r_{2}=0,128$, respectivamente. Observa-se então que tanto a 2-etilanilina quanto a anilina reagem preferencialmente com monômeros de 2-etilanilina, porém a 2-etilanilina tem uma razão de reatividade maior, enquanto que a anilina tem uma razão de reatividade maior em relação à monômeros de anilina. Isto sugere a formação de um copolímero em bloco, com grandes blocos contendo unidades de 2-etilanilinas e blocos menores contendo unidades de anilina.

Copolímeros formados a partir de soluções contendo menos que $30 \%$ (em moles) de 2etilanilina apresentam propriedades intermediárias em relação aos homopolímeros, e estas propriedades variam gradualmente com a quantidade de unidades de 2-etilanilina. 


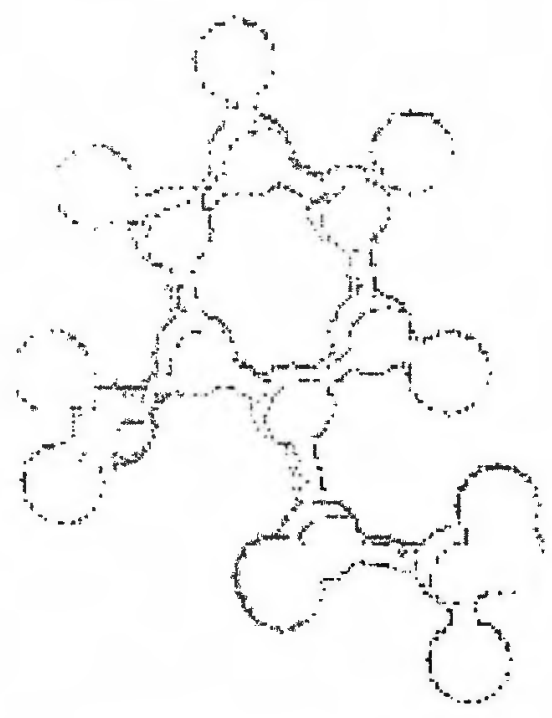

\section{Parte Experimental}

\subsection{Materiais}

\subsubsection{Célula Eletroquímica}

A célula eletroquímica utilizada na preparação e caracterização dos filmes de polianilina e polianilinas substituídas consiste de uma célula convencional de vidro, com apenas um compartimento, cuja capacidade era de cerca de $25 \mathrm{~mL}$ de solução eletrolítica, e entrada para três eletrodos (Figura 2.1).

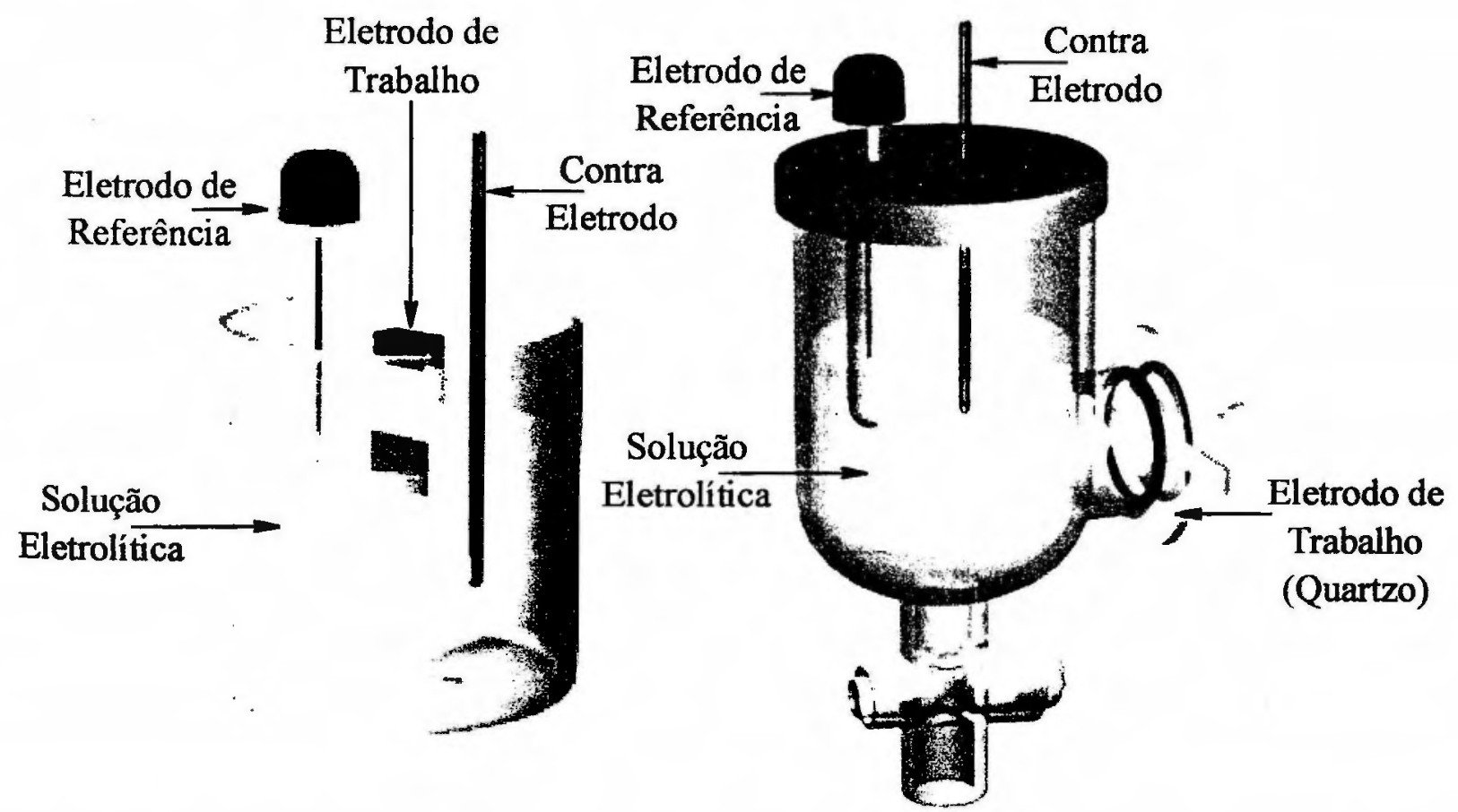

Figura 2.1: Esquema da célula eletroquímica utilizada nos experimentos eletroquímicos e eletrogravimétricos. 


\subsubsection{Eletrodos de Trabalho}

Para estudos espectroeletroquímicos utilizou-se como eletrodo de trabalho uma lâmina de vidro transparente com camada condutora de $\mathrm{SnO}_{2}(16 \Omega / \square)$, ou então contendo uma camada condutora de $\mathrm{SnO}_{2}$ dopado com In (ITO), dependendo da disponibilidade destes eletrodos no laboratório.

Estes eletrodos foram previamente limpos com acetona em banho de ultra-som para remover qualquer resíduo de gordura. Em um dos lados do eletrodo colocou-se uma fita adesiva condutora de cobre para melhorar o contado entre o eletrodo e os fios do potenciostato. E com uma fita adesiva resistente à solução eletrolítica delimitou-se uma área de $0,7 \mathrm{~cm}^{2}$ do eletrodo que ficou exposta à solução, para facilitar o controle da quantidade de material depositado no eletrodo (Figura 2.2).

Nos estudos eletrogravimétricos utilizou-se como eletrodo de trabalho um eletrodo de cristal de quartzo polido opticamente, isto é, foi utilizado

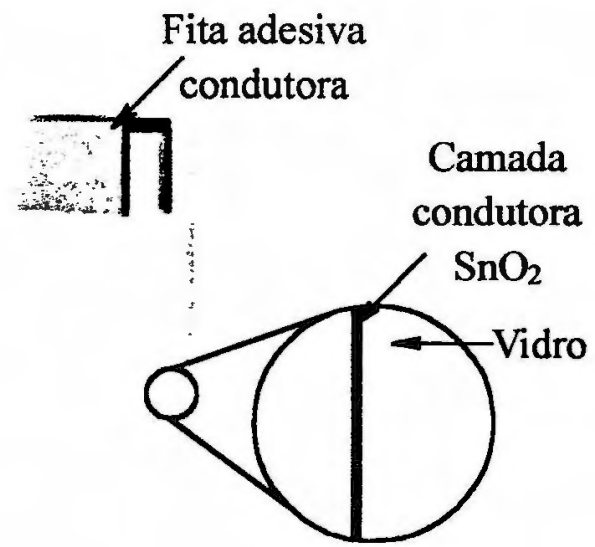

Figura 2.2: Esquema do eletrodo de trabalho utilizado nos experimentos eletroquímicos, eletrodo de vidro com camada condutora de $\mathrm{SnO}_{2}$. um polimento com o mesmo grau de acabamento que o utilizado em dispositivos ópticos. Estes eletrodos possuem $26 \mathrm{~mm}$ de diâmetro, corte AT, e $6 \mathrm{MHz}$ de ressonância padrão. Em ambas as faces do cristal, uma camada de ouro na forma de filme com área ativa de $0,2 \mathrm{~cm}^{2}$ foi depositado por evaporação a vácuo. Estes eletrodos foram previamente limpos com acetona para remoção de gordura da superficie (Figura 2.3).

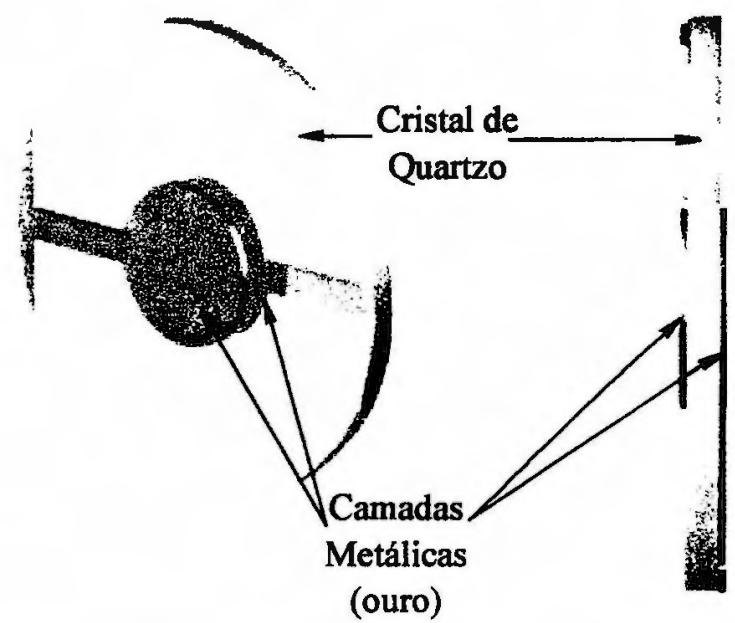

Figura 2.3: Esquema da vista superficial e lateral de um cristal de quartzo com camadas metálicas em ambos os lados. 


\subsubsection{Eletrodos de Referência}

$\mathrm{Na}$ síntese eletroquímica dos polímeros e caracterização espectroeletroquímica o eletrodo de referência utilizado foi o de $\mathrm{Ag} / \mathrm{AgCl}$. Nas medidas eletrogravimétricas utilizou-se um eletrodo de calomelano (ECS), confeccionado no laboratório do Instituto de Química de São Carlos, onde as medidas foram obtidas (Figura 2.4).

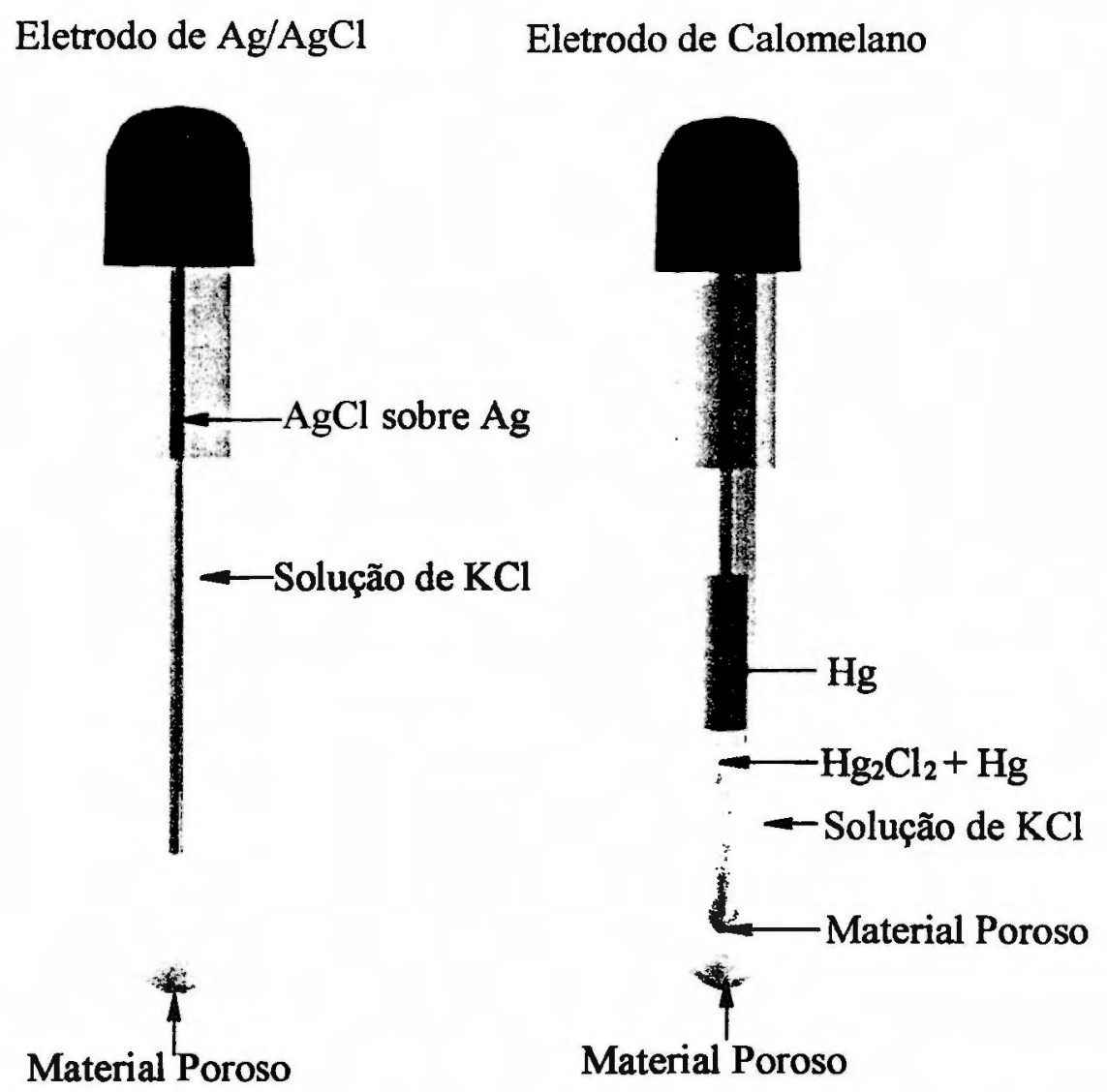

Figura 2.4: Esquema dos eletrodos de referência, eletrodo de $\mathrm{Ag} / \mathrm{AgCl}$ e calomelano.

\subsubsection{Contra Eletrodos}

Em todas as medidas eletroquímicas o contra eletrodo utilizado foi um fio de platina enrolado em espiral ou não, dependendo do tamanho da célula eletroquímica. Estes contraeletrodos foram previamente limpos com a aplicação de chama na parte em que o eletrodo entra em contato com a solução. 


\subsubsection{Soluções Utilizadas}

No preparo das soluções utilizou-se anilina, 2-etilanilina e N-etilanilina obtidos da Aldrich, destilados, armazenados em geladeira e protegidos da luz. $\mathrm{O}$ ácido clorídrico $(\mathrm{HCl})$, ácido perclórico $\left(\mathrm{HClO}_{4}\right)$, ácido $p$-tolueno sulfônico (PTSA), hidróxido de potássio $(\mathrm{KOH})$, perssulfato de potássio $\left(\mathrm{K}_{2} \mathrm{~S}_{2} \mathrm{O}_{8}\right)$ acetato de etila, $\mathrm{NN}$ '-dimetilformamida (DMFA), foram obtidos da Merk em grau analítico e utilizados sem nenhum tratamento prévio. $\mathrm{O}$ ácido canforssulfônico (HCSA) foi obtido da Aldrich e para as medidas espectroscópicas este ácido foi previamente recristalizado em acetato de etila para a remoção de algumas impurezas coloridas. Acetona e clorofórmio $\left(\mathrm{CHCl}_{3}\right)$ grau analítico foram obtidos da Nuclear e também utilizados sem qualquer tratamento prévio, assim como a $\mathrm{N}$-metil-2-pirrolidona obtida da Aldrich. Em todas as preparações utilizou-se água deionizada (purificador Elga UHQ).

\subsubsection{Soluções Eletrolíticas}

Na síntese eletroquímica dos polímeros (Tabela 2.1) utilizou-se uma concentração de monômero ou mistura de monômeros de $0,5 \mathrm{~mol} / \mathrm{L}$. As soluções contendo monômeros foram preparadas, guardadas em geladeira e protegidas da luz para evitar a oxidação. Todos os eletrólitos utilizados nos experimentos eletroquímicos consistiam de soluções ácidas aquosas (Tabela 2.2).

Tabela 2.1: Concentrações das soluções utilizadas na síntese eletroquímica dos homopolímeros e copolímeros.

\begin{tabular}{|c|c|}
\hline \multicolumn{2}{|l|}{ Soluções Utilizadas na Sintese Eletroquímica } \\
\hline Anilina $(0,50 \mathrm{~mol} / \mathrm{L})+\mathrm{HCl}(1,00 \mathrm{~mol} / \mathrm{L})$ & $\mathrm{f}_{1}=0,0$ \\
\hline Anilina $(0,45 \mathrm{~mol} / \mathrm{L})+2$-etilanilina $(0,05 \mathrm{~mol} / \mathrm{L})+\mathrm{HCl}(1,00 \mathrm{~mol} / \mathrm{L})$ & $\mathrm{f}_{1}=0,1$ \\
\hline Anilina $(0,35 \mathrm{~mol} / \mathrm{L})+2$-etilanilina $(0,15 \mathrm{~mol} / \mathrm{L})+\mathrm{HCl}(1,00 \mathrm{~mol} / \mathrm{L})$ & $f_{1}=0,3$ \\
\hline Anilina $(0,25 \mathrm{~mol} / \mathrm{L})+2$-etilanilina $(0,25 \mathrm{~mol} / \mathrm{L})+\mathrm{HCl}(1,00 \mathrm{~mol} / \mathrm{L})$ & $f_{1}=0,5$ \\
\hline Anilina $(0,15 \mathrm{~mol} / \mathrm{L})+2$-etilanilina $(0,35 \mathrm{~mol} / \mathrm{L})+\mathrm{HCl}(1,00 \mathrm{mo} / \mathrm{L})$ & $f_{1}=0,7$ \\
\hline Anilina $(0,05 \mathrm{~mol} / \mathrm{L})+2$-etilanilina $(0,45 \mathrm{~mol} / \mathrm{L})+\mathrm{HCl}(1,00 \mathrm{mo} / \mathrm{L})$ & $f_{1}=0,9$ \\
\hline 2-etilanilina $(0,50 \mathrm{mo} / \mathrm{L})+\mathrm{HCl}(1,00 \mathrm{~mol} / \mathrm{L})$ & $f_{1}=1,0$ \\
\hline \multicolumn{2}{|l|}{ N-etilanilina $(0,50 \mathrm{~mol} / \mathrm{L})+\mathrm{HCl}(1,00 \mathrm{~mol} / \mathrm{L})$} \\
\hline \multicolumn{2}{|l|}{ Anilina $(0,50 \mathrm{~mol} / \mathrm{L})+\mathrm{HCSA}(1,00 \mathrm{~mol} / \mathrm{L})$} \\
\hline 2-etilanilina $(0,50 \mathrm{mo} / \mathrm{L})+\operatorname{HCSA}(1,00 \mathrm{~mol} / \mathrm{L})$ & \\
\hline
\end{tabular}


Tabela 2.2: Soluções eletroliticas utilizadas nos experimentos eletroquimicos.

\begin{tabular}{|c|}
\hline Soluções Eletrolíticas \\
\hline $\mathrm{HCl}(0,8 \mathrm{~mol} / \mathrm{L})$ \\
\hline $\mathrm{HClO}_{4}(0,8 \mathrm{~mol} / \mathrm{L})$ \\
\hline $\operatorname{PTSA}(0,8 \mathrm{~mol} / \mathrm{L})$ \\
\hline $\mathrm{HCSA}(0,8 \mathrm{~mol} / \mathrm{L})$ \\
\hline
\end{tabular}

\subsubsection{Soluções para Síntese Química}

Para a síntese química utilizou-se uma solução contendo cerca de $0,165 \mathrm{~mol} / \mathrm{L}$ de agente oxidante $\left(\mathrm{K}_{2} \mathrm{~S}_{2} \mathrm{O}_{8}\right)$ e 1,0 mol/L de $\mathrm{HCl}$, em meio aquoso. Esta solução foi preparada no dia de síntese e mantida em banho de gelo até sua utilização. Foi feita uma solução com concentração de $0,165 \mathrm{~mol} / \mathrm{L}$ de monômero ou mistura de monômeros, e 1,0 mol/L de $\mathrm{HCl}$ em meio aquoso. Esta solução também foi mantida em banho de gelo. Foram escolhidas estas concentrações de monômero e agente oxidante pois na síntese química destes polímeros a razão molar entre agente oxidante e monômeros pode variar de 1 a 2 , sendo que pode ocorrer degradação do polímero se uma quantidade muito grande de oxidante for usada [124].

Para a síntese dos copolímeros com frações molares de 2 -etilanilina $\left(f_{1}\right)$ diferentes, foram preparadas várias soluções contendo uma mistura de anilina e 2-etilanilina com diferentes concentrações, porém a concentração total de monômero na solução ficou em $0,165 \mathrm{~mol} / \mathrm{L}$ (Tabela 2.3).

Tabela 2.3: Concentrações das soluções utilizadas na sintese química dos homopolimeros e copolímeros.

\begin{tabular}{|l|l|}
\hline \multicolumn{2}{|c|}{ Soluções Utilizadas na Síntese Química } \\
\hline $\mathrm{K}_{2} \mathrm{~S}_{2} \mathrm{O}_{8}(0,165 \mathrm{~mol} / \mathrm{L})+\mathrm{HCl}(1,0 \mathrm{~mol} / \mathrm{L})$ & $\mathrm{f}_{1}=0,0$ \\
\hline Anilina $(0,165 \mathrm{~mol} / \mathrm{L})+\mathrm{HCl}(1,0 \mathrm{~mol} / \mathrm{L})$ & $\mathrm{f}_{1}=0,1$ \\
\hline Anilina $(0,149 \mathrm{~mol} / \mathrm{L})+$ 2-etilanilina $(0,017 \mathrm{~mol} / \mathrm{L})+\mathrm{HCl}(1,0 \mathrm{~mol} / \mathrm{L})$ & $\mathrm{f}_{1}=0,3$ \\
\hline Anilina $(0,116 \mathrm{~mol} / \mathrm{L})+$ 2-etilanilina $(0,050 \mathrm{~mol} / \mathrm{L})+\mathrm{HCl}(1,0 \mathrm{~mol} / \mathrm{L})$ & $\mathrm{f}_{1}=0,5$ \\
\hline Anilina $(0,083 \mathrm{~mol} / \mathrm{L})+$ 2-etilanilina $(0,083 \mathrm{~mol} / \mathrm{L})+\mathrm{HCl}(1,0 \mathrm{~mol} / \mathrm{L})$ & $\mathrm{f}_{1}=0,7$ \\
\hline Anilina $(0,050 \mathrm{~mol} / \mathrm{L})+$ 2-etilanilina $(0,116 \mathrm{~mol} / \mathrm{L})+\mathrm{HCl}(1,0 \mathrm{~mol} / \mathrm{L})$ & $\mathrm{f}_{1}=0,9$ \\
\hline Anilina $(0,017 \mathrm{~mol} / \mathrm{L})+$ 2-etilanilina $(0,149 \mathrm{~mol} / \mathrm{L})+\mathrm{HCl}(1,0 \mathrm{~mol} / \mathrm{L})$ & $\mathrm{f}_{1}=1,0$ \\
\hline 2-etilanilina $(0,165 \mathrm{~mol} / \mathrm{L})+\mathrm{HCl}(1,0 \mathrm{~mol} / \mathrm{L})$ &
\end{tabular}




\subsubsection{Equipamentos}

Para a desdopagem destes polímeros e copolímeros foi preparada uma solução de $1,0 \mathrm{~mol} / \mathrm{L}$ de $\mathrm{KOH}$, e para a posterior dopagem, foi preparado uma solução de $1,0 \mathrm{~mol} / \mathrm{L}$ do ácido de interesse.

Nas medidas envolvendo voltametria cíclica foi utilizado um potenciostato da Eco Chemie, Autolab PGSTAT30 quer seja durante a eletrosíntese dos filmes de polímero, ou nos experimentos espectroeletroquímicos nos quais não há variação do comprimento de onda durante a medida. Nestes experimentos foi utilizado um espectrofotômetro Micronal modificado, e os eletrodos conectados ao Autolab.

Nas medidas espectroeletroquímicas onde há variação do comprimento de onda durante o experimento (espectros de absorbância) foi utilizado um potenciostato/galvanostato EG\&G PAR modelo 362 conectado a um registrador $X-Y_{1}-Y_{2}$ (Kipp Zonen), e um espectrofotômetro Hewlett Packard 8453.

Para medidas eletrogravimétricas a variação de freqüência de ressonância padrão foi medido com um contador de tempo universal HP-5370B e as medidas eletroquímicas foram feitas com um potenciostato/galvanostato FAC-2001.

Foi utilizado um equipamento Renishaw Raman Imaging Microscope (system 3000) contendo um microscópio Olympus e um detector CCD (Wright, 600x400 pixels) para obtenção dos espectros Raman Ressonante, com um laser de He-Ne (Spectra Physics, mod. 127) cujo comprimento de onda foi de $632,8 \mathrm{~nm}$. O feixe do laser foi focado na amostra utilizando uma lente de $80 \mathrm{x}$. A potência do laser foi mantido abaixo de $0,7 \mathrm{~mW}$ para evitar a degradação da amostra.

Para medidas de resistividade utilizou-se o método de duas pontas com auxílio do Analisador de Impedância do Autolab PGSTAT30 (Eco Chemie) com o módulo FRA.

\subsection{Metodologias Experimentais}

\subsubsection{Eletroquímica}

A polianilina tem uma grande associação com a eletroquímica, pois ela foi sintetizada e estudada eletroquimicamente por vários cientistas desde a primeira publicação em 1962 [125]. Muito do interesse na polianilina vem dos estudos de Diaz e Logan [126] que observaram que filmes de polianilina preparados a potencial constante não se aderem bem ao eletrodo, enquanto que filmes preparados em varredura cíclica de potencial possuem boa aderência, além de serem mais homogêneos. A investigação eletroquímica das polianilinas por voltametria cíclica é importante no entendimento de suas propriedades físico-químicas e na exploração de suas aplicações. 
Voltametria cíclica (VC) é um experimento eletroquímico reversível controlado pelo potencial, sendo que uma varredura cíclica de potencial é aplicada a um eletrodo e a resposta de corrente é observada. A análise da resposta de corrente pode fornecer informações sobre a termodinâmica e cinética de transferência de elétrons na interface formada pela solução e o eletrodo, assim como informações sobre a cinética e o mecanismo da reação química iniciada na solução por uma transferência heterogênea de elétrons.

Um potenciostato controla todos os parâmetros do experimento, uma varredura cíclica linear de potencial é aplicado a um eletrodo (o eletrodo de trabalho). Esta varredura de potencial é. caracterizada por um potencial inicial $\left(E_{\mathrm{i}}\right)$, um potencial de mudança $\left(\mathrm{E}_{\mathrm{m}}\right)$, um potencial final $\left(\mathrm{E}_{\mathrm{f}}\right)$ è a velocidade de varredura ( $\mathrm{v}$, em $\mathrm{V} / \mathrm{s})$, varreduras mais complicadas podem ser feitas, além da utilização de múltiplos ciclos (Figura 2.5).

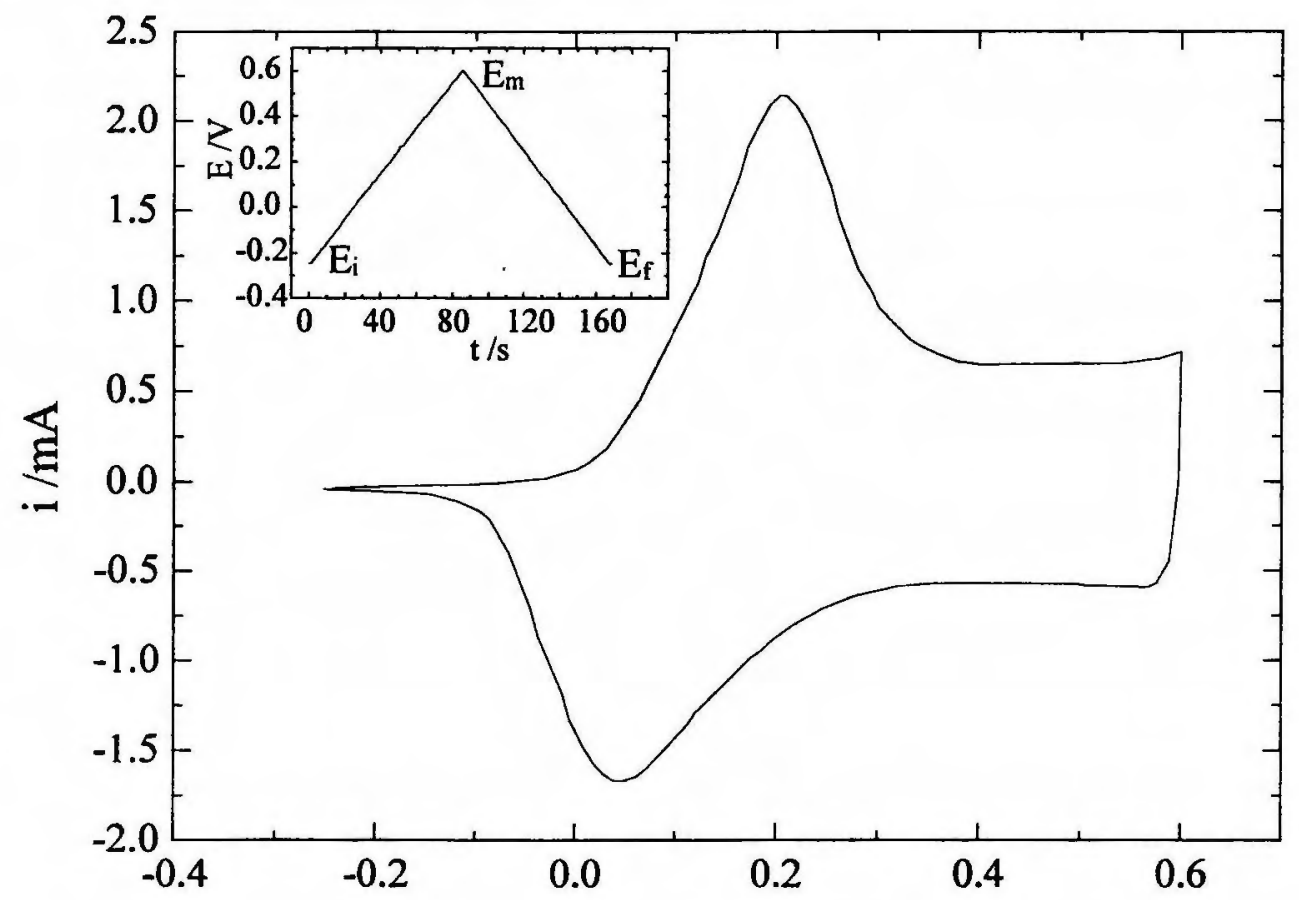

$\mathrm{E} / \mathrm{V}$

Figura 2.5: Voltamograma cíclico da polianilina em $0,8 \mathrm{~mol} / \mathrm{L}$ de $H C l, v=10 \mathrm{mV} / \mathrm{s}$ e a varredura de potencial aplicada à polianilina, em função do tempo.

A reação eletroquímica de interesse ocorre no eletrodo de trabalho, e a corrente elétrica devido à transferência de elétrons para/do eletrodo de trabalho é chamada de corrente faradaica. Um eletrodo auxiliar, o contra eletrodo, é controlado pelo potenciostato para contrabalançar o processo faradaico que ocorre no eletrodo de trabalho, com uma transferência de elétrons na direção oposta, ou seja, se ocorre uma redução no eletrodo de trabalho, no contra eletrodo ocorrerá uma oxidação. Geralmente o processo que ocorre no contra eletrodo não é de interesse para o experimento eletroquímico. A resposta da voltametria cíclica é registrada como corrente em função do potencial aplicado. 
A célula eletroquímica mais simples é composta de três eletrodos imersos em uma solução contendo o solvente, eletrólito, e uma ou mais espécies eletroativas de interesse (Figura 2.6), pode ser adicionado reagentes que reajam com os produtos formados durante a reação. Normalmente é necessário remover o oxigênio dissolvido na solução, pois este poderá ser reduzido produzindo uma corrente catódica que poderá interferir na resposta de corrente. Isto normalmente é feito com a introdução de gases inertes como $\mathrm{N}_{2}$ ou Ar, através de borbulhamento na solução.

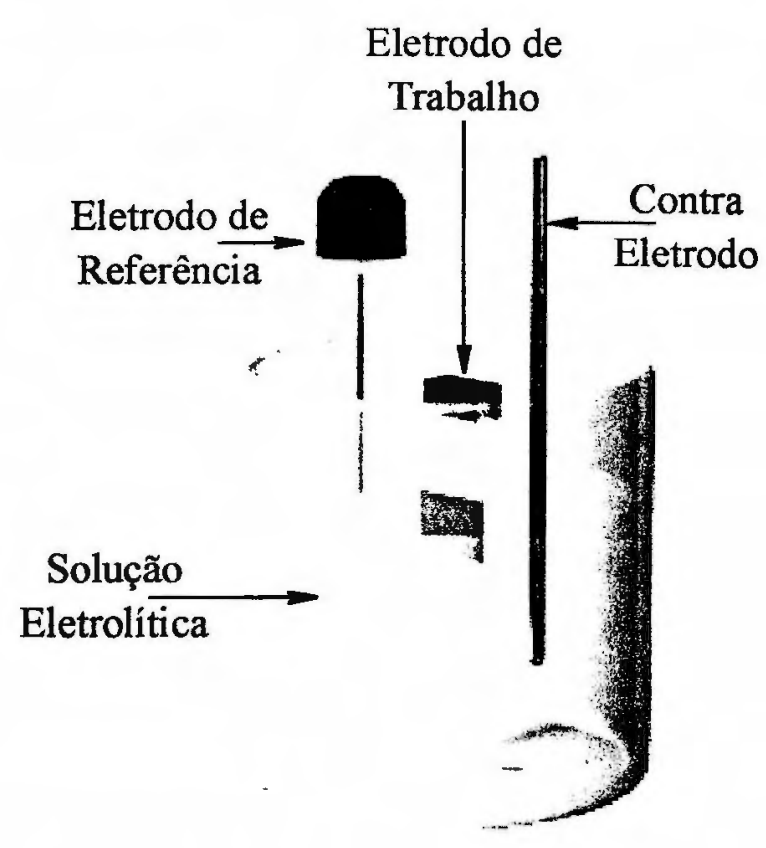

A escolha do solvente é determinada por vários fatores, como condutância, solubilidade do eletrólito e das substâncias

Figura 2.6: Esquema da célula eletroquímica utilizada nos experimentos. eletroativas, reatividade com produtos eletrolíticos, dentre outros. $O$ solvente também pode ter propriedades importantes, como por exemplo diminuir efeitos indesejados como a adsorção das espécies eletroativas no eletrodo. Devido a importância do solvente em experimentos eletroquímicos é necessário levar em consideração as propriedades físicas e químicas do solvente.

O eletrólito adicionado à solução é utilizado para aumentar a condutividade, minimizar a dupla camada elétrica e efeitos de migração de corrente. $O$ eletrólito é escolhido com base em sua solubilidade no solvente utilizado, assim como na sua inabilidade de reagir com as espécies eletroativas ou produtos do processo eletroquímico.

Eletrodos sólidos na forma de discos são os mais comumente empregados em voltametria cíclica como eletrodo de trabalho devido a facilidade de manufatura e utilização. Dentre os materiais são utilizados platina, carbono vítreo, ouro, prata, ou amalgamas. O eletrodo de trabalho deve facilitar a transferência de elétrons com a espécie eletroativa. Fatores que facilitam a transferência heterogênea ainda não foram bem entendidos, porém um pré-tratamento como polimento do eletrodo de trabalho, banho em ultra-som, ciclagem no potencial do eletrodo pode melhorar o seu desempenho, provavelmente pela remoção de sujeira e rugosidade do eletrodo. Alguns efeitos que prejudicam a resposta na voltametria cíclica como resistência da solução ou corrente capacitiva podem ser minimizados utilizando eletrodos de trabalho com área pequena, e aproximando os eletrodos.

Os eletrodos de referência mais comumente utilizados em soluções aquosas, são os eletrodos de $\mathrm{Ag} / \mathrm{AgCl}$ e calomelano. Se eletrodos de referência para meio aquoso forem utilizados em soluções não aquosas, aparecerá altos valores de potencial de junção, e geralmente ocorrerão contaminações das 
soluções não-aquosas. É sugerido o uso de eletrodo de $\mathrm{Ag} / \mathrm{AgCl}$ em meio não aquoso para soluções não aquosas.

Os potenciais de junção líquida são o resultado das diferentes mobilidades de cátions e ânions, sob a influência de um campo elétrico. O potencial manifesta-se na interface entre duas soluções diferentes, separadas por um separador poroso ou por uma membrana. Para evitar valores elevados de potencial de junção líquida, recomenda-se que os íons presentes no solvente utilizado tenha mobilidade e concentração semelhante aos do solvente do eletrodo de referência. É necessário uma boa manutenção do eletrodo de referência para evitar qualquer variação de potencial com o tempo.

Uma célula eletroquímica, devido aos seus componentes: solvente-eletrólito-eletrodo de trabalho, possui um certo intervalo de potencial na qual as informações podem ser coletadas, esta faixa de potencial é chamada de "janela" de potencial.

\subsubsection{Estudo Voltamétrico do Substrato}

Os perfis voltamétricos dos eletrodos nos diferentes eletrólitos foram obtidos por Voltametria Cíclica (Varredura Linear de Potenciais) de forma à garantir que não haveria nenhum processo redox devido apenas ao eletrodo, ou ao eletrólito, no intervalo de potenciais utilizado para os estudos eletroquímicos. Estes eletrodos foram ciclados em uma solução contendo $0,8 \mathrm{~mol} / \mathrm{L}$ de eletrólito $\left(\mathrm{HCl}, \mathrm{HClO}_{4}, \mathrm{PTSA}\right.$ ou $\mathrm{HCSA}$ ) entre $-0,2 \mathrm{~V}$ e $1,0 \mathrm{~V}$ contra $\mathrm{Ag} / \mathrm{AgCl}$ e com velocidade de varredura de $10 \mathrm{mV} / \mathrm{s}$. Observou-se que neste intervalo de potencial não aparece qualquer processo faradaico, mostrando que o eletrólito, solvente e eletrodo são inertes na zona de potencial da experiência.

\subsubsection{Síntese Eletroquímica dos Polímeros}

Os filmes de polianilina, poli(2-etilanilina), poli(N-etilanilina) e poli(anilina-co-2-etilanilina) foram sintetizados eletroquímicamente através de varreduras triangulares de potencial (método potenciodinâmico), sobre o eletrodo de vidro com camada de $\mathrm{SnO}_{2}$, (área ativa de $0,7 \mathrm{~cm}^{2}$ ) para medidas eletroquímicas e espectroeletroquímicas, ou sobre cristal de quartzo, (área ativa de $0,2 \mathrm{~cm}^{2}$ ) para medidas eletrogravimétricas. As células eletroquímicas estão mostradas na Figura 2.1 .

Os intervalos de potencial foram de $-0,25 \mathrm{~V}$ até $0,75 \mathrm{~V}$ para polianilina, e de $-0,25 \mathrm{~V}$ até $0,85 \mathrm{~V}$ para a poli(2-etilanilina) e copolímeros, com velocidade de varredura de $50 \mathrm{mV} / \mathrm{s}$ e $10 \mathrm{mV} / \mathrm{s}$, a temperatura ambiente. Os polímeros formados estão relacionados na Tabela 2.4. 
Tabela 2.4: Polimeros formados eletroquimicamente, as porcentagens referem-se a composição (em moles) da solução de sintese.

\begin{tabular}{|l|l|}
\hline \multicolumn{2}{|c|}{$\begin{array}{c}\text { Composição (em moles) da solução de síntese } \\
\text { dos polimeros formados eletroquimicamente }\end{array}$} \\
\hline $100 \%$ anilina & $\mathrm{f}_{1}=0,0$ \\
\hline $90 \%$ anilina $+10 \%$ 2-etilanilina & $\mathrm{f}_{1}=0,1$ \\
\hline $70 \%$ anilina $+30 \%$ 2-etilanilina & $\mathrm{f}_{1}=0,3$ \\
\hline $50 \%$ anilina $+50 \%$ 2-etilanilina & $\mathrm{f}_{1}=0,5$ \\
\hline $30 \%$ anilina $+70 \%$ 2-etilanilina & $\mathrm{f}_{1}=0,7$ \\
\hline $10 \%$ anilina $+90 \%$ 2-etilanilina & $\mathrm{f}_{1}=0,9$ \\
\hline $100 \%$ 2-etilanilina & $\mathrm{f}_{1}=1,0$ \\
\hline
\end{tabular}

Os potenciais estão referidos em relação ao eletrodo de referência de $\mathrm{Ag} / \mathrm{AgCl}$, sendo utilizado um contra eletrodo de platina. Para cada um dos experimentos realizados um novo filme foi sintetizado.

Para filmes de poli(N-etilanilina) tentou-se várias faixas de potencial, técnicas de varreduras diferentes, e diferentes concentrações de monômero e ácido, porém os filmes formados não possuíam aderência suficiente ao eletrodo. Para os estudos eletroquímicos e espectroeletroquímicos deste polímero, foi necessário sintetizá-lo quimicamente, dissolvê-lo em NMP e através da pintura do eletrodo com a solução contendo o polímero ("casting"), formar um filme sobre o eletrodo de vidro com camada condutora de $\mathrm{SnO}_{2}$.

$\mathrm{O}$ tempo de crescimento dos filmes sobre eletrodo de vidro com camada de $\mathrm{SnO}_{2}$ foi controlado pela carga registrada em cada ciclo de potencial, deixou-se atingir uma carga catódica de $4,2 \times 10^{-3} \mathrm{C}$ para todos os filmes formados. Utilizou-se a carga catódica para avaliar a quantidade de polímero formado sobre o eletrodo, pois na carga anódica tem-se também a contribuição da oxidação dos monômeros, e não apenas a oxidação do polímero. Após a formação do filme, o eletrodo era lavado com água deionizada.

Para os filmes formados sobre o eletrodo de cristal de quartzo o tempo de crescimento foi controlado pela variação de freqüência registrada a partir do eletrodo limpo. Como os polímeros e copolímeros de 2-etilanilina crescem muito lentamente sobre estes eletrodos, os filmes obtidos foram extremamente finos (Tabela 2.5). 
Tabela 2.5: Polimeros formados eletroquimicamente para medidas eletrogravimétricas, as porcentagens referemse a composição (em moles) da solução de síntese.

\begin{tabular}{|c|c|c|c|c|}
\hline \multicolumn{5}{|c|}{ 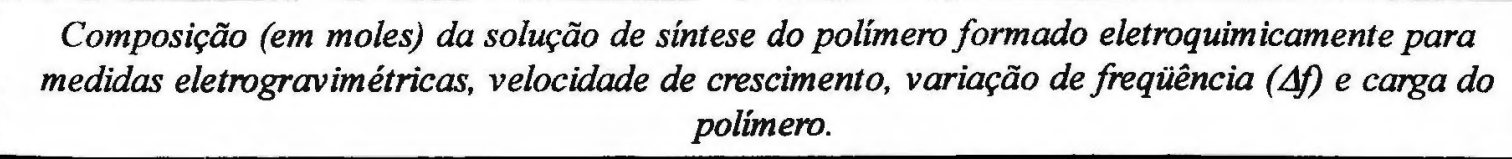 } \\
\hline & $\mathrm{f}$ & $\begin{array}{c}\text { Velocidade } \\
(\mathrm{mV} / \mathrm{s})\end{array}$ & $\begin{array}{l}\text { Variação de } \\
\text { freqüência } \\
\quad(\mathrm{Hz})\end{array}$ & $\begin{array}{l}\text { Carga } \\
\text { (C) }\end{array}$ \\
\hline $100 \%$ anilina $\mathrm{em} 0,8 \mathrm{~mol} / \mathrm{L}$ & 0,0 & 10 & $\sim 7300$ & $2,9 \times 10^{-1}$ \\
\hline $100 \%$ anilina em $0,8 \mathrm{~mol} / \mathrm{L}$ & 0,0 & 50 & $\sim 1100$ & $9,0 \times 10^{-3}$ \\
\hline $100 \%$ 2-etilanilina em $0,8 \mathrm{~mol} / \mathrm{HCl}$ & 1,0 & 50 & $\sim 1200$ & $4,2 \times 10^{-3}$ \\
\hline $100 \%$ 2-etilanilina em $0,8 \mathrm{~mol} / \mathrm{L}$ de $\mathrm{HCSA}$ & 1,0 & 50 & $\sim 1200$ & $3,0 \times 10^{-3}$ \\
\hline $50 \%$ anilina $+50 \%$ 2-etilanilina em $0,8 \mathrm{molL}$ de $\mathrm{HCl}$ & 0,5 & 10 & $\sim 700$ & $1,9 \times 10^{-2}$ \\
\hline $50 \%$ anilina $+50 \%$ 2-etilanilina em $0,8 \mathrm{~mol} / \mathrm{L}$ de $\mathrm{HCl}$ & 0,5 & 50 & $\sim 600$ & $7,0 \times 10^{-3}$ \\
\hline
\end{tabular}

\subsubsection{Espectroeletroquímica e Espectroscopia UV-Vis}

Quando uma radiação contínua passa através de um material transparente, uma fração desta radiação pode ser absorvida. Se isto ocorrer, a radiação residual, quando atravessa um prisma, gera um espectro descontínuo, chamado de espectro de absorção. Como resultado, com a energia desta radiação absorvida, átomos ou moléculas passam de um estado de menor energia (estado fundamental) para um estado de maior energia (estado excitado).

No caso da espectroscopia no ultravioleta e visível, que está compreendida na região de comprimento entre $190 \mathrm{~nm}$ e $800 \mathrm{~nm}$, as transições resultantes da absorção desta radiação eletromagnética estão na mesma região de energia das transições eletrônicas. Conforme a molécula absorve energia, um elétron é promovido de um orbital ocupado para um orbital vazio de maior energia. Geralmente, as transições mais prováveis são do orbital molecular ocupado de maior energia (HOMO) para o orbital molecular vazio de menor energia (LUMO). As diferenças de energia entre estes níveis eletrônicos da maioria das moléculas variam entre 125 e $650 \mathrm{~kJ} / \mathrm{mol}$.

Para a maioria das moléculas, os orbitais moleculares ocupados de menor energia são os orbitais $\sigma$, que correspondem às ligações $\sigma$. Os orbitais $\pi$ estão em níveis mais altos de energia, e orbitais que possuem pares de elétrons não compartilhados, os orbitais não-ligantes ( $n$ ), estão em níveis ainda maiores. Os orbitais moleculares vazios de maior energia são os orbitais anti-ligantes $\left(\pi^{*}\right.$ e $\left.\sigma^{*}\right)$.

A partir da constatação de que quanto maior o número de moléculas capazes de absorver uma radiação de um determinado comprimento de onda, e quanto mais eficiente for este processo, maior será a absorção, uma expressão empírica surgiu, a lei de Lambert-Beer (Equação 2.1). 


$$
A=\log \left(\frac{I_{0}}{I}\right)=\varepsilon c b
$$

Onde $A$ é a absorbância do material, $I_{0}$ a intensidade da luz incidente na amostra, $I$ a intensidade da luz após passar pela amostra, $c$ é a concentração molar do soluto, $b$ o caminho óptico, e $\varepsilon$ é a absortividade molar.

Embora os elétrons é que sofram a excitação do estado fundamental para o estado excitado, o núcleo ao qual os elétrons estão presos através das ligações, também é importante na determinação do comprimento de onda na qual a absorção acontece. $O$ núcleo determina a força com a qual os elétrons estão presos, influenciando assim na energia do espaçamento entre os estados excitado e o fundamental. A energia característica da transição e o comprimento da radiação absorvida são propriedades de um grupo de átomos, e a este grupo de átomos deu-se o nome de grupo cromóforo. Quando ocorre uma mudança estrutural com o cromóforo, a energia e a intensidade de absorção se alteram, alterando também o comprimento de onda da radiação absorvida.

Com a oxidação da polianilina, ocorrem mudanças estruturais no cromóforo, alterando o comprimento de onda da absorção, e a cor do material. Esta alteração da cor do material em função do potencial aplicado é chamado de eletrocromismo.

Se toda a carga elétrica aplicada durante o processo eletroquímico for utilizada para a formação/alteração do cromofóro, pode-se correlacionar esta carga à absorbância, desde que toda a carga consumida durante o processo eletroquímico seja faradaico [127-128].

Derivando a equação de Lambert-Beer pelo tempo tem-se:

$$
\left(\frac{d A}{d t}\right)=\varepsilon b\left(\frac{d c}{d t}\right)
$$

Derivando-se a carga pelo tempo tem-se a corrente:

$$
\begin{gathered}
Q=n z F \quad \quad i=\frac{d Q}{d t}=\frac{d n}{d t} z F \\
\frac{d n}{d t}=\frac{i}{z F}
\end{gathered}
$$

Considerando uma área $a$ na superfície do eletrodo e um volume $V$ de polímero ou material eletroativo de interesse aderido à superfície do mesmo, pode-se relacionar a concentração de sítios cromóforos com o número de moles das espécies eletroativas, se toda corrente foi utilizada para formação ou alteração da espécie cromófora. 


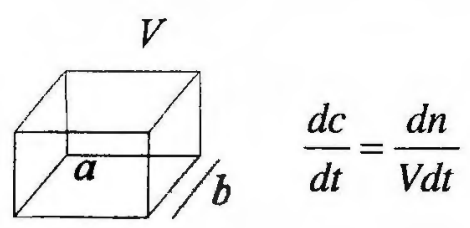

Da equação 2.3 com a equação 2.4 obtém-se:

$$
\frac{d c}{d t}=\frac{i}{V z F} \quad \frac{d c}{d t}=\frac{i}{a b z F}
$$

A densidade de carga é dada por:

$$
\begin{gathered}
j=\frac{i}{a} \\
\frac{d c}{d t}=\frac{j}{b z F}
\end{gathered}
$$

Da equação 2.2 com a equação 2.7 obtém-se:

$$
\begin{gathered}
\left(\frac{d A}{d t}\right)=\varnothing b\left(\frac{d c}{d t}\right)=\varnothing b \frac{j}{b z F}=\left(j \frac{\varepsilon}{z F}\right) \\
\left(\frac{d A}{d t}\right)=\left(j \frac{\varepsilon}{z F}\right)
\end{gathered}
$$

onde $c$ é a concentração de sítios opticamente ativos formados ou alterados durante o processo eletroquímico, $j$ é a densidade de corrente, $z$ é o número de elétrons que participam da reação, e $F$ é a constante de Faraday.

\subsubsection{Caracterização Espectroeletroquímica dos Polímeros}

Registrou-se tanto o espectro de absorbância na região do visível dos polímeros e copolímeros em vários potenciais, quanto a variação de transmitância para comprimentos de onda fixos.

Para registro do espectro de absorbância o eletrodo contendo o filme polimérico foi colocado em uma cubeta de acrílico, cuja "janela espectral" é adequada ao experimento. Além de ser uma cubeta barata e facilmente modificável conforme as necessidades do experimento.

A cubeta foi posicionada no caminho óptico do espectrofotômetro e preenchida com uma solução $0,8 \mathrm{~mol} / \mathrm{L}$ de eletrólito sem monômero. Adaptou-se uma tampa para a cubeta, na qual 
acoplou-se o eletrodo de referência de $\mathrm{Ag} / \mathrm{AgCl}$ e um fio de platina como contra-eletrodo.

Foram feitas algumas varreduras cíclicas de potencial entre $-0,25 \mathrm{~V}$ e $0,75 \mathrm{~V}$ até que o voltamograma ficasse estável, a uma velocidade de $10 \mathrm{mV} / \mathrm{s}$. Em seguida foi registrado o espectro de absorbância de $350 \mathrm{~nm}$ até $900 \mathrm{~nm}$, a cada $0,10 \mathrm{~V}$ desde $-0,25 \mathrm{~V}$ até $0,75 \mathrm{~V}$, para cada um dos eletrólitos, à temperatura ambiente.

Registrou-se também a variação de transmitância em função do potencial para quatro comprimentos de onda fixos, $420,520,620$ e $700 \mathrm{~nm}$. O filme foi colocado na mesma célula eletroquímica utilizada nos estudos eletroquímicos com uma solução $0,8 \mathrm{~mol} / \mathrm{L}$ de eletrólito, e esta célula foi colocada no caminho óptico do espectrofotômetro (Figura 2.7). Para cada comprimento de onda e eletrólito, foi registrado o voltamograma e a variação de transmitância em função do potencial, na faixa de $-0,25 \mathrm{~V}$ até $0,75 \mathrm{~V}$, a uma velocidade de $10 \mathrm{mV} / \mathrm{s}$, à temperatura ambiente.

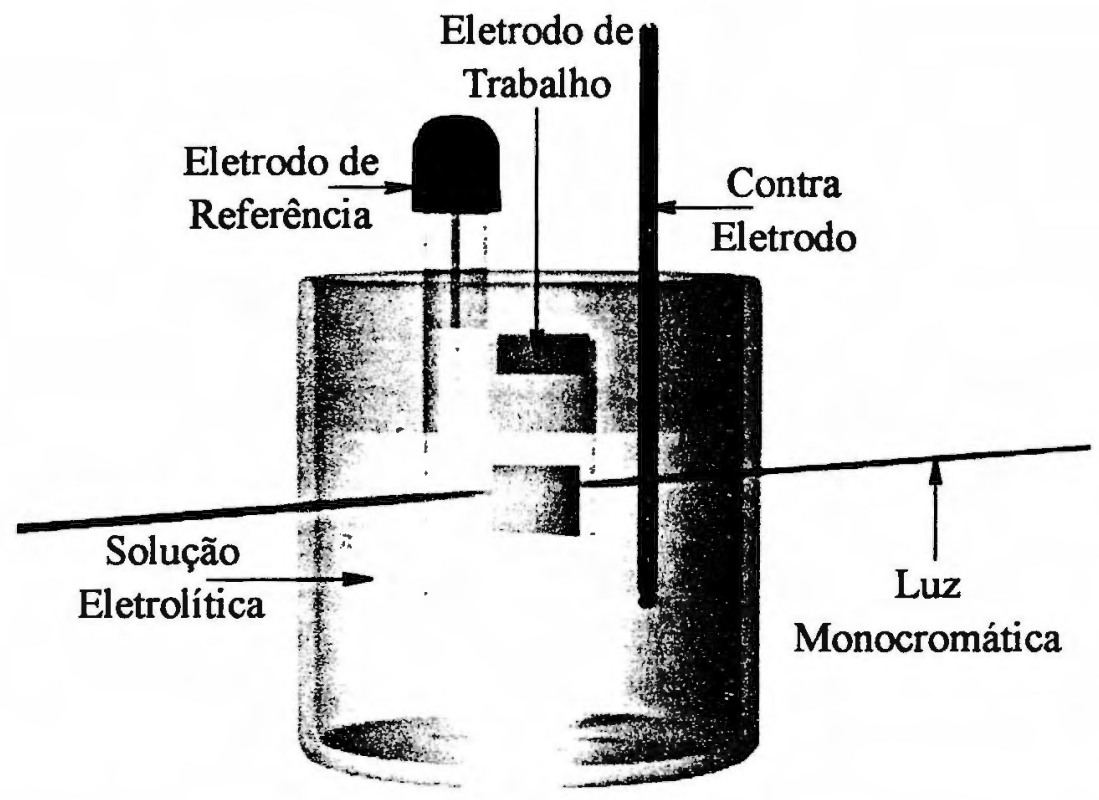

Figura 2.7: Esquema da célula eletroquimica utlizada para medidas espectroeletroquimicas.

\subsubsection{Medidas Eletrogravimétricas}

Como a eletroquímica estuda fundamentalmente sistemas interfaciais e volumétricos (inserções), é extremamente importante o conhecimento dos fluxos de carga e massa através da interface eletrodo-solução, para entender como a estrutura e a natureza físico-química das espécies afetam a transferência de carga. Incluída no grupo das técnicas in-situ, a microbalança eletroquímica a cristal de quartzo (MECQ) tem se mostrado uma ferramenta importante no 
estudo de reações eletroquímicas que produzam modificações na interface eletrodo-eletrólito, e que sejam detectados pela técnica, já que esta é uma técnica de baixo custo quando comparado com outras técnicas eletroquímicas.

Nos primeiros trabalhos, a microbalança a cristal de quartzo (MCQ) foi utilizada ex-situ para medir massas de metais eletrodepositados sobre eletrodos [129-130]. Posteriormente, os métodos experimentais requeridos para utilização da microbalança a cristal de quartzo como sensor de massa in-situ para estudo de filmes finos sobre eletrodos foram desenvolvidos independentemente por vários grupos [131-135]. Uma vez que a microbalança começou a ser utilizada in-situ em sistemas eletroquímicos, esta técnica passou a ser denominada MECQ em lugar de MCQ. Nos últimos anos, a MECQ começou a ser utilizada de maneira mais sofisticada, empregando além das medidas de variação de freqüência, medidas de impedância eletroacústica do cristal de quartzo.

O princípio de operação da microbalança a cristal de quartzo está relacionado com o princípio piezoelétrico. Este efeito se deve à propriedade de certos materiais de gerarem um campo elétrico quando submetidos à deformações ou pressões externas, e uma variação na polaridade da perturbação mecânica, provoca uma variação na polaridade do campo elétrico gerado. Este fenômeno é denominado efeito piezoelétrico direto e os cristais que possuem esta propriedade são chamados de cristais piezoelétricos. Também é possível aplicar um campo elétrico sobre o material piezoelétrico provocando deformações mecânicas no cristal, as quais podem variar com a variação do campo elétrico aplicado. Neste caso, observa-se a ocorrência do efeito piezoelétrico reverso.

Quando a perturbação elétrica tem as características adequadas (amplitude e freqüência), as quais são determinadas pela geometria e propriedades do cristal, este oscilará mecanicamente em um modo ressonante [136]. Nestas condições o cristal piezoelétrico pode oscilar em seu modo de cisalhamento (propagação da onda perpendicular ao campo elétrico). No caso da microbalança a cristal de quartzo, o campo elétrico é aplicado sobre as deposições metálicas em ambas as faces do cristal (Figura 2.8).

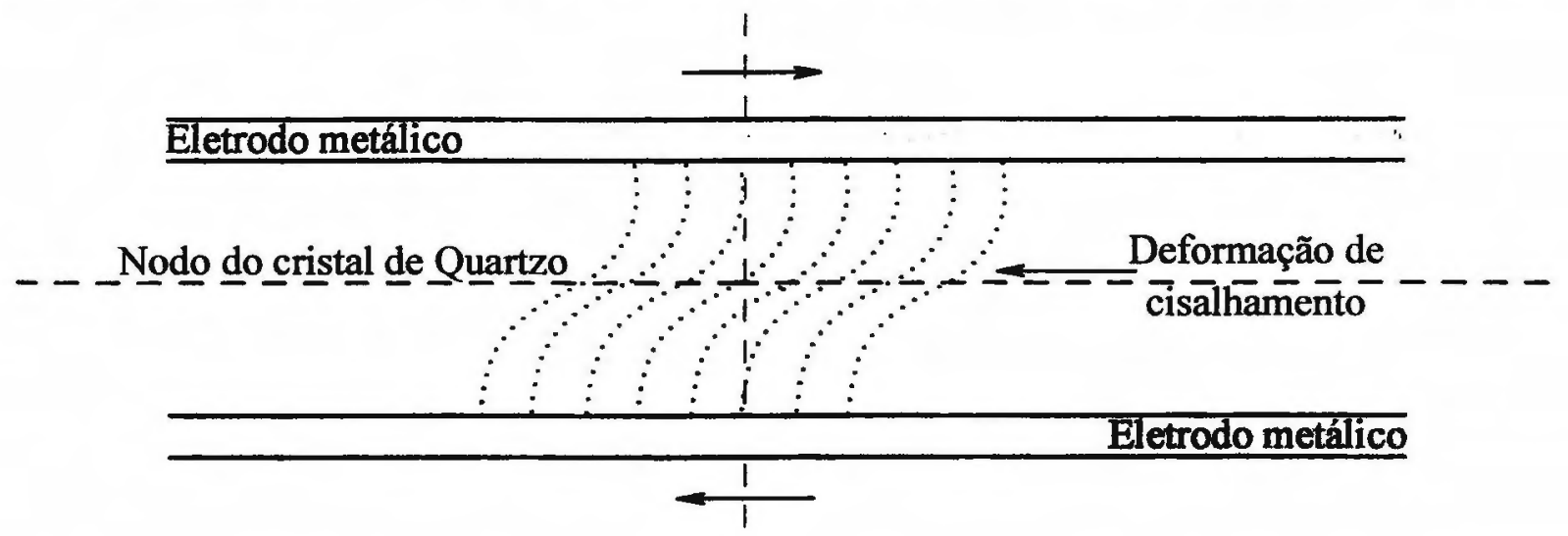

Figura 2.8: Representação esquemática de um cristal de quartzo, mostrando o nodo da onda acústica passando pelo centro do disco e a deformação causada pelo cisalhamento. 
Com uma excitação de $1 \mathrm{~V}$ e utilizando freqüências entre 5 e $15 \mathrm{MHz}$, com um dos eletrodos conectados à terra, se cria uma onda de cisalhamento no cristal com um deslocamento físico paralelo ao plano da superfície e perpendicular ao campo elétrico aplicado. A freqüência da onda acústica está relacionada com a espessura do cristal segundo a equação:

$$
f_{0}=\frac{v}{2 t_{c}} \quad v=\left(\frac{\mu_{C}}{\rho_{c}}\right)^{\frac{1}{2}}
$$

Onde $v$ é a velocidade de propagação da onda acústica no quartzo $(3340 \mathrm{~m} / \mathrm{s}$ para um cristal de corte AT), $t_{c}$ é a espessura do disco, $\mu_{C}$ é o módulo de cisalhamento $\left(2,9 \times 10^{11} \mathrm{~g} / \mathrm{cms}^{2}\right)$ e $\rho_{\mathrm{C}}$ é a densidade do quartzo $\left(2,65 \mathrm{~g} / \mathrm{cm}^{2}\right)$.

Os distintos tipos de cristais são obtidos dependendo do ângulo de corte em relação ao eixo do monocristal. No caso de aplicações utilizando a microbalança a cristal de quartzo os mais comuns são AT, BT e SC, definidos de acordo com o ângulo de corte em relação ao eixo $\mathrm{z}$, como por exemplo $35^{\circ} \mathrm{e}-45^{\circ}$ para cortes $\mathrm{AT}$ e BT, respectivamente. $\mathrm{O}$ mais utilizado é o corte AT pois praticamente independe da temperatura de trabalho. O corte SC apresenta uma particularidade importante porque elimina a influência de pressões externas sobre as variações de freqüências, mas não tem sido muito utilizado no caso da microbalança a cristal de quartzo. No entanto, é importante ressaltar que a dependência com a temperatura, no caso da microbalança a cristal de quartzo em líquido, está relacionada fundamentalmente com as variações de viscosidade do mesmo.

Os cristais podem ser obtidos comercialmente com diferentes tratamentos superficiais. Os mais comuns são os polidos mecanicamente e opticamente rugosos. As superfícies com estas características incrementam a aderência do metal sobre o cristal, mas podem causar problemas na determinação das variações de freqüência quando o cristal é transferido do ar para o líquido. Superfícies com outras características são obtidas com polimento químico, tais tratamentos produzem superfícies com polimento de qualidade óptica, e estes cristais têm uma boa estabilidade em altas freqüências.

As freqüências fundamentais mais utilizadas estão entre 5 e $10 \mathrm{MHz}$ porque os cristais têm espessuras razoáveis que facilitam o manuseio e o arranjo experimental. Como a sensibilidade de deteç̧ão depende da freqüência de ressonância, a sensibilidade é maior para freqüências maiores, o compromisso entre facilidade de manuseio e a sensibilidade indica que, para a maioria dos casos, excelentes resultados são obtidos com cristais cuja freqüência característica está entre 5 e $10 \mathrm{MHz}$.

Em geral, um dos maiores problemas experimentais está relacionado com a aderência dos depósitos metálicos sobre as faces do cristal de quartzo, pois uma má aderência produz uma grande instabilidade na freqüência de ressonância medida. Normalmente utiliza-se cromo 
para aumentar a aderência, no entanto isto representa um problema do ponto de vista eletroquímico tendo em vista que o cromo pode se difundir através do metal de interesse. Outra possibilidade é fazer um tratamento químico sobre a superfície do cristal com um adesivo molecular como o (3-mercaptopropil) trimetoxisilano antes de depositar o metal por evaporação [137], este processo produz filmes metálicos com excelente aderência e uma alta qualidade sob o ponto de vista eletroquímico.

No experimento eletroquímico uma das faces do cristal é o eletrodo de trabalho, entrando em contado com a solução eletrolítica. Neste eletrodo, uma reação redox é produzida pela aplicação de um potencial ou corrente. Para induzir a oscilação mecânica, um campo elétrico é aplicado entre os dois depósitos metálicos sobre o cristal. A aplicação de um campo elétrico alternado produz a oscilação do cristal, esta oscilação está confinada pela superfície do filme metálico depositado. Para prender o cristal à célula eletroquímica pode-se utilizar anéis com alta resistência química e elasticidade (silicone ou viton), sendo que o diâmetro destes anéis devem ser maiores que a superfície ativa (definida pelo diâmetro do filme metálico depositado) para evitar tensões mecânicas na zona de oscilação do cristal. É necessário também que o circuito elétrico utilizado para produzir a oscilação mecânica e medir a freqüência de ressonância esteja situado o mais próximo possível do quartzo para evitar interferências que produzam variações da freqüência de oscilação.

O circuito oscilador é que determina as características da microbalança a cristal de quartzo, sendo necessário produzir oscilações no cristal em meios altamente viscosos. Existem vários tipos diferentes de circuitos utilizados, alguns dos quais utilizam um quartzo de referência externo à célula eletroquímica e medem a diferença entre as variações de freqüência de ressonância do quartzo de trabalho em relação ao de referência. Os circuitos mais utilizados são em geral baseados no oscilador de Pierce-Miller [138], onde modificações são realizadas para aumentar a potência, podendo assim estudar meios mais viscosos. Nestes circuitos um dos eletrodos está conectado à terra, facilitando sua conexão com os equipamentos eletroquímicos, como por exemplo um potenciostato. Esta configuração determina que o eletrodo de trabalho do potenciostato/galvanostato tem que estar conectado à terra real.

As variações na freqüência que correspondem a uma adição ou subtração de massa podem ser descritas utilizando a equação de Sauerbrey [139]:

$$
\Delta f=-\left(\frac{2 f_{0}^{2}}{A \sqrt{\mu_{c} \rho_{c}}}\right) \Delta M=-K \Delta M
$$

Onde $\Delta f$ é a variação de frequiência de ressonância em $\mathrm{Hz}, A$ é a área geométrica piezoelétricamente ativa $\mathrm{em} \mathrm{cm}^{2}$ definida pela projeção dos filmes metálicos depositados sobre o cristal e $f_{0}$ é a freqüência fundamental do cristal. 
Durante o processo redox, a variação global de massa causada pela participação das moléculas de cátions, ânions e solvente pode ser escrito como [140]:

$$
\Delta m(E)=W_{C^{+}} \xi_{C^{+}}(E)+W_{A^{-}} \xi_{A^{-}}(E)+W_{s} \xi_{s}(E)
$$

onde $W$ é a massa molar de cátions $\left(\mathrm{C}^{+}\right)$, ânions $\left(\mathrm{A}^{-}\right)$, ou solventes $(\mathrm{S})$ e $\xi$ é quantidade de cátions, ânions ou moléculas de solvente. Para atingir a eletroneutralidade, a carga envolvida no processo redox em função da quantidade de moles de espécies iônicas podem ser escritas como:

$$
q(E)=-F \xi_{C^{+}}(E)+F \xi_{A^{-}}(E)
$$

onde $F$ é a constante de Faraday. $O$ número da carga de cátions e ânions é considerada 1 e -1 , respectivamente. A partir das equações anteriores, a contribuição $\xi_{\mathrm{A}-}$ pode ser calculada junto com a participação do solvente como função do potencial segundo a equação:

$$
\xi_{A^{-}}(E)+\frac{W_{S}}{W_{C A}} \xi_{s}(E)=\frac{\Delta m(E)}{W_{C A}}+\frac{W_{C^{+}} q(E)}{W_{C A} F}
$$

Da mesma maneira, $\xi_{C+}$ para cátions pode ser obtida:

$$
\xi_{C+}(E)+\frac{W_{S}}{W_{C A}} \xi_{s}(E)=\frac{\Delta m(E)}{W_{C A}}+\frac{W_{A-} q(E)}{W_{C A} F}
$$

Diferenciando estas equações obtém-se os fluxos de cátions e ânions com a contribuição do solvente, em função da densidade de corrente e do fluxo de massa:

$$
\begin{aligned}
& \frac{d\left(\xi_{C^{+}}(E)+\frac{W_{S}}{W_{C A}} \xi_{s}(E)\right)}{d t}=\frac{1}{W_{C A}} \frac{d(\Delta m(E))}{d t}+\frac{W_{A^{-}} j(E)}{W_{C A} F} \\
& \frac{d\left(\xi_{A^{-}}(E)+\frac{W_{S}}{W_{C A}} \xi_{s}(E)\right)}{d t}=\frac{1}{W_{C A}} \frac{d(\Delta m(E))}{d t}+\frac{W_{C^{+}} j(E)}{W_{C A} F}
\end{aligned}
$$


Fluxos negativos se referem à ejeção e positivos à incorporação de espécies no filme. A participação de solvente no processo é estimada fundamentalmente quando o sinal do fluxo é contrário ao esperado. Este tipo de tratamento pode ser considerado mais eficiente do que as estimativas convencionais utilizadas em trabalhos de microbalança a cristal de quartzo, conduzindo muitas vezes a interpretações dúbias do processo.

Para utilizar a equação de Sauerbrey, e consequentemente determinar a variação de massa, é necessário que os filmes estejam rigidamente ligados ao metal e as variações de freqüência devem ser menores que $2 \%$ da freqüência de ressonância. Também é necessário lembrar que variações na viscosidade do meio ou do filme, assim como variações na tensão mecânica sobre o cristal produzem variações na freqüência fundamental. Somente quando estas condições são estabelecidas é que as variações de freqüência podem ser relacionadas às variações de massa (através das equações de Sauerbrey)

Duas estratégias tem sido utilizadas no sentido de obter informações a respeito da relação entre freqüência e massa. A primeira é a obtenção de um perfil linear da freqüência em função da carga, pois como a carga está relacionada à quantidade de material depositado, freqüência também estará caso o material seja rígido, pode-se relacioná-las então com a equação de Sauerbrey. A segunda é a análise dos resultados de impedância eletroacústica feita através de um circuito equivalente ao sistema eletromecânico representando o compoi tamento do quartzo.

$\mathrm{O}$ transporte de massa em polímeros condutores acontece devido à necessidade de manter a eletroneutralidade na matriz polimérica. Estes estudos visam entender como se realiza a transferência de massa de íons e de solvente entre a matriz polimérica e o eletrólito, já que o fluxo de espécies na interface filme-solução determina a cinética de transferência de carga. $O$ intercâmbio de íons está associado com as propriedades físico químicas dos mesmos, como por exemplo, raio iônico, força ácido-base de Lewis, tamanho atômico [141], etc. O intercâmbio do solvente pode ser associado com a camada de solvatação dos ions ou com a diferença de atividade do solvente fora e dentro do filme polimérico [142].

\subsubsection{Caracterização Eletrogravimétrica}

Voltamogramas cíclicos dos filmes de polianilina, poli(2-etilanilina) e poli(anilina-co-2etilanilina) $\left(\mathrm{f}_{1}=0,5\right)$, juntamente com medidas de variação de freqüência, foram obtidos utilizando $0,8 \mathrm{~mol} / \mathrm{L}$ de diferentes eletrólitos $\left(\mathrm{HCl}, \mathrm{HClO}_{4}, \mathrm{PTSA}\right.$ e $\left.\mathrm{HCSA}\right)$, com varreduras de potencial entre $-0,25 \mathrm{~V}$ e $0,75 \mathrm{~V}$ para a poli(2-etilanilina) e copolímeros, e entre $-0,25 \mathrm{~V}$ e $0,65 \mathrm{~V}$ para a polianilina, utilizando velocidades de varredura de $10 \mathrm{mV} / \mathrm{s}$ e $50 \mathrm{mV} / \mathrm{s}$. A célula eletroquímica é a mesma da eletrossíntese. 


\subsubsection{Síntese Química dos Polímeros}

A solução contendo o agente oxidante é adicionada através de gotejamento à solução contendo os monômeros ou mistura de monômeros. Esta mistura é deixada em banho de gelo e agitação por cerca de 6 horas. O precipitado formado é então filtrado com funil de Büchner com auxílio de bomba de vácuo, lavado com solução $1,0 \mathrm{~mol} / \mathrm{L}$ de $\mathrm{HCl}$ e deixado para secar por dois dias em temperatura ambiente.

Parte deste polímero é deixado em $100 \mathrm{~mL}$ de solução $1,0 \mathrm{~mol} / \mathrm{L}$ de $\mathrm{KOH}$ em agitação por 4 horas para a desdopagem do polímero, ou seja, para a desprotonação e remoção do contraíon, onde o polímero passa da forma salina para a forma básica. Em seguida o polímero é filtrado, lavado com solução de $\mathrm{KOH}$, e seco em meio ambiente também por dois dias. Parte deste material básico é separado para efetuar medidas por Raman Ressonante, parte é dopado com $\mathrm{HCl}$ ou qualquer um dos outros ácidos de interesse, onde deixa-se o material em $100 \mathrm{~mL}$ de solução $1,0 \mathrm{~mol} / \mathrm{L}$ do ácido efetuando os mesmos procedimentos feitos na desdopagem (Figura 2.9).

\section{Monômero + Ag. Oxidante em $1,0 \mathrm{~mol} / \mathrm{L}$ de $\mathrm{HCl}$}

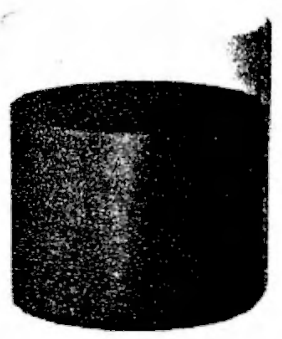

Banho de gelo e agitação
Polímero em solução $\mathrm{KOH}$

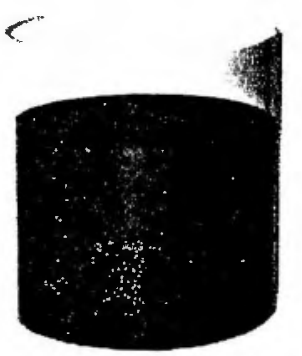

Agitação

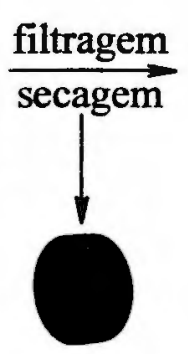

Polímero

básico
Polímero em solução ácida

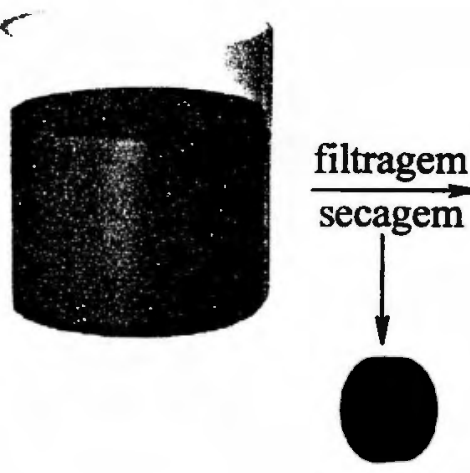

Polímero sal

Figura 2.9: Esquema da sintese quimica dos polímenos, formação da forma básica e de sua forma salina.

Para medidas de solubilidade foi feita uma mistura de homopolímeros com a mesma composição da solução de síntese dos copolímeros, para comparar a solubilidade destes materiais (Tabela 2.6) 
Tabela 2.6: Composição das misturas mecânicas de homopolímeros.

\begin{tabular}{|l|c|}
\hline \multicolumn{2}{|c|}{ Composição das misturas mecânicas de homopolímeros. } \\
\hline & $\begin{array}{c}\% \text { (em moles de unidades } \\
\text { de 2-etilanilina) }\end{array}$ \\
\hline $1,00 \mathrm{~g}$ poli(2-etilanilina) & $100 \%$ \\
\hline $0,92 \mathrm{~g}$ poli(2-etilanilina) $+0,07 \mathrm{~g}$ polianilina & $90 \%$ \\
\hline $0,75 \mathrm{~g}$ poli(2-etilanilina) $+0,25 \mathrm{~g}$ polianilina & $70 \%$ \\
\hline $0,57 \mathrm{~g}$ poli(2-etilanilina) $+0,43 \mathrm{~g}$ polianilina & $50 \%$ \\
\hline $0,36 \mathrm{~g}$ poli(2-etilanilina) $+0,64 \mathrm{~g}$ polianilina & $30 \%$ \\
\hline $0,12 \mathrm{~g}$ poli(2-etilanilina) $+0,87 \mathrm{~g}$ polianilina & $10 \%$ \\
\hline $1,00 \mathrm{~g}$ polianilina & $0 \%$ \\
\hline
\end{tabular}

\subsubsection{Espectroscopia Raman Ressonante}

A energia de uma molécula consiste da soma de sua energia translacional, rotacional, vibracional e eletrônica. Energias de transições eletrônicas estão relacionadas com absorções ou emissões do espectro eletromagnético na região visível e ultravioleta, rotações puras estão relacionadas com absorções na região de microonda, e vibrações moleculares geram bandas de absorção na região do infravermelho do espectro eletromagnético.

Quando a radiação eletromagnética de energia $h v$ irradia uma molécula, a energia pode ser transmitida, absorvida ou espalhada. No efeito Tyndall a radiação é espalhada por partículas (fumaça, por exemplo), no efeito Rayleigh as moléculas é que espalham a luz, porém em nenhum destes efeitos ocorre qualquer alteração no comprimento de onda dos fótons. Em 1928 C. V. Raman descreveu um novo tipo de espalhamento, conhecido como efeito Raman.

Em um espectrómetro Raman a amostra é irradiada com uma radiação monocromática intensa, geralmente na região do visível do espectro eletromagnético. Normalmente a freqüência desta radiação é muito maior que as freqüências das transições vibracionais, mas menor que as freqüências das transições eletrônicas. A radiação espalhada pela amostra é analisada no espectrómetro. $O$ espalhamento Rayleigh pode ser observado como uma colisão elástica entre o fóton incidente e a molécula. Como a energia vibracional e rotacional da molécula não se alteram com uma colisão elástica, a energia, e portanto a freqüência do fóton espalhado é a mesma que a do fóton incidente. 
O efeito Raman pode ser comparado à uma colisão inelástica entre o fóton incidente e a molécula, onde como resultado desta colisão ocorre uma alteração na energia vibracional e rotacional da molécula, por uma quantidade $\Delta E_{m}$. Devido à conservação de energia, a energia do fóton espalhado $\left(h v_{\mathrm{S}}\right)$ deve ser diferente da energia do fóton incidente $\left(h v_{\mathrm{i}}\right)$ pela mesma quantidade $\Delta E_{m}$.

$$
h v_{i}-h v_{s}=\Delta E_{m}
$$

Se a molécula ganha energia, então $\Delta E_{m}$ é positivo e $v_{\mathrm{S}}$ é menor que $v_{\mathrm{i}}$, e a frequência do fóton espalhado é menor que a freqüência do fóton incidente, dando origem às linhas Stokes no espectro Raman. Se a molécula perde energia, então $\Delta E_{m}$ é negativo, e $v_{\mathrm{S}}$ é maior que $v_{i}$, e a freqüência do fóton espalhado é maior que a freqüência do fóton incidente, dando origem às linhas anti-Stokes no espectro Raman. Na Figura 2.10 as linhas $v=0$ e $v=1$ representam os níveis de energia vibracional de uma molécula, a diferença de energia entre estes níveis é dado pela equação:

$$
\Delta E_{m}=h v_{m}
$$

A transição direta entre estes dois níveis causa uma absorção de um fóton no infravermelho, cuja freqüência é a mesma da freqüência molecular $v_{m}$.

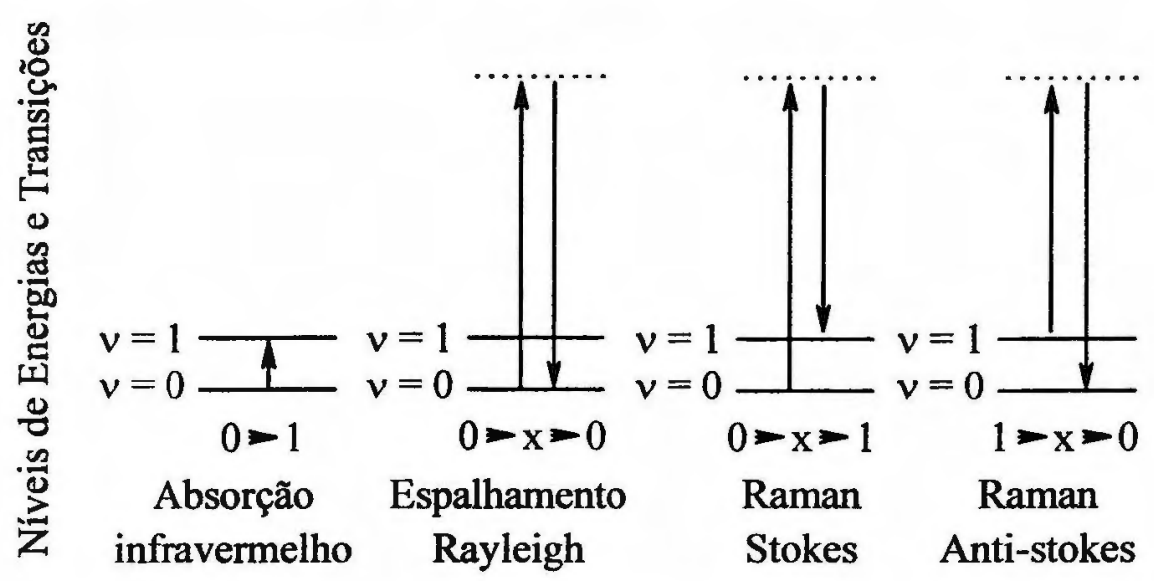

Figura 2.10: Ilustração esquemática do espalhamento Reyleigh e Raman, e absorção no infravermelho [143].

Quando o fóton incidente interage com a molécula no estado vibracional fundamental, a molécula absorve a energia do fóton e sua energia aumenta momentaneamente para um nível instável de energia. Desta maneira a molécula perde energia rapidamente voltando ao seu estado fundamental, este é o espalhamento Rayleigh, gerando uma linha muito intensa no espectro Raman. Porém uma pequena proporção de moléculas no nivel instável de energia pode voltar não ao estado fundamental, mas para um nível vibracional excitado, assim o fóton espalhado tem energia menor que o fóton incidente, dando origem às linhas Stokes no 
espectro Raman. As linhas anti-Stokes aparecem quando as moléculas já estão no estado vibracional excitado durante a interação com o fóton, e a molécula volta ao seu estado fundamental. Como à temperatura ambiente a maioria das moléculas estão no estado vibracional fundamental, as linhas Stokes são mais intensas que as linhas anti-Stokes no espectro Raman.

As propriedades vibracionais dos polímeros têm sido estudadas por muitos anos através de duas técnicas complementares, a espectroscopia no infravermelho e a espectroscopia Raman [144-147]. Todo polímero tem um espectro vibracional único que é determinado pela estrutura física e química do polímero. Com a espectroscopia no infravermelho e Raman pode-se fazer uma identificação química de um polímero, determinar as concentrações relativas em sistemas contendo mais de um componente, assim como determinar a quantidade relativa de polímero amorfo e cristalino em uma amostra com a ajuda de um feixe polarizado.

Em espectroscopia Raman normal a espécie é transparente ao feixe do laser incidente, as freqüências das bandas são independentes do comprimento de onda do laser. Porém quando o comprimento de onda do laser é absorvido pela molécula, a intensidade das bandas Raman associadas aos modos vibracionais, as quais estão fortemente acopladas com o estado eletrônico excitado, pode ser muito intensificada, facilitando assim o seu registro (Figura 2.11).

O efeito Raman Ressonante, esquema mostrado na Figura 2.11, difere do efeito Raman normal, esquema mostrado na Figura 2.10, no sentido que o fóton incidente tem energia correspondente à da transição eletrônica e o estado intermediário se torna próximo a um auto-estado da molécula. Em termos de balanço de energia a situação é a mesma em ambos os casos (a energia do fóton espalhado é a diferença entre a do fóton incidente e a energia do estado excitado final), mas no que se refere a intensidade da radiação Raman o efeito é bastante drástico.

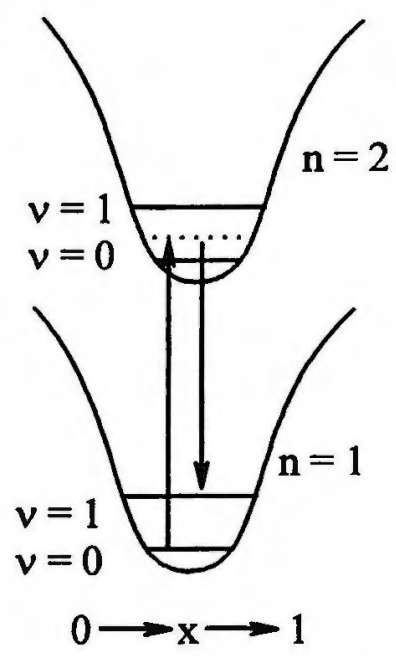

Figura 2.11: Ilustração esquemática do espalhamento Reyleigh e Raman, e absorção no infravermelho. 
A espectroscopia Raman Ressonante também permite a separação de bandas Raman de um cromóforo, que é a parte da molécula que sofre a transição eletrônica, em situações onde seria impossível usando a espectroscopia Raman normal. É este atributo de seletividade cromófora que torna esta técnica tão atrativa para o estudo de polímeros conjugados. Moléculas poliméricas podem ser distinguidas das moléculas de solventes em concentrações menores que $10^{-8}$ moles $/ \mathrm{L}$.

As condições experimentais para estudo Raman Ressonante diferem um pouco da espectroscopia Raman normal, a maior diferença é a necessidade de se ter vários lasers com diferentes comprimentos de onda, ou um laser cujo comprimento de onda seja ajustável, para que haja excitação eletrônica na cadeia polimérica. Como o polímero normalmente vai sofrer uma intensa absorção no comprimento de onda do laser, deve-se tomar cuidado para que não haja degradação da amostra. Geralmente é necessário restringir a potência do laser em menos de $1 \mathrm{~mW}$, ou reduzir a exposição ao mínimo necessário. Felizmente o ganho de sinal devido ao efeito Raman Ressonante compensa as restrições impostas à exposição do laser.

\subsubsection{Caracterização por Raman Ressonante}

Com os polímeros e copolímeros na forma de pastilhas ou pó, com o polímero básico (desprotonado), obteve-se os espectros Raman Ressonante com comprimento de onda da radiação excitante de $632,8 \mathrm{~nm}$ (Figura 2.12).

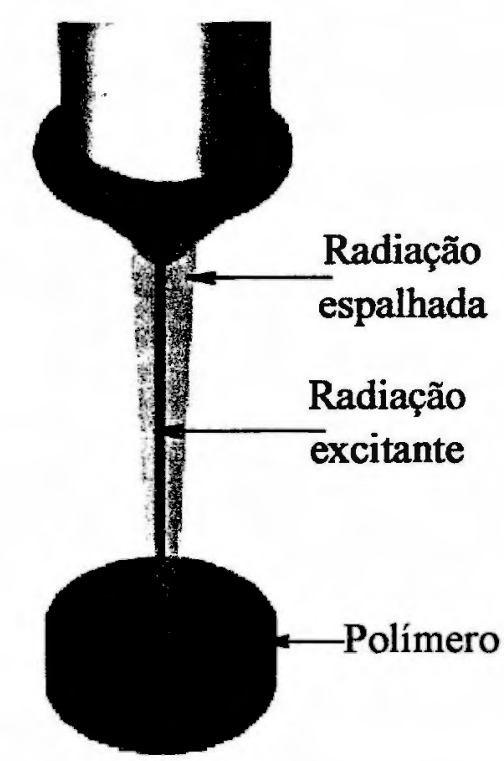

Figura 2.12: Esquema da geometria do espectrofotómetro Raman Ressonante. 


\subsubsection{Medidas de Condutividade Elétrica}

A condução elétrica em sólidos ocorre através da migração de elétrons (ou buracos), ou carregadores iônicos. Na condução de um material geralmente um tipo de carregador de carga predomina. A condutividade específica de um material $\sigma(\mathrm{Scm})$, que é a soma da condutividade eletrônica, $\sigma_{\text {el }}$, e da condutividade iônica, $\sigma_{\text {ion }}$, é dada por:

$$
\sigma=\sigma_{e l}+\sigma_{i o n}
$$

E é definido como a corrente i (A), que flui através de um cubo de $1 \mathrm{~cm}$ de material, exposto a um potencial de $1 \mathrm{~V}$.

Por simplicidade, a condutividade específica pode ser tratada como escalar, presumindo que a corrente induzida flui paralelamente ao campo imposto ao material. A condutividade específica $\sigma$ está relacionada com dois parâmetros básicos, a densidade de carregadores de carga $\eta\left(\mathrm{cm}^{-3}\right)$ e a mobilidade destes carregadores de carga $\mu\left(\mathrm{cm}^{2} / \mathrm{Vs}\right)$, e neste caso a condutividade específica pode ser expressa como:

$$
\sigma=\sum_{i} q_{i} n_{i} \mu_{i}
$$

onde $q_{i}$ é a carga da espécie $i$. Com materiais poliméricos, cada parâmetro $n_{i}$ ou $\mu_{\mathrm{i}}$ pode variar com o ambiente, com o potencial, ou influenciado pelas condições de síntese do material.

$\mathrm{O}$ estudo da condutividade de metais é facilitada pela pouca resistência que geralmente existe entre a amostra e os eletrodos de medida. Assim a condutividade DC (corrente contínua) de uma amostra pode ser determinada medindo-se a corrente constante (i) por um circuito externo quando aplicado um potencial conhecido (V) à amostra. A condutividade total $(\sigma)$ de uma amostra é:

$$
\sigma=\frac{i}{V} \frac{L}{A}
$$

onde o comprimento de amostra é $L(\mathrm{~cm})$ e sua área $A\left(\mathrm{~cm}^{2}\right)$. Uma representação simples de uma célula de duas pontas (dois eletrodos) é mostrado na Figura 2.13-A. Para obter dados mais precisos é comum empregar uma célula com quatro pontas, Figura 2.13-B, a qual compensa alguns efeitos relacionados com resistência interfacial.

Como as pastilhas obtidas em nossos experimentos quebram-se facilmente em contato com os eletrodos da célula quatro pontas, foi necessário utilizar medidas de condutividade AC (corrente alternada). 
A)

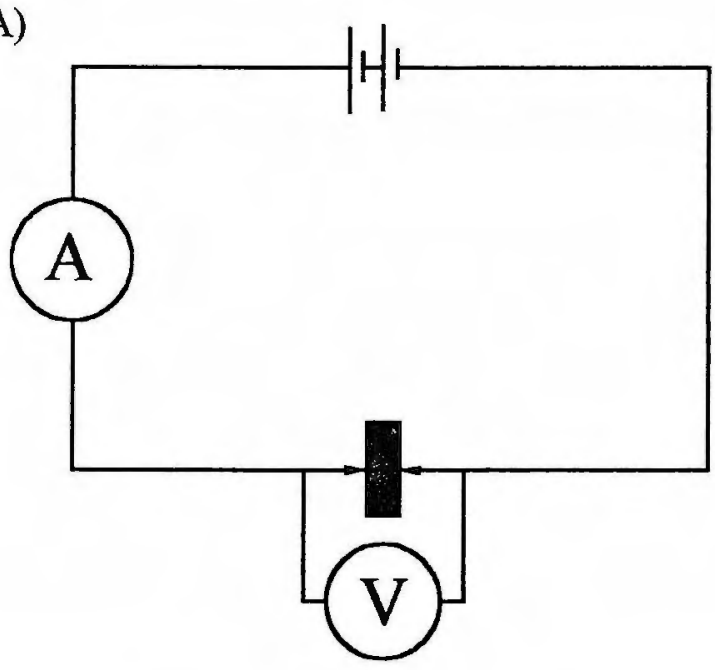

B)

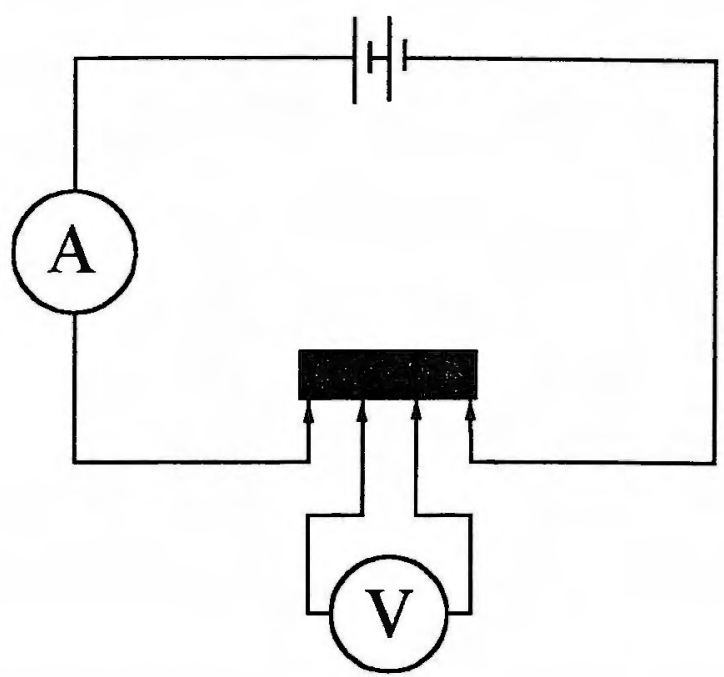

Figura 2.13: Diagramas dos circuitos para medida de condutividade DC da célula de duas pontas (A) e quatro pontas (B).

Os sistemas eletroquímicos podem ser estudados com métodos baseados em medições de impedância. Estes métodos envolvem a aplicação de uma pequena perturbação, enquanto métodos baseados em varredura linear ou degrau de potencial o sistema é perturbado longe do equilíbrio. Esta pequena perturbação imposta pode ser uma perturbação de potencial, de corrente ou ainda em eletrodos hidrodinâmicos uma perturbação de velocidade de convecção. É utilizado uma perturbação pequena para facilitar o cálculo das equações matemáticas.

A resposta à perturbação aplicada, que é geralmente senoidal, pode diferir em fase e amplitude do sinal aplicado. A medida da diferença de fase e amplitude permite análise do processo eletródico em relação às contribuições de difusão, cinética, de dupla camada elétrica, de reações homogêneas acopladas, etc.. Este método é importante em estudos de corrosão, membranas, sólidos iônicos, eletrólitos sólidos, polímeros condutores e interfaces líquido/ líquido.

A comparação é usualmente feita entre a célula eletroquímica e um circuito elétrico equivalente que contém combinações de resistências, de capacitâncias, e de indutâncias. Uma outra estratégia consiste em escolher um modelo para o mecanismo da reação e os parâmetros cinéticos, deduzir a expressão da impedância e comparar com a experiência. Dado que as medições de impedância para diferentes freqüências podem, em princípio, fornecer toda a informação acerca do sistema eletroquímico, tem havido muito interesse em desenvolver técnicas de impedância eletroquímica [148-158].

Ao aplicar uma voltagem senoidal num sistema elétrico:

$$
V=V_{0} \operatorname{sen} \omega t
$$


onde $V_{0}$ é a amplitude máxima e $\omega$ a freqüência $\left(\mathrm{rad} \mathrm{s}^{-1}\right)$ de um circuito elétrico que contém combinações de resistências e capacitâncias que, se espera, podem representar adequadamente a célula eletroquímica. A resposta é uma corrente, dada por:

$$
I=I_{0} \operatorname{sen}(\omega t+\phi)
$$

Onde $\phi$ é o ângulo de fase entre a perturbação e a resposta. $O$ fator de proporcionalidade entre $V$ e $I$ é a impedância, $Z$. As impedâncias consistem em resistências, reatâncias (derivadas dos elementos capacitivos) e indutâncias, que surgem para freqüências muito elevadas ( $>1 \mathrm{MHz}$ ). A impedância é o fator de proporcionalidade entre potencial e corrente; se estes têm fases diferentes, então pode-se dividir a impedância numa parte resistiva, $R$, onde a voltagem e a corrente estão em fase, e numa parte reactiva, $X_{c}=1 / \omega C$, onde a diferença de fase entre a corrente e a voltagem é de $90^{\circ}$.

No caso de uma resistência pura, $R$, a lei de Ohm $V=I R$ conduz a:

$$
I=\frac{V_{0}}{R} \operatorname{sen} \omega t
$$

não havendo diferença de fase entre potencial e corrente, sendo $\phi=0$. Para um capacitor puro:

$$
I=C \frac{d V}{d t}=\omega C V_{0} \operatorname{sen}\left(\omega t+\frac{\pi}{2}\right)=\frac{V_{0}}{X_{C}} \operatorname{sen}\left(\omega t+\frac{\pi}{2}\right)
$$

Observa-se que $\phi=\pi / 2$ ou seja, a corrente fica atrasada em relação ao potencial por $\pi / 2$, sendo que $X_{C}=(\omega C)^{-1}$ é conhecida como a reatância (medida em ohms). Dados os diferentes ângulos de fase das resistências e das reatâncias torna-se útil uma representação em duas dimensões.

No eixo $x$ o ângulo de fase é zero, ao girar à esquerda, ao redor da origem aumenta o ângulo de fase, as reatâncias puras são representadas no eixo dos y (Figura 2.14). A distância a origem corresponde à amplitude. Isto é precisamente a representação dos números complexos representados vetorialmente no plano complexo, porém aqui o eixo real é para as resistências e o eixo imaginário para as reatâncias.

Por convenção, a corrente está sempre no eixo real. Portanto torna-se necessário multiplicar as reatâncias por $-i(\sqrt{-1})$.

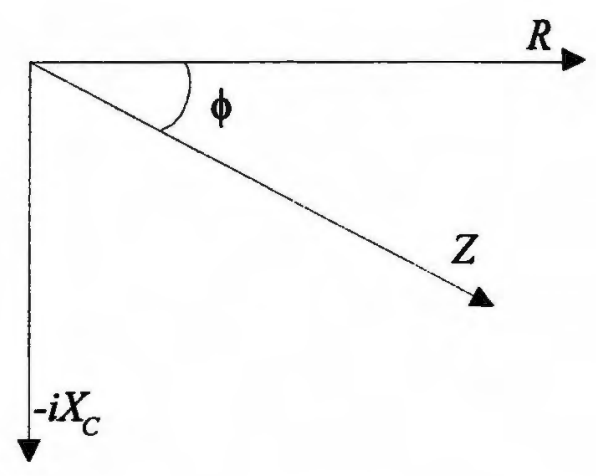

Figura 2.14: Representação de uma impedância contendo as componentes resistivas e capacitivas no plano complexo. 
No caso mais simples, de apenas uma resistência e uma capacitância, em série, a diferença de potencial total é a soma das diferenças de potencial através dos dois elementos. Pela lei de Kirchoff as correntes têm de ser iguais, ou seja, $I=I_{R}=I_{C}$.

As diferenças de potencial são proporcionais a $R$ e $X_{C}$, respectivamente. A sua representação como vetores está indicada na Figura 2.15. A soma vetorial de $-i X_{c}$ e de $R$ dá a impedância $Z$.

$$
\vec{Z}=\vec{R}-i \vec{X}_{C}
$$

Freqüentemente, o componente da impedância em fase é designado de $Z$ ' e o componente fora de fase designa-se por $Z^{\prime \prime}, \operatorname{assim} Z=Z^{\prime}+Z^{\prime \prime}$. Portanto neste caso $Z^{\prime}=R$ e $Z^{\prime \prime}=-X_{C}$. Aparece então uma linha vertical no gráfico de impedância no plano complexo, visto que $Z$ ' é constante mas $Z$ " varia com a freqüência.

No caso de medidas de resistência feitas em polianilina e polianilinas alquil substituídas, tem-se apenas uma resistência, assim no gráfico $Z^{\prime \prime}=0$, e $Z^{\prime}=R$, observando-se assim apenas um ponto para todas as frequiências, e com esta resistência pode ser calculado a condutividade do material.

\subsubsection{Medidas de Condutividade AC}

Para efetuar as medidas de condutividade AC utilizou-se o método de duas pontas, onde o polímero dopado foi comprimido entre dois eletrodos de ouro embutidos em teflon, os quais podem ser rosqueados em um envoltório maior, formando um compartimento para o polímero, Figura 2.15. Os eletrodos de ouro foram ligados à um equipamento Eco Chemie Autolab PGSTAT30 com módulo de impedância.

A espessura do polímero comprimido foi medida pela diferença de distância entre os eletrodos com e sem polímero entre eles, utilizando um paquímetro. A área ativa do eletrodo é de $3,8 \times 10^{-3} \mathrm{~cm}^{-2}$. Foi imposto ao sistema um potencial de $0,0 \mathrm{~V}$ com uma perturbação de $5 \mathrm{mV}$ (rms) , e com variação de freqüência entre $100 \mathrm{kHz}$ e $10 \mathrm{mHz}$.

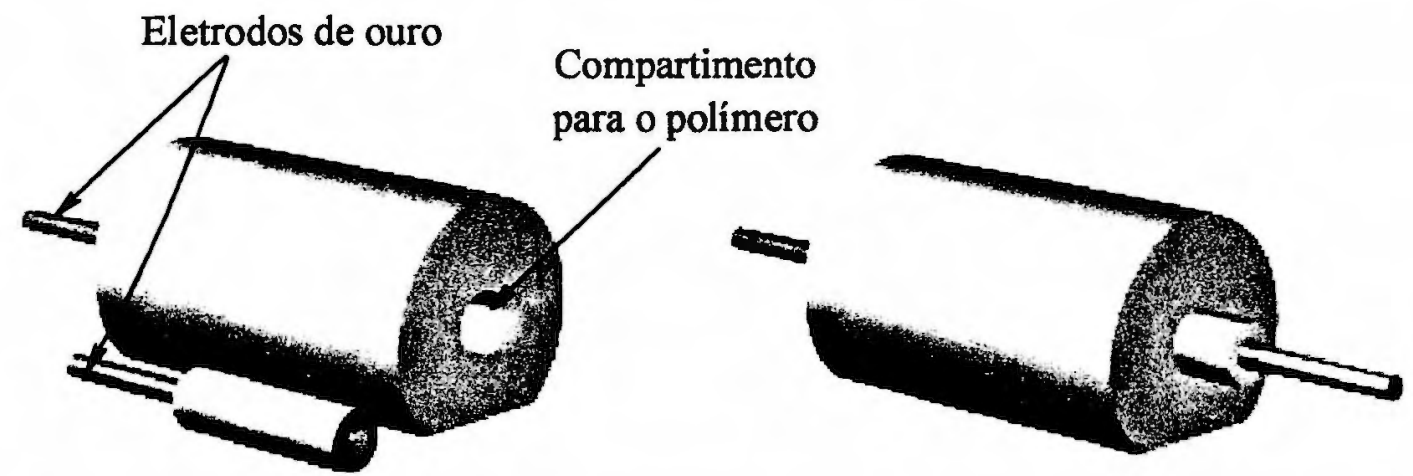

Figura 2.15: Esquema dos eletrodos utilizados para medida de resistividade dos polímeros. 


\subsubsection{Solubilidade dos Polímeros}

Quando um polímero amorfo é misturado em um solvente apropriado, ele se dispersa no solvente e se comporta como se fosse um líquido. Em um bom solvente, o qual tem uma grande compatibilidade com o polímero, a interação polímero-solvente expande a cadeia polimérica, enquanto que em um mau solvente a interação polímero-solvente é pequena, restringindo a expansão do polímero.

Muitas teorias foram desenvolvidas de modo a entender o comportamento de soluções poliméricas, e dentre elas a teoria de Flory-Huggins é a pedra angular na termodinâmica destas soluções, mesmo contendo muitas limitações.

Segundo a teoria de Flory-Huggins o processo de dissolução de um polímero em um solvente acontece em dois estágios. $O$ polímero existe inicialmente em um estado sólido, restrito em apenas uma conformação das várias conformações possíveis caso o polímero fosse apenas uma molécula isolada. Quando o polímero entra em contato com o líquido, sua cadeia polimérica ganha uma relativa liberdade e pode agora alterar rapidamente sua conformação dentre as múltiplas possíveis conformações energeticamente equivalentes. Estas conformações possíveis dependem da flexibilidade da cadeia polimérica e da interação entre o polímero e o solvente.

\subsubsection{Estudos de Solubilidade}

Os polímeros de polianilina, poli(2-etilanilina), poli(anilina-co-2-etilanilina) e as misturas dos homopolímeros foram peneirados em uma peneira de 80 meshes, $0,5 \mathrm{~g}$ deste material foi pesado, colocado em um béquer com $10 \mathrm{~mL}$ de solvente, e deixado em agitação por 1 hora. O papel de filtro que estava em uma estufa com baixa pressão é pesado e molhado com o solvente.

O material foi então filtrado, lavado com uma pequena quantidade de água, e deixado em estufa à pressão de 200 mbar e temperatura de $30^{\circ} \mathrm{C}$, e todos os dias, durante uma semana, este material foi pesado, juntamente com o papel de filtro (Figura 2.16). Com a massa de material retido no papel de filtro pode-se calcular a solubilidade do polímero em $10 \mathrm{~mL}$ de solvente e comparar estes valores com a solubilidade da mistura de homopolímeros. Os solventes utilizados foram NN'-dimetilformamida (DMFA), N-metilpirrolidona (NMP) e clorofórmio $\left(\mathrm{CHCl}_{3}\right)$. 


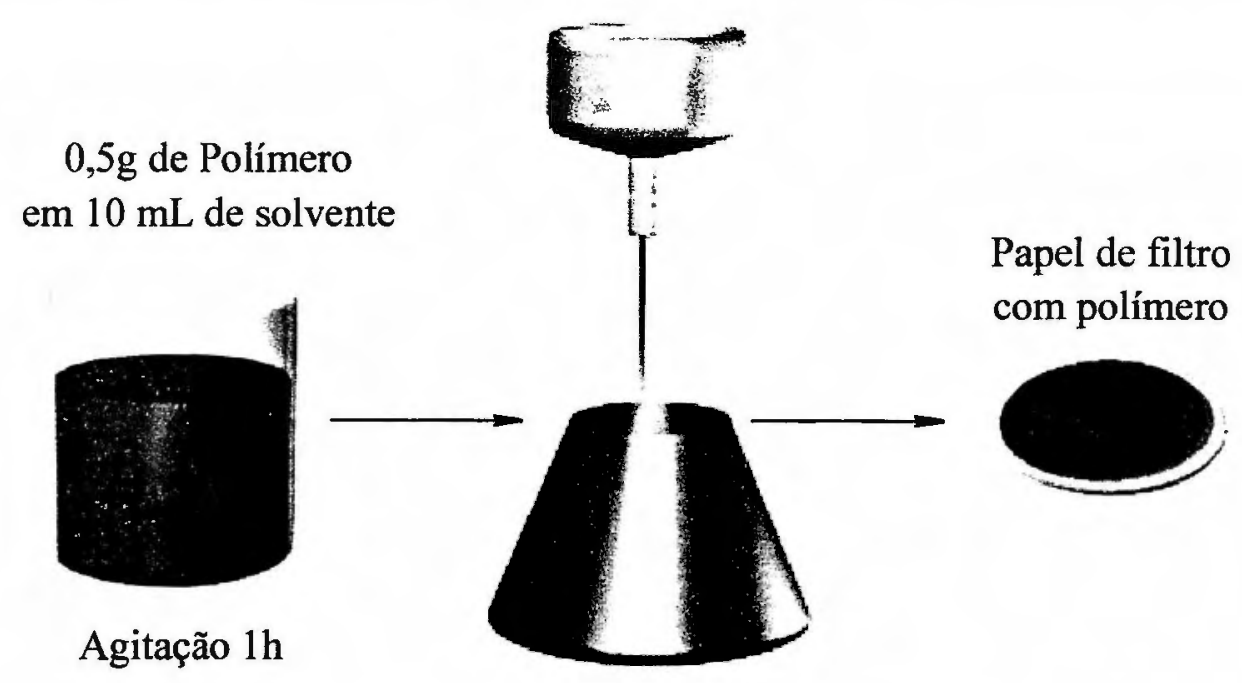

Figura 2.16: Esquema dos estudos de solubilidade. 


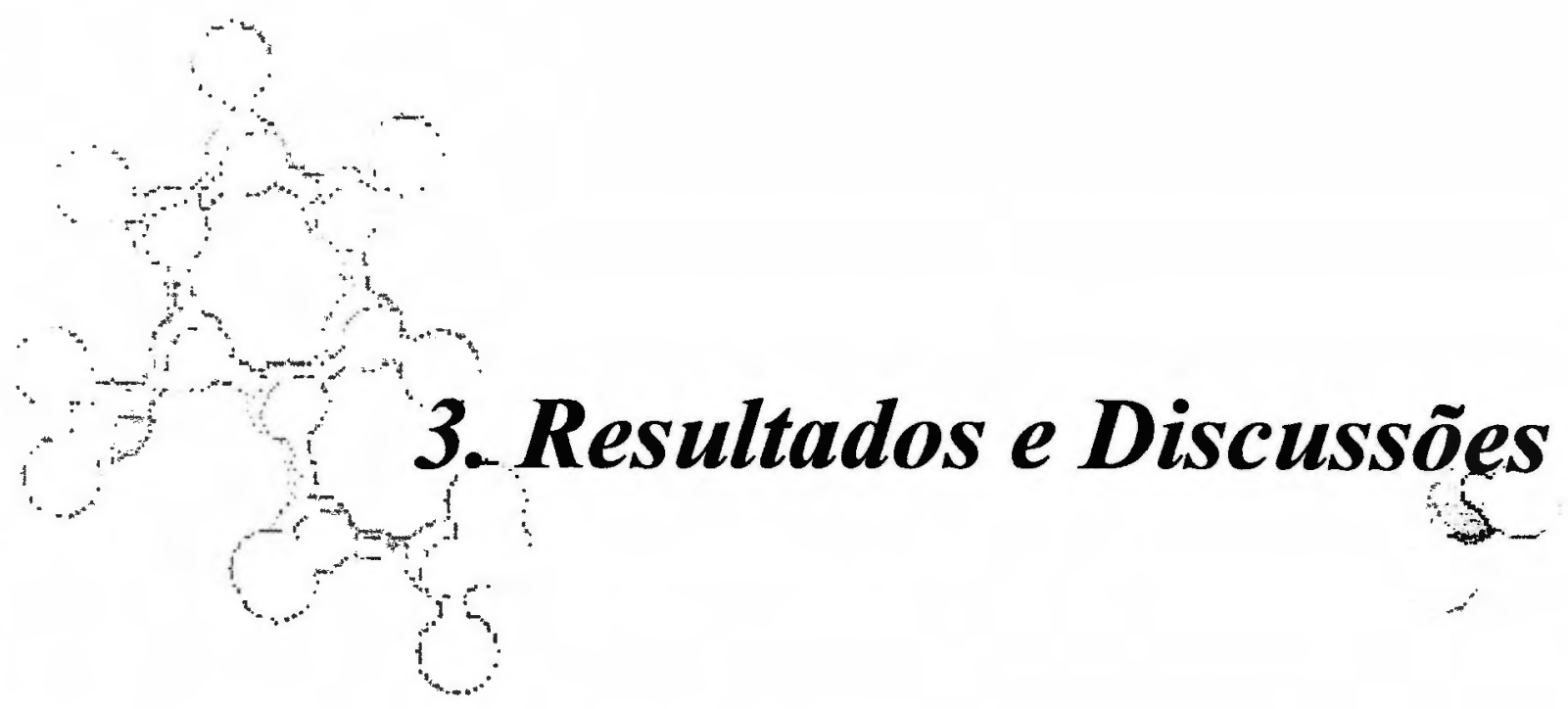

\subsection{Síntese Eletroquímica e Química}

\subsubsection{Síntese Eletroquímica}

Foram registrados os voltamogramas do eletrodo de vidro/ $\mathrm{SnO}_{2}$ limpo nas diferentes soluções eletrolíticas, para evidenciar a inexistência de processos redox na faixa de potencial utilizado nos estudos eletroquímicos. A Figura 3.1 mostra uma janela de potencial para o eletrodo entre os potenciais de $-0,4$ e $1,5 \mathrm{~V}$ utilizando como eletrólito $0,8 \mathrm{~mol} / \mathrm{L}$ de $\mathrm{HCl}$. Para os outros eletrólitos obtivemos os mesmos resultados.

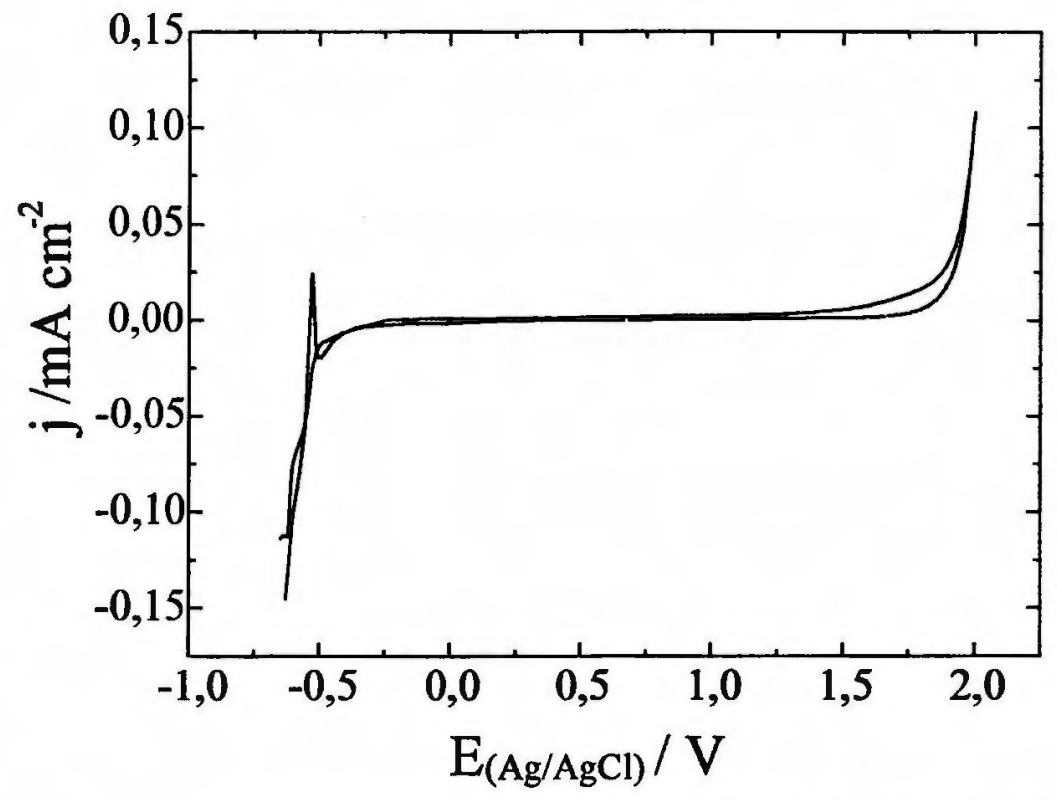

Figura 3.1: Voltamograma do eletrodo de vidro/ $\mathrm{SnO}_{2}$ em $0,8 \mathrm{~mol} / \mathrm{L}$ de $\mathrm{HCl}$ 
Voltamogramas de crescimento dos filmes de polianilina, poli(2-anilina) e poli(N-etilanilina) são mostrados nas Figuras 3.2-3.4.

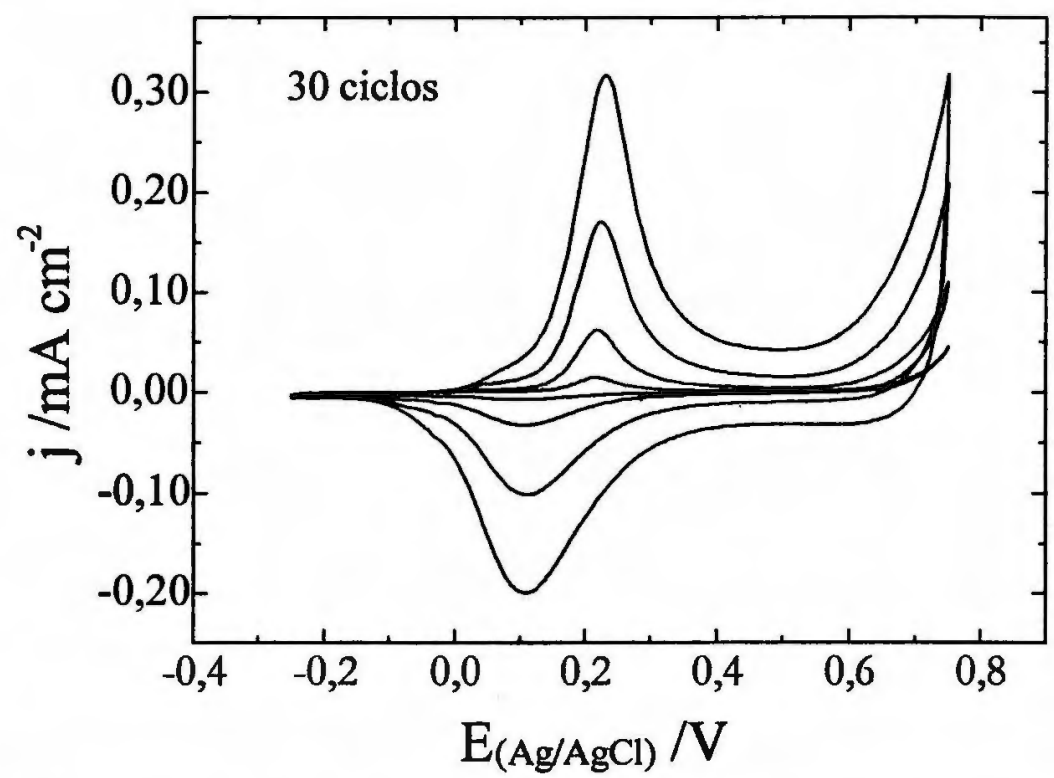

Figura 3.2: Voltamograma de crescimento da polianilina em $1,0 \mathrm{~mol} / \mathrm{L}$ de $\mathrm{HCl}, \mathrm{v}=10 \mathrm{mV} / \mathrm{s}$.

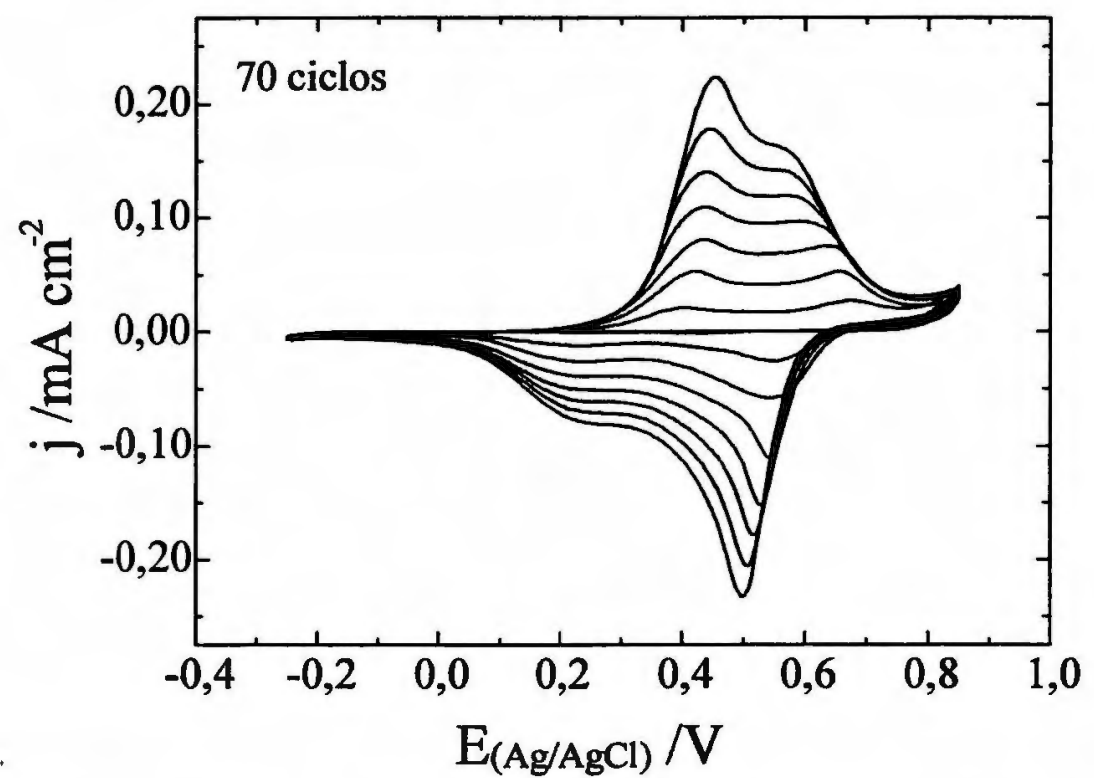

Figura 3.3: Voltamograma de crescimento da poli(2-etilanilina) em 1,0 mol/L de $\mathrm{HCl}$, $v=10 \mathrm{mV} / \mathrm{s}$.

Tanto os filmes de polianilina, quanto os de poli(2-etilanilina) cresceram sem qualquer problema nas condições mencionadas, obtendo-se filmes com boa aderência sobre os eletrodos, independentemente do número de ciclos. A quantidade de material sobre o eletrodo foi controlada através da carga catódica registrada durante o crescimento do polímero. 


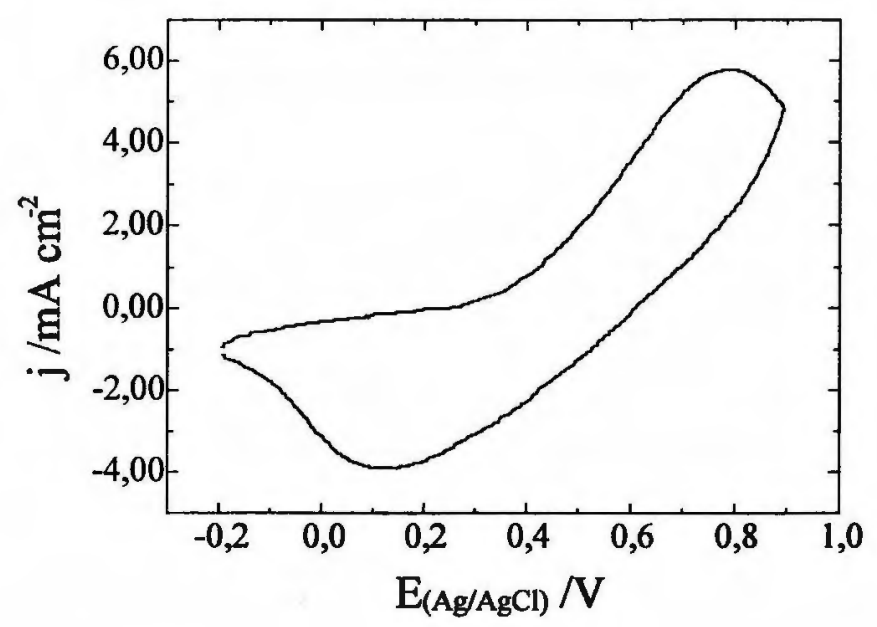

Figura 3.4: Voltamograma de crescimento da poli(N-etilanilina) em 1,0 mol/L de $\mathrm{HCl}$, $v=10 \mathrm{mV} / \mathrm{s}$.

Porém a poli(N-etilanilina) mostrou pouca aderência em relação ao eletrodo utilizado, sendo que boa parte do material formado desprendeu-se do eletrodo, ficando suspenso na solução de síntese. Como não foi possível estimar a quantidade de material sobre o eletrodo, não foi realizado nenhum estudo eletroquímico ou espectroscópico com este filme formado eletroquimicamente, pois não seria possíyel fazer comparações com os outros polímeros. Além disso, como a quantidade de material era pequena a resposta espectroscópica seria da mesma intensidade do ruído.

Nas Figuras 3.5-3.6 estão registrados os primeiros ciclos de crescimento dos filmes de poli(2etilanilina) e poli(anilina-co-2-etilanilina) $\left(f_{1}=0,50\right)$ respectivamente, onde em ambos os gráficos, observa-se um pico intenso na região de $0,8 \mathrm{~V}$.

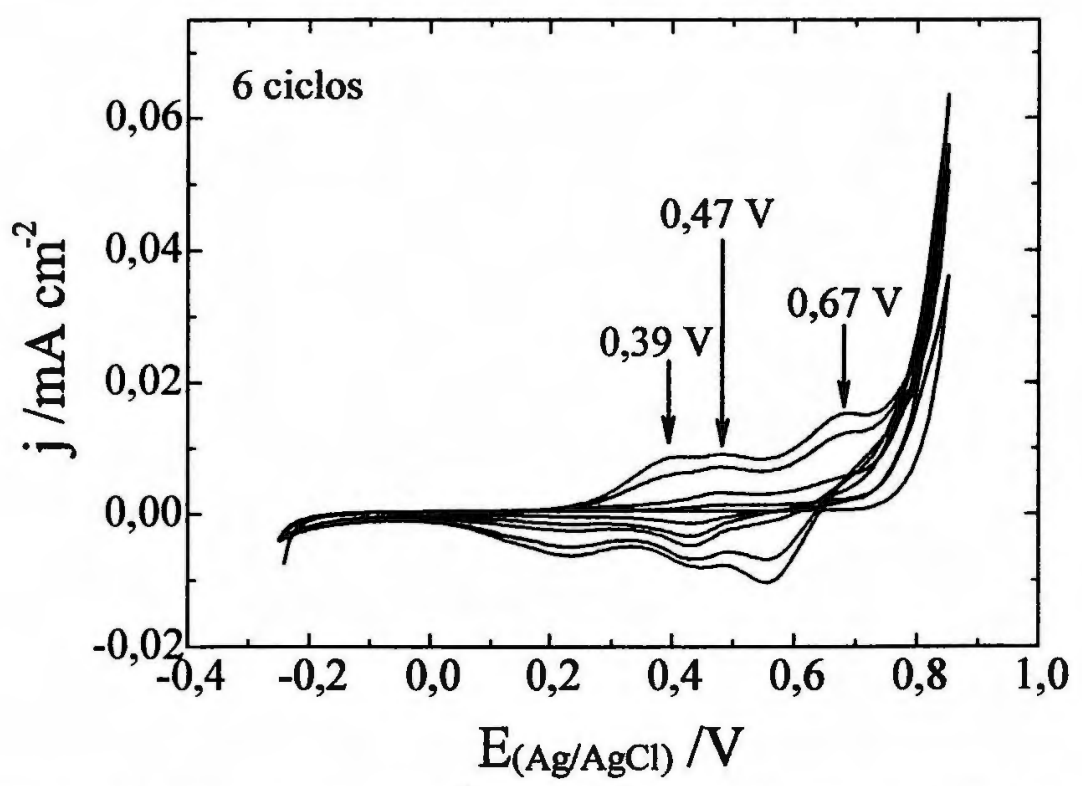

Figura 3.5: Voltamograma dos primeiros ciclos de crescimento da poli(2-etilanilina) em 1,0 mol/L de $\mathrm{HCl}, v=$ $10 \mathrm{mV} / \mathrm{s}$ 


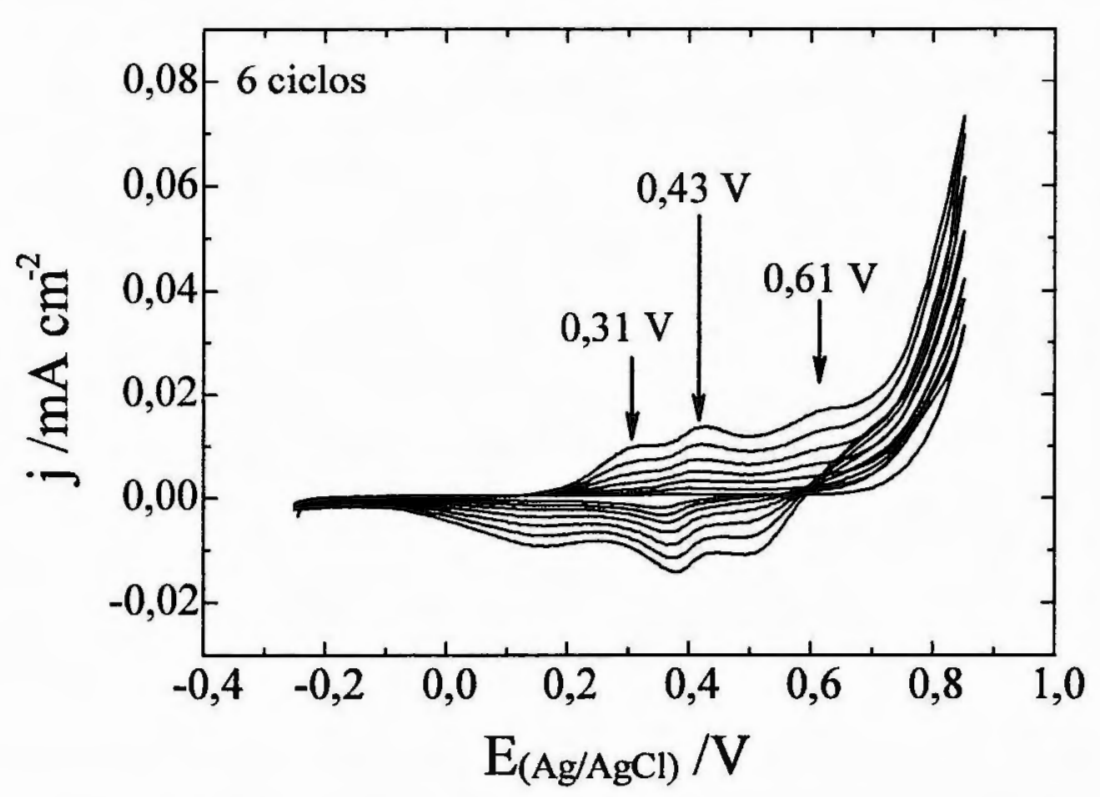

Figura 3.6: Voltamograma dos primeiros ciclos do crescimento do poli(anilina-co-2-etilanilina) $\left(f_{1}=0,5\right)$ em 1,0 $\mathrm{mol} / \mathrm{L}$ de $\mathrm{HCl}, v=10 \mathrm{mV} / \mathrm{s}$

Este pico deve-se à oxidação dos monômeros, que perdem um elétron formando um radical cátion. Com os ciclos subseqüentes observa-se a formação de três novos picos em regiões de menor potencial, tanto para a poli(2-etilanilina) como para os copolímeros.

Estes três novos picos de oxidação que aparecem em regiões de menor potencial provavelmente estão associados à oxidação de dímeros [118]. Conforme já foi discutido na introdução deste trabalho (seção 1.2.1), os radicais formados se acoplam rapidamente formando dímeros, sendo estes dímeros oxidados com maior facilidade que os monômeros.

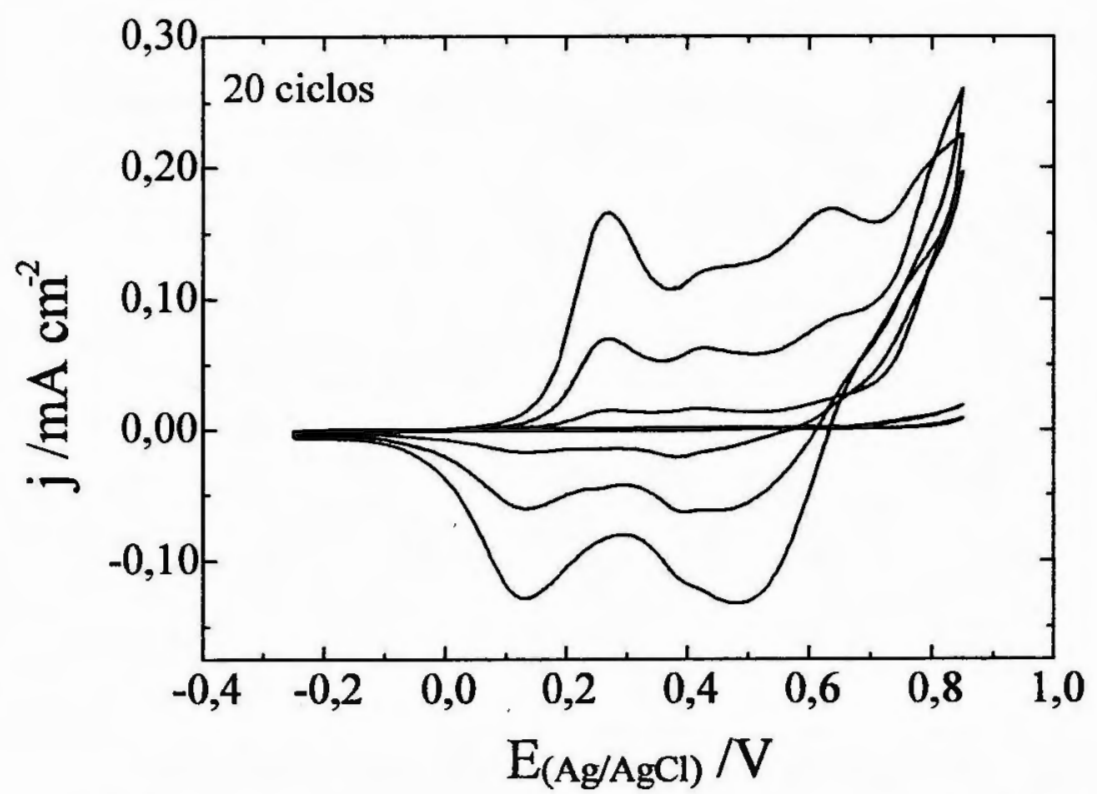

Figura 3.7: Voltamograma de crescimento do poli(anilina-co-2-etilanilina) $\left(f_{t}=0,1\right)$ em $1,0 \mathrm{~mol} / \mathrm{L}$ de $\mathrm{HCl}, \mathrm{v}=10 \mathrm{mV} / \mathrm{s}$ 
Com a posterior oxidação destes dímeros inicia-se a formação da cadeia polimérica, intensificando-se então os picos correspondentes à oxidação do polímero, cuja intensidade vai aumentando gradualmente, devido ao aumento de sítios eletroativos com o aumento de material polimérico no eletrodo. Voltamogramas de crescimento dos diferentes copolímeros poli(anilina-co-2-etilanilina) são mostrados nas Figuras 3.7-3.11.

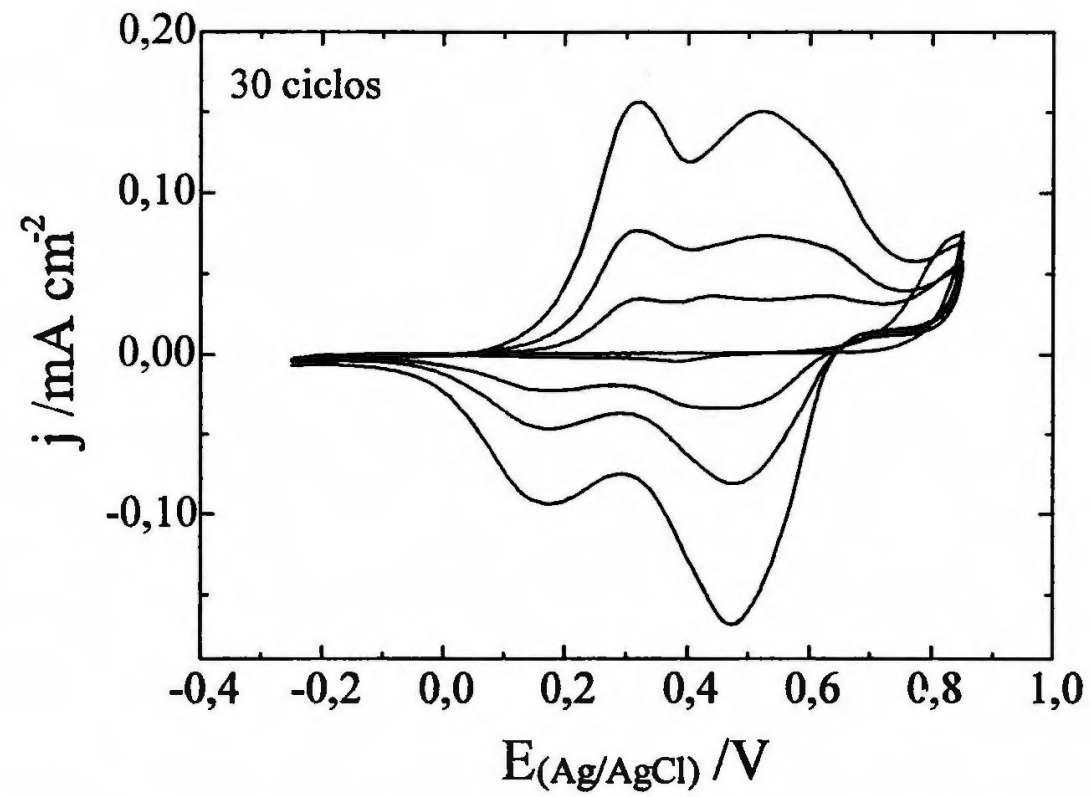

Figura 3.8: Voltamograma de crescimento do poli(anilina-co-2-etilanilina) $\left(f_{1}=0,3\right)$ em $1,0 \mathrm{~mol} / \mathrm{L}$ de $\mathrm{HCl}, v=10 \mathrm{mV} / \mathrm{s}$

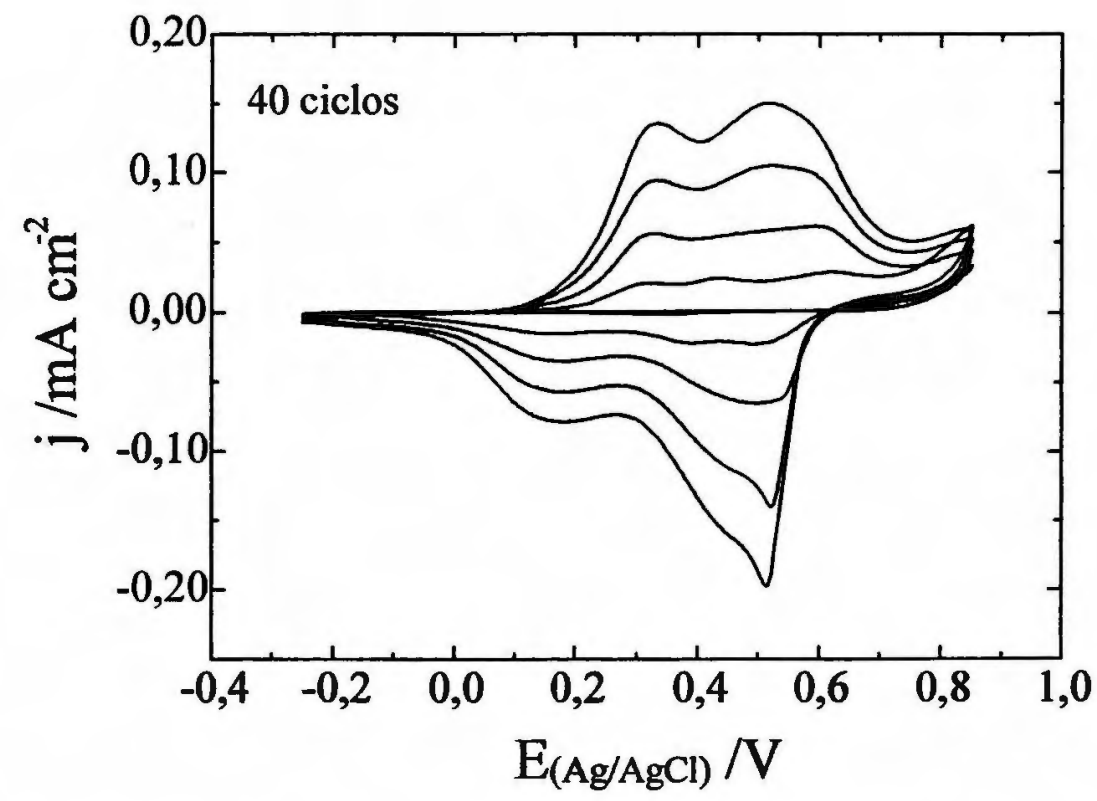

Figura 3.9: Voltamograma de crescimento do poli(anilina-co-2-etilanilina) $\left(f_{1}=0,5\right)$ em $1,0 \mathrm{~mol} / \mathrm{L}$ de $\mathrm{HCl}, \mathrm{v}=10 \mathrm{mV} / \mathrm{s}$ 
Comparando os voltamogramas de crescimento dos copolímeros com os dos homopolímeros, observa-se que o voltamograma do copolímero $f_{1}=0,1$ (Figura 3.7) apresenta um pico em cerca de $0,25 \mathrm{~V}$ muito semelhante ao pico da polianilina (Figura 3.2), aparecendo porém dois picos nos mesmos potenciais em que aparecem os picos de oxidação da poli(2-etilanilina) (Figura 3.3).Uma outra semelhança deste copolímero com a polianilina é o fato de seu crescimento ser muito rápido, na faixa de potencial escolhido.

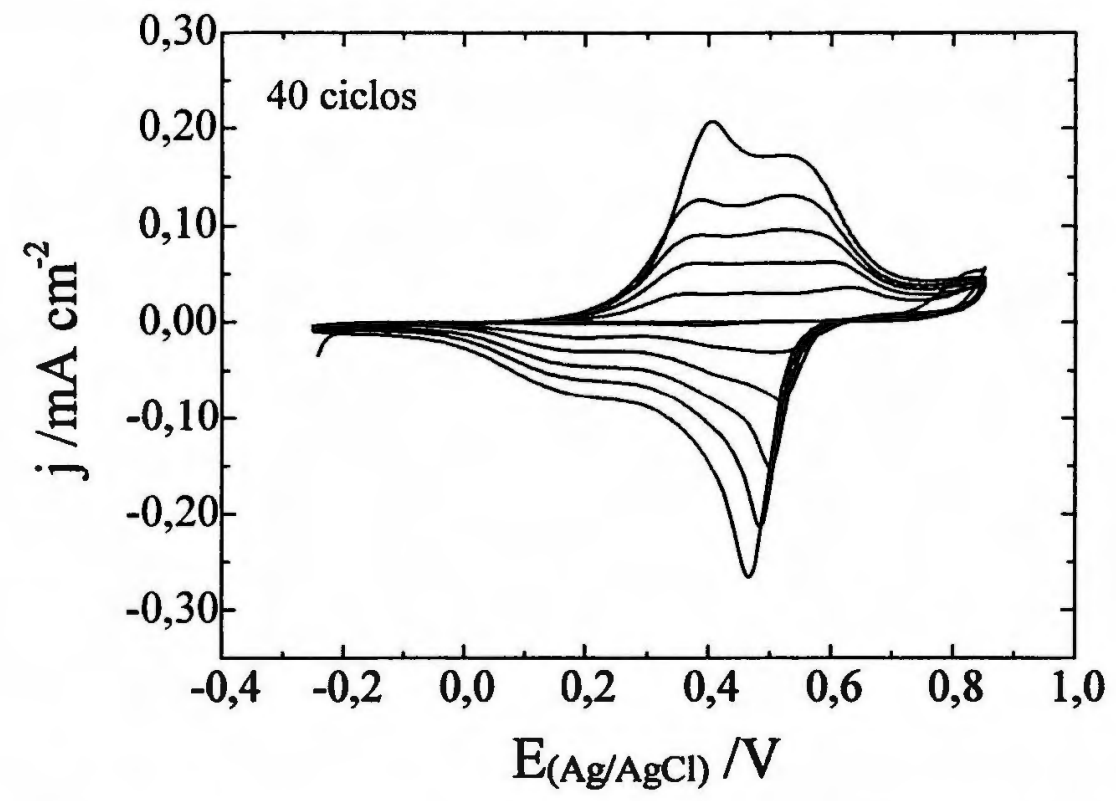

Figura 3.10: Voltamograma de crescimento do poli(anilina-co-2-etilanilina) $(f=0,7)$ em $1,0 \mathrm{~mol} / \mathrm{L}$ de $\mathrm{HCl}, v=10 \mathrm{mV} / \mathrm{s}$

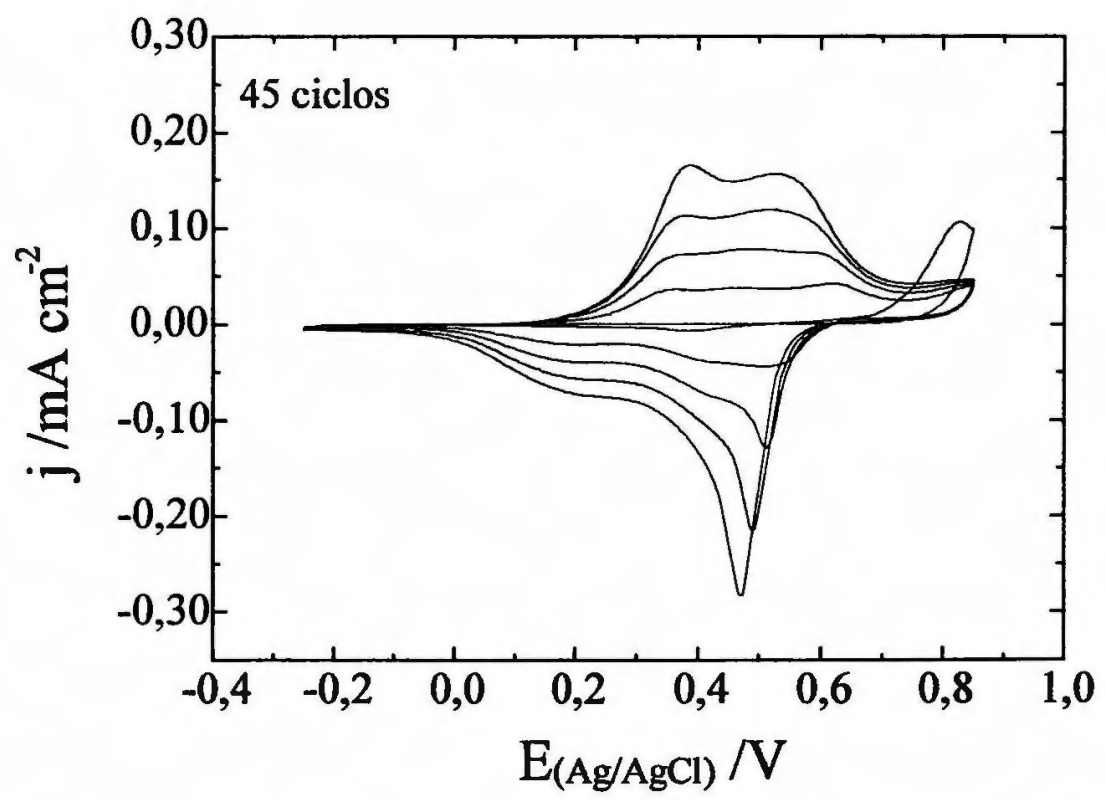

Figura 3.11: Voltamograma de crescimento do poli(anilina-co-2-etilanilina) $\left(f_{1}=0,9\right)$ em $1,0 \mathrm{~mol} / \mathrm{L}$ de $\mathrm{HCl}, v=10 \mathrm{mV} / \mathrm{s}$ 
Para os copolímeros com $f_{1}$ entre 0,3 e 0,5 (Figuras 3.8 e 3.9) o primeiro pico de oxidação aparece deslocado em cerca de $0,1 \mathrm{~V}$ para regiões de menor potencial quando comparado com o voltamograma da poli(2-etilanilina) (Figura 3.3). Enquanto que para copolímeros com $f_{1}$ entre 0,7 e 0,9 os voltamogramas (Figuras 3.10 e 3.11) são semelhantes ao voltamograma da poli(2-etilanilina).

A velocidade de crescimento eletroquímico da poli(2-etilanilina) e dos copolímeros é menor que a da polianilina, principalmente quanto se utiliza como eletrodo de trabalho um eletrodo a cristal de quartzo com camada de ouro ao invés do eletrodo de vidro/ $\mathrm{SnO}_{2}$. Comparando os dados obtidos através da eletrogravimetria pode-se entender a causa desta diferença de velocidade de crescimento. A Figura 3.12 mostra a variação de massa com o tempo de polimerização da polianilina em $1,0 \mathrm{~mol} / \mathrm{L}$ de $\mathrm{HCl}, \mathrm{v}=50 \mathrm{mV} / \mathrm{s}$ entre $-0,25$ e $0,70 \mathrm{~V}$ obtidos da literatura [159]. Onde pode-se observar um crescimento exponencial de massa em função do tempo, mostrando que o crescimento da polianilina é um processo autocatalítico. Mesmo para tempos menores de crescimento, o perfil do aumento de massa da polianilina em função do tempo é o mesmo que o observado na Figura 3.12.

Diferente do observado para a poli(2-etilanilina) (Figura 3.13) onde inicialmente tem-se um grande aumento de massa que tende a se estabilizar com o tempo, mostrando que o mecanismo de crescimento é diferente quando comparado com a polianilina, não há autocatálise, e a massa não aumenta mais depois de um determinado tempo.

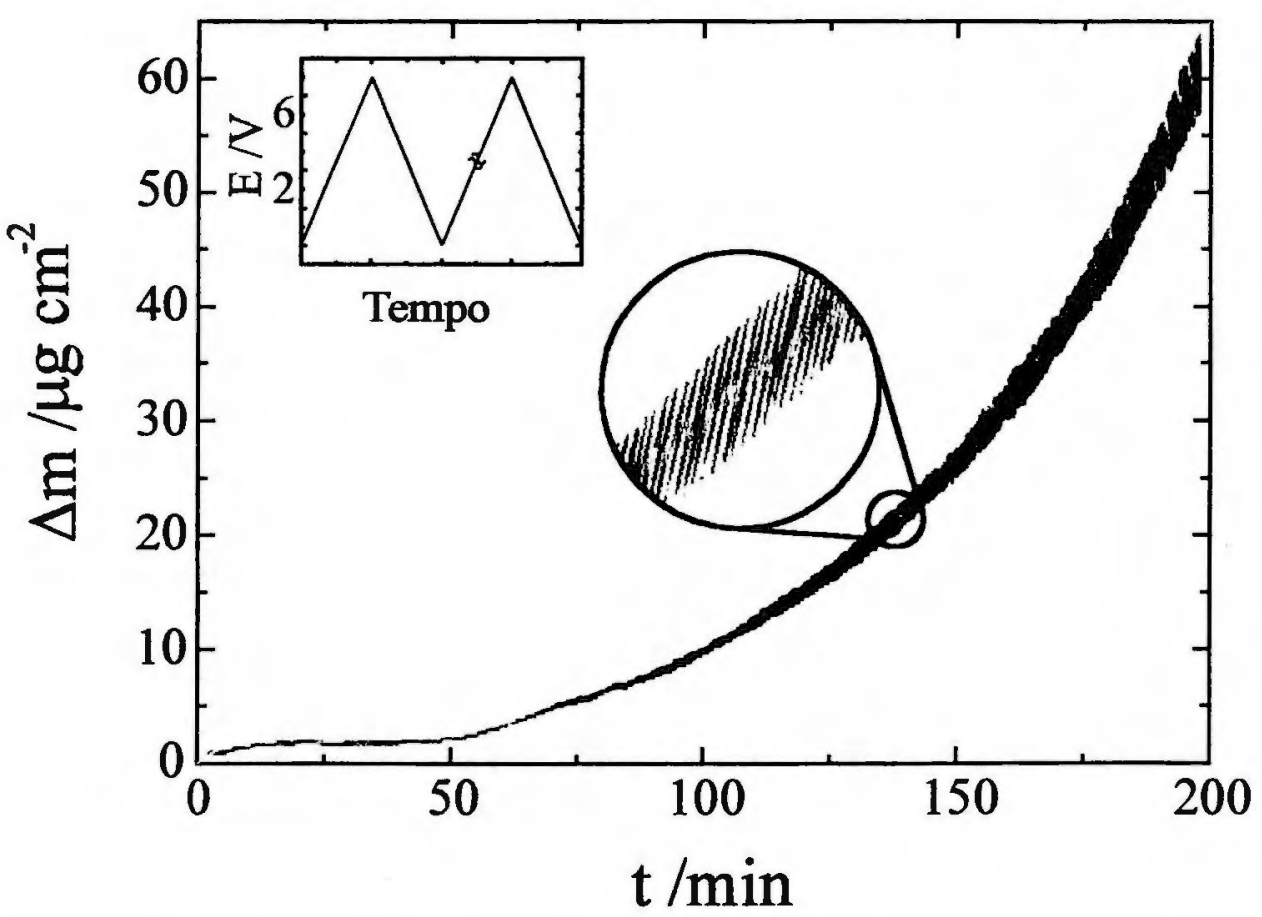

Figura 3.12: Variação de massa em função do tempo para a eletrodeposição da polianilina em $1,0 \mathrm{~mol} / \mathrm{L}$ de $\mathrm{HCl}, v=50 \mathrm{mV} / \mathrm{s}$ [159]. 


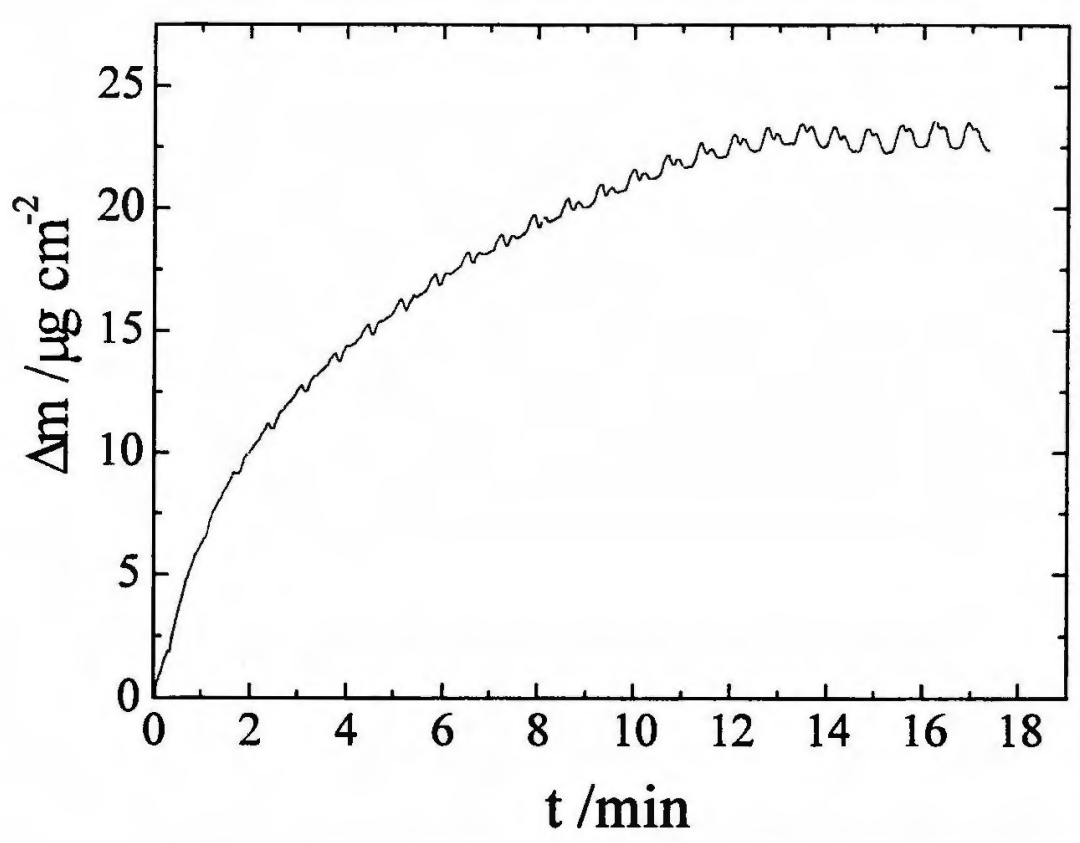

Figura 3.13: Variação de massa em função do tempo para a eletrodeposição da poli(2-etilanilina) em $1,0 \mathrm{~mol} / \mathrm{L}$ de $\mathrm{HCl}, v=50 \mathrm{mV} / \mathrm{s}$.

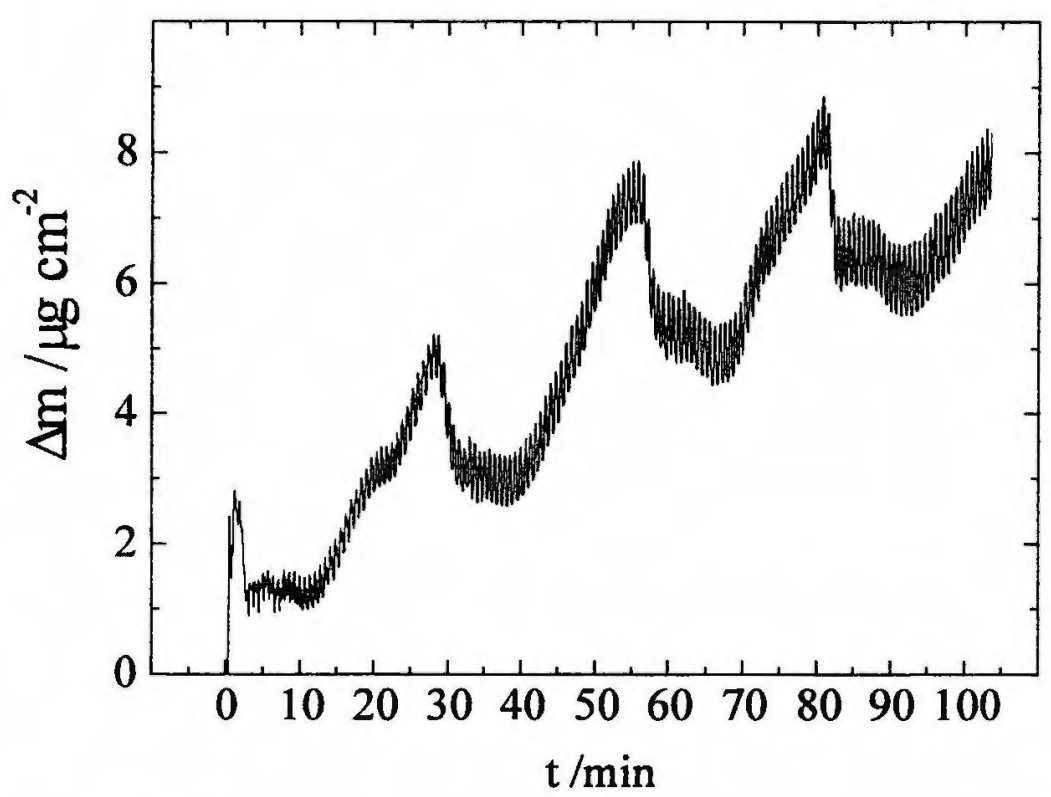

Figura 3.14: Variação de massa em função do tempo para eletrodeposição da poli(anilina-co-2-etilanilina) $f_{1}=0,5$ ) em 1,0 mol/L de $\mathrm{HCl}, v=50 \mathrm{mV} / \mathrm{s}$

Para o copolímero tem-se um aumento linear de massa com o tempo (Figura 3.14), porém esse aumento de massa não é constante, tem-se uma variação regular de massa com o tempo, ou seja, durante o crescimento do copolímero tem-se um aumento e uma perda periódica de massa. Estas perdas de massa podem estar relacionadas à formação de produtos solúveis que se desprendem do eletrodo. Possivelmente cadeias de oligômeros que são formados durante o processo de copolimerização. 
Com estes dados pode-se observar que este material formado é um material diferente dos homopolímeros, uma vez que a cinética de seu crescimento é diferenciada, e a curva de crescimento do copolímero não corresponde simplesmente à soma das curvas obtidas para os homopolímeros.

\subsubsection{Síntese Química}

$\mathrm{Na}$ síntese química os polímeros e copolímeros foram sintetizados com $\mathrm{K}_{2} \mathrm{~S}_{2} \mathrm{O}_{8}$ e desdopados com $\mathrm{KOH}$, e não com $\left(\mathrm{NH}_{4}\right)_{2} \mathrm{~S}_{2} \mathrm{O}_{8}$ e $\mathrm{NH}_{4} \mathrm{OH}$ como usualmente descrito na literatura [116,160161], devido à disponibilidade destes materiais no laboratório. Após 10 minutos da adição de gente oxidante à solução de síntese, esta começa a adquirir uma coloração esverdeada, que vai se intensificando com a formação do polímero.

Com a síntese química obtém-se um polímero na forma de pó de coloração verde, devido a presença de $\mathrm{HCl}$ na solução de síntese. Com a desdopagem do polímero com $\mathrm{KOH}$ obtém-se um pó de cor azul escura.

\subsection{Caracterização dos Polímeros}

\subsubsection{Caracterização Eletroquímica}

Registraram-se os voltamogramas em diferentes eletrólitos dos filmes de polianilina, poli(2etilanilina), dos copolímeros poli(anilina-2-etilanilina), obtidos via síntese eletroquímica, e dos filmes de poli(N-etilanilina) obtidos quimicamente, dissolvido em NMP e depositado em eletrodo de vidro/ $\mathrm{SnO}_{2}$.

A Figura 3.15 mostra o voltamograma cíclico da poli(2-etilanilina) em $0,8 \mathrm{~mol} / \mathrm{L}$ de $\mathrm{HCl}$ a uma velocidade de $10 \mathrm{mV} / \mathrm{s}$. Como o filme é lavado com água deionizada após a síntese e seco em meio ambiente, o primeiro ciclo do voltamograma mostra-se diferente dos demais, devido à entrada de água e eletrólito na matriz polimérica. Pode-se observar também que dois picos distintos aparecem inicialmente, e juntam-se em um único pico com o tempo, sendo que a corrente também vai diminuindo. O mesmo acontece com os copolímeros, porém em menor intensidade, por isso, todas as medidas espectroeletroquímicas foram realizadas com os filmes recém sintetizados e previamente ciclados no eletrólito de estudo ( 10 a 15 ciclos). 


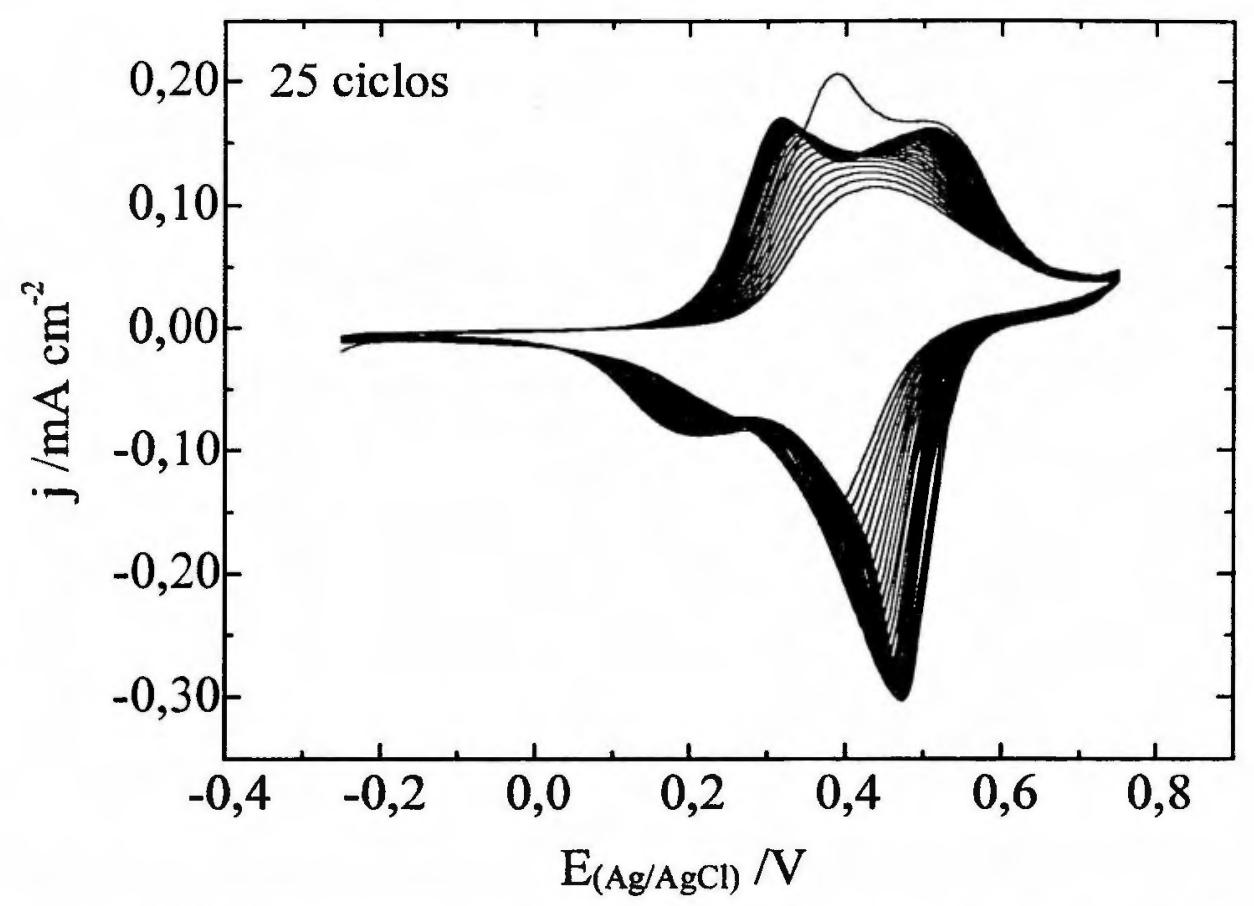

Figura 3.15: Voltamograma da poli(2-etilanilina) em $0,8 \mathrm{~mol} / \mathrm{L}$ de $\mathrm{HCl}, v=10 \mathrm{mV} / \mathrm{s}$.

Esta junção dos picos de oxidação no voltamograma também é observado para a poli(Netilanilina) em $0,8 \mathrm{~mol} / \mathrm{L}$ de $\mathrm{HCl}$ a uma velocidade de $10 \mathrm{mV} / \mathrm{s}$, onde nos primeiros ciclos pode-se observar dois picos distintos. Com o aumento do número de ciclos, o primeiro pico vai se deslocando para regiões de maior potencial até se juntar com o segundo pico, formando um pico largo (Figura 3.16).

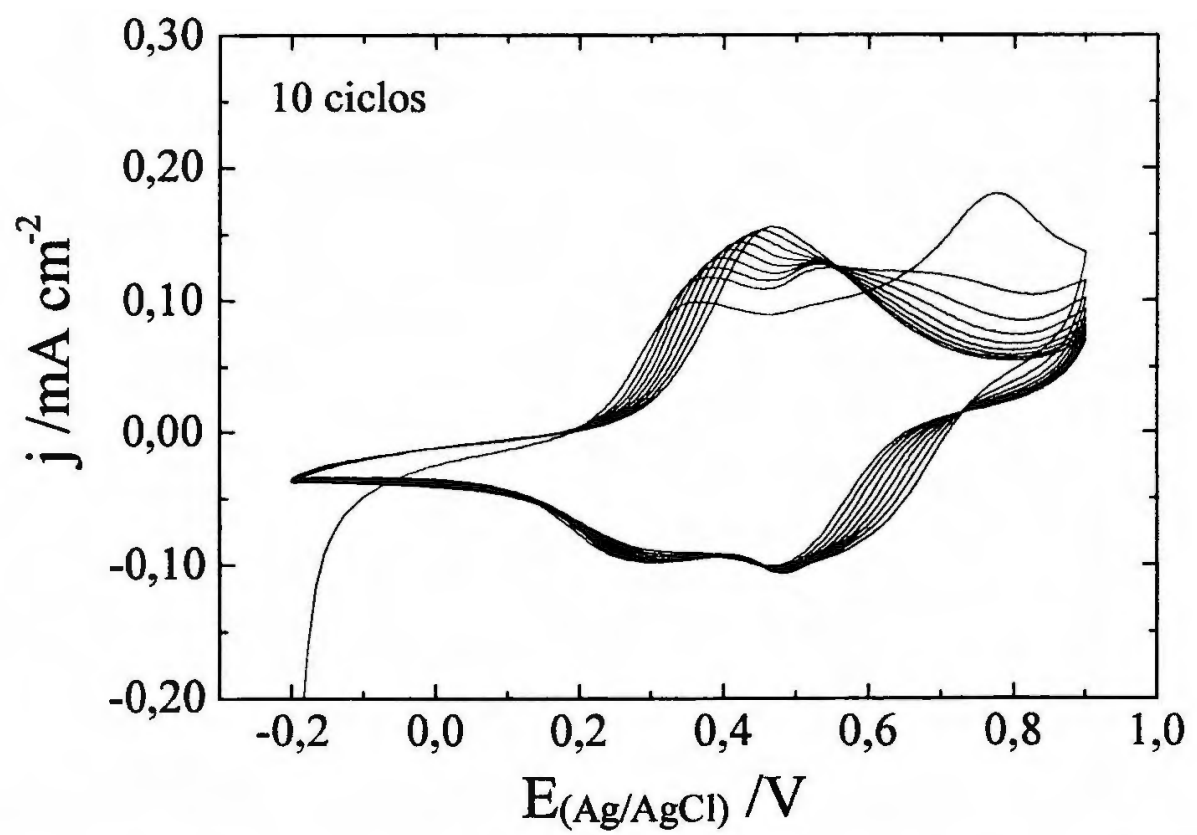

Figura 3.16: Voltamograma da poli(N-etilanilina) em $0,8 \mathrm{~mol} / \mathrm{L}$ de $\mathrm{HCl}, v=10 \mathrm{mV} / \mathrm{s}$. 
Estudos realizados com poli(o-toluidinas) $[123,162]$ e com poli( $\mathrm{N}$-alquilanilinas) [163] mostram também dois picos distintos nos voltamogramas utilizando como eletrólitos $\mathrm{HCl} \mathrm{e} \mathrm{HClO}_{4}$, onde estes dois picos anódicos foram atribuídos. $O$ primeiro pico deve-se à oxidação do átomo de nitrogênio do grupo amina, formando um radical cátion (semiquinonas), (Figura 3.17).

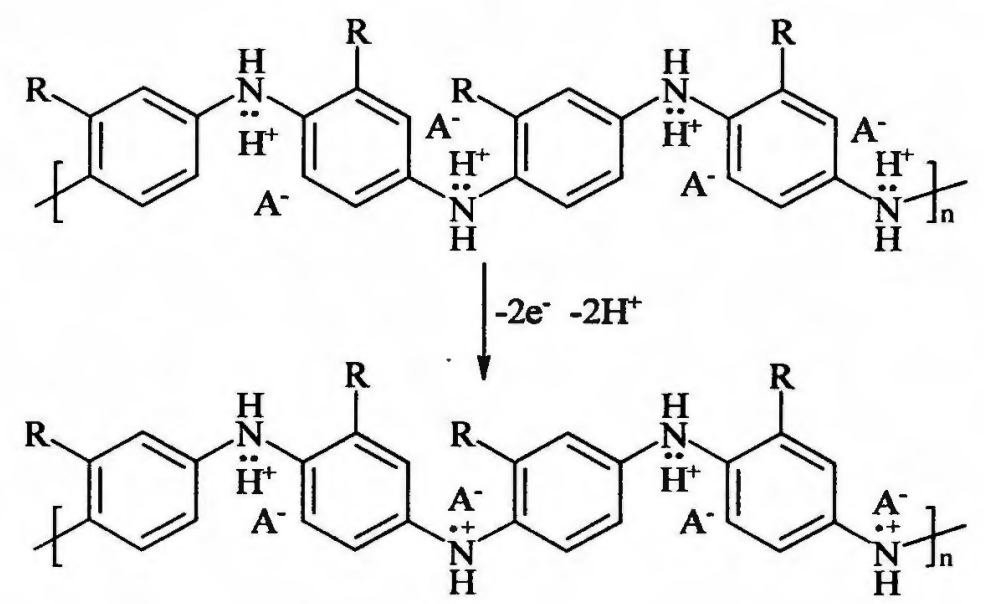

Figura 3.17: Esquema da oxidação do nitrogênio do grupo amina da cadeia polimérica, formação do radical cátion (pólarons), e primeiro pico observado no voltamograma do polímero.

O segundo processo de oxidação, a um potencial mais alto e dependente do $\mathrm{pH}$ da solução eletrolítica é atribuído à conversão do radical cátion na sua forma totalmente oxidada, que posteriormente se relaxa para uma estrutura quinoidal (Figura 3.18) [164].

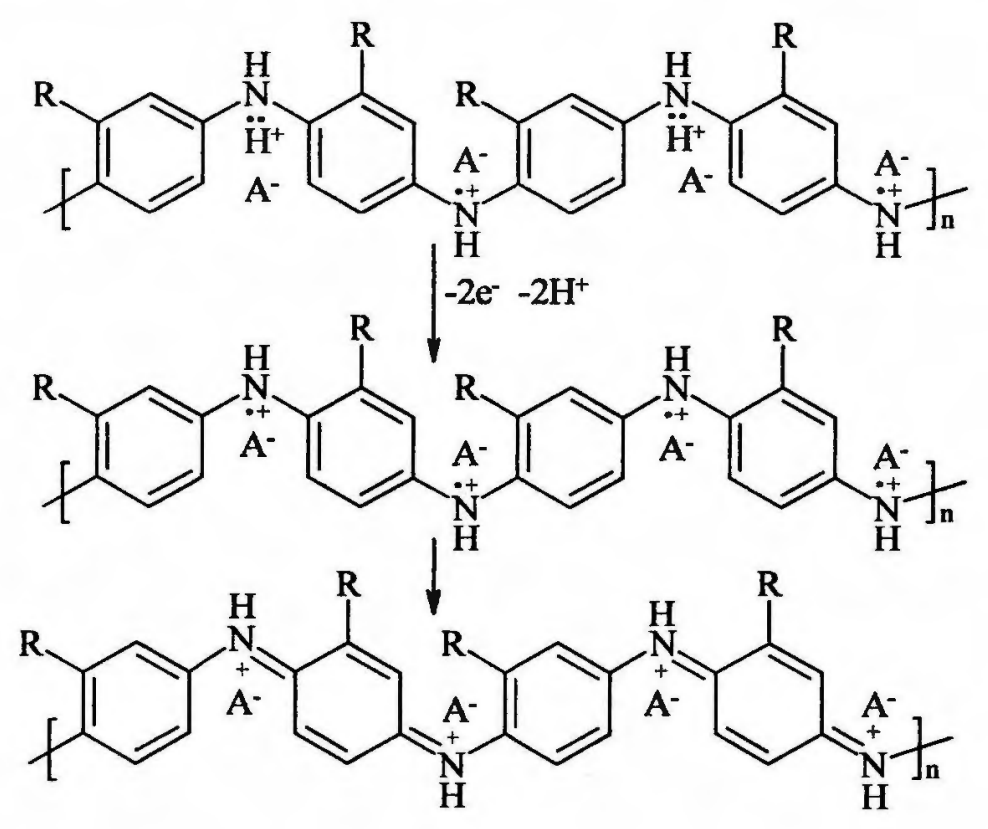

Figura 3.18: Esquema da oxidação em dicátions (bipólarons), segundo pico no voltamograma do polímero e relaxação para estrutura quinoidal, [164]. 
Os valores de potencial do primeiro e segundo processo redox e a diferença entre estes valores de potencial $(\Delta E)$, para a polianilina e polianilinas substituídas estão indicadas na Tabela 3.1.

Tabela 3.1: Valores de potencial para o primeiro e segundo processo de oxidação, e diferença de potencial entre estes dois processos, para os polimeros.

\begin{tabular}{|c|c|c|c|c|}
\hline Polímero & Condiçōes & $\begin{array}{c}\text { Primeiro pico } \\
\text { (V) }\end{array}$ & $\begin{array}{c}\text { Segundo pico } \\
\text { (V) }\end{array}$ & $\begin{array}{c}\text { Diferença de } \\
\text { potencial }(\Delta \mathrm{E}) \\
(\mathrm{V})\end{array}$ \\
\hline Polianilina & $0,8 \mathrm{~mol} / \mathrm{L} \mathrm{HCl} \mathrm{v}=10 \mathrm{mV} / \mathrm{s}$ & 0,24 & 0,80 & 0,56 \\
\hline Poli(o-toluidina) & $\begin{array}{l}1,0 \mathrm{mo} / \mathrm{L} \mathrm{HCl} \mathrm{v}=50 \mathrm{mV} / \mathrm{s} \\
{[162]}\end{array}$ & 0,20 & 0,57 & 0,37 \\
\hline \multirow{3}{*}{ Poli(2-etilanilina) } & $0,8 \mathrm{mo} / \mathrm{L} \mathrm{HCl} \mathrm{v}=10 \mathrm{mV} / \mathrm{s}$ & & & \\
\hline & $1^{\circ}$ ciclo & 0,31 & 0,51 & 0,20 \\
\hline & $15^{\circ}$ ciclo & 0,36 & 0,50 & 0,14 \\
\hline \multirow{3}{*}{ Poli(N-etilanilina) } & $0,8 \mathrm{mo} / \mathrm{L} \mathrm{HCl} \mathrm{v}=10 \mathrm{mV} / \mathrm{s}$ & & & \\
\hline & $1^{\circ}$ ciclo & 0,37 & 0,53 & 0,16 \\
\hline & $10^{\circ}$ ciclo & 0,46 & 0,53 & 0,07 \\
\hline
\end{tabular}

Através destes dados pode-se concluir que estes polímeros substituídos, necessitam de um potencial maior para o primeiro processo de oxidação (polarização), quando comparados com a polianilina, e de um potencial menor para o segundo processo de oxidação (despolarização) Figura 3.19.

A introdução de grupos metil e etil nos anéis e no nitrogênio, e o conseqüente aumento no ângulo de torção entre os anéis diminui a extensão da conjugação $\pi$ aumentando a energia para formação do radical cátion, quando comparado com a polianilina, aumentando assim o potencial de oxidação da amina em semiquinona na cadeia polimérica. Apesar destes substituintes possuírem um efeito de estabilização do radical cátion, o que poderia diminuir o potencial de oxidação, pode-se observar que os efeitos estéricos são mais importantes neste primeiro processo redox, que os efeitos eletrônicos.

No segundo processo de oxidação o efeito eletrônico do substituinte metil e alquil é mais importante, pois este processo é facilitado com o aumento da basicidade do grupo imina. Como o substituinte aumenta esta basicidade, estabilizando a carga positiva formada, tem-se uma diminuição no potencial de oxidação.

A polianilina, poli( $\mathrm{N}$-etilanilina), poli(2-etilanilina), e os diferentes copolímeros de poli(anilinaco-2-etilanilina) mostraram a mesma variação de cor conforme o estado de oxidação, passando de amarelo, para verde e finalmente azul, com o aumento de potencial de $-0,25$ a $0,75 \mathrm{~V}$. Este 


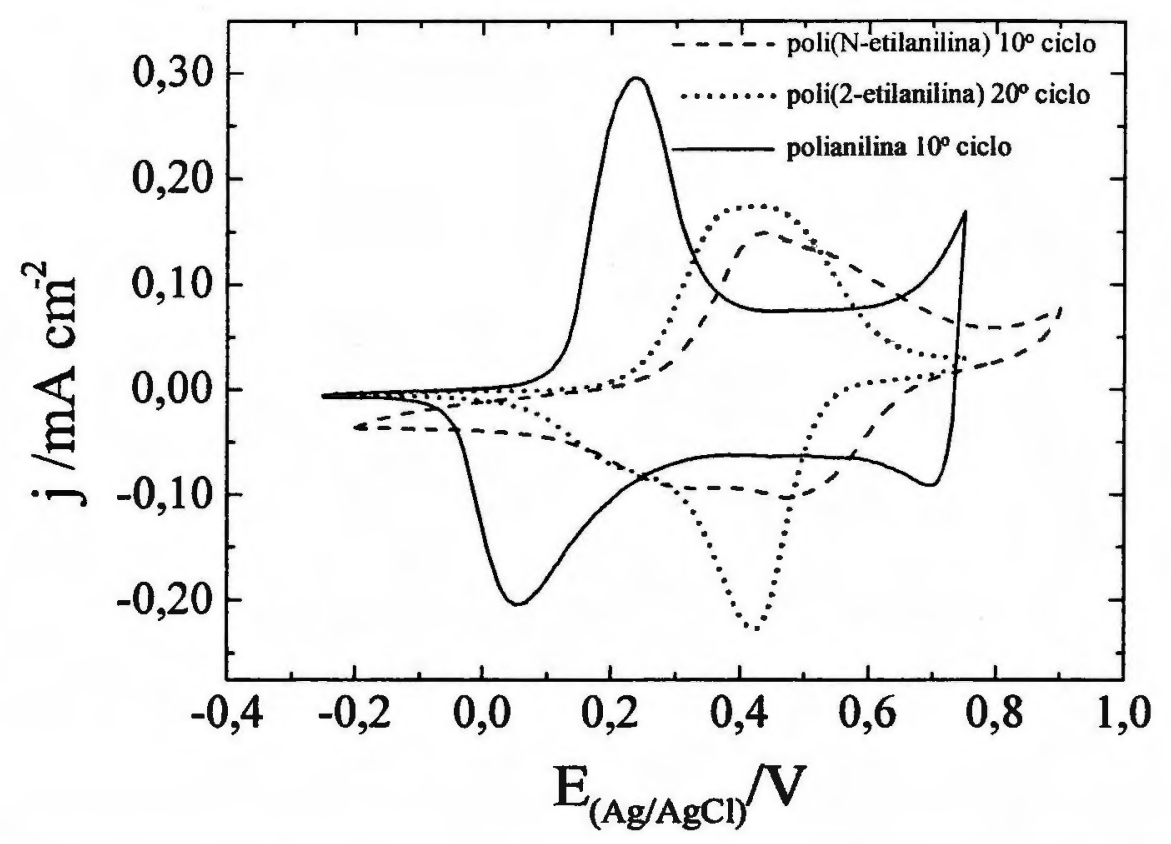

Figura 3.19: Voltamograma da polianilina, poli(2-etilanilina) e poli( $\mathrm{N}$-etilanilina) em 0,8 mol/L de $\mathrm{HCl}$.

eletrocromismo é provocado por alterações nas bandas de valência e condução causadas por inserções/remoções de elétrons nestas bandas alterando a energia de separação entre elas [165].

A resposta eletroquímica tanto da polianilina, quanto da poli(2-etilanilina) e copolímeros dependem do eletrólito utilizado, porém a variação na resposta da polianilina (Figura 3.20) é muito pequena quando comparada com a da poli(2-etilanilina) (Figura 3.21) onde a separação e intensidade dos picos variam muito.

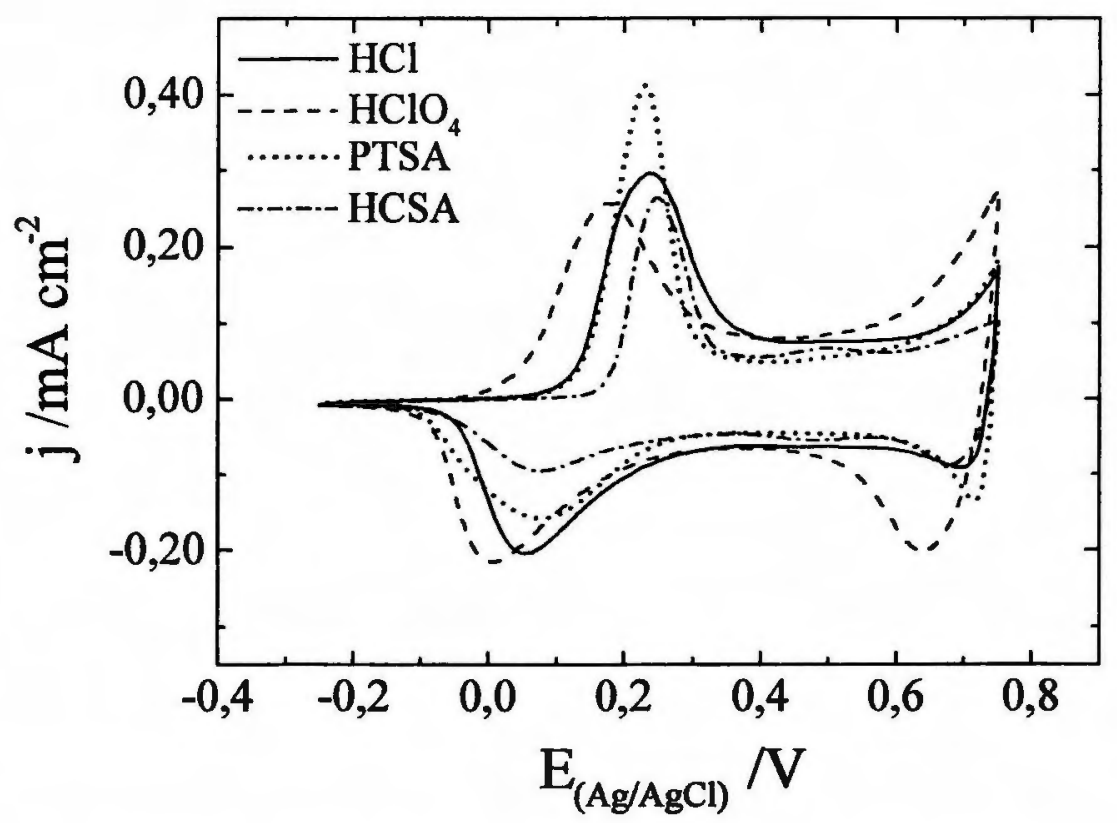

Figura 3.20: Voltamograma da polianilina em $0,8 \mathrm{~mol} / \mathrm{L}$ de diferentes eletrólitos, $v=10 \mathrm{mV} / \mathrm{s}$. 


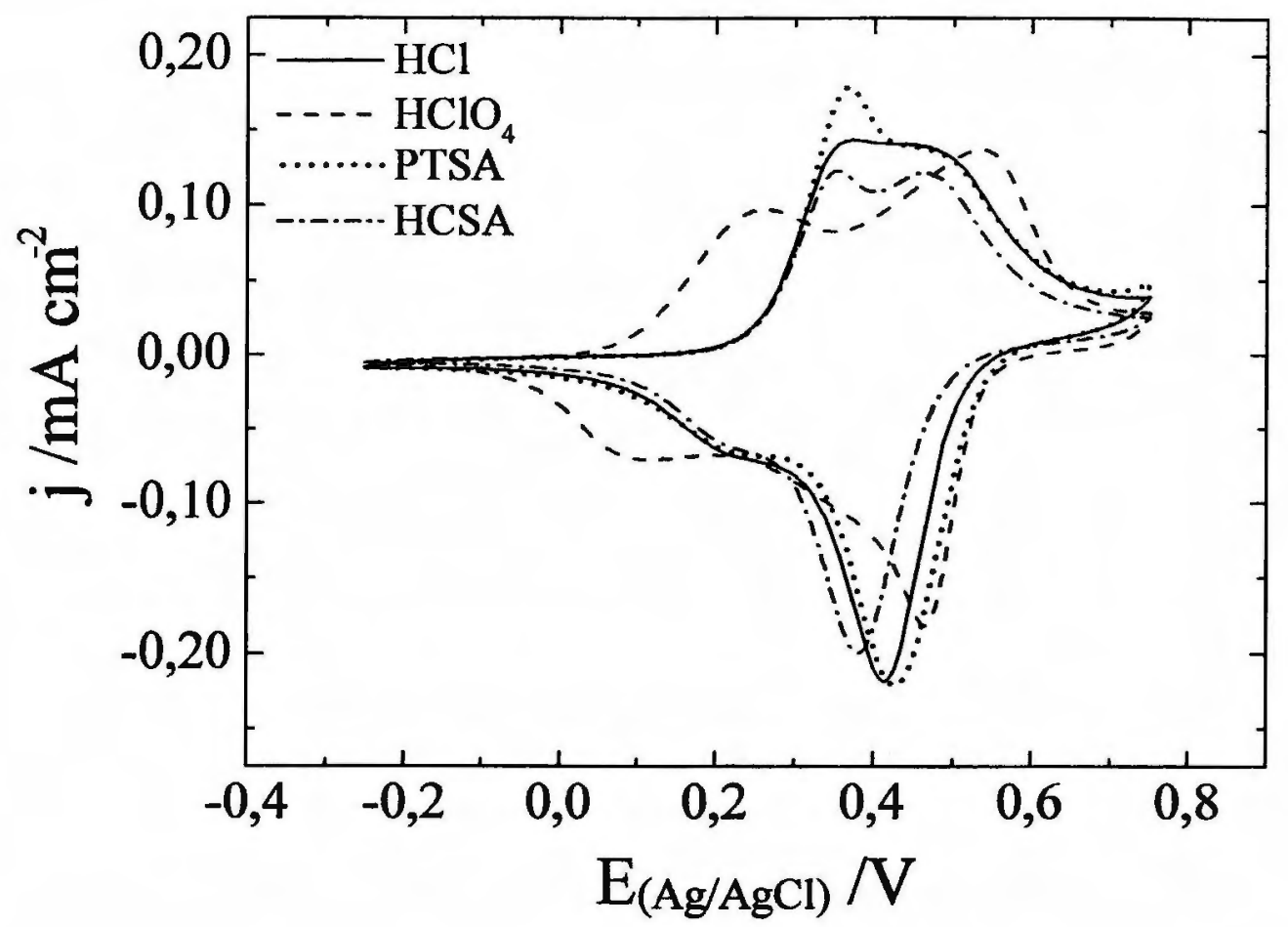

Figura 3.21: Voltamograma da poli(2-etilanilina) em $0,8 \mathrm{~mol} / \mathrm{L}$ de difenentes eletrólitos, $v=10 \mathrm{mV} / \mathrm{s}, v_{\text {sint }}=10 \mathrm{mV} / \mathrm{s}$.

É interessante observar que quando se utiliza PTSA como eletrólito tem-se uma intensificação e estreitamento no pico do primeiro processo de oxidação, e quando a poli(2-etilanilina) sintetizada quimicamente é dopada com PTSA tem-se um material consistente e não na forma de pó como o obtido com os outros ácidos, mostrando que a interação do PTSA com a cadeia polimérica ocorre de maneira diferenciada, provavelmente devido ao anel aromático do PTSA. Não foi efetuado qualquer caracterização morfológica ou mecânica deste material, em termos táteis e visuais este material se assemelha à argila, passível de ser moldado, porém um tanto quanto quebradiço.

Para contra-íons menores como o $\mathrm{Cl}^{-}$, o voltamograma da poli(2-etilanilina) apresenta apenas um único pico largo, enquanto que na presença de contra íons maiores os picos dos dois processos eletroquímicos podem ser distinguidos.

Em filmes de poli(2-etilanilina) que foram formados a uma velocidade maior, $50 \mathrm{mV} / \mathrm{s}$ (Figura 3.22) observa-se que para contra-ion maiores como o $\mathrm{CSA}^{-}$tem-se uma densidade de corrente muito menor quando comparado com os outros contra íons, mostrando um impedimento na passagem do $\mathrm{CSA}^{-}$pela matriz polimérica. Na Figura 3.20, os filmes foram obtidos a uma velocidade de $10 \mathrm{mV} / \mathrm{s}$, e nestas condições, as cadeias poliméricas provavelmente tiveram mais tempo para se organizarem durante sua formação, de maneira à facilitar a passagem dos eletrólitos durante os processos de oxidação/redução, por isso a densidade de corrente não varia muito em função do tamanho do ânion presente no eletrólito utilizado. 


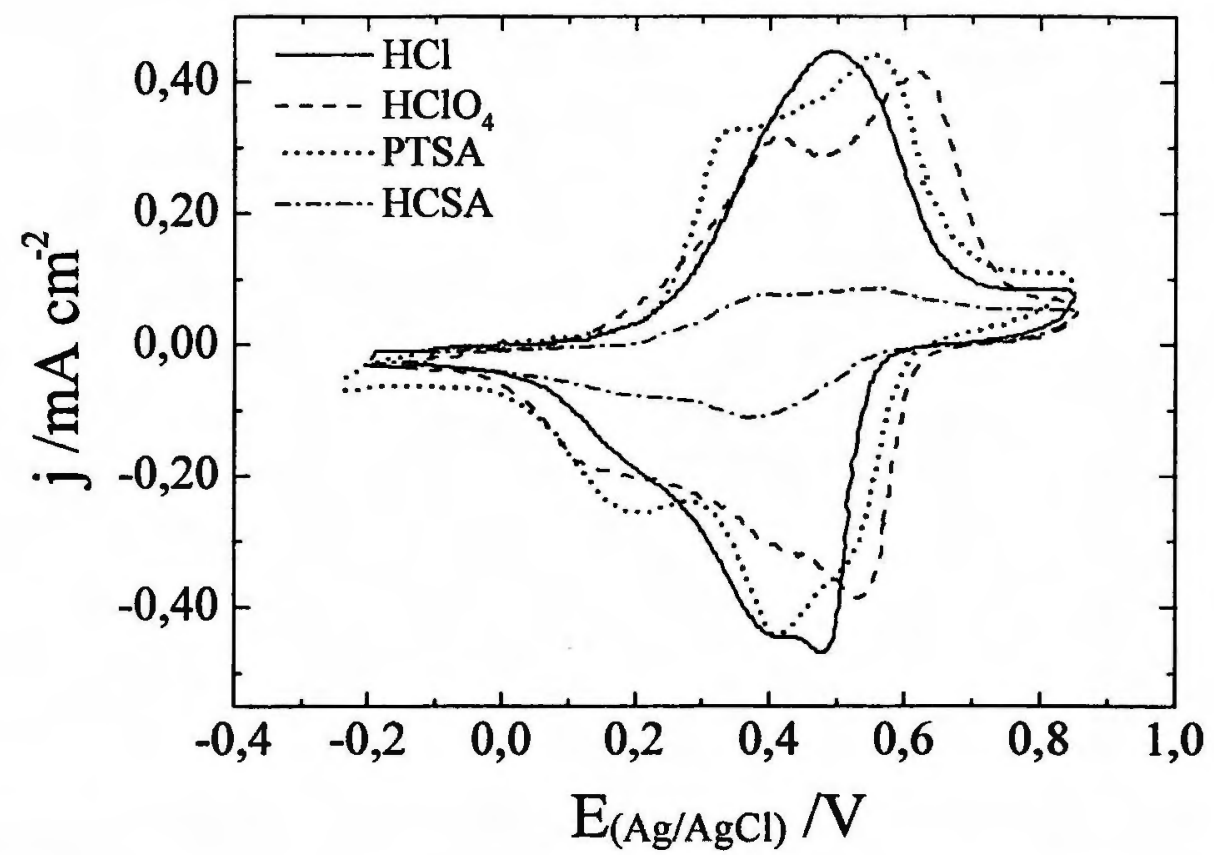

Figura 3.22: Voltamograma da poli(2-etilanilina) em $0,8 \mathrm{~mol} / \mathrm{L}$ de diferentes soluções eletroliticas $v=10 \mathrm{mV} / \mathrm{s}, v_{\text {simt }}=50 \mathrm{mV} / \mathrm{s}$.

Quando o polímero é preparado em uma solução de HCSA a uma velocidade de varredura alta, a estrutura do polímero obtida permite uma densidade de corrente maior quando ciclado em HCSA, em comparação com os filmes obtidos em $\mathrm{HCl}$ e ciclados em HCSA (Figura 3.23).

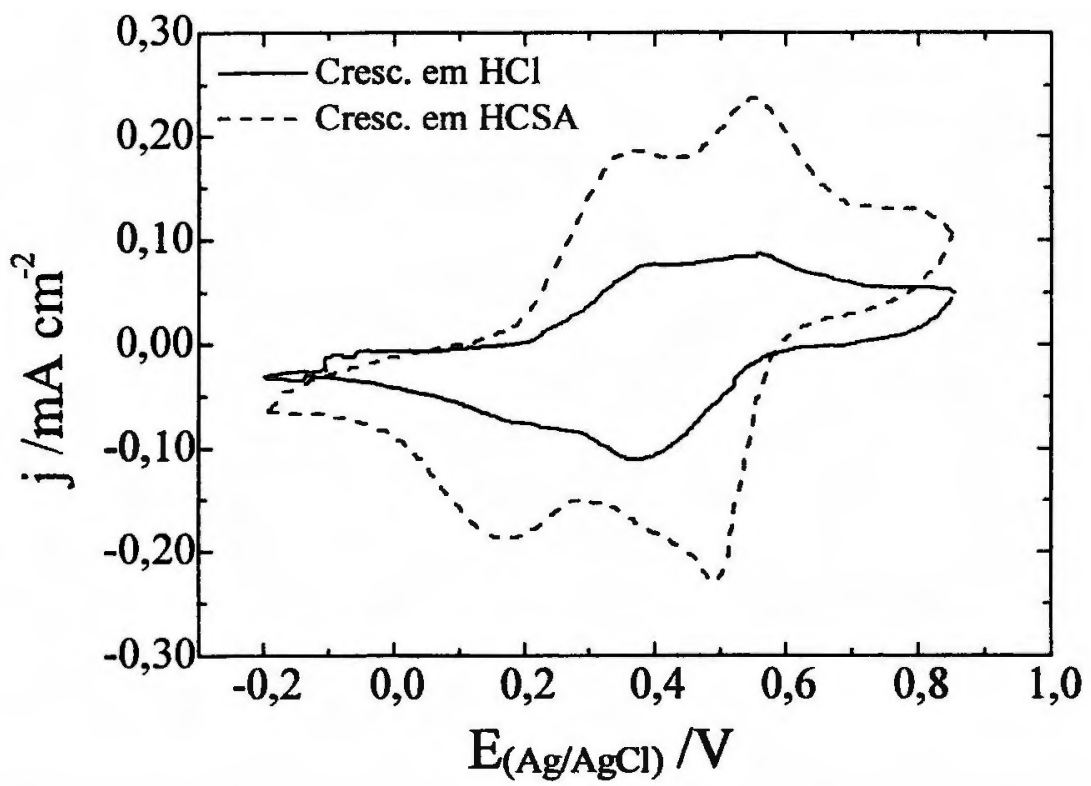

Figura 3.23: Voltamograma da poli(2-etilanilina) em $0,8 \mathrm{~mol} / \mathrm{L}$ de HCSA, filmes crescidos em HCl e HCSA, $v=50 \mathrm{mV} / \mathrm{s}$. 
Durante o crescimento do polímero as cadeias poliméricas se organizam de forma a permitir a passagem dos ânions através de sua matriz, para que ocorra a compensação de carga durante o processo redox. Quando o filme cresce em presença de ânion pequenos as cadeias estão mais próximas, fazendo com que ânions maiores tenham dificuldade em se movimentar pela matriz. Porém quando o polímero cresce em presença de ânions maiores as cadeias ficam mais afastadas, de maneira que estes ânions possam se movimentar pela matriz polimérica durante o processo redox, facilitando a transferência de carga e consequentemente aumentando a densidade de corrente.

A resposta eletroquímica da poli(N-etilanilina) (Figura 3.24) tem a mesma variação observada para a polianilina em função do eletrólito utilizado, o pico sofre apenas um pequeno deslocamento e intensificação em função do eletrólito. Esta indiferença da poli( $\mathrm{N}$-etilanilina) em relação ao eletrólito talvez se deva à facilidade do substituinte em alterar sua conformação para facilitar a passagem dos eletrólitos, já que o substituinte se encontra preso ao nitrogênio, podendo ser rotacionado com maior liberdade, e não ao anel aromático, que é uma estrutura rígida.

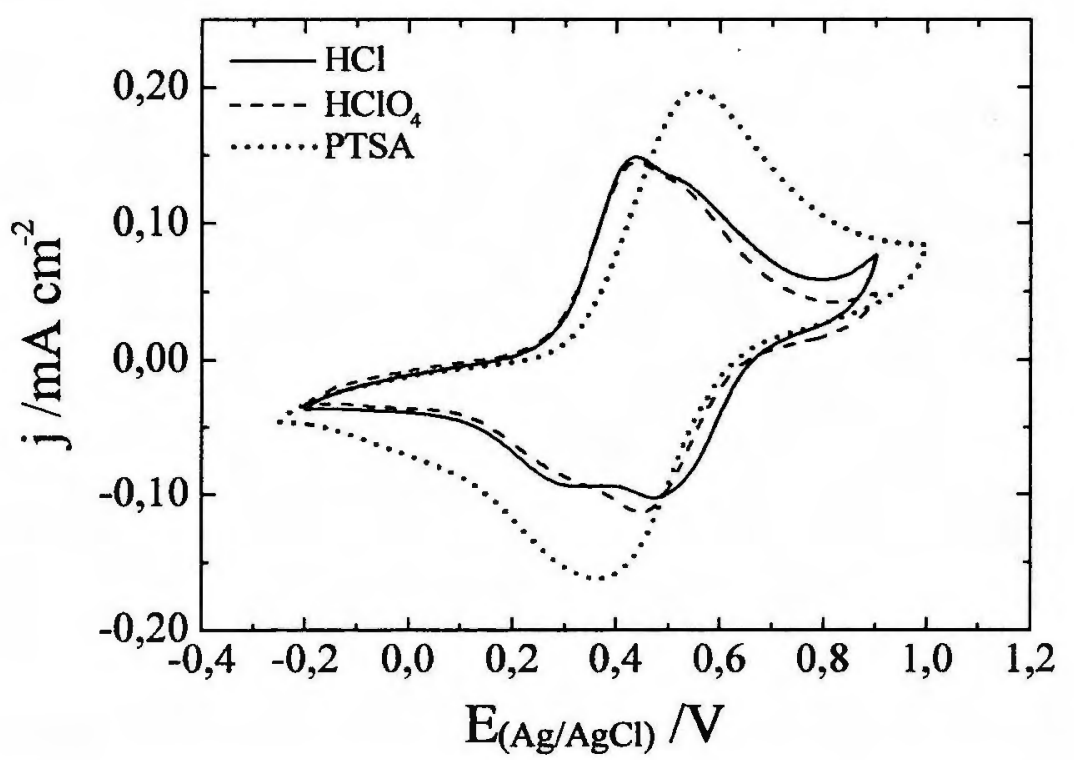

Figura 3.24: Voltamograma da poli(N-etilanilina) em $0,8 \mathrm{~mol} / \mathrm{L}$ de diferentes eletrólitos, $v=50 \mathrm{mV} / \mathrm{s}$.

Apesar destes filmes de poli( $\mathrm{N}$-etilanilina) terem sido preparados quimicamente e não eletroquimicamente como os outros polímeros, esta comparação da resposta eletroquímica pode ser feita, pois segundo a literatura [161], o voltamograma teria um perfil semelhante tanto para o polímero sintetizado quimicamente quanto eletroquimicamente.

Na Figura 3.25 é mostrado o voltamograma dos copolímeros e homopolímeros em $0,8 \mathrm{~mol} / \mathrm{L}$ de $\mathrm{HCl}$, a uma velocidade de $10 \mathrm{mV} / \mathrm{s}$. Pode-se observar que o potencial dos dois processos redox nos copolímeros estão entre os dos homopolímeros, o que sugere a presença de um copolímero e não apenas uma mistura de homopolímeros no filme [123]. 


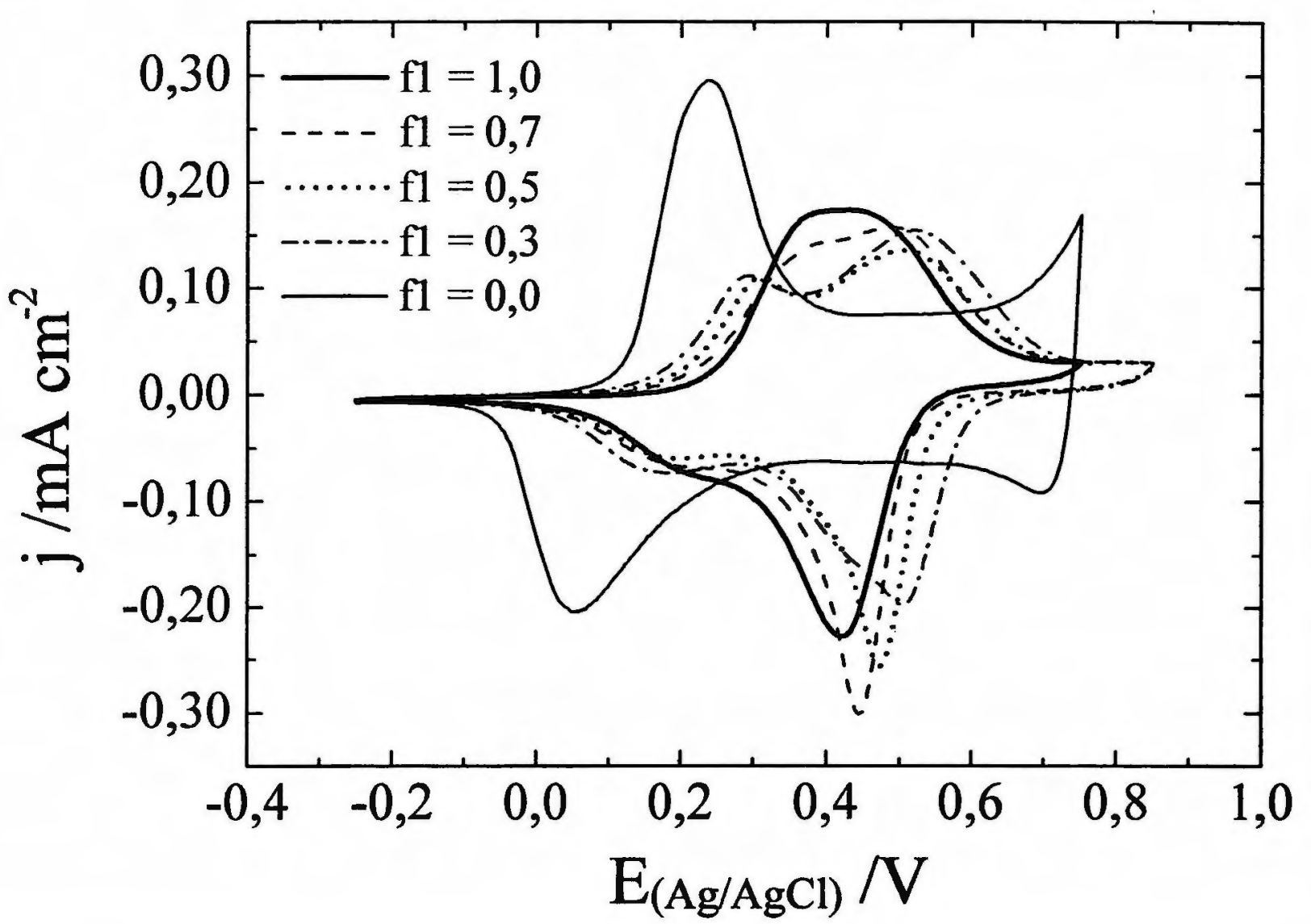

Figura 3.25: Voltamograma da polianilina, poli(2-etilanilina) e poli(anilina-co-2-etilanilina) para diferentes $f_{t}$ em 0,8 $\mathrm{mol} / \mathrm{L}$ de $\mathrm{HCl}$.

Para copolímeros contendo uma quantidade maior de unidades de 2-etilanilina, $f_{1}=0,7, o$ voltamograma se assemelha muito ao da poli(2-etilanilina), onde pode-se observar a soma dos dois picos de oxidação em um único pico largo. Com a diminuição de unidades de 2-etilanilina é possível distinguir os dois picos, pois há um ligeiro afastamento entre eles. Para os copolímeros com maior quantidade de unidades de anilina, $f_{1}=0,3$, os picos estão mais separados, mais semelhante ao voltamograma da polianilina. A distância entre os dois picos diminui com o aumento de unidades de 2-etilanilina.

No entanto a separação entre os dois picos não varia continuamente com a quantidade de unidades de 2-etilanilina, como seria de se esperar, tem-se uma diminuição gradual para $f_{1}$ de 0,0 até 0,3 , e acima de 0,3 a distância entre os picos é praticamente constante independentemente do eletrólito utilizado (Figura 3.26). 


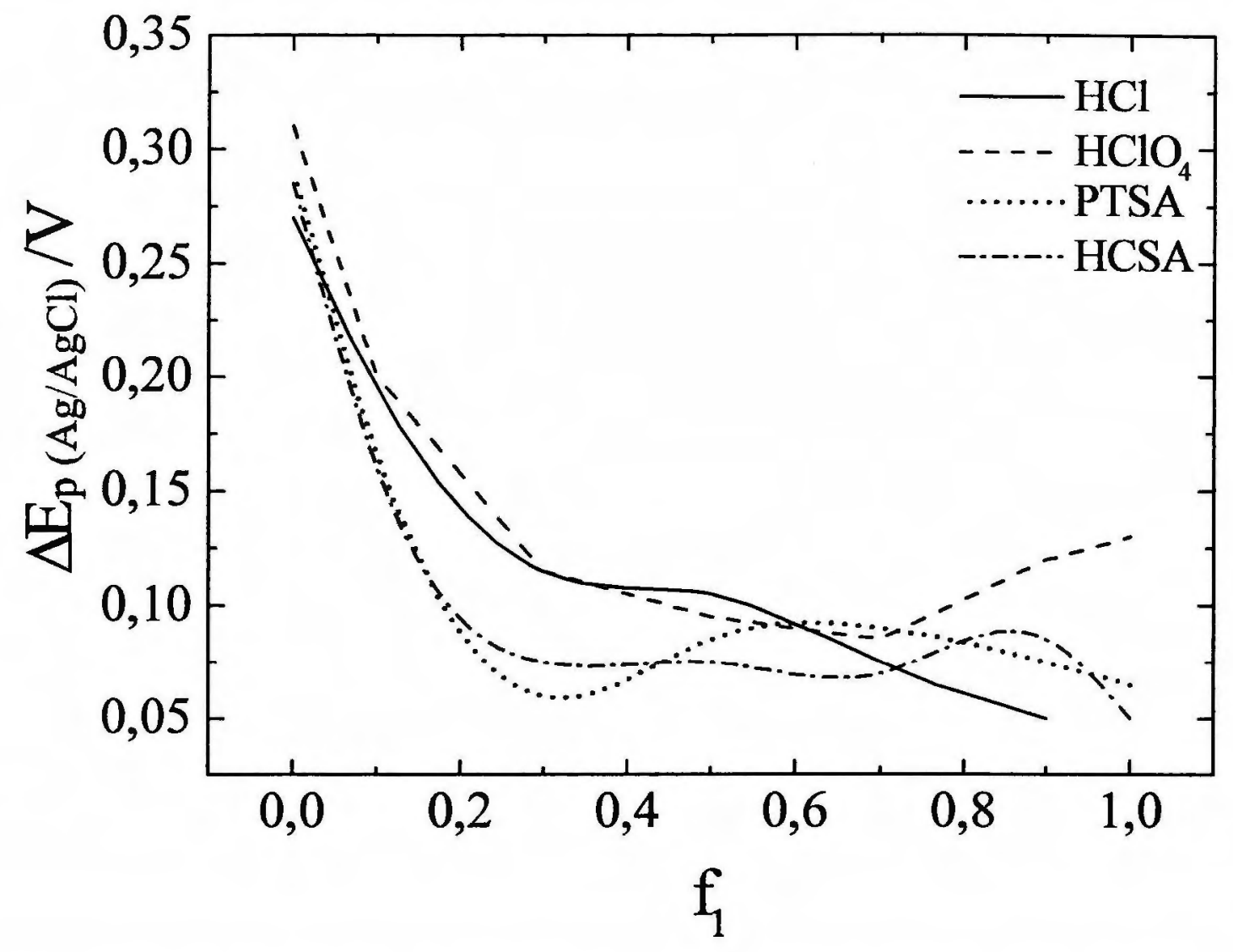

Figura 3.26: Diferença de potencial entre os dois picos (UE) para os diferentes copolimeros em função de $f_{1}$ para os eletrólitos utilizados.

A Figura 3.27 mostra o potencial do primeiro $\left(\mathrm{E}_{\mathrm{p} 1}\right)$ e do segundo $\left(\mathrm{E}_{\mathrm{p} 2}\right)$ processo de oxidação para os copolímeros e homopolímeros em função da fração de unidades de 2-etilanilina $\left(f_{1}\right) \mathrm{em}$ mols, em $0,8 \mathrm{~mol} / \mathrm{L}$ dos vários eletrólitos. Pode-se observar que o aumento de potencial do primeiro processo e decréscimo do segundo potencial de oxidação varia gradualmente para $f_{1}$ entre 0,0 e 0,3 . Para $f_{1}$ maior que 0,3 a diferença de potencial entre o primeiro e segundo processo de oxidação permanece praticamente constante para toda esta faixa de concentração. Isto pode indicar que para $\mathrm{f}_{1}$ entre 0,0 e 0,3 tem-se realmente a formação de um copolímero, cuja composição varia gradualmente com o aumento de concentração de monômeros de 2-etilanilina na solução de síntese, enquanto que para $\mathrm{f}_{1}$ maior que 0,3 a composição do copolímero seria a mesma.

Esta diferença de composição entre a solução de síntese e a composição do copolímero foi observada para poli(anilina-co-2-etilanilina) formada quimicamente [123]. Onde a composição do copolímero foi calculada através de ressonância magnética nuclear, e chegou-se a conclusão de que para $f_{1}$ menor que 0,3 tem-se a formação de um copolímero cuja a composição varia com a variação da concentração da solução de síntese, enquanto que para $f_{1}$ acima de 0,3 tem-se praticamente poli(2etilanilina) pura. 


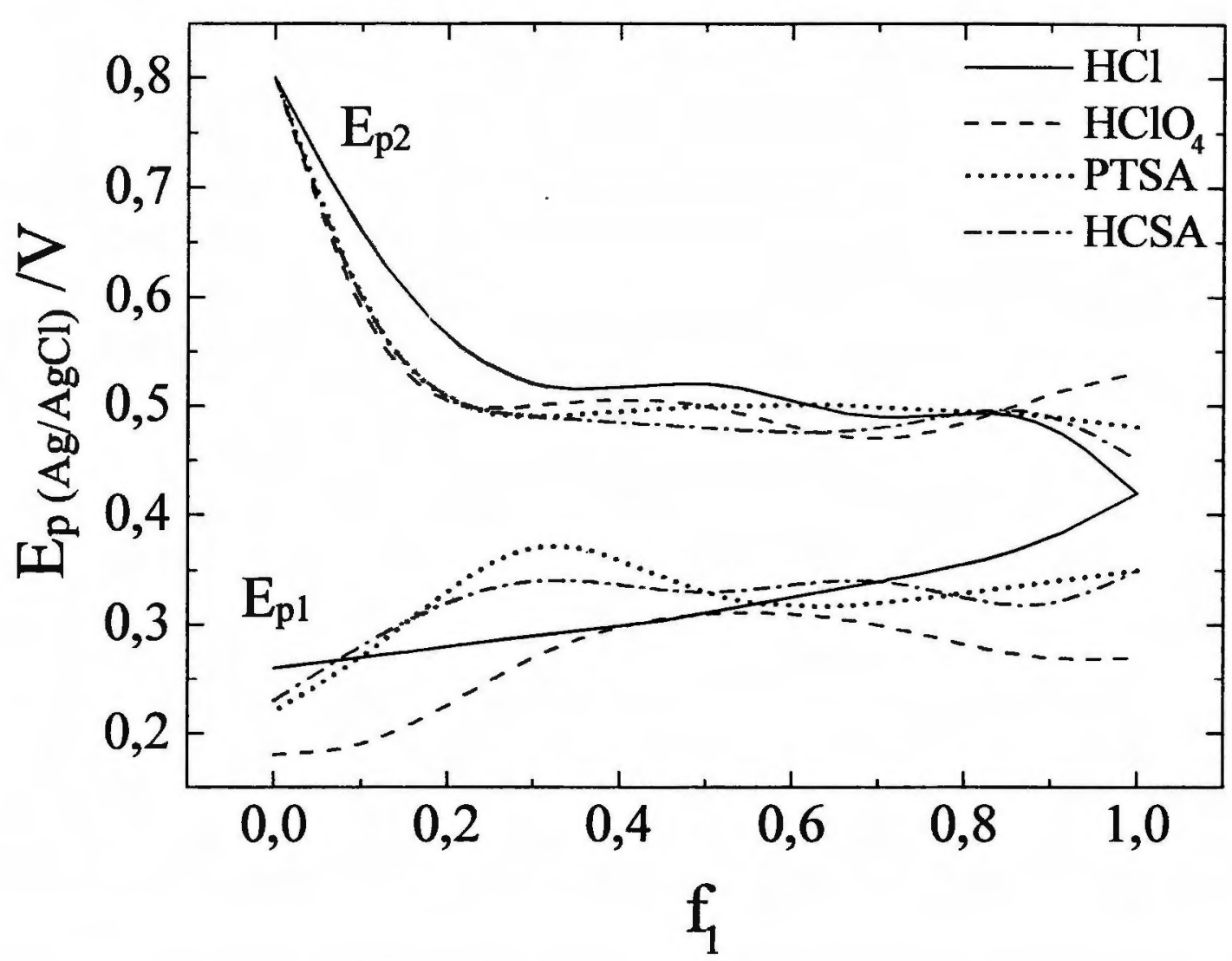

Figura 3.27: Potencial do primeiro (Ep) e segundo processo (Ep $)$ de oxidação dos diferentes copolimeros em função de $f_{p}$, para os diferentes eletrólitos estudados.

Comparando os dados da literatura com dados eletroquímicos (Figuras 3.26 e 3.27) pode-se concluir que copolímeros formado por métodos eletroquímicos tem a mesma variação de composição que os copolímeros formados quimicamente, e esta variação de composição pode ser observada também através de métodos eletroquímicos.

É interessante observar que a resposta do segundo processo de oxidação em função da quantidade de unidades de 2-etilanilina da solução de sintese é praticamente a mesma para todos os eletrólitos. Isto mostra que o tamanho do contra íon não tem muita influência sobre este processo de oxidação, e confirma o fato que este processo é influenciado predominantemente por efeitos eletrônicos do substituinte etil na cadeia polimérica. $O$ mesmo não é observado para o primeiro processo de oxidação, onde pode-se observar que as variações da resposta em função do eletrólito utilizado é maior. Neste caso, a análise evidencia que este processo é influenciado pelo volume do contraín presente no eletrólito, devido ao impedimento estérico pela presença do substituinte. 


\subsubsection{Medidas Eletrogravimétricas}

Com os filmes de polianilina, poli(2-etilanilina) e poli(anilina-co-2-etilanilina) obtidos via síntese eletroquímica registrou-se tanto os voltamogramas para os diferentes eletrólitos quanto as variações de freqüência. Através da equação de Sauerbrey, a variação de freqüência foi transformada em variação de massa, sabendo-se que para o equipamento utilizado $\mathrm{K}=5,2 \times 10^{7} \mathrm{~Hz} \mathrm{~cm}^{2} \mathrm{~g}^{-1}$.

Apesar de não ter sido realizado nenhum experimento que mostre que pode-se utilizar diretamente esta equação, ou seja, que mostre que durante o processo redox não há variação das propriedades mecânicas do material, alguns destes experimentos já estão descritos na literatura para a polianilina $[159,166-167]$.

Com os voltamogramas obtidos para poli(2-etilanilina) pode-se observar que o comportamento eletroquímico observado para o eletrodo de vidro com camada de $\mathrm{SnO}_{2}$, é diferente do comportamento observado quando o substrato é o ouro. Utilizando-se um eletrodo de ouro não há muita diferença na intensidade de corrente para ânions grandes ou pequenos, como o que é visto quando o substrato é o eletrodo de vidro com camada condutora de $\mathrm{SnO}_{2}$. Para um filme crescido sobre o eletrodo de vidro a uma velocidade de $50 \mathrm{mV} / \mathrm{s}$, a corrente obtida para ânions grandes como o HCSA, é praticamente a metade da corrente observada quando o eletrólito é o $\mathrm{HCl}$. O mesmo não acontece com a diminuição na velocidade de crescimento para $10 \mathrm{mV} / \mathrm{s}$, provavelmente devido à diferenças na morfologia dos filmes.

Com os dados de variação de massa (Figura 3.28) pode-se calcular também sua derivada (Figura 3.29), que representa a variação total de massa de/para a matriz polimérica. Com estes dados vê-se que durante o processo de oxidação da polianilina em $0,8 \mathrm{~mol} / \mathrm{L}$ de $\mathrm{HCl}$, a massa praticamente não varia até $0,20 \mathrm{~V}$, e a partir deste potencial, que é o potencial do primeiro processo de oxidação da polianilina, tem-se um grande aumento da massa total. Este aumento de massa provavelmente se deve a entrada de ânions para compensar as cargas positivas formadas na matriz polimérica.

Com a redução do polímero tem-se uma diminuição gradual de massa até cerca de $0,10 \mathrm{~V}$ devido a saída dos ânions, ficando constante até $-0,25 \mathrm{~V}$. Durante a redução tem-se uma diminuição de cargas positivas no polímero, e conseqüentemente, ocorre a saída de ânions. Deve-se lembrar que esta variação de massa se deve ao fluxo total de íons e solvente, ou seja, é a soma tanto da entrada, quanto da saída de íons e solvente da matriz polimérica.

É importante ressaltar que não foi efetuado qualquer medida para determinar a espessura dos filmes utilizados nas medidas eletrogravimétricas, o controle da quantidade de material sobre o eletrodo foi feito através da corrente catódica durante o crescimento do polímero. Desta maneira um filme espesso corresponde a uma corrente catódica de $10^{-1} \mathrm{C}$, enquanto que para um filme fino tem-se uma corrente catódica de aproximadamente $10^{-3} \mathrm{C}$. 


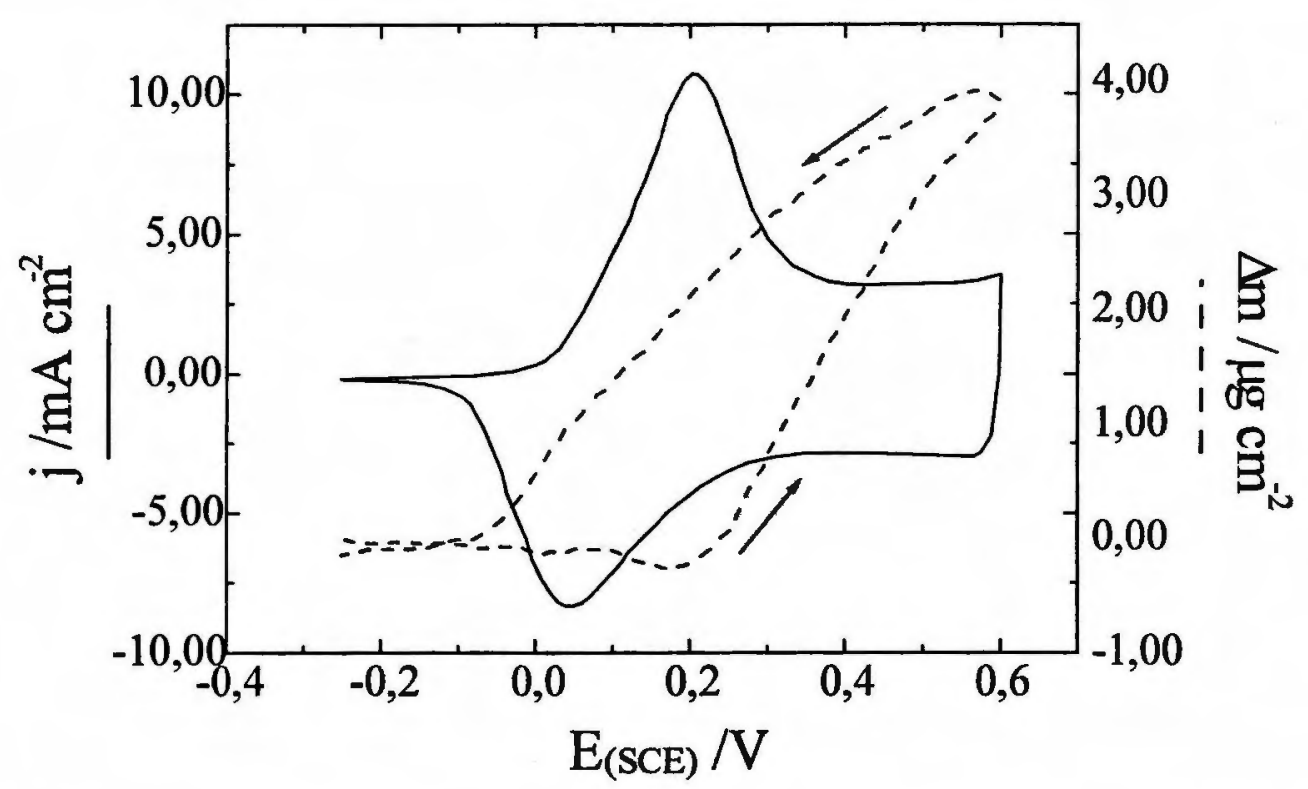

Figura 3.28: Voltamograma e voltamassograma de um filme espesso de polianilina em $0,8 \mathrm{~mol} / \mathrm{L} \mathrm{de} \mathrm{HCl}$, $v=10 \mathrm{mV} / \mathrm{s}, Q \sin t=2,9 \times 10^{-1} \mathrm{C}$.

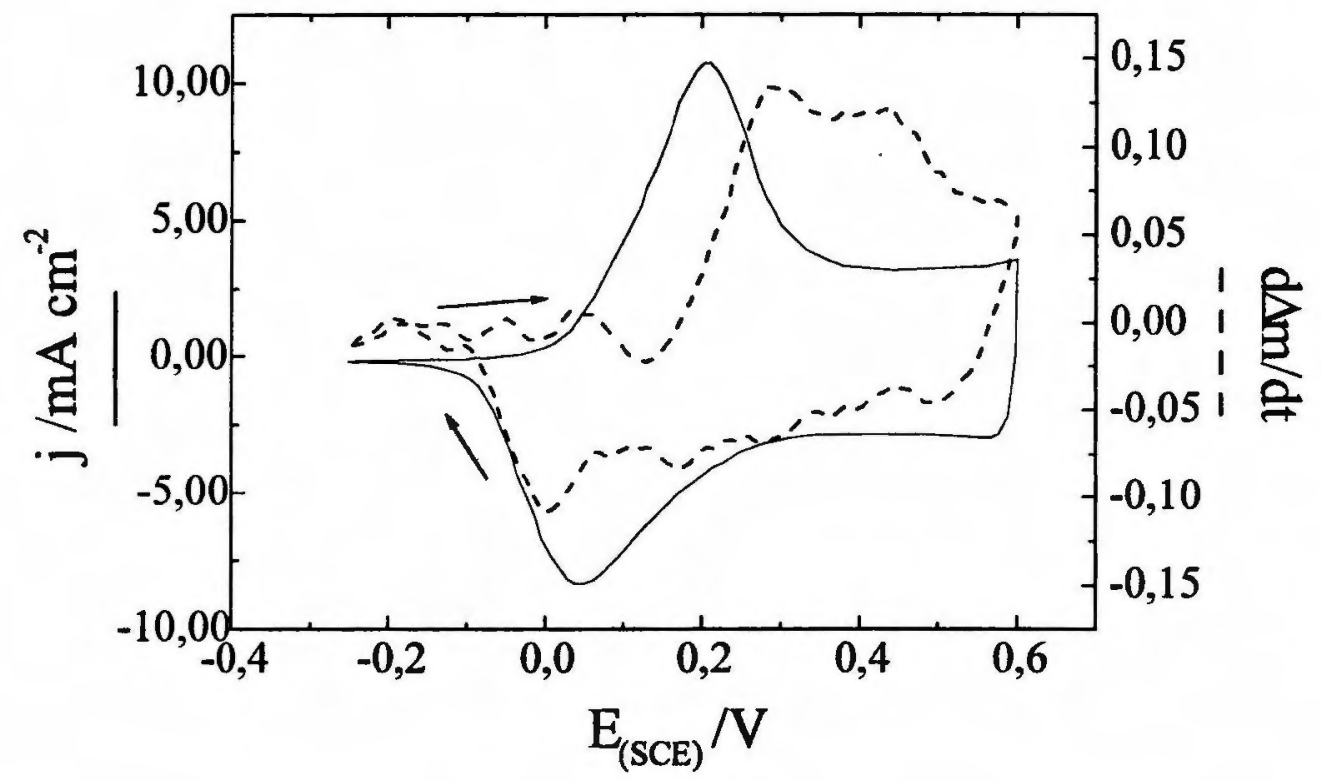

Figura 3.29: Voltamograma e derivada do voltamassograma de um filme espesso de polianilina em 0,8 mol/L de $\mathrm{HCl}, \mathrm{v}=10 \mathrm{mV} / \mathrm{s}, \mathrm{Qsint}=2,9 \times 10^{-1} \mathrm{C}$.

Para um filme espesso de polianilina ciclado em $0,8 \mathrm{~mol} / \mathrm{L}$ de $\mathrm{HCl}$, pode-se observar no gráfico da derivada (Figura 3.28) uma defasagem entre o máximo de corrente e o máximo de variação de massa. Esta defasagem mostra a difusão sofrida pelos eletrólitos e solvente na espessa matriz polimérica, o que não é observado em filmes mais finos (figura 3.30 e 3.31). 
Em um filme fino a passagem de íons e solvente de/para a matriz polimérica é mais rápida, devido a menor espessura da matriz polimérica, não apresentando neste caso uma defasagem entre o máximo de corrente e o máximo da variação de massa. É importante observar que quando o filme é fino a relação ruído/resposta registrado na freqüência é bem maior.

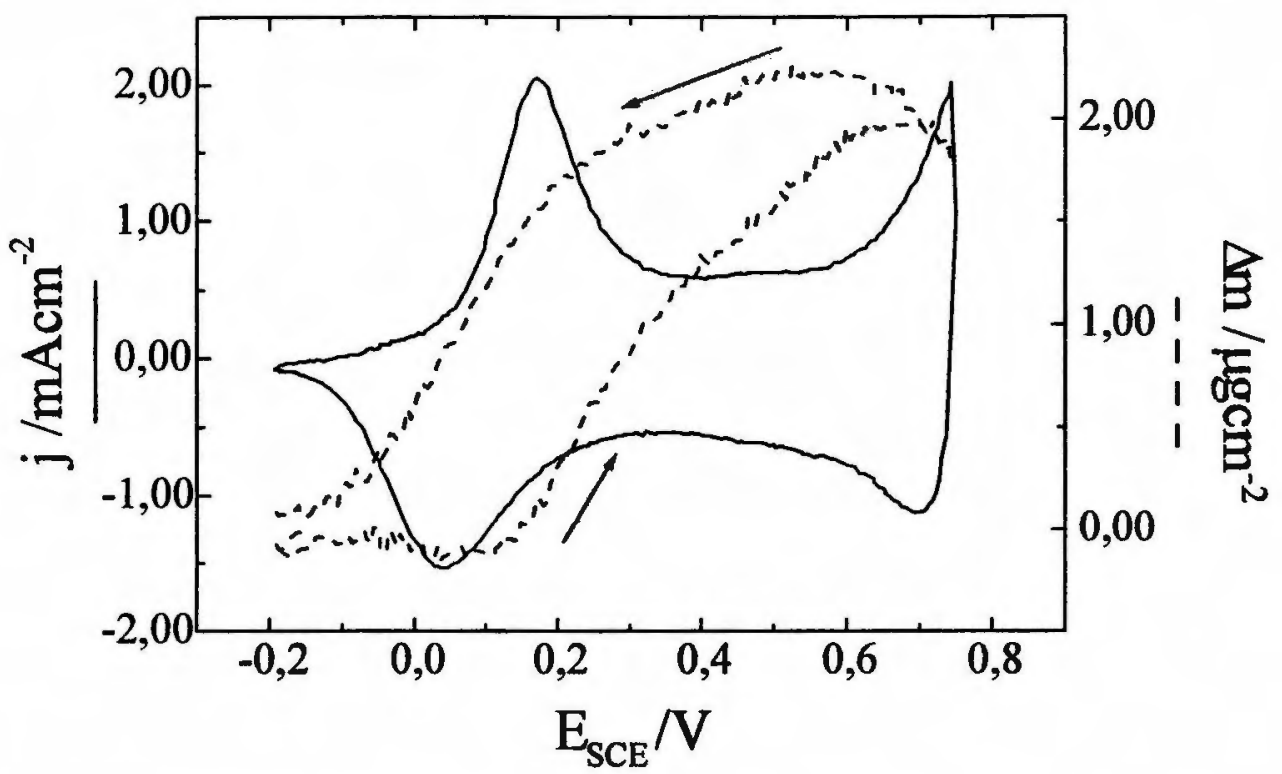

Figura 3.30: Voltamograma e voltamassograma de um filme fino de polianilina em $0,8 \mathrm{~mol} / \mathrm{L}$ de $\mathrm{HCl}$, $v=50 \mathrm{mV} / \mathrm{s}$.

Na Figura 3.31 pode-se observar uma inversão no perfil da derivada da variação de massa em $0,6 \mathrm{~V}$. Como este gráfico corresponde a uma derivada, conclui-se que nessa região de $0,6 \mathrm{~V}$ tem-se uma alteração na tangente da curva de variação de massa nos dois processos redox, originando a inversão na curva da derivada. Esta alteração na tangente da curva de variação de massa pode ser observada na Figura 3.30 em $0,6 \mathrm{~V}$, que tanto no processo de oxidação quanto no de redução corresponde a um patamar na curva de variação de massa. Este patamar representa o máximo de variação de massa total no sistema durante os processos redox.

Com a variação de eletrólito, pode-se observa-se que a curva de variação de massa para filmes de polianilina praticamente independe do eletrólito utilizado, ou seja, tem-se o mesmo comportamento que o observado para o $\mathrm{HCl}$. Entretanto a variação máxima de massa no estado oxidado, a diferença entre a massa no estado reduzido e o máximo de variação de massa no estado oxidado, é maior com o aumento de massa molar do ânion estudado.

Enquanto que para o $\mathrm{HCl}$ tem-se uma variação de massa de $4 \mu \mathrm{g} \mathrm{cm}^{-2}$ (Figura 3.28), para HCSA esta variação é de $16 \mu \mathrm{g} \mathrm{cm}^{-2}$ (Tabela 3.2), comparando estes valores com a massa molar dos ácidos nota-se que estes valores de variação de massa são proporcionais à massa molar, ou seja, para ânions pequenos a variação máxima de massa foi pequena, aumentando com o aumento do tamanho do ânion (Tabela 3.2). 


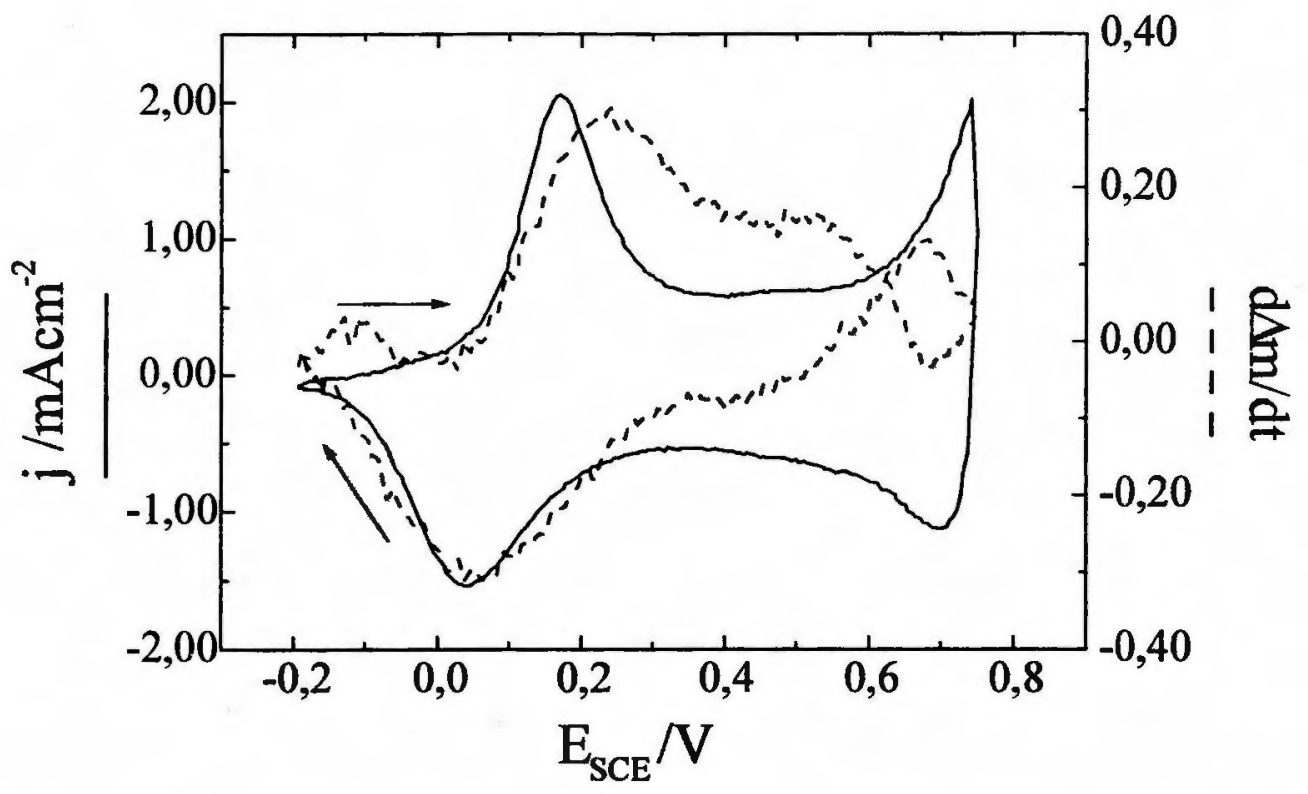

Figura 3.31: Voltamograma e derivada do voltamassograma de um filme fino de polianilina em 0,8 mol/L de $\mathrm{HCl}, v=50 \mathrm{mV} / \mathrm{s}$.

Porém para ânions grandes, PTSA e HCSA, a variação máxima de massa foi menor que o esperado considerando apenas a relação entre as massas molares dos ácidos (Tabela 3.2), onde observa-se que o valor da relação de massa molar para $\mathrm{HClO}_{4}$ é muito próximo do valor da relação da variação de massa. Para ânions de maior volume a relação de massa molar é bem maior em comparação com a relação da variação de massa, mostrando que ânions grandes tem certa dificuldade de entrar na matriz polimérica, mesmo para a polianilina.

Tabela 3.2: Relação entre a massa molar dos ânions e a variação de massa observado nos experimentos eletrogravimétricos para um filme grosso de polianilina em $0,8 \mathrm{~mol} / \mathrm{L}$ de eletrólito, $v=10 \mathrm{mV} / \mathrm{s}$.

\begin{tabular}{|c|c|c|c|c|}
\hline Ácido & $\begin{array}{c}\text { Massa Molar } \\
(\mathrm{g} / \mathrm{mol})\end{array}$ & $\begin{array}{c}\text { Variação de } \\
\text { Massa } \\
\left(\mu \mathrm{g} / \mathrm{cm}^{2}\right)\end{array}$ & $\begin{array}{c}\text { Relação de } \\
\text { Massa Molar }\end{array}$ & $\begin{array}{c}\text { Relação de } \\
\text { Variação de } \\
\text { Massa }\end{array}$ \\
\hline $\mathrm{HCl}$ & 36,46 & 4 & 1 & 1 \\
\hline $\mathrm{HClO}_{4}$ & 100,46 & 10 & 2,8 & 2,5 \\
\hline PTSA & 190,22 & 11 & 5,2 & 2,7 \\
\hline HCSA & 232,30 & 16 & 6,4 & 4,0 \\
\hline
\end{tabular}


Para poli(2-etilanilina) e para os copolímeros poli(anilina-co-2-etilanilina) ciclados em $0,8 \mathrm{~mol} / \mathrm{L}$ de eletrólitos com ânions pequenos como $\mathrm{HCl}$ e $\mathrm{HClO}_{4}$, a resposta de massa se assemelha ao da polianilina (Figura 3.32). Durante o processo de oxidação tem-se um aumento de massa por volta de $0,30 \mathrm{~V}$. E durante o processo de redução tem-se uma pequena redução até $0,20 \mathrm{~V}$, seguida de uma grande diminuição de massa.

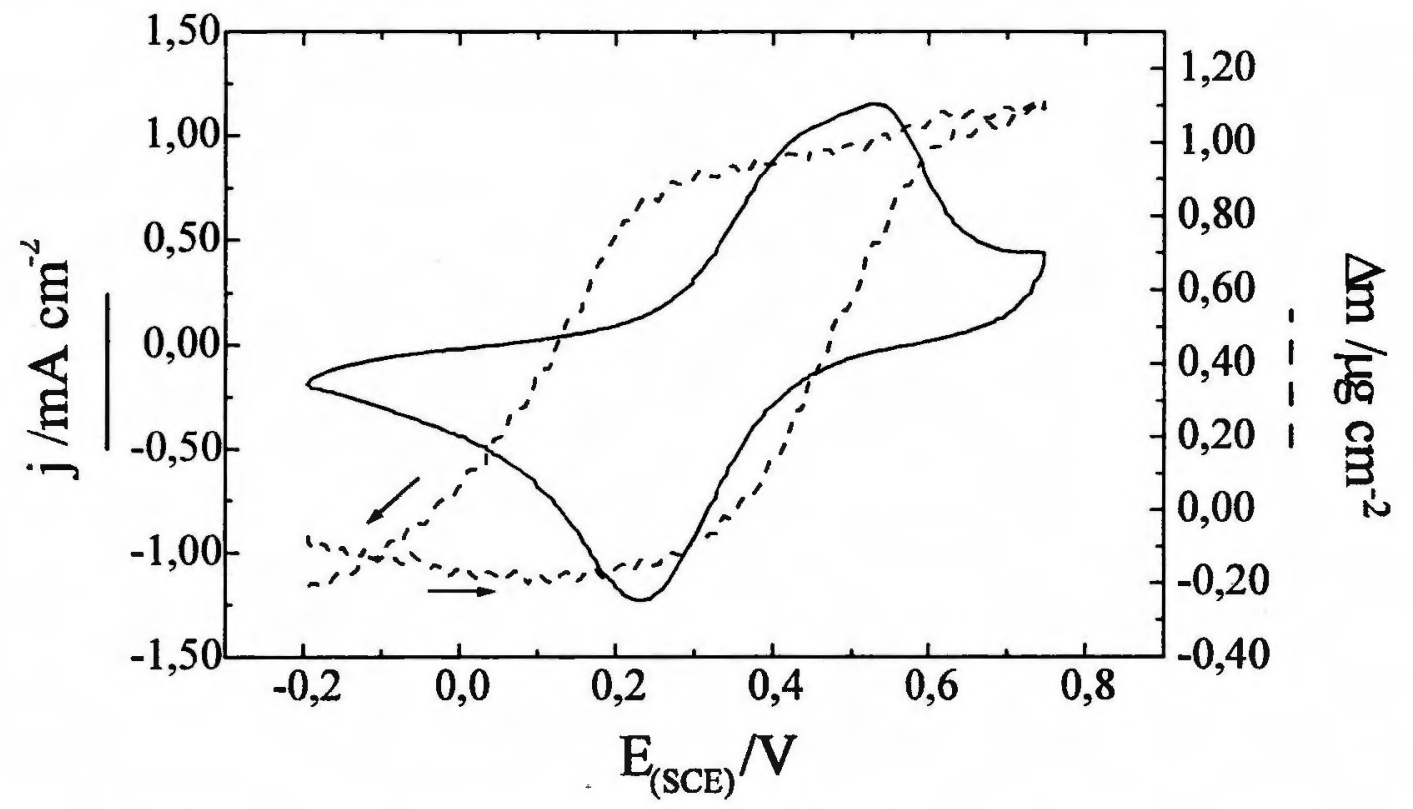

Figura 3.32: Voltamograma e voltamassograma de filme fino de poli(2-etilanilina) em $0,8 \mathrm{~mol} / \mathrm{L}$ de $\mathrm{HCl}$, $v=50 \mathrm{mV} / \mathrm{s}$

Quando a poli(2-etilanilina) é ciclada em eletrólitos que possuem ânions maiores, PTSA e HCSA (Figura 3.33), tem-se um comportamento completamente diferente, durante o processo de oxidação ocorre uma diminuição de massa até $0,20 \mathrm{~V}$, provavelmente devido à saída de prótons da matriz polimérica na tentativa de remover cargas positivas de uma maneira mais fácil que a entrada de ânions grandes, já que a entrada destes é dificultada devido ao empedimento estérico pela presença do substituinte na cadeia polimérica. Esta diminuição de massa é seguida por um aumento de massa chegando a um valor máximo por volta de $0,60 \mathrm{~V}$, que se deve à entrada de ânions.

Durante o processo de redução tem-se inicialmente uma pequena diminuição de massa até $0,40 \mathrm{~V}$, seguido de um rápido aumento até $0,25 \mathrm{~V}$, provavelmente devido a entrada de solvente e prótons na matriz polimérica, seguido de uma grande diminuição até $-0,25 \mathrm{~V}$, talvez devido a saída do excesso de prótons. É importante observar também que para ânions menores a variação máxima de massa durante o processo de oxidação é muito maior quando comparado com ânions maiores, mostrando que a entrada de eletrólito durante o processo de oxidação para ânions grandes ocorre com dificuldade. 


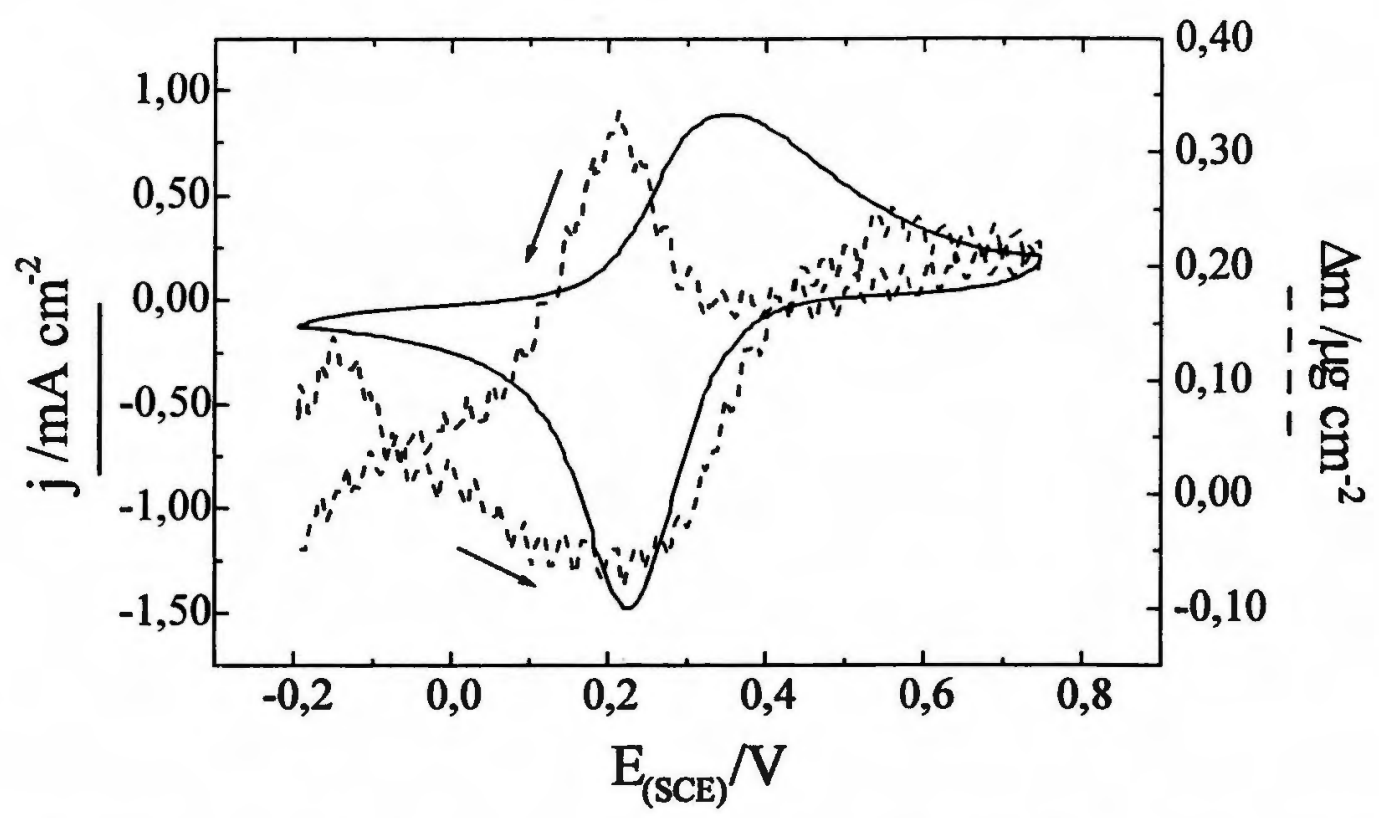

Figura 3.33: Voltamograma e voltamassograma de filme fino de poli(2-etilanilina) em 0,8 mol/L de HCSA, $v=50 \mathrm{mV} / \mathrm{s}$

Para o $\mathrm{HCl}$ tem-se uma variação máxima de massa de $1,2 \mu \mathrm{g} \mathrm{cm}^{-2}$, enquanto que para o HCSA esta variação é de $0,4 \mu \mathrm{g} \mathrm{cm}^{-2}$, esta dificuldade na entrada de ânions maiores devido ao impedimento estérico provocado pelo substituinte alquil na poli(2-etilanilina) pode ser observado melhor na Tabela 3.3.

Tabela 3.3: Relação entre a massa molar dos ânions e a variação de massa observado nos experimentos eletrogravimétricos para um filme fino de poli(2-etilanilina) em 0,8 mol/L de eletrólito, $v=10 \mathrm{mV} / \mathrm{s}$.

\begin{tabular}{|c|c|c|c|c|}
\hline Ácido & $\begin{array}{c}\text { Massa Molar } \\
(\mathrm{g} / \mathrm{mol})\end{array}$ & $\begin{array}{c}\text { Variação de } \\
\text { Massa } \\
\left(\mu \mathrm{g} / \mathrm{cm}^{2}\right)\end{array}$ & $\begin{array}{c}\text { Relação de } \\
\text { Massa Molar }\end{array}$ & $\begin{array}{c}\text { Relação de } \\
\text { Variação de } \\
\text { Massa }\end{array}$ \\
\hline $\mathrm{HCl}$ & 36,46 & 1,2 & 1 & 1 \\
\hline $\mathrm{HClO}_{4}$ & 100,46 & 4,0 & 2,8 & 3,3 \\
\hline PTSA & 190,22 & 0,7 & 5,2 & 0,6 \\
\hline HCSA & 232,30 & 0,3 & 6,4 & 0,3 \\
\hline
\end{tabular}


Para ânions volumosos pode-se observar que o perfil da variação de massa total apresenta uma relação maior rúdo/resposta, isto se deve a uma da variação de massa menor, uma vez que ânions maiores possuem maior dificuldade de entrar na matriz polimérica. Além disso, como os ânions são mais pesados, qualquer movimentação destes ânions provoca uma variação maior no voltamassograma, fazendo com que a relação ruído/resposta pareça maior.

Quando o filme de poli(2-etilanilina) é crescido em HCSA, e ciclado nos diferentes eletrólitos a variação de massa é semelhante ao comportamento de um filme crescido em $\mathrm{HCl}$ e ciclado nos mesmos eletrólitos. Para eletrólitos contendo ânions pequenos como $\mathrm{HClO}_{4}$ tem-se um aumento de massa que se inicia por volta de $0,10 \mathrm{~V}$ e termina em $0,40 \mathrm{~V}$, e o no processo de redução é observado o processo inverso, a redução se inicia em $0,40 \mathrm{~V}$ e termina em $0,10 \mathrm{~V}$ (Figura 3.34).

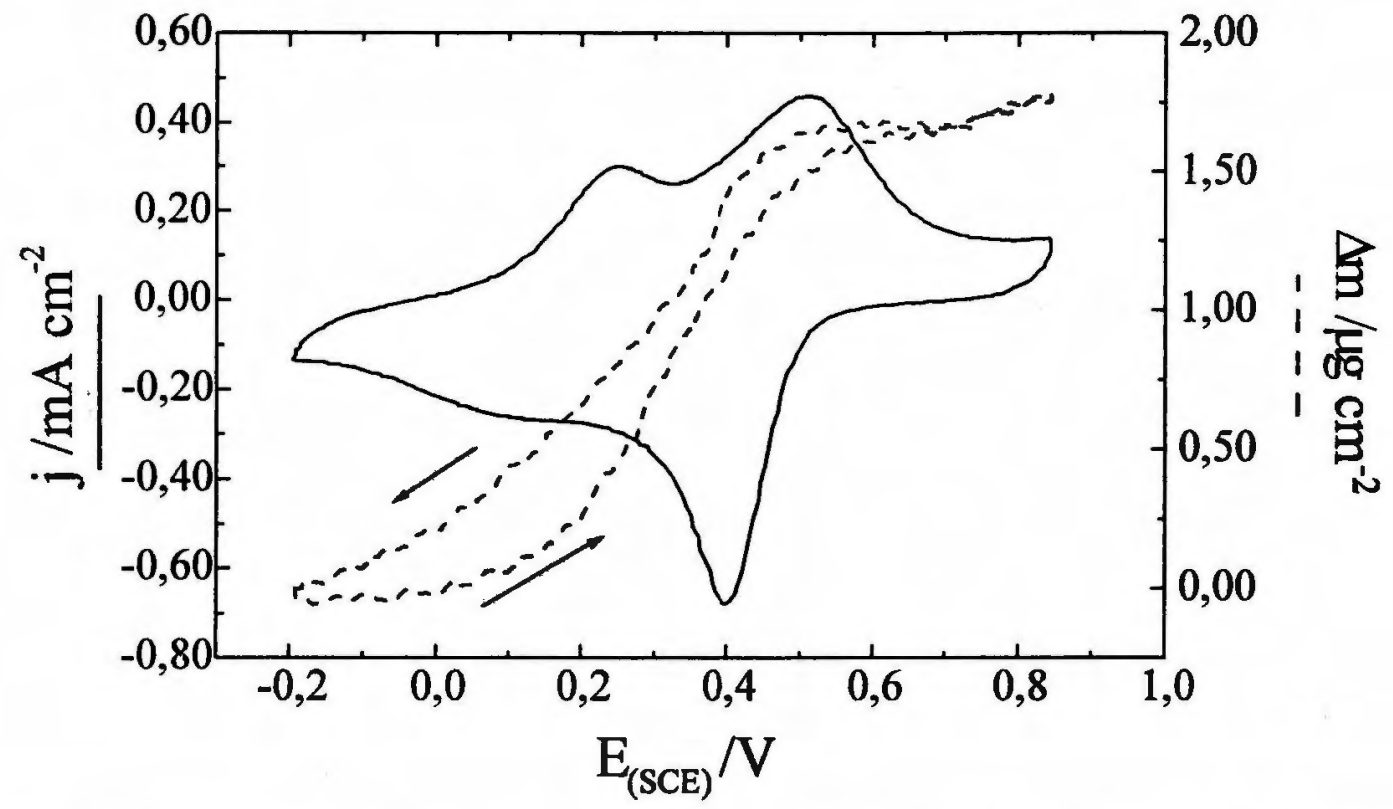

Figura 3.34: Voltamograma e voltamassograma de filme fino de poli(2-etilanilina) crescido em 1,0 mol/L de HCSA e ciclado em em 0,8 mol/L de $\mathrm{HClO}, v=50 \mathrm{mV} / \mathrm{s}$

Para eletrólitos contendo ânions grandes como o PTSA e o HCSA (Figura 3.35) tem-se inicialmente uma pequena diminuição de massa até $0,20 \mathrm{~V}$, que estaria associado a saída de prótons para compensar a carga positiva formada dentro da matriz polimérica, uma vez que os ânions volumosos tem certa dificuldade de entrar na matriz. Desta maneira seria mais fácil fazer a compensação de carga através da saída de prótons.

Acima de $0,20 \mathrm{~V}$ tem-se um grande aumento de massa até $0,45 \mathrm{~V}$, provavelmente devida a entrada dos ânions para neutralizar o restante das cargas positivas formadas durante a oxidação na matriz polimérica. Este aumento de massa é seguido de uma diminuição, sendo que quando o filme é preparado em $\mathrm{HCl}$ esta diminuição é mínima. Esta diminuição poderia estar relacionado a saída de solvente e também de ânions que entraram em excesso na matriz polimérica, e como estes ânions são volumosos a saída é lenta. 


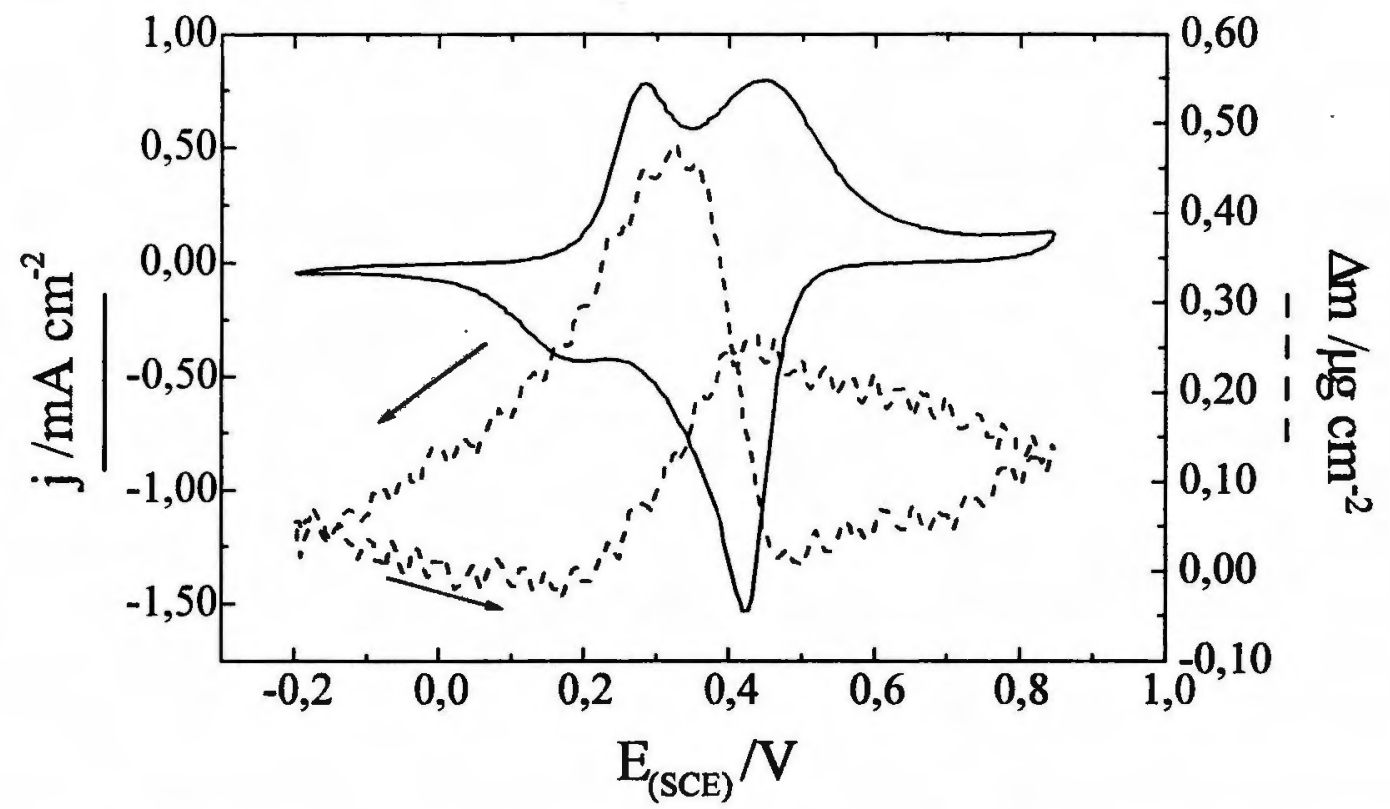

Figura 3.35: Voltamograma e voltamassograma de filme fino de poli(2-etilanilina) crescido em 1,0 mol/L de HCSA e ciclado em em $0,8 \mathrm{~mol} / \mathrm{L}$ de $H C S A, v=50 \mathrm{mV} / \mathrm{s}$

Durante o processo inverso, tem-se uma pequena diminuição até $0,40 \mathrm{~V}$, seguido de um grande aumento de massa até $0,20 \mathrm{~V}$. Durante o processo de redução as cargas positivas formadas durante a oxidação desaparecem, os ânions devem sair da matriz polimérica para dar lugar aos prótons, porém os ânions são volumosos e tem dificuldade em sair da matriz, enquanto os prótons podem entrar rapidamente. Esta diferença de mobilidade poderia resultar em uma carga positiva na matriz devido a entrada rápida dos prótons, fazendo com que mais ânions entrassem na matriz polimérica, resultando numa variação de massa grande durante este processo. Com a redução total do polímero este excesso de ânions e prótons sairiam da matriz, resultando numa grande diminuição de massa.

Quando este polímero é crescido em HCSA e ciclado em $\mathrm{HCl}$ observa-se um comportamento diferente do polímero formado $\mathrm{em} \mathrm{HCl}$ e ciclado em $\mathrm{HCl}$ (Figura 3.36). O perfil do voltamassograma quando a poli(2-etilanilina) crescida em HCSA e ciclada em $\mathrm{HCl}$ é mais parecido com o voltamassograma observado para ânions grandes, que com o voltamassograma do $\mathrm{HClO}_{4}$, talvez devido a presença de ânion de HCSA ainda na matriz polimérica, e como a relação de massa entre estes dois ânions é muito diferente, uma pequena quantidade de HCSA já provocaria grande variação no voltamassograma.

É interessante observar também que a entrada dos ânions na matriz de poli(2-etilanilina) quando crescido em $\mathrm{HCSA}$ ocorre em um potencial $0,10 \mathrm{~V}$ menor que o observado para o mesmo polimero crescido em $\mathrm{HCl}$. Talvez devido a morfologia do material formado, pois como durante o processo de crescimento só havia ânions de grande volume na solução, as cadeias poliméricas estariam mais afastadas facilitando a entrada destes ânions, e consequentemente facilitando o primeiro processo de oxidação do polímero independente do eletrólito com o qual o polímero será ciclado. 


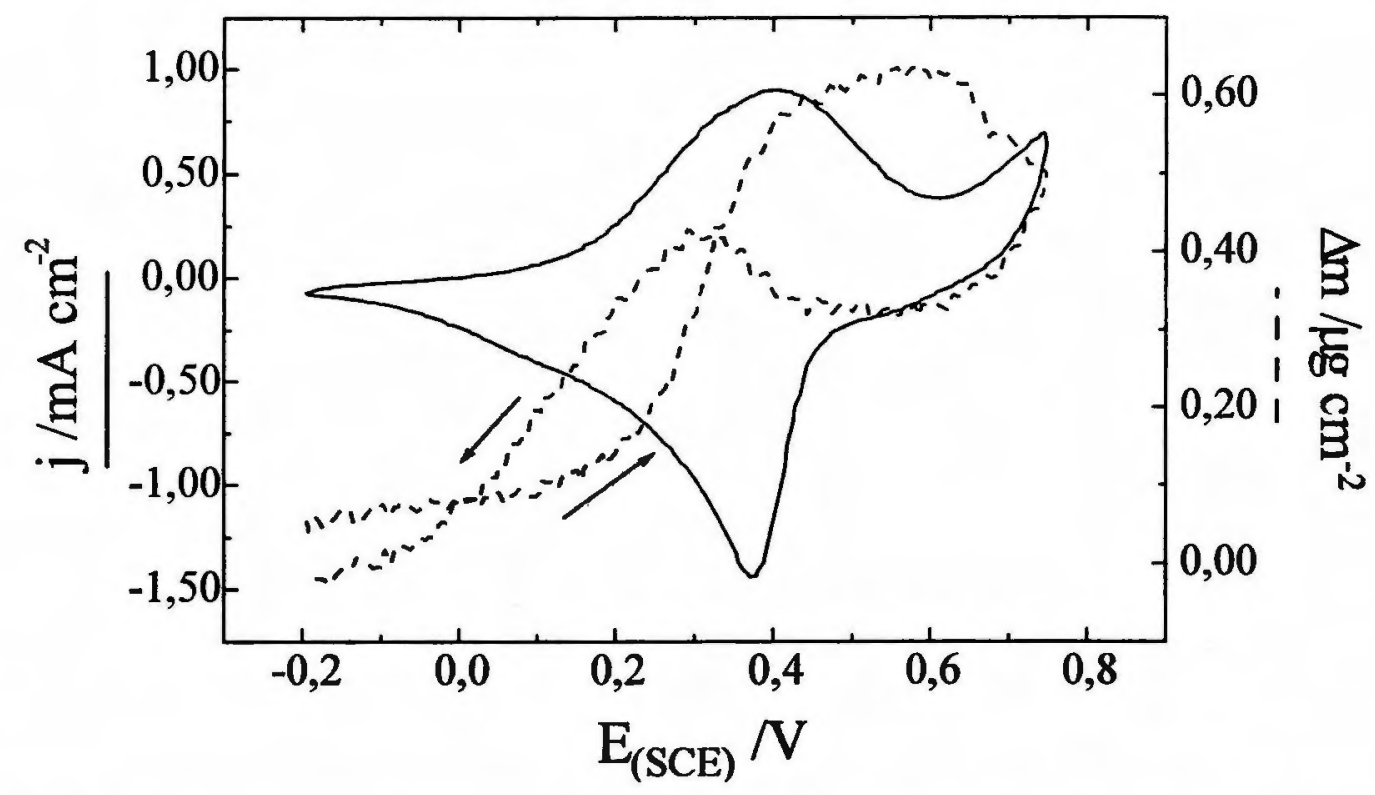

Figura 3.36: Voltamograma e voltamassograma de filme fino de poli(2-etilanilina) crescido em $1,0 \mathrm{~mol} / \mathrm{L}$ de HCSA e ciclado em em $0,8 \mathrm{~mol} / \mathrm{L}$ de $\mathrm{HCl}, v=50 \mathrm{mV} / \mathrm{s}$

A contribuição em separado dos ânions e cátions, somados à contribuição do solvente, pode ser calculado com as equações diferenciais (Equações 3.1 e 3.2):

$$
\begin{aligned}
& \frac{d\left(\xi_{C^{+}}(E)+\frac{W_{S}}{W_{C A}} \xi_{s}(E)\right)}{d t}=\frac{1}{W_{C A}} \frac{d(\Delta m(E))}{d t}+\frac{W_{A^{-}} j(E)}{W_{C A} F} \\
& \frac{d\left(\xi_{A^{-}}(E)+\frac{W_{S}}{W_{C A}} \xi_{s}(E)\right)}{d t}=\frac{1}{W_{C A}} \frac{d(\Delta m(E))}{d t}+\frac{W_{C^{+}} j(E)}{W_{C A} F}
\end{aligned}
$$

A Figura 3.29 mostra a derivada do voltamograma de um filme espesso de polianilina em $0,8 \mathrm{~mol} / \mathrm{L}$ de $\mathrm{HCl}$. Esta derivada do voltamassomograma representa a variação total de massa de/para a matriz polimérica. Calcula-se então a contribuição dos prótons+solvente e ânions+solvente nesta variação de massa (Figura 3.37).

Nesta figura pode-se observar que o fluxo de prótons é bem maior que o de ânions durante o processo eletroquímico, porém, como o ânion é mais pesado que o próton, a contribuição do ânion é mais significativa na variação total de massa de/para a matriz polimérica que a dos prótons, e é por isso que o fluxo de ânions+solvente tem o mesmo perfil que a derivada do voltamassograma. 


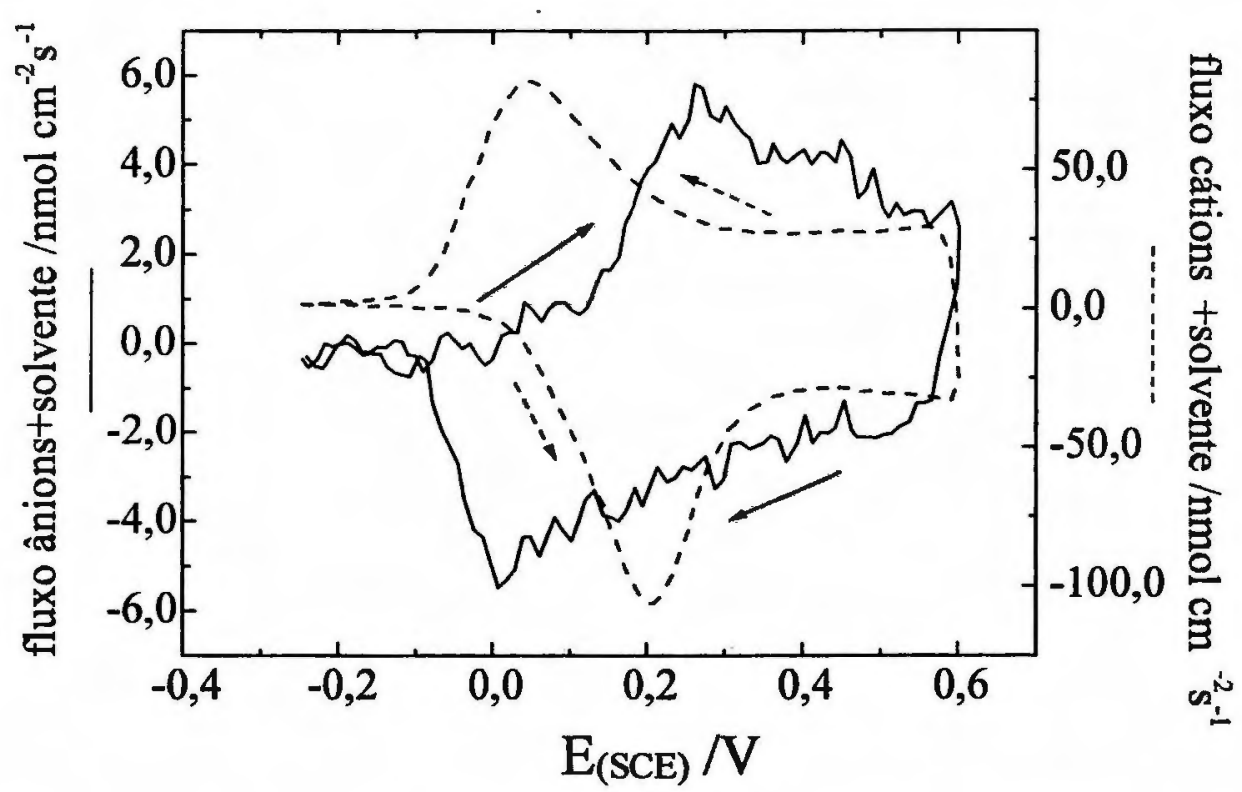

Figura 3.37: Fluxo de cátions (prótons) + solvente e de ânions + solvente para um filme espesso de polianilina em $0,8 \mathrm{~mol} / \mathrm{L}$ de $\mathrm{HCl}, v=10 \mathrm{mV} / \mathrm{s}$.

É interessante notar que o fluxo de prótons+solvente é o inverso do voltamograma do polímero, isto ocorre porque com a oxidação do polímero há uma remoção de elétrons da matriz polimérica, formando cargas positivas que expulsam os prótons do material. No processo inverso, ou seja com a redução do polímero, os elétrons são injetados na matriz polimérica, as cargas positivas desaparecem e os prótons voltam novamente à matriz polimérica. Como a mobilidade dos prótons é alta, tem-se uma rápida resposta no fluxo de prótons ao aparecimento/desaparecimento de cargas no filme. Os ânions por serem maiores e mais pesados, possuem um tempo de resposta maior, fazendo com que o perfil do voltamograma não seja igual ao perfil do fluxo de ânions+solvente.

Outro dado interessante a ser observado é que para eletrólitos com ânions pequenos como o $\mathrm{HCl}$ ou $\mathrm{HClO}_{4}$, a entrada de ânions e a saída de cátions ocorrem quase que simultaneamente durante a oxidação destes polímeros, enquanto que para ânions maiores, primeiro os prótons deixam a matriz polimérica, para que então os ânions entrem (Figura 3.38). A compensação de carga é inicialmente feita com a expulsão de prótons e em seguida com a ejeção de ânions, mostrando que os ânions maiores tem uma maior dificuldade em entrar na matriz polimérica, mesmo para a polianilina.

Com o aumento do tamanho do ânion tem-se uma diminuição no fluxo máximo de ânions para a matriz polimérica durante o processo de oxidação, tanto para a polianilina e poli(2-etilanilina), (Tabela 3.4). Por esta tabela pode-se observar, mais uma vez, que estes polímeros tem uma interação diferenciada com o PTSA, quando comparado com os outros eletrólitos. 


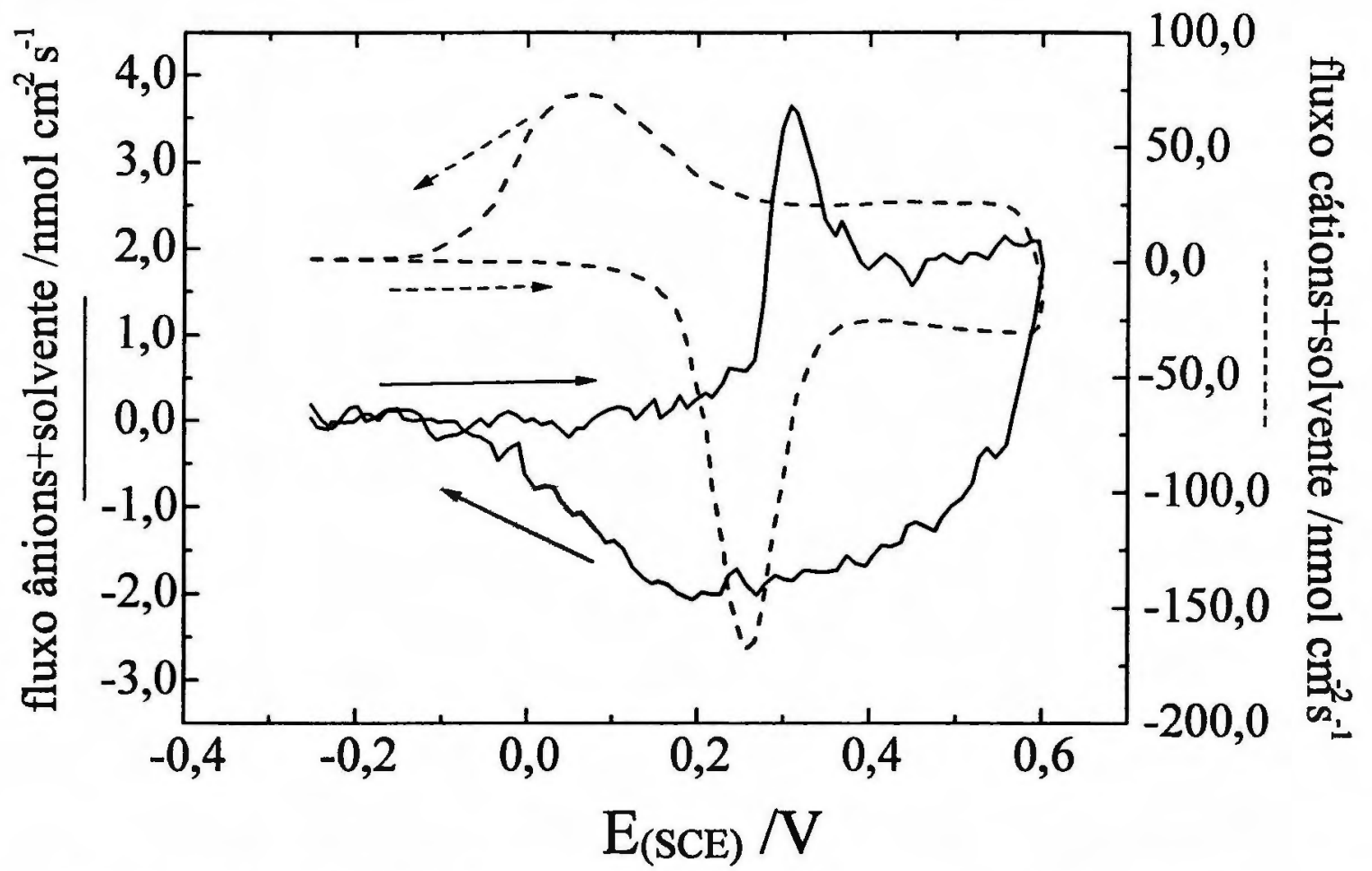

Figura 3.38: Fluxo de cátions (prótons) + solvente e de ânions + solvente para um filme espesso de polianilina em $0,8 \mathrm{~mol} / \mathrm{L}$ de PTSA, $v=10 \mathrm{mV} / \mathrm{s}$.

Tabela 3.4: Fluxo máximo de ânion +solvente para a matriz polimérica durante o processo de oxidação da polianilina e poli(2-etilanilina) para os diferentes eletrólitos, $v=10 \mathrm{mV} / \mathrm{s}$.

Fluxo máximo de ânions e solventes para a matriz polimérica ( $\mathrm{nmol} \mathrm{cm}^{-2} \mathrm{~s}^{-1}$ ) observada para os polímeros em $0,80 \mathrm{~mol} / \mathrm{L}$ de diferentes eletrólitos, $v=10 \mathrm{mV} / \mathrm{s}$.

\begin{tabular}{|c|c|c|}
\hline & polianilina & poli(2-etilanilina) \\
\hline $\mathrm{HCl}$ & 6,0 & 1,8 \\
\hline $\mathrm{HClO}_{4}$ & 3,0 & 1,0 \\
\hline PTSA & 4,0 & 0,5 \\
\hline $\mathrm{HCSA}$ & 0,3 & 0,02 \\
\hline
\end{tabular}

É interessante observar também que quando a poli(2-etilanilina) é ciclada com $0,8 \mathrm{~mol} / \mathrm{L}$ de eletrólitos contendo ânions pequenos como o $\mathrm{HCl}$ e o $\mathrm{HClO}_{4} \circ$ perfil do fluxo de ânions é parecido ao perfil do voltamograma (Figura 3.39), enquanto para ânions maiores o mesmo não acontece (Figura 3.40). 


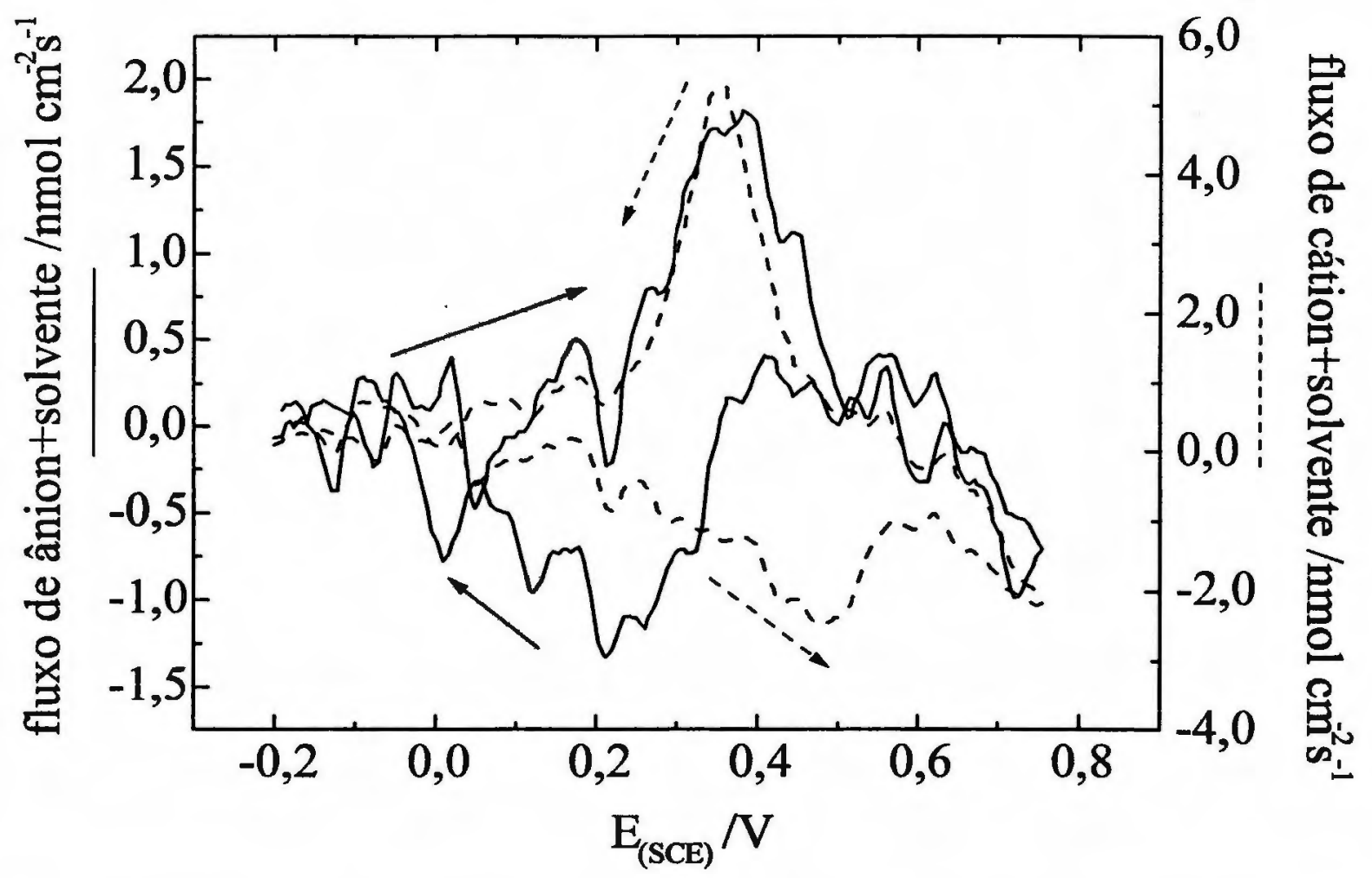

Figura 3.39: Fluxo de cátions (prótons) + solvente e de ânions + solvente para um filme fino de poli(2-etilanilina) em $0,8 \mathrm{~mol} / \mathrm{L}$ de $\mathrm{HCl}, v=10 \mathrm{mV} / \mathrm{s}$.

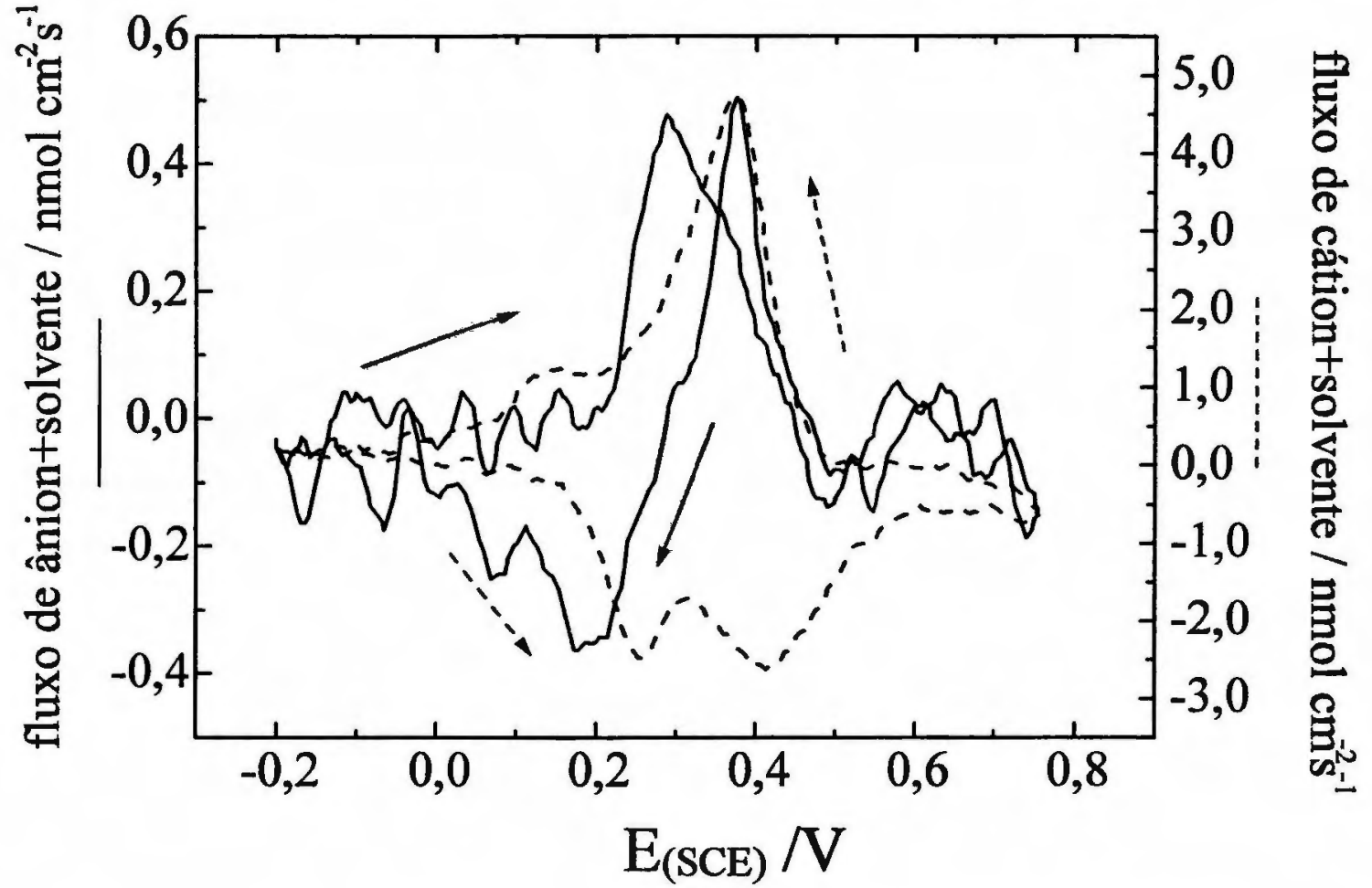

Figura 3.40: Fluxo de cátions (prótons) + solvente e de ânions + solvente para um filme fino de poli(2-etilanilina) em 0,8 mol/L de PTSA, $v=10 \mathrm{mV} / \mathrm{s}$. 
Estes estudos foram feitos também para um dos copolímeros $\left(f_{1}=0,5\right)$, onde registrou-se o voltamograma e voltamassograma deste copolímero nos diferentes eletrólitos. Através dos gráficos da Figura 3.41 a 3.43 pode-se observar que os voltamassogramas do copolímero são semelhantes aos voltamassogramas da poli(2-etilanilina) (Figura 3.32-3.33), nas mesmas condições.

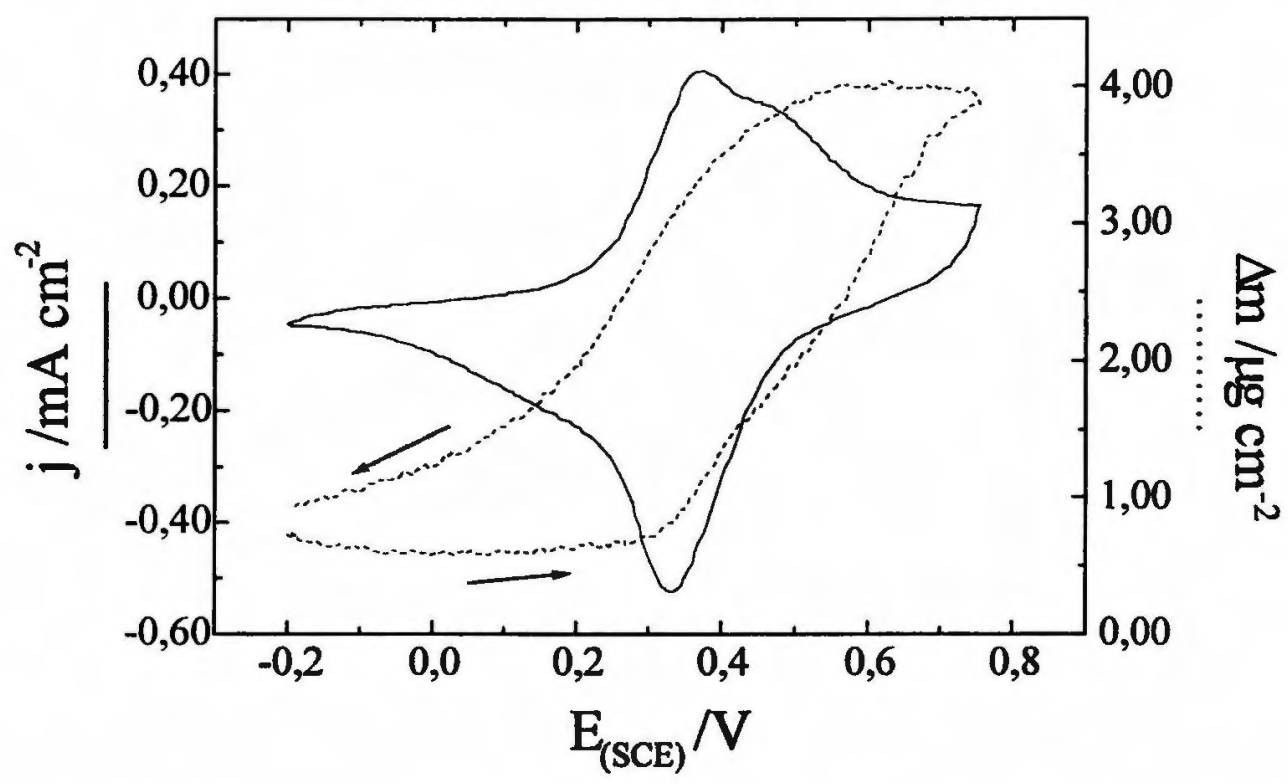

Figura 3.41: Voltamograma e voltamassograma de filme do copolimero poli(anilina-co-2-etilanilina) em $0,8 \mathrm{~mol} / \mathrm{L}$ de $\mathrm{HCl}, v=10 \mathrm{mV} / \mathrm{s}$

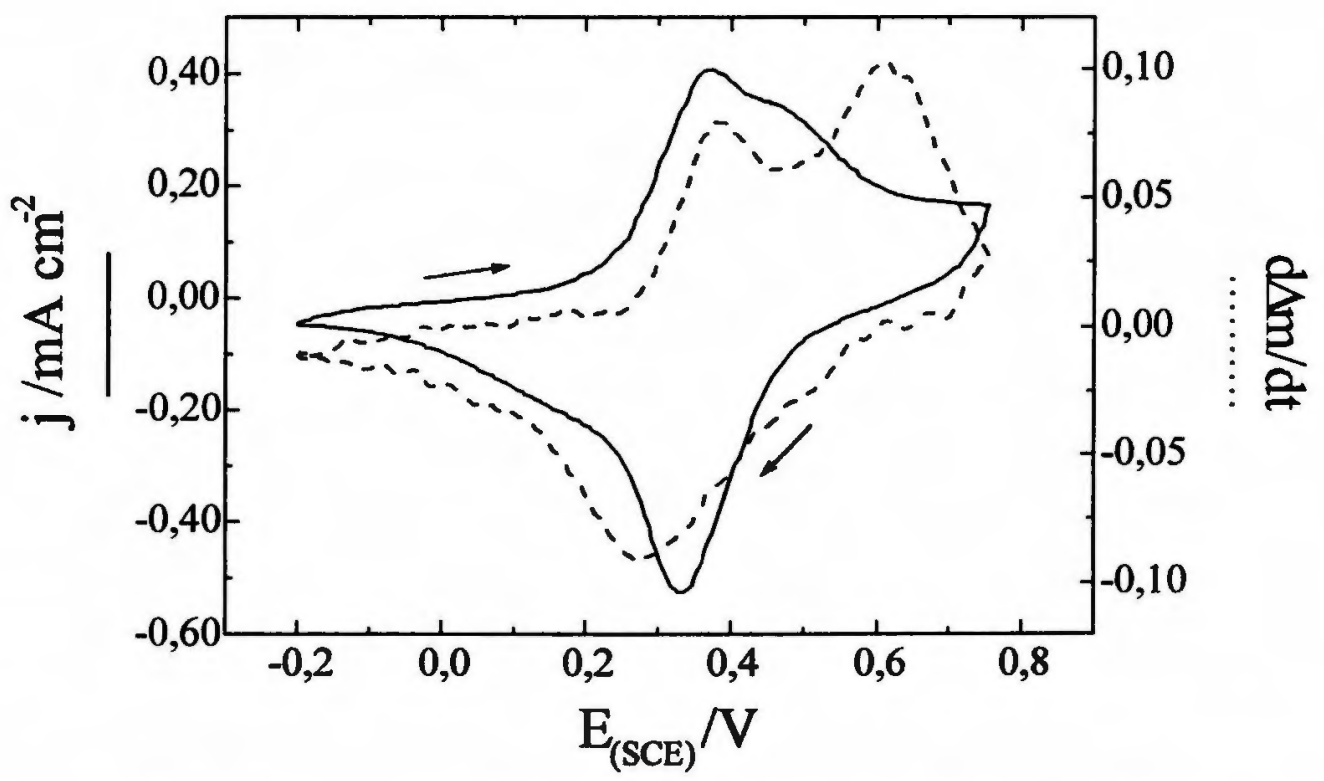

Figura 3.42: Voltamograma e derivada do voltamassograma de um filme do copolimero poli(anilina-co-2-etilanilina) em 0,8 mol/L de $\mathrm{HCl}, v=10 \mathrm{mV} / \mathrm{s}$. 


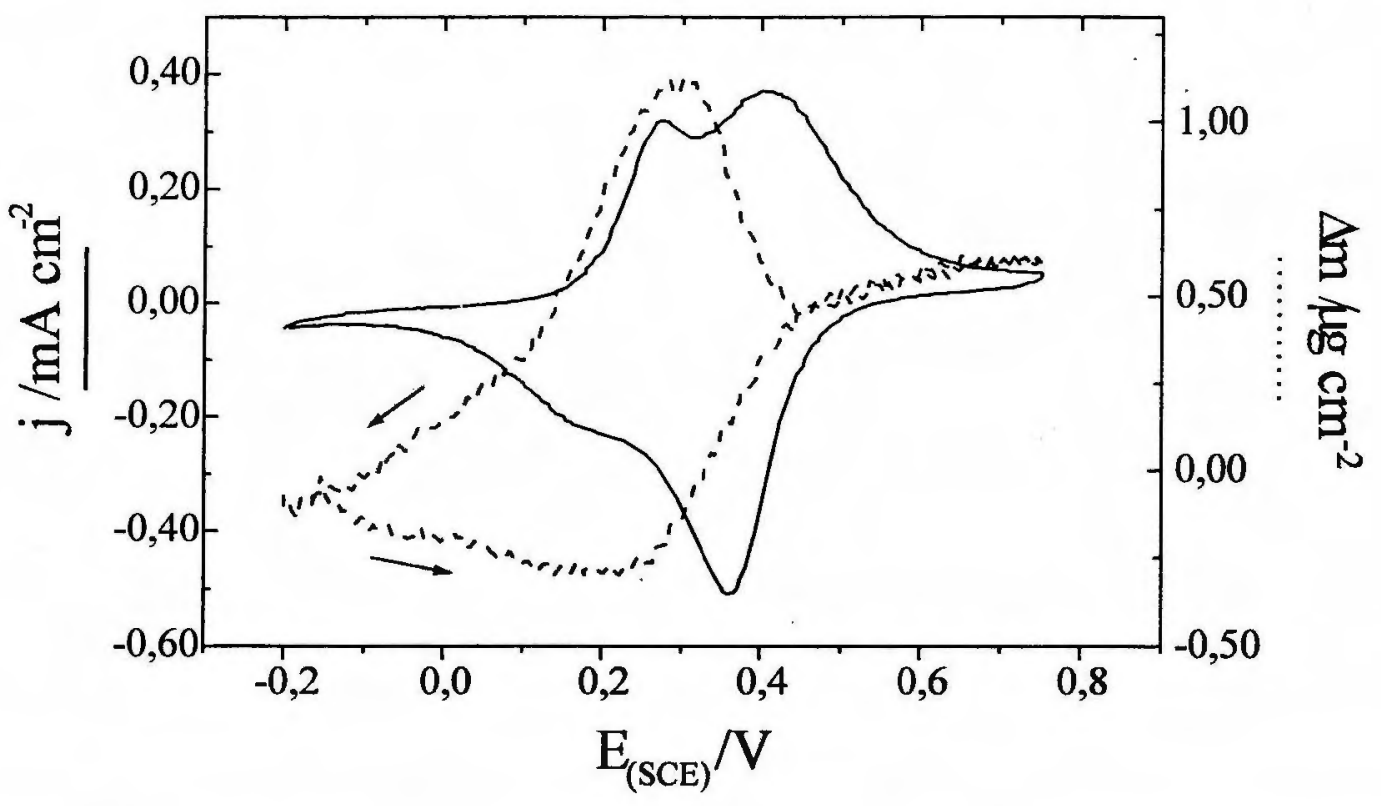

Figura 3.43: Voltamograma e voltamassograma de filme do copolímero poli(anilina-co-2-etilanilina) em $0,8 \mathrm{~mol} / \mathrm{L}$ de $H C S A, v=10 \mathrm{mV} / \mathrm{s}$

Para o copolímero também foi calculado o fluxo de cátions+solvente e ânions+solvente durante os processos de oxidação e redução (Figuras 3.44 e 3.45). Onde pode-se observar o mesmo comportamento que para a poli(2-etilanilina) nas mesmas condições (Figuras 3.39 e 3.40). Observa-se que para ânions pequenos, como o $\mathrm{HCl}$, durante o processo de oxidação têm-se um aumento no fluxo de ânions+solvente, indicando entrada de ânions para a matriz polimérica, ao mesmo tempo em que ocorre a saída de prótons, seguida de uma entrada do mesmo. Como o próton se movimenta facilmente na matriz polimérica, pode ser que, durante o processo de oxidação tenha saído muito mais prótons que o necessário e agora tenha que entrar mais prótons para contrabalancear as cargas na matriz, ou este aumento no fluxo de cátions+solvente se deva a movimentação de solvente.

Com o processo de redução têm-se uma saída de ânions da matriz polimérica enquanto ocorre uma entrada de cátions. Em seguida vê-se uma diminuição no fluxo de cátions+solvente e aumento no fluxo de ânions+solvente. Este fluxo que representaria a entrada de ânions e saída de prótons com a redução total do polímero, pode ser causado pela movimentação do solvente, ou talvez devase à saída do excesso de prótons que tenham entrado, e entrada de ânions que saíram em excesso durante o processo de redução, de forma a neutralizar a matriz polimérica. Uma vez que estes íons movem-se facilmente pela matriz polimérica.

Para ânions mais volumosos, cuja movimentação é mais dificil na matriz polimérica, durante o processo de oxidação têm-se inicialmente uma saída de prótons, seguida da entrada de ânions. Com a oxidação total do polímero têm-se uma diminuição no fluxo de ânions+solvente e aumento no fluxo de cátions +solvente, talvez devido ao excesso de íons que entraram e saíram, ou à movimentação 
do solvente, ou até uma alteração estrutural na matriz polimérica com a oxidação que provoque esta expulsão de ânions e entrada de prótons.

No processo inverso, durante a redução, têm-se uma entrada tanto prótons quanto de ânions, como o ânion tem dificuldade de sair da matriz e o próton pode entrar rapidamente, isto poderia provocar um aumento brusco na quantidade de cargas positivas na matriz fazendo com que mais ânions entrassem. Com o tempo, os ânions conseguem sair da matriz, seguida pela saída do excesso de prótons e a carga nas cadeias poliméricas é devidamente neutralizada.

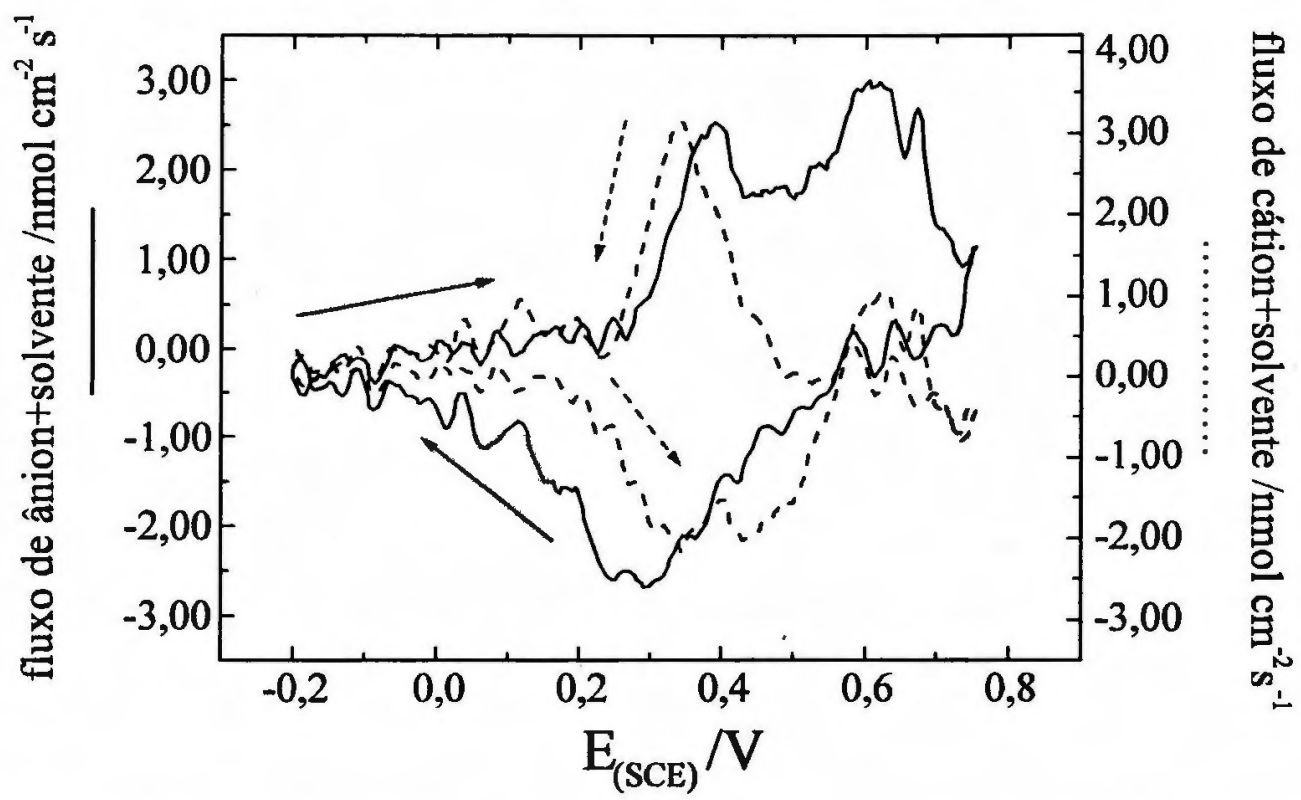

Figura 3.44: Fluxo de cátions (prótons) + solvente e de ânions + solvente para um filme do copolímero de poli(anilina-co-2-etilanilina) em 0,8 mol/L de $\mathrm{HCl}, v=10 \mathrm{mV} / \mathrm{s}$.

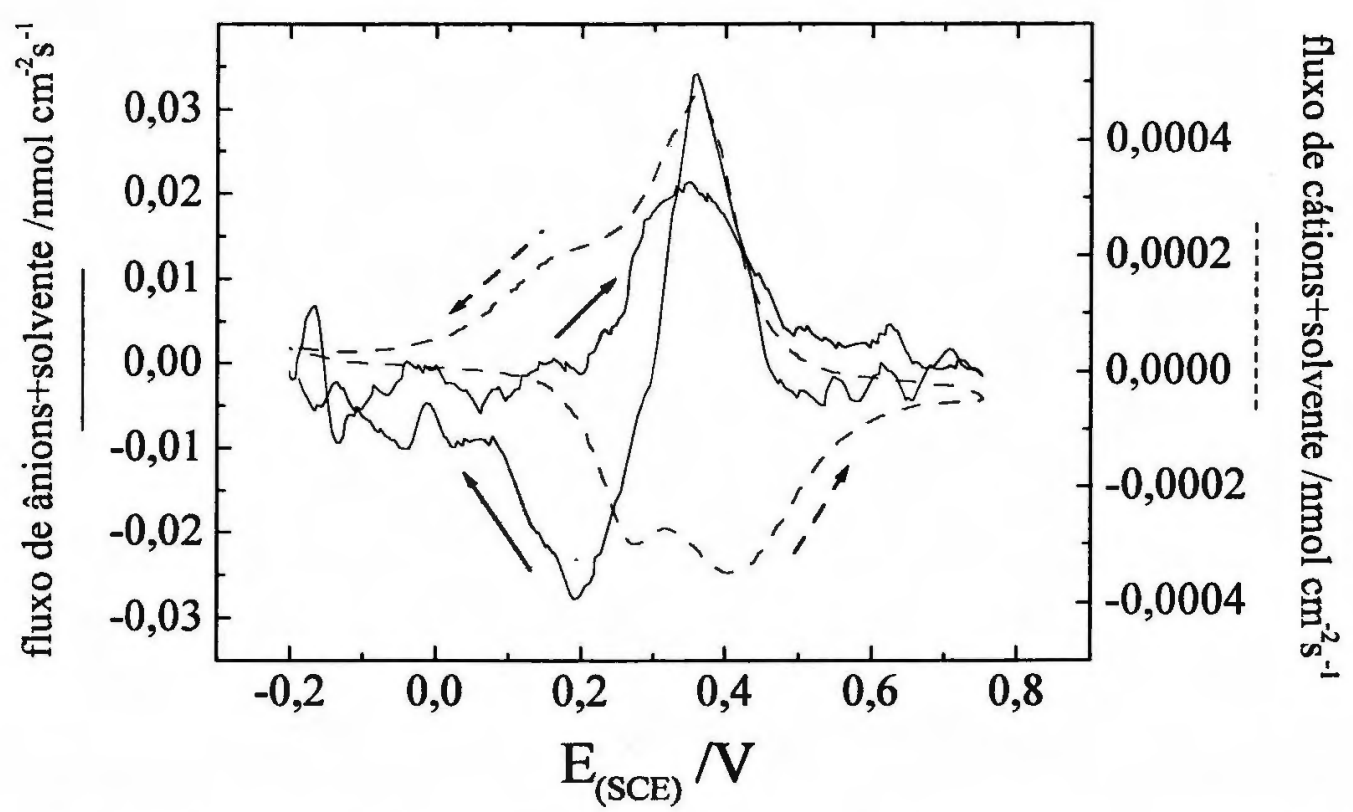

Figura 3.45: Fluxo de cátions (prótons) + solvente e de ânions + solvente para um filme do copolímero de poli(anilina-co-2-etilanilina) em 0,8 mol/L de HCSA, $v=10 \mathrm{mV} / \mathrm{s}$. 


\subsubsection{Caracterização Espectroeletroquímica}

Estudos espectroeletroquímicos realizados para a polianilina [168], mostraram quatro espécies ópticas diferentes dependendo do potencial aplicado, a forma "leucoesmeraldina" que se observa em cerca de $3,9 \mathrm{eV}(\sim 318 \mathrm{~nm})$, o radical cátion apresenta uma banda de absorção em cerca de $2,8 \mathrm{eV}(\sim 443 \mathrm{~nm})$, a forma quinoidal absorve em cerca de $1,9 \mathrm{eV}(\sim 652 \mathrm{~nm})$, e os elétrons livres deslocalizados absorvem em cerca de 1,55 eV ( $800 \mathrm{~nm})$. Na Figura 3.46 é mostrado o espectro de absorbância da polianilina em $0,8 \mathrm{~mol} / \mathrm{L}$ de $\mathrm{HCl}$, para diferentes potenciais.

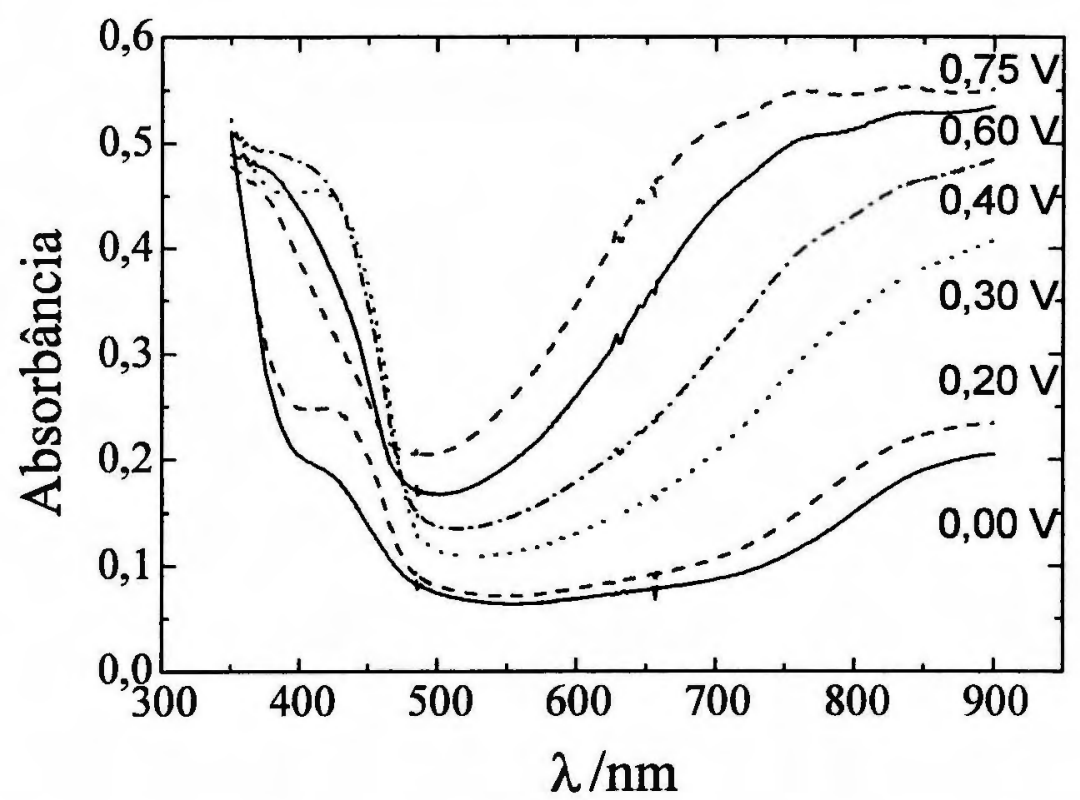

Figura 3.46: Espectro de absorbância da polianilina em 0,8 mol/L de $\mathrm{HCl}$, para diferentes potenciais.

Este espectro da polianilina pode ser explicado [169] com base em diagramas das transições eletrônicas proposto por MacDiarmid e Huang [165] (Figura 3.47). Na faixa de potencial entre $-0,25 \mathrm{~V}$ a $0,0 \mathrm{~V}$, o polímero está completamente reduzido na forma de leucoesmeraldina. A polianilina apresenta uma banda intensa em $318 \mathrm{~nm}(\sim 3,9 \mathrm{eV})$. Esta banda está relacionada com transições eletrônicas $\pi \rightarrow \pi^{*}$, onde o elétron passa da banda de valência, banda ocupada mais energética, para a banda de condução, banda vazia menos energética.

Quando o polímero começa a se oxidar, entre 0,10 e 0,30 V, ocorre a transição para a forma esmeraldina, onde metade dos elétrons da banda ocupada são removidos. Com a remoção destes elétrons ocorre um rearranjo energético, e, quando isso acontece aparecem duas bandas de absorção no espectro da polianilina, as bandas polarônicas, uma em cerca de $430 \mathrm{~nm}(\sim 3,0 \mathrm{eV})$ que atinge seu máximo em $0,25 \mathrm{~V}$, potencial do primeiro processo de oxidação, e onde verifica-se um máximo na quantidade de radicais cátions, e outra em $830 \mathrm{~nm}(\sim 1,5 \mathrm{eV})$. 


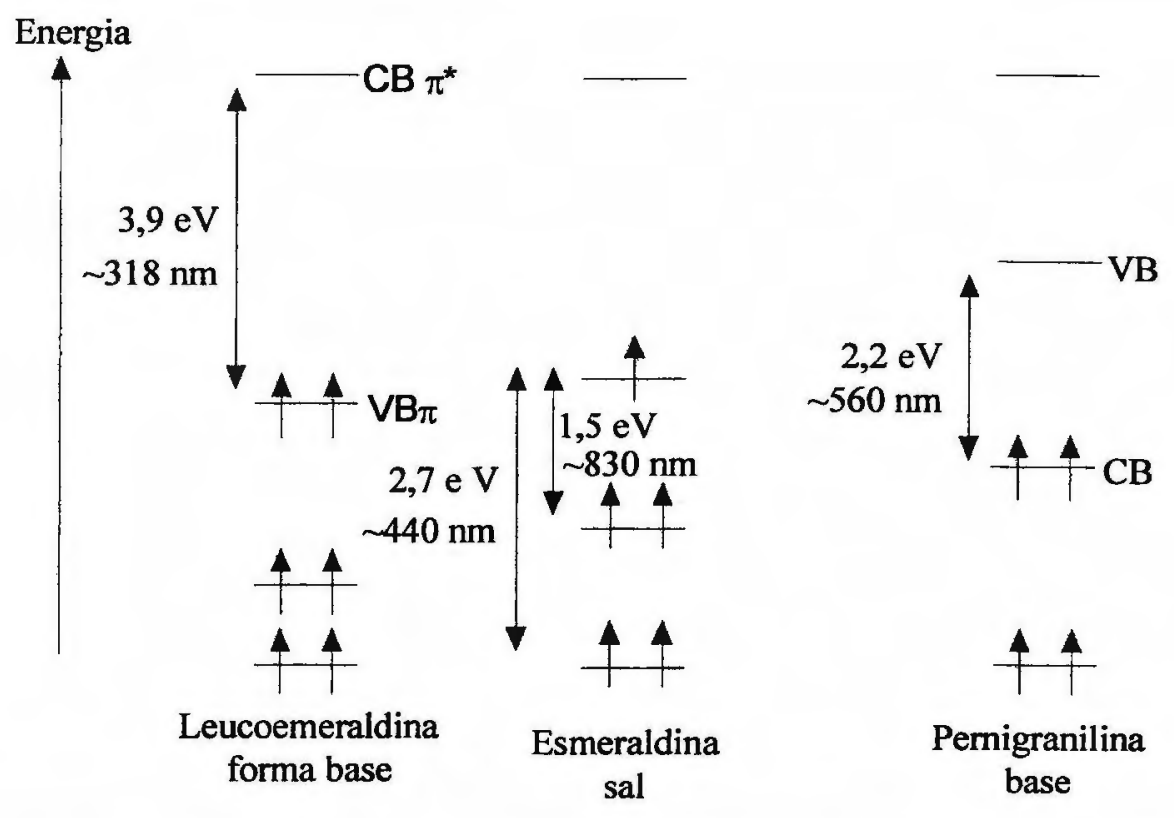

Figura 3.47: Esquema dos diagramas dos niveis de energia para as diversas formas da polianilina ( $C B$, banda de condução; VB, banda de valência) [165]

Aumentando-se ainda mais o potencial, na faixa de $0,30 \mathrm{~V}$ a $0,55 \mathrm{~V}$, mais elétrons são removidos, ocorrendo um novo rearranjo energético, e a intensidade da banda polarônica centrada em $830 \mathrm{~nm}(\sim 1,5 \mathrm{eV})$ aumenta, e vai se deslocando para regiões de maior energia, (Figura 3.46).

Quando o polímero é oxidado ainda mais, $0,75 \mathrm{~V}$, o espectro muda completamente, as bandas em $430 \mathrm{~nm}(\sim 3,0 \mathrm{eV})$ e $830 \mathrm{~nm}(\sim 1,5 \mathrm{eV})$ desaparecem, restando apenas uma única banda centrada em $700 \mathrm{~nm}(\sim 1,75 \mathrm{eV})$. Se o polímero fosse oxidado ainda mais de forma à garantir uma oxidação completa, esta banda de deslocaria ainda mais para $560 \mathrm{~nm}(\sim 2,2 \mathrm{eV})$, que corresponde a transição eletrônica $\pi^{\prime} \rightarrow \pi^{*}$, da forma pernigranilina.

Espectros de absorbância da poli(2-etilanilina) em $0,8 \mathrm{~mol} / \mathrm{L}$ de $\mathrm{HCl}$ para diferentes potenciais são mostrados na Figura 3.48. O comportamento dos espectros é parecido com o da polianilina nas mesmas condições.

Ocorrem diferenças relacionadas aos valores de potencial no qual as bandas atingem seu máximo. Enquanto que para os filmes de polianilina, a intensidade da banda polarônica é máxima em $0,25 \mathrm{~V}$, no caso da poli(2-etilanilina) esta banda é máxima em $0,40 \mathrm{~V}$, potencial no qual observamos o primeiro pico de oxidação no voltamograma da poli(2-etilanilina). Com a oxidação da poli(2etilanilina), a banda que na forma reduzida estava centrada em $900 \mathrm{~nm}(\sim 1,35 \mathrm{eV})$ se desloca para regiões de maior energia $750 \mathrm{~nm}(\sim 1,65 \mathrm{eV})$.

Pode-se observar também que no espectro de absorção da poli(2-etilanilina) em 0,60 V tem-se uma banda larga com seu máximo em $800 \mathrm{~nm}$, porém para a polianilina esta mesma banda inicia-se em $750 \mathrm{~nm}$ e prossegue em um patamar para regiões de menor energia, o que indicaria que a polianilina tem uma maior conjugação em sua cadeia nesse potencial que a poli(2-etilanilina). 


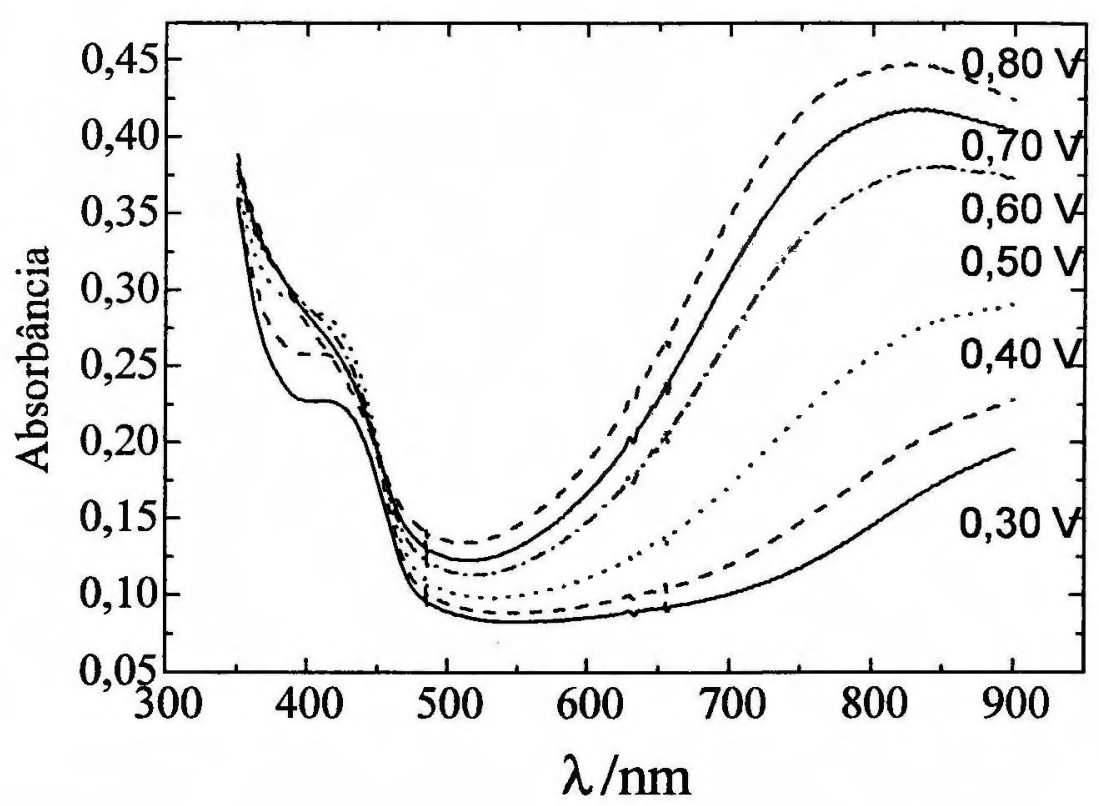

Figura 3.48: Espectro de absorbância da poli(2-etilanilina) em 0,8 mol/L de $H C l$, para diferentes potenciais.

Quando o eletrólito é trocado, de $\mathrm{HCl}$ para $\mathrm{HClO}_{4}$ e $\mathrm{HCSA}$ tem-se o mesmo comportamento observado para $\mathrm{HCl}$. Para o PTSA entretanto, observa-se um deslocamento para regiões de maior energia, quando comparado com a poli(2-etilanilina) em $\mathrm{HCl}$, pois a banda polarônica localizada inicialmente em $430 \mathrm{~nm}(\sim 1,5 \mathrm{eV})$ e $900 \mathrm{~nm}(\sim 1,35 \mathrm{eV})$ se deslocam para $400 \mathrm{~nm}$ $(\sim 3,1 \mathrm{eV})$ e $800 \mathrm{~nm}(\sim 1,55 \mathrm{eV})$ entre os potenciais 0,30 e $0,50 \mathrm{~V}$, e a segunda banda se desloca ainda mais, para $750 \mathrm{~nm}(\sim 1,71 \mathrm{eV})$ em potenciais maiores (Figura 3.49). Indicando mais uma vez a interação diferenciada entre a cadeia polimérica e o PTSA.

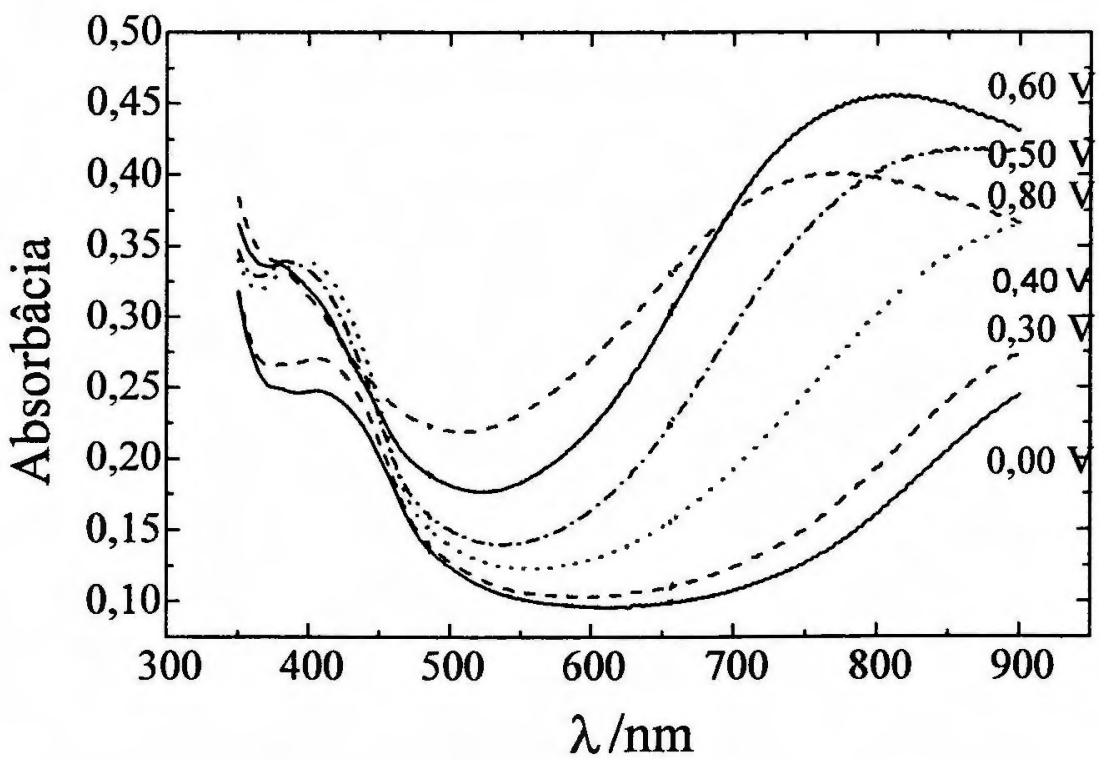

Figura 3.49: Espectro de absorbância da poli(2-etilanilina) em 0,8 mol/L de PTSA, para diferentes potenciais. 
Nas Figuras 3.50 e 3.51 são mostrados os espectros de absorção dos diferentes copolímeros poli(anilina-co-2-etilanilina) em $0,8 \mathrm{~mol} / \mathrm{L}$ de $\mathrm{HCl}$ para potenciais de $0,30 \mathrm{~V}, \mathrm{e} 0,70 \mathrm{~V}$, respectivamente.

Para os copolímeros de $\mathrm{f}_{1}$ 0,9 a 0,7 a intensidade máxima das bandas polarônicas é atingida por volta de $0,40 \mathrm{~V}$ e o deslocamento da banda oxidada chega à $800 \mathrm{~nm}(\sim 1,55 \mathrm{eV})$, semelhante à poli(2etilanilina). Para $\mathrm{f}_{1}$ de 0,3 a 0,1 o máximo de intensidade é obtida por volta de $0,25 \mathrm{~V}$, e o deslocamento chega à $650 \mathrm{~nm}(\sim 1,85 \mathrm{eV})$, semelhante à polianilina. Mostrando que os copolímeros fornecem respostas espectroeletroquímicas intermediárias às dos homopolímeros, porém não trata-se de uma variação gradual.

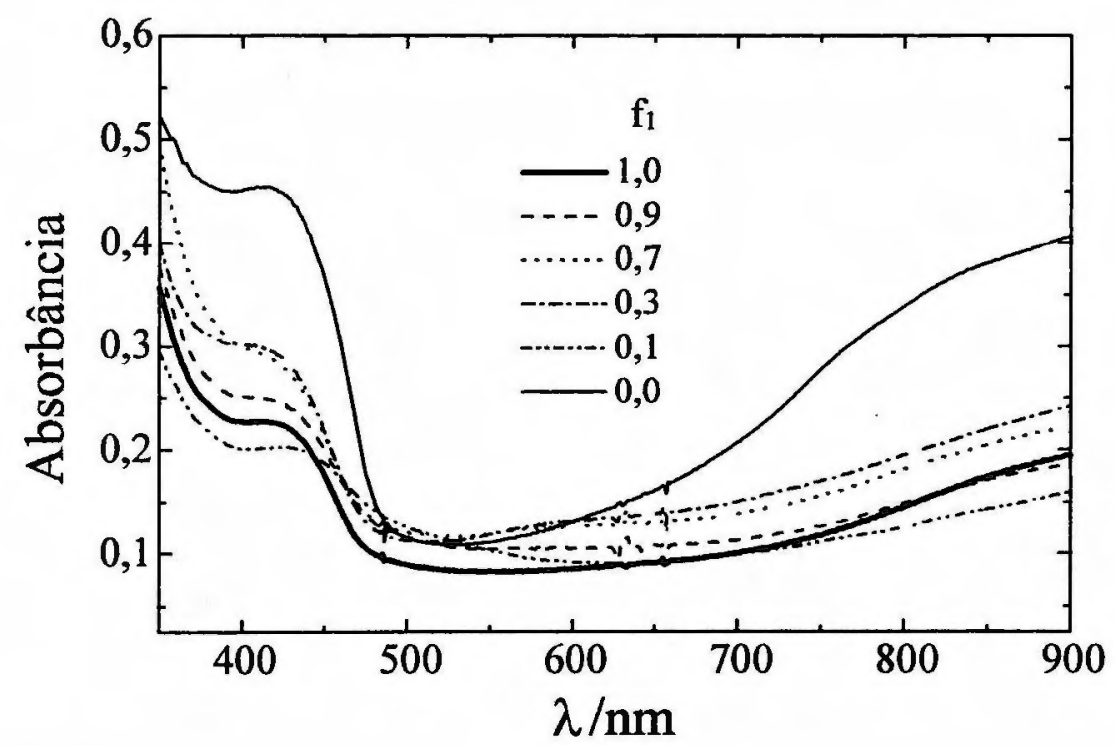

Figura 3.50: Espectro de absorbância para os diferentes copolímeros (f) em 0,8 mol/L de $\mathrm{HCl}$, em $0,30 \mathrm{~V}$.

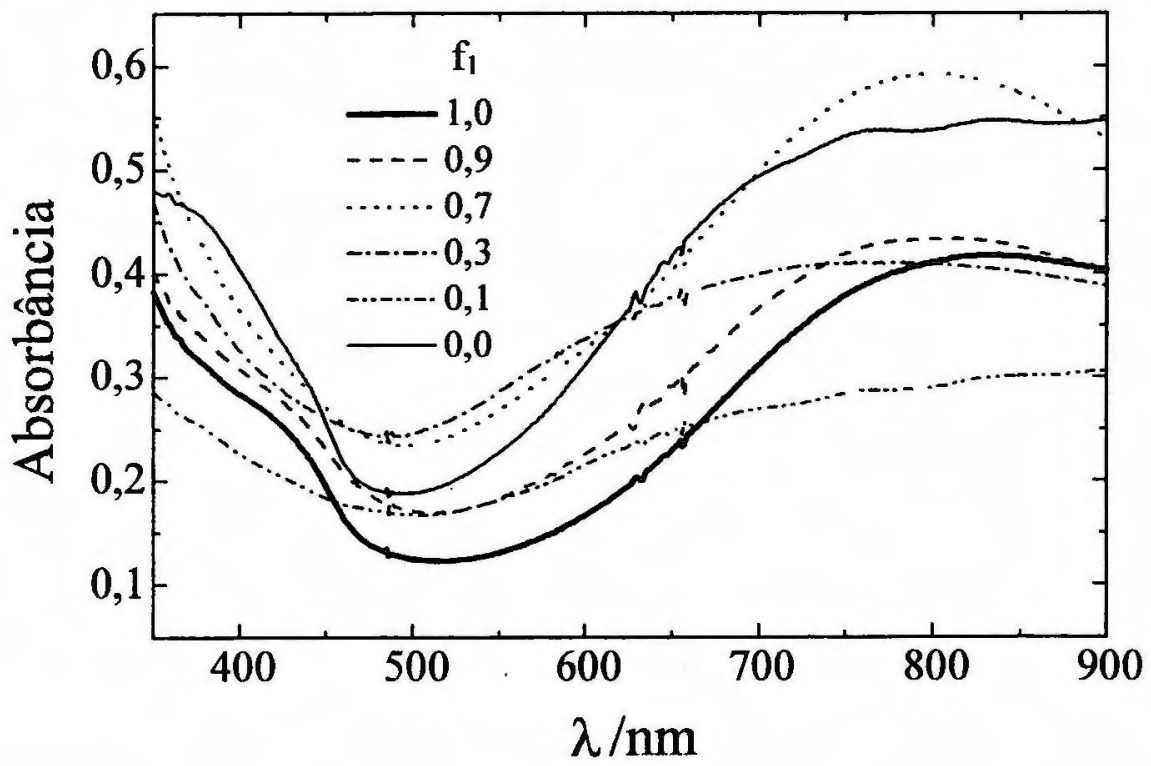

Figura 3.51: Espectro de absorbância para os diferentes copolímeros $(f)$ em 0,8 mol/L de $\mathrm{HCl}$, em $0,70 \mathrm{~V}$. 
Foi registrado a variação de transmitância em função do potencial para a polianilina, poli(2etilanilina) e poli(anilina-co-2-etilanilina) nos diferentes eletrólitos para quatro comprimentos de onda diferentes. A Figura 3.52 mostra a variação de transmitância e a variação da derivada da absorbância em função do potencial para a poli(anilina-co-2-etilanilina) $\left(f_{1}=0,1\right) \mathrm{em} 0,8 \mathrm{~mol} / \mathrm{L}$ de $\mathrm{HCl}$ para os quatro comprimentos de onda. Como este polímero apresenta uma grande separação entre os picos do voltamograma é mais fácil correlacionar os picos do voltamograma com os picos do perfil dA/dE.
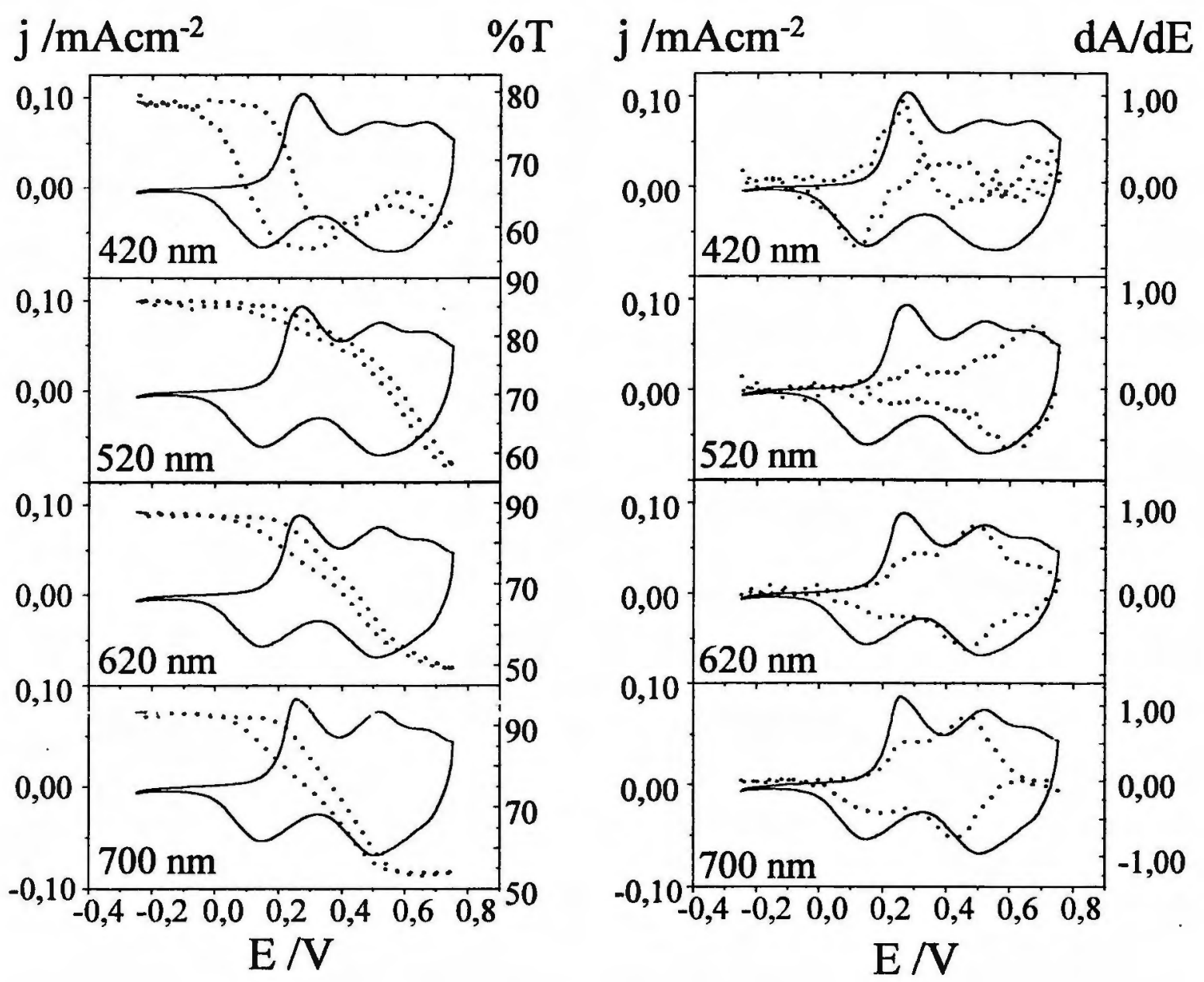

Figura 3.52: Voltamogramas, transmitâncias e derivada da absorbância para a poli(anilina-co-2-etilanilina) $\left(f_{l}=0,1\right)$ em $0,8 \mathrm{~mol} / \mathrm{L}$ de $\mathrm{HCl}$ para quatro diferentes comprimentos de onda.

Este tratamento é feito pois comparando-se quantidades diferenciais (corrente), com quantidades integrais (transmitância ou absorbância) torna dificil a análise das relações entre os diferentes grupos cromóforos formados/consumidos durante o processo de oxidação/redução. 
Em $420 \mathrm{~nm}$ o primeiro pico do voltamograma encontra-se no mesmo potencial que o pico observado no perfil $\mathrm{dA} / \mathrm{dE}$, o que indica que a espécie cromófora formada neste potencial, na transformação leucoesmeraldina/esmeraldina, absorve em $420 \mathrm{~nm}$. O que pode ser confirmado com o espectro de absorção deste copolímero em função do potencial (Figura 3.53), onde observa-se que em $420 \mathrm{~nm}$ a maior variação na intensidade desta banda ocorre entre 0,20 e 0,30 V.

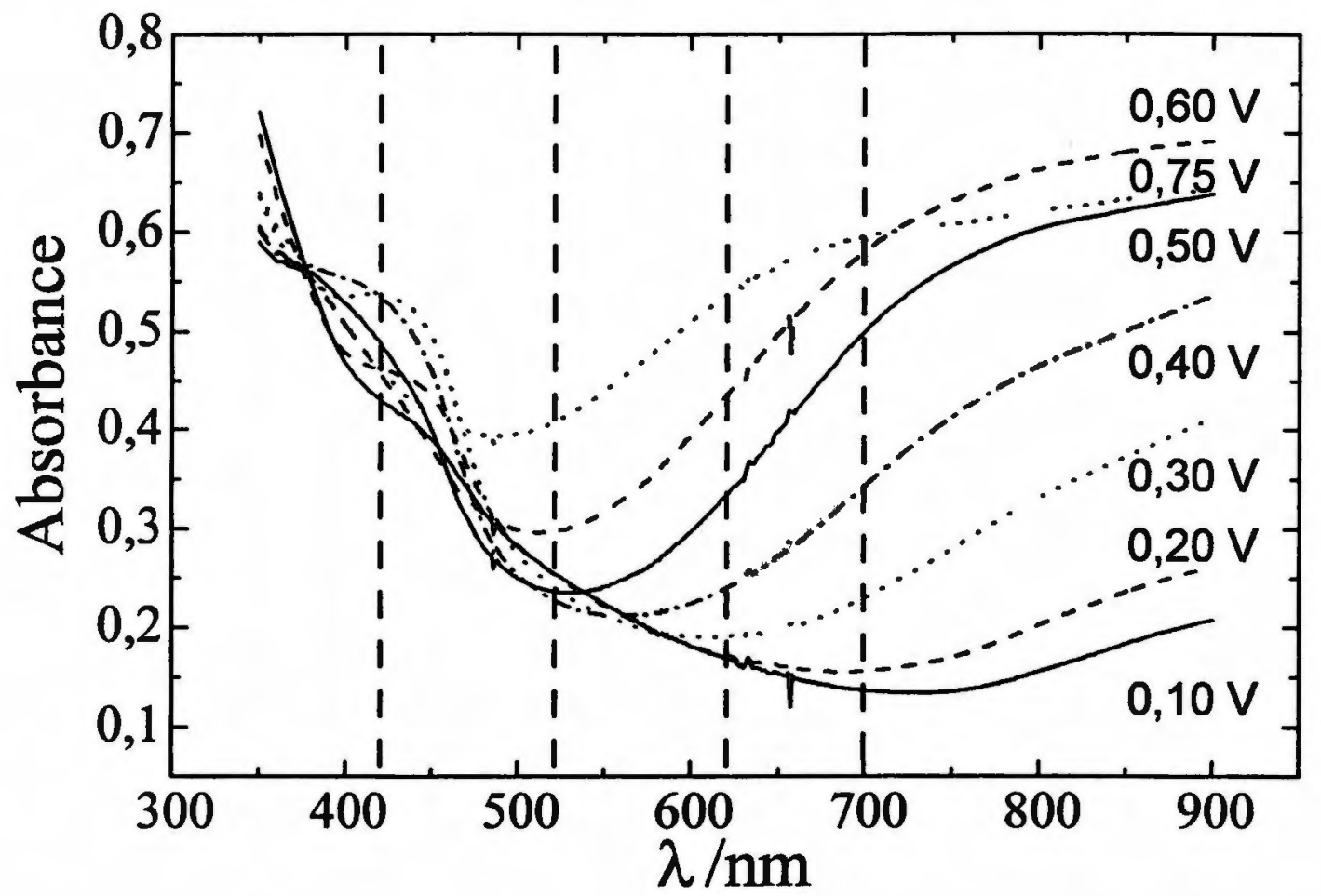

Figura 3.53: Espectro de absorção da poli(anilina-co-2-etilanilina) $\left.f_{1}=0,1\right)$ em $0,8 \mathrm{~mol} / \mathrm{L}$ de $\mathrm{HCl}$ em diferentes potenciais.

Em $520 \mathrm{~nm}$ tem-se uma correlação entre o terceiro pico do voltamograma, em $0,60 \mathrm{~V}$, com o pico do perfil $\mathrm{dA} / \mathrm{dE}$, que corresponderia as espécies cromóforas formadas na transição entre as estruturas esmeraldina/pernigranilina. Todavia em $620 \mathrm{~nm}$ é difícil correlacionar qualquer pico do voltamograma com o pico do perfil $\mathrm{dA} / \mathrm{dE}$, havendo contribuição de todos os processos redox na absorção deste comprimento de onda.

$O$ mesmo pode ser observado no espectro de absorção, onde em $620 \mathrm{~nm}$ tem-se um aumento contínuo na intensidade do espectro em função do potencial, sendo que em nenhum potencial vê-se um salto de intensidade no espectro. Em $700 \mathrm{~nm}$ também é difícil correlacionar os picos do voltamograma com os picos observado no perfil $\mathrm{dA} / \mathrm{dE}$.

Com este tipo de estudo pode-se separar, com o auxilio da luz, cada uma das contribuições que cada espécie cromófora formada/consumida durante o processo de oxidação/ redução, fornece ao voltamograma. 
Assim, voltamogramas como o da poli(2-etilanilina) (Figura 3.54) que apresenta apenas um único pico largo de corrente, pode ser separado, da mesma maneira que foi feito para o copolímero, e pode-se observar a mesma correlação, ou seja, o primeiro processo redox está relacionado com a absorção em $420 \mathrm{~nm}$, o segundo processo de oxidação esta relacionado com a absorção em $520 \mathrm{~nm}$, e tanto para $620 \mathrm{~nm}$ quanto para $700 \mathrm{~nm}$ tem-se a contribuição dos dois processos.
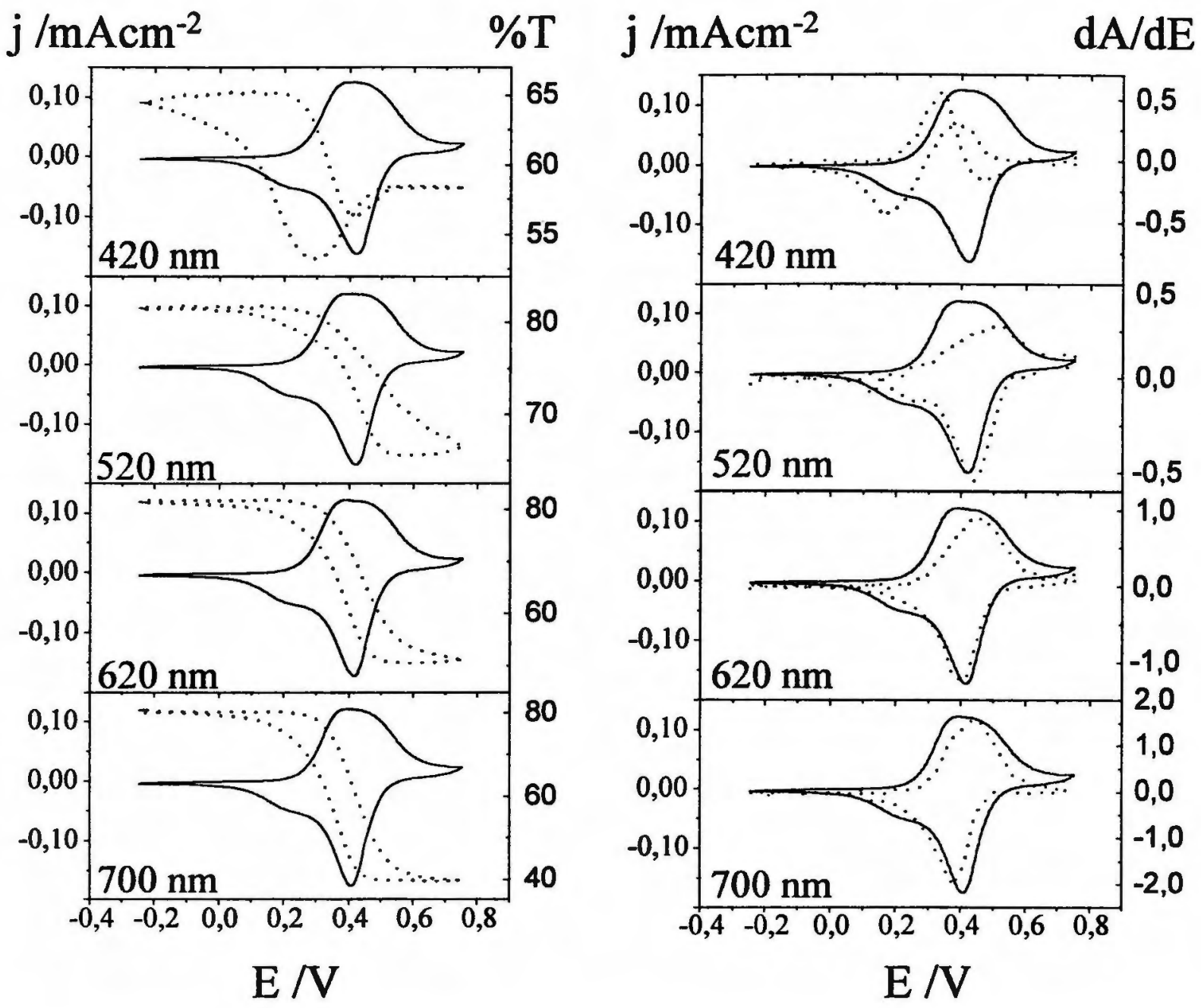

Figura 3.54: Voltamogramas, transmitâncias e derivada da absorbância para a poli(2-etilanilina) em 0,8 mol/L de $\mathrm{HCl}$ para quatro diferentes comprimentos de onda.

\subsubsection{Caracterização por Raman Ressonante}

Em sistemas conjugados, como a polianilina, o comprimento de onda do laser excitante tem uma grande influência nos espectros Raman Ressonante, pois a absorção destes materiais é diferente para cada comprimento de onda. A excitação vermelha $(632,8 \mathrm{~nm})$ tende à aumentar a intensidade 
das bandas originárias das deformações dos segmentos oxidados, em espectros de polianilinas sintetizados tanto por via química quanto eletroquímica. $\mathrm{Na}$ forma básica, as bandas de segmentos quinoidais estão sempre bem representadas no espectro.

Com os pós ou pastilhas dos homopolímeros e copolímeros obtidos quimicamente registraramse os espectros Raman Ressonante. Com o espectro estendido destes polímeros na forma básica (Figura 3.55) pode-se observar que as maiores alterações no espectro em função da quantidade de unidades de 2-etilanilina ( $\left.\mathrm{f}_{1}\right)$ estão na região de 1000 a $1700 \mathrm{~nm}$, e por isso foram registrados espectros mais detalhados desta região.

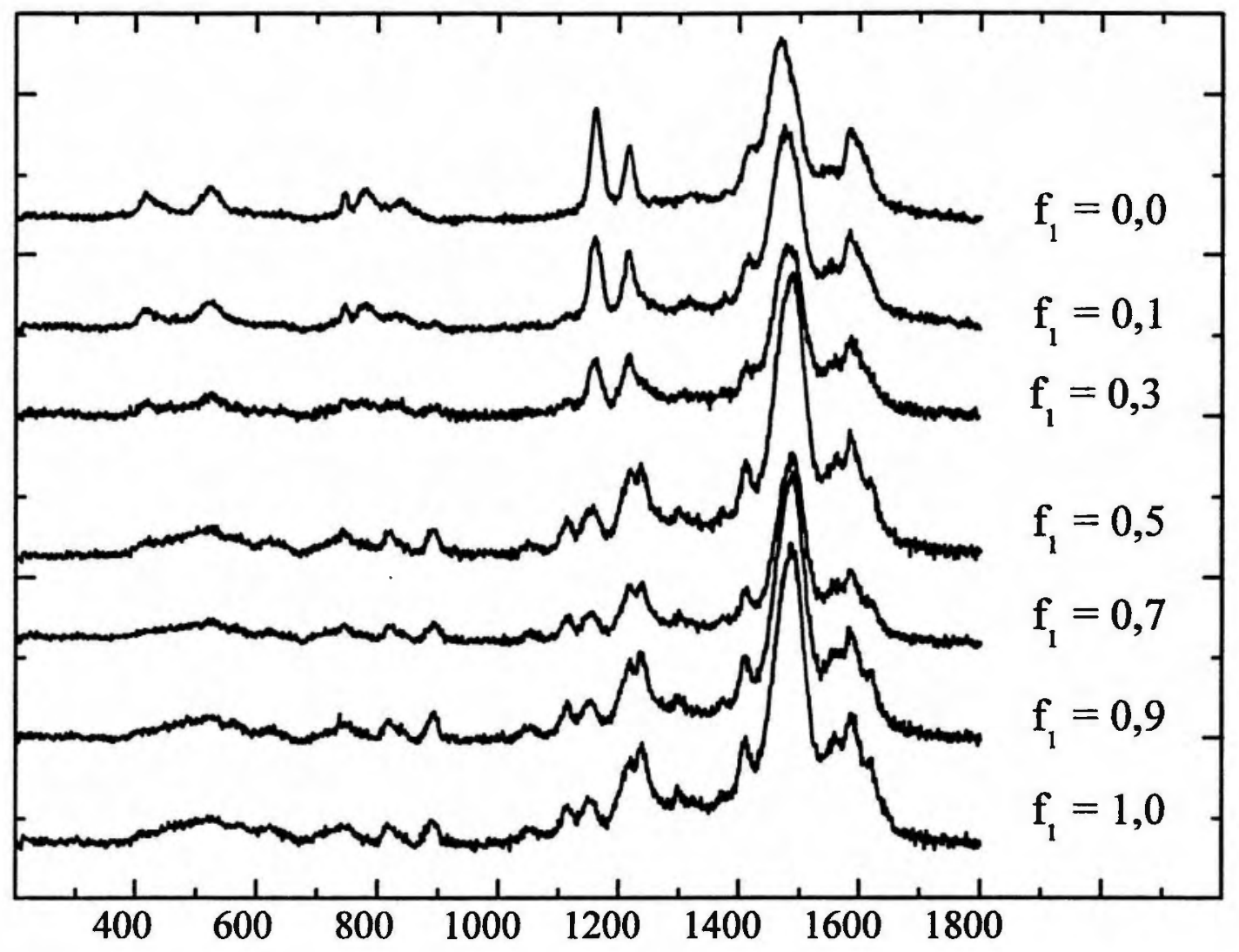

\section{Deslocamento Raman $/ \mathrm{cm}^{-1}$}

Figura 3.55: Espectros Raman Ressonante dos homopolimeros e copolímeros com diferentes quantidades de unidades de 2-etilanilina na solução de sintese (f) na forma base, $\lambda=632,8 \mathrm{~nm}$.

Pode-se observar também que não há uma alteração gradual no aparecimento e desaparecimento das bandas, e sim uma alteração abrupta para $f_{1}$ entre 0,3 e 0,5 . Isto provavelmente se deve à diferença de reatividade entre os monômeros de entrar na cadeia copolimérica fazendo com que a composição desta cadeia copolimérica seja diferente da composição da solução de crescimento do copolímero. 
Em estudos de poli(2-metilanilina) [170] o espectro Raman Ressonante na forma básica com radiação excitante de $676 \mathrm{~nm}$, é muito semelhante ao da poli(2-etilanilina) básica em 623,8 nm. Assim pode-se fazer algumas comparações e atribuições de bandas.

Nos espectros da Figura 3.56 observa-se que a polianilina apresenta duas bandas intensas, uma em $1164 \mathrm{~cm}^{-1}$ e outra em $1220 \mathrm{~cm}^{-1}$. A banda em $1164 \mathrm{~cm}^{-1}$ se deve à deformação angular C-H da estrutura quinoidal. Enquanto que a banda em $1220 \mathrm{~cm}^{-1}$ se deve ao estiramento C-N em segmentos benzênicos.

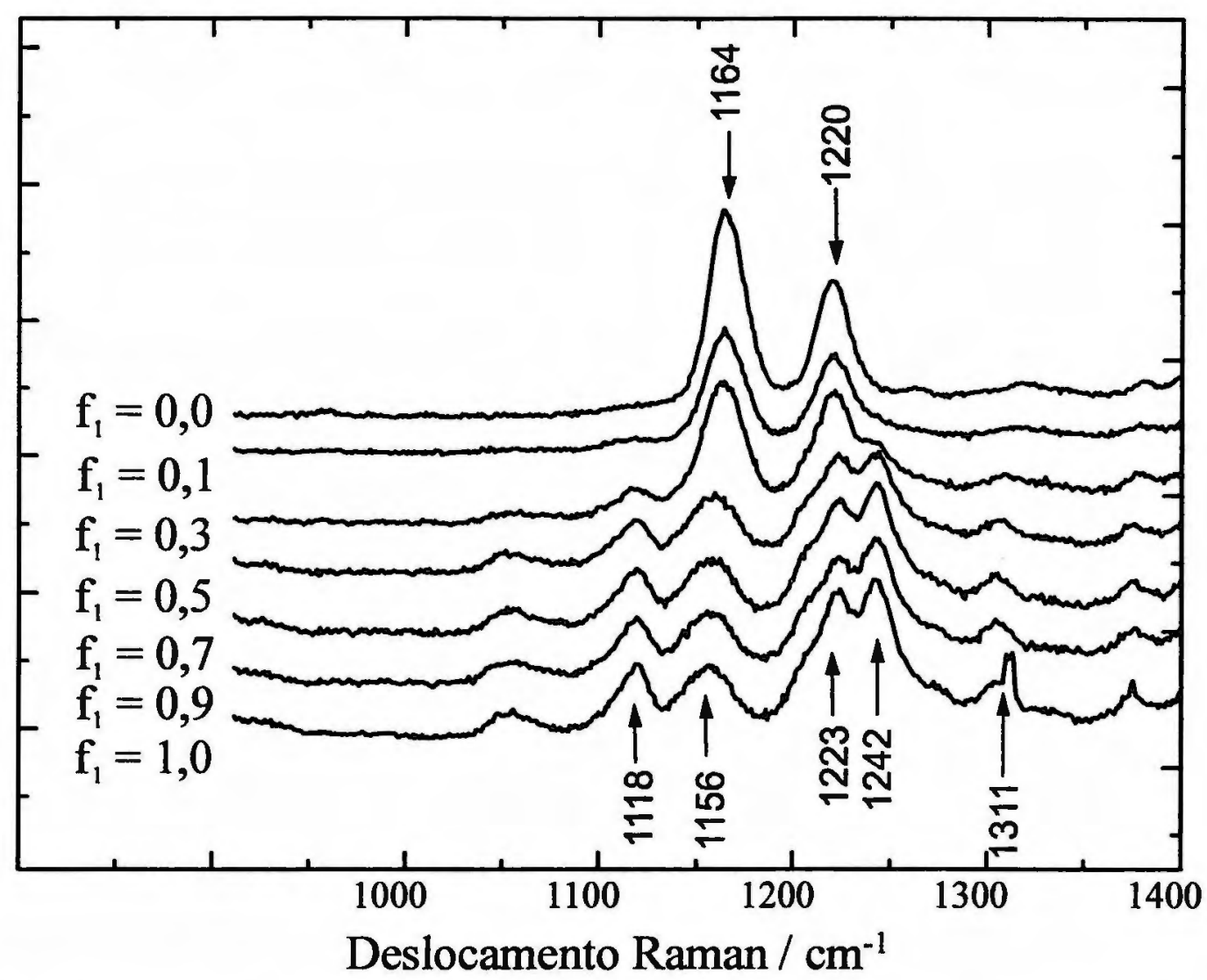

Figura 3.56: Espectros Raman Ressonante dos homopolímeros e copolímenos com diferentes quantidades de unidades de 2-etilanilina na solução de síntese $(f)$ na forma base, $\lambda=632,8 \mathrm{~nm}$.

Para a poli(2-etilanilina) a banda que é atribuída à deformação $\mathrm{C}-\mathrm{H}$ da estrutura quinoidal é a banda observada em $1156 \mathrm{~cm}^{-1}$, esta diferença se deve à presença das cadeias alquílicas que deslocam as bandas para freqüências menores, se houvesse um grupo metil esta banda se deslocaria ainda mais, para $1154 \mathrm{~cm}^{-1}$. A banda atribuída ao estiramento $\mathrm{C}-\mathrm{N}$ dos segmentos benzênicos para a poli(2etilanilina) está deslocado para freqüências maiores, em $1223 \mathrm{~cm}^{-1}$.

A banda observada em $1118 \mathrm{~cm}^{-1}$ para a poli(2-etilanilina) se deve ao estiramento das ligações C-C da cadeia alquílica, e a banda em $1242 \mathrm{~cm}^{-1}$, se deve à torção da mesma ligação. A intensidade destas duas bandas diminuem com o aumento de unidades de anilina, o que seria esperado, já que tem-se menos cadeias alquílicas na cadeia copolimérica. 
No espectro da polianilina $\left(f_{1}=0,0\right)$ (Figura 3.57) tem-se uma banda intensa em $1476 \mathrm{~cm}^{-1}$, devido ao estiramento da ligação $\mathrm{C}=\mathrm{N}$ nos segmentos quinoidais. Esta banda vai se deslocando gradualmente para freqüências maiores, com o aumento de unidades de 2-etilanilina até $f_{1}=0,3$, o que confirmaria a presença de um copolímero, nesta faixa de composição.

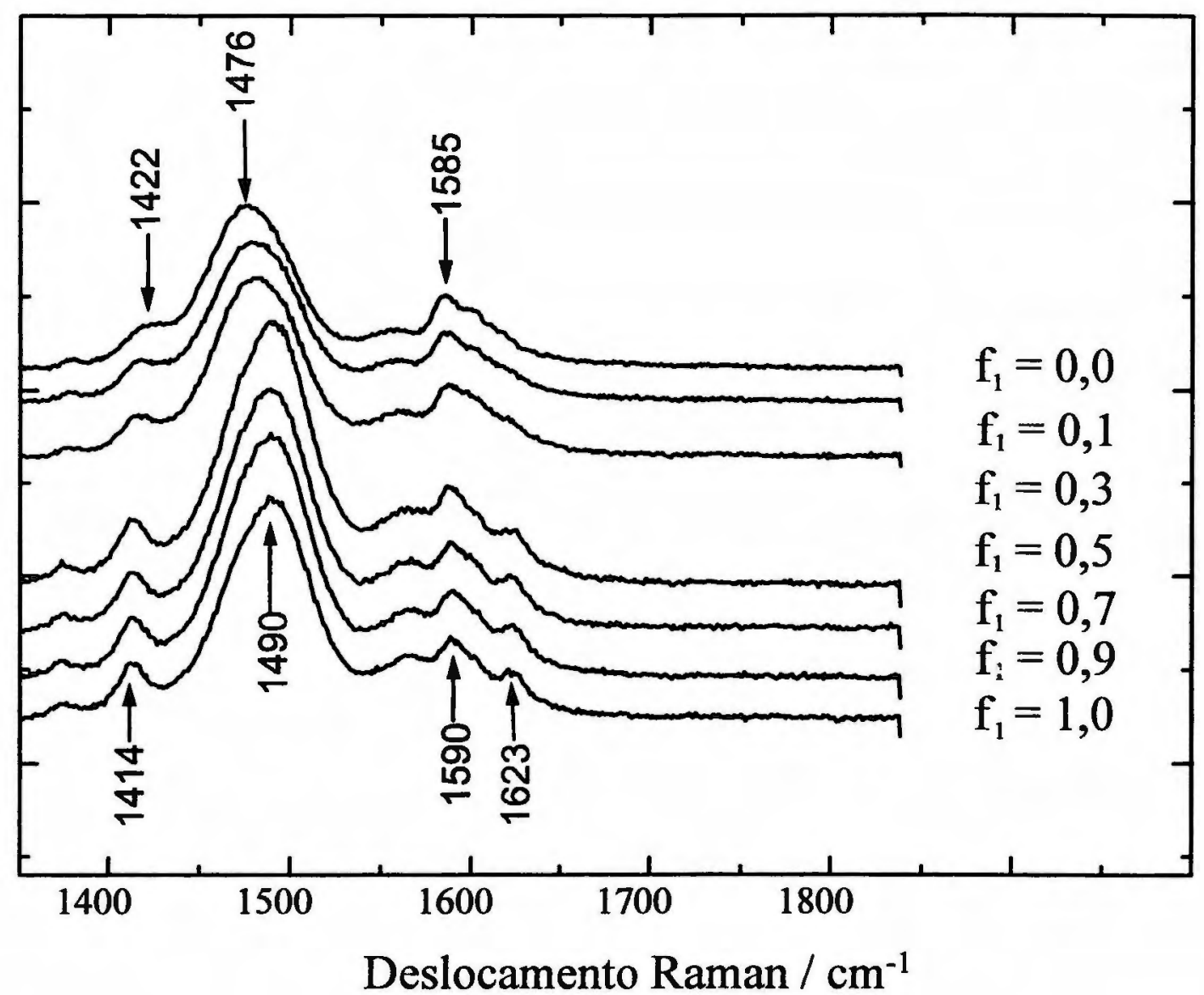

Figura 3.57: Espectros Raman Ressonante dos homopolimeros e copolimeros com diferentes quantidades de unidades de 2-etilanilina na solução de síntese (f) na forma base, $\lambda=632,8$.

Acima de $\mathrm{f}_{1}=0,3$ os espectros dos copolímeros são exatamente iguais ao da poli(2-etilanilina), mostrando que estes copolímeros, muito provavelmente, tem uma quantidade grande de unidades de 2-etilanilina, reafirmando que a composição do copolímero difere da composição da solução de síntese.

Na poli(2-etilanilina) a banda devido ao estiramento da ligação $\mathrm{C}=\mathrm{N}$ dos segmentos quinoidais, está em $1490 \mathrm{~cm}^{-1}$. A banda observada em $1585 \mathrm{~cm}^{-1}$ para a polianilina e a banda em $1590 \mathrm{~cm}^{-1}$ para a poli(2-etilanilina) é atribuída ao estiramento $\mathrm{C}=\mathrm{C}$ do anel quinônico. $\mathrm{A}$ banda observada em $1623 \mathrm{~cm}^{-1}$ se deve ao estiramento do anel quinônico, assim como a banda $1412 \mathrm{~cm}^{-1}$, e a banda $1422 \mathrm{~cm}^{-1}$ da polianilina. Como estas bandas são atribuídas ao anel quinônico elas estão presentes em todos os copolímeros. 


\subsubsection{Medidas de Resistência}

Cada um dos polímeros e copolímeros sintetizados quimicamente na forma salina (dopados com $\mathrm{HCl}$ ) foram comprimidos entre dois eletrodos de ouro, que foram ligados ao Autolab, e o gráfico de impedância foi obtido. Como neste arranjo o polímero comporta-se como uma resistência, tem-se apenas um ponto no gráfico de impedância, que corresponde à resistência do material, pode-se calcular a resistividade facilmente, através da expressão:

$$
\sigma=\frac{\rho}{R A}
$$

Onde $R$ é a resistência obtida no gráfico de impedância, $A$ é a área do eletrodo, e $\rho$ a espessura do polímero. Os dados obtidos estão resumidos na Tabela 3.5, a partir da qual pode-se construir o gráfico da condutividade em função da composição da solução de sintese dos copolímeros Figura 3.58.

Tabela 3.5: Tabela dos resultados obtidos das medidas de impedância e calculo de condutividade

\begin{tabular}{|ccccc|}
\hline $\begin{array}{c}\text { Composição } \\
(\mathrm{f})\end{array}$ & $\begin{array}{c}\text { Espessura } \\
(\mathrm{cm})\end{array}$ & $\begin{array}{c}\text { Resistência } \\
(\Omega)\end{array}$ & $\begin{array}{c}\text { Resistividade } \\
(\Omega \mathrm{cm})\end{array}$ & $\begin{array}{c}\text { Condutividade } \\
\left(\mathrm{Scm}^{-1}\right)\end{array}$ \\
\hline 1,0 & 0,105 & $2,58 \times 10^{4}$ & 933 & $1,1 \times 10^{-3}$ \\
\hline 0,9 & 0,155 & $3,05 \times 10^{3}$ & 74 & $1,3 \times 10^{-2}$ \\
\hline 0,7 & 0,115 & $3,00 \times 10^{3}$ & 95 & $1,0 \times 10^{-2}$ \\
\hline 0,5 & 0,210 & $4,70 \times 10^{3}$ & 85 & $1,2 \times 10^{-2}$ \\
\hline 0,3 & 0,150 & $2,54 \times 10^{3}$ & 64 & $1,6 \times 10^{-2}$ \\
\hline 0,1 & 0,085 & 3,23 & 0,14 & 7,0 \\
\hline 0,0 & 0,160 & 3,96 & 0,09 & 10,6 \\
\hline
\end{tabular}

Pode-se observar através deste gráfico que a presença de algumas unidades de anilina na cadeia copolimérica da poli(2-etilanilina) já aumenta a condutividade deste polímero em uma ordem de grandeza, provavelmente pelo aumento da conjugação na cadeia polimérica devido a presença de unidades ou blocos de unidades de anilina, facilitando a passagem eletrônica pela cadeia. 


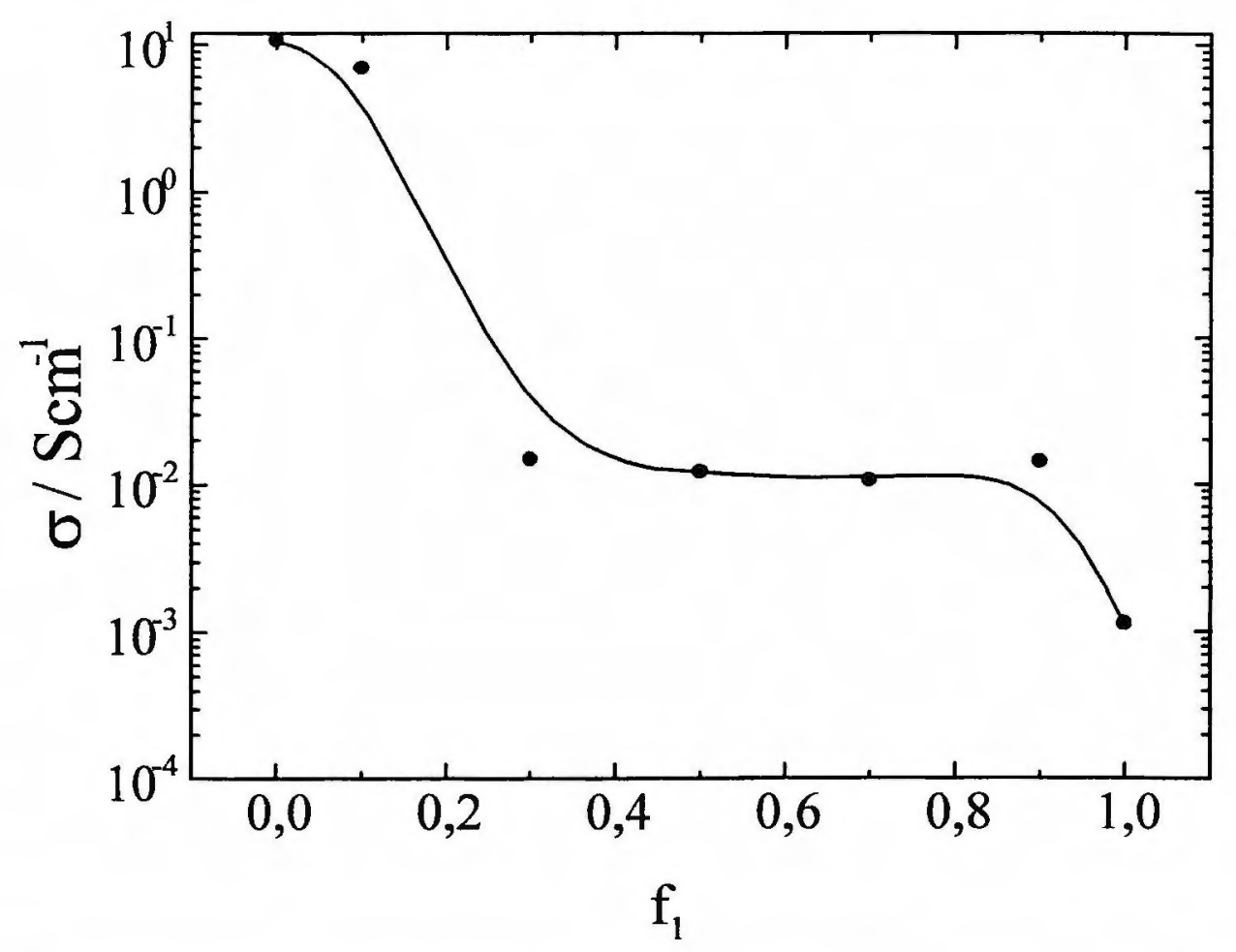

Figura 3.58: Condutividade dos copolímeros em função da composição da solução de síntese, forma salina.

\subsubsection{Estudos de Solubilidade}

Entre as frações molares de unidades de 2-etilanilina $\left(\mathrm{f}_{1}\right)$ 0,9 e 0,3 tem-se um patamar de condutividade por volta de $10^{-2} \mathrm{~S} / \mathrm{cm}$ e abaixo disso a condutividade aumenta gradualmente até $10 \mathrm{~S} / \mathrm{cm}$, o que seria de se esperar de um copolímero, cujas unidades monoméricas incluem um bom condutor (polianilina) e um material menos condutor (poli(2-etilanilina)), quanto maior a quantidade de unidades de anilina no copolímero maior é a condutividade do copolímero.

Os resultados obtidos com os estudos de solubilidade estão mostrados na Tabela 3.6, onde podese observar que em geral os copolímeros são mais solúveis que misturas de homopolímeros na mesma proporção molar que a solução de síntese dos copolímeros. Isto é um indício da formação de um copolímero, e não apenas a formação de uma mistura de homopolímeros durante a síntese, já que a maioria dos copolímeros se dissolveram completamente, enquanto que uma quantidade considerável de material insolúvel foi observado nas soluções que continham as misturas mecânicas.

Esta maior solubilidade dos copolímeros está relacionada com a introdução de grupos alquílicos na cadeia polimérica, que devido a sua interação com o solvente facilita a cadeia polimérica a se distender no solvente, provocando a dissolução do sólido polimérico. 
Pode-se observar que quanto maior a quantidade de unidades de 2-etilanilina na cadeia polimérica, maior é a solubilidade do copolímero nestes solventes, mostrando que uma maior solubilidade para a polianilina pode ser conseguida através da copolimerização. Como este tipo de experimento é muito trabalhoso e os dados de solubilidade em NMP estão de acordo com a literatura [123], estes experimentos não foram repetidos.

Tabela 3.6: Solubilidade (em g/10 mL \pm 0,01) de polianilina, poli(anilina-co-2-etilanilina) e poli(2-etilanilina) em sua forma básica em $\mathrm{NMP}, \mathrm{DMF}$ e $\mathrm{CHCl}_{3}$.

\begin{tabular}{|c|c|c|c|c|c|c|}
\hline $\begin{array}{c}\text { Polímero } \\
\text { (f) }\end{array}$ & \multicolumn{2}{|c|}{ NMP } & \multicolumn{2}{c|}{$\mathrm{CHCl}_{3}$} & \multicolumn{2}{c|}{ DMF } \\
\hline 0,0 & \multicolumn{2}{|c|}{0,22} & \multicolumn{2}{c|}{0,26} & \multicolumn{2}{c|}{0,27} \\
\hline 0,1 & 0,30 & 0,27 & 0,26 & 0,24 & 0,34 & 0,29 \\
\hline 0,3 & 0,49 & 0,39 & 0,35 & 0,35 & 0,49 & 0,28 \\
\hline 0,5 & 0,49 & 0,44 & 0,46 & 0,34 & 0,50 & 0,40 \\
\hline 0,7 & 0,50 & 0,46 & 0,48 & 0,35 & 0,49 & 0,43 \\
\hline 0,9 & 0,49 & 0,48 & 0,47 & 0,35 & 0,49 & 0,48 \\
\hline 1,0 & \multicolumn{2}{|c|}{0,49} & \multicolumn{2}{|c|}{0,48} & \multicolumn{2}{c|}{0,49} \\
\hline
\end{tabular}




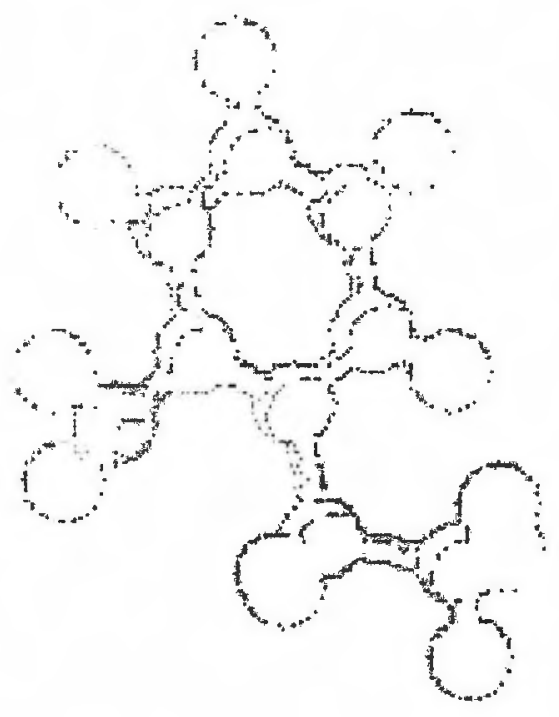

\section{Conclus̃̃es}

Este trabalho mostrou um estudo comparativo entre polianilina, poli(2-etilanilina) e copolímeros de anilina e 2-etilanilina. O qual mostrou ser possível sintetizar facilmente copolímeros de anilina e 2etilanilina tanto por métodos químicos quanto eletroquímicos. A síntese química da poli(N-etilanilina) é simples, porém a síntese eletroquímica mostrou-se problemática quando utiliza-se um eletrodo de vidro com camada condutora de $\mathrm{SnO}_{2}$.

No entanto a cinética de crescimento destes materiais se diferencia muito, como foi observado através dos dados eletrogravimétricos. Pode-se observar que enquanto a polianilina apresenta um crescimento autocatalítico, o crescimento da poli(2-etilanilina) mostrou o comportamento oposto, ou seja, a velocidade de crescimento da poli(2-etilanilina) vai diminuindo com o aumento de material sobre o eletrodo. Já os copolímeros mostraram uma variação cíclica de massa durante seu crescimento, e seria interessante um estudo mais detalhado para determinar o que realmente está acontecendo neste sistema.

Com dados de vários experimentos efetuados neste trabalho pode-se confirmar os dados da literatura que afirmam uma diferença entre a composição da cadeia copolimérica e a composição da solução de síntese. Este trabalho evidenciou que copolímeros formados via métodos eletroquímicos também apresentam a mesma diferenciação entre a composição da solução de síntese e a composição do polímero, que foi observada na literatura para copolímeros formados quimicamente. Além disso este trabalho mostra que através de experimentos eletroquímicos simples, como voltametria cíclica, é possível observar esta diferenciação na composição do copolímero. Uma vez que uma variação na composição do copolímero altera o potencial dos processos redox do mesmo. Esta variação de potencial com a composição do copolímero é reprodutível, desde que os experimentos sejam feitos sempre nas mesmas condições. No caso deste trabalho, os valores de potencial dos processos redox apresentados são uma média de vários voltamogramas. E durante o trabalho observou-se que, embora houvesse pequenas variações de potencial, os resultados foram reprodutíveis dentro das mesmas condições. 
As propriedades destes copolímeros variam conforme a quantidade de unidades de 2-etilanilina na cadeia polimérica. Copolímeros contendo muitas unidades de 2-etilanilina são mais solúveis, por outro lado são menos condutores. Porém é interessante observar que com uma pequena quantidade de anilina $\left(f_{1}=0,9\right)$ tem-se um aumento de uma ordem de grandeza na condução da poli(2-etilanilina).

Dados espectroeletroquímicos e eletrogravimétricos mostraram que dependendo do volume do contra-íon e da presença de um grupo alquil na posição orto a resposta eletroquímica será diferente devido à efeitos estéricos e eletrônicos. Onde, os efeitos estéricos influenciam muito o primeiro processo de oxidação, enquanto que efeitos eletrônicos são mais importantes no segundo processo.

Pode-se também, por medidas espectroeletroquímicas, utilizando a derivada da absorbância, relacionar o cromó foro formado durante um processo redox com o comprimento de onda que ele absorve.

Com os dados obtidos pode-se associar a espécie formada durante o primeiro processo de oxidação destes polímeros (leucoesmeraldina/esmeraldina), com a espécie cromófora que absorve na região de $420 \mathrm{~nm}$. Enquanto que o segundo processo de oxidação, a transição esmeraldina/ pernigranilina, está relacionado com os grupos cromóforos que absorvem em $520 \mathrm{~nm}$.

Os dados eletrogravimétricos mostram que a variação de massa para estes materiais depende do eletrólito utilizado. Para ânions de pequeno volume durante o processo de oxidação e formação de cargas positivas no polímero têm-se um fluxo de ânions para a matriz polimérica, de forma à neutralizar estas cargas positivas formadas.

No entanto para ânions de maior volume, ocorre inicialmente uma expulsão de prótons para em seguida os ânions entrarem na matriz polimérica, que indica uma dificuldade na entrada de ânions volumosos. $E$ isto ocorre também para a polianilina, porém em menor intensidade. No processo inverso, durante a redução da poli(2-etilanilina) e copolímeros, têm-se um grande aumento de massa na matriz polimérica, que vai diminuindo aos poucos, até a redução total do polímero. Isto talvez se deva a dificuldade que estes ânions maiores têm para sair da matriz polimérica, enquanto os prótons conseguem entrar rapidamente para compensar a perda da carga positiva na matriz, o que pode dificultar ainda mais a saída dos ânions, gerando este grande aumento de massa momentâneo.

Este trabalho mostrou que é possível formar copolímeros de anilina e 2-etilanilinas, e que as propriedades destes copolímeros depende da quantidade de unidades de 2-etilanilina na cadeia polimérica. É importante lembrar, no entanto, que para que haja a formação de um copolímero é necessário que na composição da solução de síntese a quantidade de 2-etilanilina seja menor que $30 \%$ (em moles), pois acima deste valor tem-se praticamente poli(2-etilanilina). 


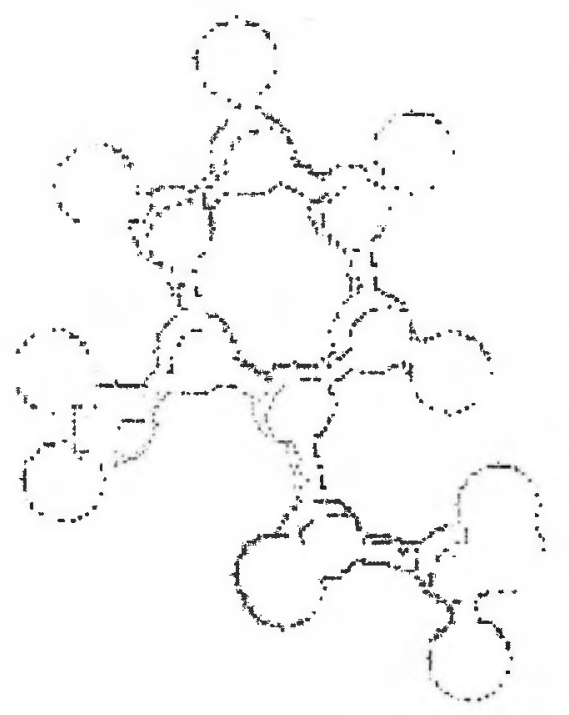

\section{Referências}

1. K. Krogman, Angew. Chem. Internat. Edn, ,8, 1969, 35.

2. M. J. Minot, J. H. Perlstein, Phys. Ver. Lett., 26, 1971, 371.

3. D. Bloor, Chem. in Brit., 19, 1983, 725.

4. D. Chapman, R. J. Warn, A. G. Fitzgerald, A. D. Yoffe, Trans. Faraday Soc., 60, 1964, 294.

5. V. V. Walatka, M. M. Labes, J. H. Perlstein, Phys. Rev. Lett., 31, 1973, 1139.

6. H. Shirakawa, S. Ikeda, Polym. J., 2, 1971, 231.

7. H. Shirakawa, E. J. Louis, A. G. MacDiarmid, C. K. Chiang, A. J. Heeger, J. Chem. Soc. Chem. Commun., 1977, 578.

8. C. Bernard, A. Herold, M. Lelaurain, G. Robert, C. R. Acad. Sci., C283, 1976, 125.

9. S. T. Wellenghoff, J. H. Lai, "Polymers for Electronic Applications", CRC Press, 1989, 93.

10. A. G. MacDiarmid, A. J. Epstein, Anais do 2o Congresso Brasileiro de Polímeros, São Paulo$S P, 1989,544$.

11. D. Cottevieille, A. L. Méhaute, C. Challioui, P. Mirebeau, J. N. Dernay, Synth. Met., 101, 1999, 703.

12. R. A. Zoppi, M. -A. De Paoli, Química Nova, 16:6, 1993, 560.

13. G. Yu, Y. Cao, M. Andersson, J. Gao, A. J. Heeger, Adv. Mater, 10, 1998, 385.

14. M. Strukelj, F. Papadimitrakopoulos, T. M. Miller, L. J. Rothberg, Science, 267, 1995, 1969.

15. M. Berggren, O. Inganäs, G. Gustafsson, J. Rasmusson, M. R. Andersson, T. Hjertberg, O. Wennerström, Nature, 372, 1994, 444. 
16. V. L. Colvin, M. C. Schlamp, A. P. Alivisatos, Nature, 370, 1994, 354.

17. T. Yamamoto, T. Inoue, T. Kanbara, Jpn J. Appl. Phys., 33, 1994, L250.

18. N. C. Greenham, S. C. Moratti, D. D. C. Bradley, R. H. Friend, A. B. Holmes, Nature, 365, 1993,628 .

19. G. Grem, G. Leditzky, B. Ulrich, G. Leising, Adv. Mater, , 4, 1992, 36.

20. T. Schauer, A. Joos, L. Dulog, C. D. Eisenbach, Progress in Organic Coatings, 33, 1998, 20.

21. R. Racicot, R. Brown, S. C. Yang, Synth. Met., 85, 1997, 1263.

22. D. M. Bigg, Adv. Polym. Techn., 4, 1984, 255.

23. G. Heywang, F. Jonas, Adv. Mater, 4, $1992,116$.

24. T. Tamamura, O niwa, Jpn. Kokai Tokkyo Koho JP 60, 228, 544., Apud. Chem. Abstr., 104, 1985, 187766k.

25. T. Asanuma, J. Takeda, Jnp. Kokai Tokkyo Koho JP 61, 283, 656., Apud. Chem. Abstr., 107, 1987, 8599a.

26. S. A. Sapp, G. A. Sotzing, J. L. Reddiger, J. R. Reynolds, Adv. Mater, , 8, 1996, 808.

27. W. A. Gazotti, G. Casalbore-Miceli, A. Geri, M.-A. De Paoli, Adv. Mater., 10, 1998, 60.

28. F. Huang, H. L. Wang, M. Feldstein, A. G. MacDiarmid, B. R. Hsieh, A. J. Epstein, Synth. Met., $85,1997,1283$.

29. B. P. Jelle, G. Hagen, O. Birketveit, J. of Applied Electrochem., 28, 1998, 483.

30. B. P. Jelle, G. Hagen, J. of Applied Electrochem., 28, 1998, 1061.

31. T. L. Rose, S. D'Antonio, M. H. Jillson, A. B. Kon, R. Suresh, F. Wang, Synth. Met., 85, 1997, 1429.

32. I. D. Raistryck, "Electrochemistry of Semiconductors and Electronics-Processes and Devices" , J. MacHardy, F. Ludwig Eds., 1992, New Jersey.

33. L. S. Roman, M. Andersson, T. Yohannes, O. Inganas, Adv. Mater, 9, 1997, 1164.

34. F. B. Li, W. J. Albery, J. Electrochem. Chem., 302, 1991, 279.

35. E. M. Geniès, New J. Chem., 15, 1991, 373.

36. B. E. Conway, J. Electrochem. Soc., 138, 1991, 1539.

37. H. Tsutsumi, S. Yamashita, T.Oishi, Synth. Met., 85, 1997, 1361. 
38. J. M. Sansiñena, V. Olazábal, T. F. Otero, C. N. Polo da Fonseca, M.-A. De Paoli, Chem. Commun., 1997, 2217.

39. C. J. Wung, Y. Pang, P. N. Prasad, F. E. Karasz, Polymer, 32, 1991, 605.

40. C. J. Wung, W. M. K. P. Wijekoon, P. N. Prasad, Polymer, 34, 1993, 1174.

41. G. S. He, C. J. Wung, G. C. Xu, P. N. Prasad, Appl. Opt., 30, 1991, 3810.

42. J. W. Gardener, P. N. Barlett, Synth. Met., 57, 1993, 3665.

43. S. Kuwabata, C. R. Martin, Anal. Chem., 66, 1994, 2757.

44. S. C. Misra, Fuel and Energy Abstracts, 38, 1997, 56.

45. C. Hsueh, A. Brajter-Toth, Anal. Chem., 66, 1994, 15.

46. P. S. Barker, A. P. Monkman, M. C. Petty, R. Pride, Synth. Met., 85, 1997, 1365.

47. P. S. Barker, A. P. Monkman, M. C. Petty, R. Pride, Circuits, Devics and Systems, 144, 1997 , 111.

48. J. Kulys, Biosensors, 2, 1986, 3.

49. D. J. Daly, C. K. O'Sullivan, G. G. Guilbault, Talanta, 49, 1999, 667.

50. R. A. Bull, F. R. Fan, A. J. Bard, J. Electrochem. Soc., 130, 1983, 1636.

51. C. T. Hable, M. S. Wrighton, Langmuir, 9, 1993, 3284.

52. T. Mäkelä, S. Pienimaa, S. Jussila, H. Isotalo, Synth. Met., 101, 1999, 705.

53. E. M. Geniès, M. Lapkowisk, J. Electroanal. Chem., 67, 1987, 220.

54. L. H. C. Mattoso, Química Nova, 19, 1996, 4.

55. W. S. Huang, B. D. Humprey, A. G. MacDiarmid, J. Chem. Soc. Faraday Trans., 82, 1986, 2385.

56. A. G. MacDiarmid, J. C. Chiang, A. F. Ritcher, A. J. Epstein, Synth. Met., 18, 1987, 285.

57. A. G. MacDiarmid, J. C. Chiang, M. Halpern, W. S. Huang, S. L. Mu, N. L. D. Somasiri, W. Wu, S. I. Yaniger, Mol. Cryst. Liq. Cryst., 121, 1985, 173.

58. A. G. MacDiarmid, A. J. Epstein, Synth. Met., 65, 1994, 103.

59. A. G. MacDiarmid, A. J. Epstein, Synth. Met., 69, 1995, 85.

60. Y. Min, Y. Xia, A. G. MacDiarmid, A. J. Epstein, Synth. Met., 69, 1995, 159. 
61. J. E. Pereira da Silva, S. I. Córdoba de Torresi, D. L. A de Faria, M. L. A. Temperini, Synth. Met., 101, 1999, 824.

62. S. Lee, J. Y. Lee, H. Lee, Synth. Met., 101, 1999, 248.

63. C. P. Melo, Ciência Hoje, 6:36, 1987, 39.

64. J. L. Bredas, G. B. Street, Acc. Chem. Res., 18, 1985, 309.

65. W. P. Su, J. R. Schrieffer, A. J. Heeger, Phys. Rev. Lett., 42, 1979, 1698.

66. J. A. Pople, S. H. Walmsley, Mol. Phys., 5, 1982, 15.

67. J. L. Bredas, R. R. Chance, Mol. Cryst. Liq. Cryst., 77, 1982, 319.

68. J. L. Bredas, R. R. Chance, R. Silbey, Phys. Rev., B26, 1982, 5843.

69. C. C. Ku, R. Liepins, “Electrical Properties of Polymers”, Hanser Publishers, 1987, Cap. 5 Part II.

70. L. I. Kotlyarevskii, L. B. Fisher, A. A. Dulov, A. A. Slinkin, A. M. Rubinstein, High Mol. Comp. USSR, 4, 1962, 174.

71. M. Hatano, S. Kambara, S. Okamoto, J. Chem. Soc. Japan, Ind. Chem. Sec., 65, $1962,716$.

72. A. V. Topchiev, J. Polym. Sci., Part A-1, 1963, 591.

73. V. V. Korshak, V. I. Kasatochkin, A. M. Sladkov, J. P. Kudrjawzew, K. Usenbaev, Dokl. Akad. Nauk. SSSR, 136, 1961, 1342.

74. V. V. Korshak, S. L. Sosin, A. M. Sladkov, J. Polym. Sci., Part C(4), 1963, 1315.

75. F. H. Wenslow, W. O. Baker, W. A. Yager, J. Am. Chem. Soc., 77, 1955, 4751.

76. H. A. Pohl, "Proceedings of the Fourth Conference on Carbon" Pergamon, London, 1960, 241.

77. H. A. Pohl, J. P. Laherrere, "Proceedings of the Fourth Conference on Carbon" Pergamon, London, 1960, 259.

78. H. A. Pohl, J. P. Laherrere, "Proceedings of the Princeton University Conference on Semiconduction in Molecular Solids", Ivy-Curtie Press, Princeton, New Jersey, 1960, 93.

79. J. P. Laherrere, M. A. Pohl, "Semiconduction in Aluminum Doped Pyropolymers", Plastic Laboratory Technical Report, 570, Princeton University Press, Princeton, 1960.

80. H. Pohl, "Modern Aspects of the Vitreous State", J. D. Mackenzie, Eds., Butterworths, London, U.K., 1962, Vol.2, 72.

81. A. M. Saxman, R. Liepins, M. Aldisse, Prog. Polym. Sci, 11(1/2), 1985, 57. 
82. J. M. G. Cowie, "Polymers: Chemistry \& Physics of Modern Materials", Blackie Academic \& Professional, New York, 1993, Cap. 7.

83. A. G. MacDiarmid, A. J. Heegar, Synth. Metals, 1, 1979/1980, 101.

84. J. A. Butcher, Jr., J. Q. Chamber, R. M. Pagni, J. Am. Chem. Soc., 100, 1978, 1013.

85. M. Aldissi, C. Linya, J. Sledz, F. Schue, L. Giral, J. M. Fabre, M. Rolland, Polymer, 23, 1982, 243.

86. M. E. Galvin, G. E. Wnek, Polym. Prep., 23(1), 1982, 99.

87. M. A. Druy, C. H. Tansg, N. Brown, A. J. Heeger, A. G. MacDiarmid, J. Polym. Sci. Poly. Phys. Edn., 18, 1980, 429.

88. T. C. Clarke, G. B. Street, Synth. Metals, 1, 1979/1980, 119.

89. G. Allen, J. C. Bevington, Eds, "Comprehensive Polymer Science", Vol 4, Pergamin Press, 1989.

90. J. Boor, "Ziegler-Natta Catalysis and Polymerization", Academic Press, 1979.

91. V. Dragutan, A. T. Balaban, M. Dimonie, "Olefin Metathesis and Ring Opening Polymerization of Cyclo Olefins”, John Willey, N. Y., 1985.

92. K. J. Ivin, “Olefin Metathesis”, Academic Press, N. Y., 1983.

93. W. Kaminsky, H. Senn, Eds., "Transition Metals and Organometallics as Catalysts for Olefin Polymerization”, Springer-Verlag, Berlin, 1988.

94. T. Kei, "Kinetics of Ziegler-Natta Polymerization", Chapman and Hall, London, 1972.

95. R. P. Quirk, Eds., “Transition Metal Catalysed Polymerization”, Hardwood Academic Press, N. Y., 1983.

96. J. Manassen, J. Wallach, J. Am. Chem. Soc., 87, 1965, 2671.

97. J. Gallard, T. Laederich, R. Salle, P. Traynard, Bull. Soc. Chem. Fr., 2204, 1963.

98. N. Grassie, J. C. McHeill, J. Polym. Sci., 17, 1958, 707.

99. A. Rembaum, J. Polym. Sci., Part C(29), 1970, 157.

100. S. D. Bruck, Polymer, 6, 1965, 319.

101. O. Vohler, P. L. Reiser, R. Martina, D. Overhoff, Angew. Chem., 82, 1970, 401.

102. L. K. H. van Beek, J. Appl. Polym. Sci., 9, 1965, 553.

103. P. J. Goodhew, A. J. Clarke, J. E. Bailey, Mat. Sci. Eng., 17, $1975,3$. 
104. A. V. Topchiev, M. A. Geiderich, V. A. Kargin, B. A. Kreuzel, B. E. Davydov, L. S. Polak, I. M. Kustanivich, Dokl. Acad. Nauk. SSSR, 128, 1959, 312.

105. A. A. Berlin, A. M. Dubinskaya, U. S. Moshkovskii, Vysokomol. Soedin, 6, 1964, 1938.

106. A. V. Vlasov, P. Y. Glazunov, V. L. Morozov, I. I. Patalakh, L. S. Polak, B. L. Tselin, R. S. Rafikov, Dokl. Akad. Nauk. SSSR, 158, 1964, 141.

107. H. Letheby, J. Chem. Soc., 15, 1862, 161.

108. W. S. Huang, B. D. Humprey, A. G. MacDiarmid, J. Chem. Soc. Faraday Trans., 82, 1986, 2385.

109. G. E. Wnek, Am. Chem. Soc. Polym. Prepr., 27(1), 1986, 277.

110. L. H. C. Mattoso, Química Nova, 19, 1996, 4.

111. M. Angelopoulos, A. Ray, A. G. MacDiarmid, A. J. Epstein, Synth. Met., 21, 1987, 21.

112. A. Andereatta, Y. Cao, J. C. Chiang, A. J. Heeger, P. Smith, Synth. Met., 26, 1988, 383.

113. J. C. Chiang, A. G. MacDiarmid, Synth. Met., 13, 1986, 193.

114. S. Stafström, J. L. Bredas, A. J. Epstein, H. S. Woo, D. B. Tanner, H. S. Huang, A. G. MacDiarmid, Phys. Rev. Lett., 59, 1987, 1464.

115. E. M. Geniès, C. Tsintavis, Mol. Cryst. Liq. Cryst., 121, 1985, 181.

116. H. S. Nalwa, Handbook of Organic Conductive Molecules and Polymers, Vol 2, 1997, Capítulo 13.

117. R. N. Adams, Electrochemistry at Solid Electrodes, Marcel Dekker, 1969, New York.

118. L. R. Sharma, A. K. Manchada, G. Singh, R. Verma, Electrochim. Acta, 27, 1982, 223.

119. H. Staudinger, "From Organic Chemistry to Macromolecules: A Scientific Autobiography Based On My Original Papers", Wiley-Interscience, New York, 1970.

120. J. M. G. Cowie, "Polymers: Chemistry \& Physics of Modern Materials", Blackie Academic \& Professional, New York, 1993, Cap. 5.

121. H. Dostal, Monatsh. Chem., 69, 1936, 424.

122. F. M. Lewis, F. R. Mayo, W. F. Hulse, J. Am. Chem. Soc., 67, 1945, 1701.

123. J. A. Conklin, S.-C. Huang, S.-M. Huang, T. Wen, R. B. Kaner, Macromolecules, 28, 1995, 6522.

124. E. M. Genies, A. A. Syed, C. Tsintavis, Mol. Cryst. Liq., 121, 1985, 181. 
125. D. M. Mohilner, R. N. Adams, W. J. Argersinger Jr., J. Am. Chem. Soc., 84, 1962, 3618.

126. A. F. Diaz, J. A. Logan, J. Electroanal. Chem., 111, 1980, 111.

127. K. Koziel, M. Lapkowski, S. Lefrant, Synth. Met., 69, 1995, 217.

128. S. I. Córdoba de Torresi, Electrochim. Acta, 40, 1995, 1101.

129. J. L. Jones, J. P. Meiure, Anal. Chem., 4l, 1969, 484.

130. J. P. Meiure, J. L. Jones, Talanta, 16, 1969, 149.

131. S. Bourkane, C. Gabrielli, M. Keddam, Electrochim. Acta, 34, 1989, 1081.

132. M. Benje, M. Eiermann, U. Pitterman, K. G. Weil, Ber. Bunsen. Ges. Phys. Chem., 90, 1986, 435.

133. O. Melroy, K. K. Kanazawa, J. G. Gordon, D. A. Buttry, langmuir, 2, 1986, 697.

134. S. Bruckenstein, M. Shay, Electrochim. Acta, 30, 1985, 1295.

135. T. Nomura, M. Iijima, Anal. Chim. Acta, 131, 1981, 97.

136. C. Lu, A. Czanderna, "Applications of the Piezoeletric Quartz Crystal Microbalance Methods and Phenomena", Eds. Elsevier, New York, 1984, Vol. 7.

137. C. A. Goss, D. H. Charych, M. Majda, Anal. Chem., 63, 1991, 85.

138. D. A. Buttry, M. D. Ward, Chem. Rev., 92, 1992, 1355.

139. G. Sauerbrey, Phys., 155, 1959, 206.

140. G. Maia, R. M. Torresi, E. A. Ticianelli, F. C. Nart, J. Phys. Chem., 100, 1996, 15910.

141. R. C. D. Peres, M. -A. De Paoli, R. M. Torresi, Synth. Met., 48, 1992, 259.

142. S. Bruckenstein, A. R. Hillman, J. Phys. Chem., 92, 1988, 4837.

143. N. B. Calthup, L. H. Daly, S. E. Wiberley, "Introduction to Infrared and Raman Spectroscopy", Academic Press, 1990, 3a edição.

144. D. J. Cutler, P. J. Hendra, "Laser Raman Spectroscopy on Synthetic Polymers", J. V. Dawkins (Ed.), Developments in Polymer Characterization - 2, Applied Science, London, 1980, 71.

145. D. I. Bower, W. F. Maddams, "Vibracional Spectroscopy of Polymers", Cambridge, 1989, Cambridge University Press.

146. P. C. Painter, M. M. Coleman, J. L. Koenig, "The Theory of Vibracional Spectroscopy and its Application to Polymeric Materials", Wiley, 1982. 
147. H. W. Siesler, "Infrared and Raman Spectroscopy of Polymers", Dekker, 1980, New York.

148. C. Gabrielli, Use and applications of electrochemical impedance spectroscopy, Schlumberger Instruments, UK, 1990.

149. J. R. Macdonald, Impedance spectroscopy,Wiley, New York, 1987.

150. M. Sluyters-Rehbach, J. H. Sluyters, Comprehensive chemical kinetics, Elsevier, Amsterdam, Vol. 26, 1986, Ed. C. H. bamford, R. G. Compton, Capítulo 4.

151. M. Sluyters-Rehbach, J. H. Sluyters, Comprehensive treatise of electrochemistry, Plenum, New York, Vol. 9, 1984, Ed. E. Yeager, J. O’M. Bockris, B. E. Conway, S. Sarabgapani.

152. C. Gabrielli, The identification of electrochemical processes by frequency response analysis , Solartron Instruments, UK, 1980 .

153. D. D. Macdonald, M. C. H. McKubre, Modern aspects of electrochemistry, Plenum, New York, Vol. 14, 1982, Ed. J. O’M. Bockris, B. E. Conway, R. E. White, p 61.

154. D. D. Macdonald, Transient techniques in electrochemistry, Plenum, New York, 1977, Capítulo 7.

155. Epelboin, Comprehensive treatise of electrochemistry, Plenum, New York, Vol. 4, 1981, Ed. J. O'M. Bockris, B. E. Conway, E. Yeager, R. E. White, Capítulo 3..

156. W. I. Archer, R. D. Armstrong, Chem. Soc. Spec. Per. Reports, Electrochemistry, 7, 1980, 157.

157. R. D. Armstrong, M. F. Bell, A. A. Metcalfe, Chem. Soc. Spec. Per. reports, Electrochemistry, $6,1978,98$.

158. M. Sluyters-Rehbach, J. H. Sluyters, Electroanalytical Chemistry, Ed. A. J. Bard, Dekker, New York, Vol. 4, 1970, 1.

159. R. M. Torresi, S. I. Córdoba de Torresi, C. Gabrielli, M. Keddam, H. Takenouti, Synth. Met., $61,1993,291$.

160. S. S. Pandley, S. Annapooni, B. D. Malhotra, Macromolecules, 26, 1993, 3190.

161. J-.W. Chevalier, J-. Y. Bergeron, L. H. Dao, Macromolecules, 25, 1992, 1991.

162. A. Watanabe, K. Mori, Y. Iwasaki, Y. Nakamura, S. Niizuma, Macromolecules, 20, 1987, 1793.

163. M. S. Pinho, M. M. Gorelova, M. Dezzoti, B. G. Soares, A. J. Pertsin, J. Appl. Polym. Sci., 70, 1998, 1543.

164. J. M. Leclerc, L. H. Dao, Macromolecules, 22, 1989, 645.

165. W. S. Huang, A. G. MacDiarmid, Polymer, 34, 1993, 1833. 
166. H. Varela, R. M. Torresi, J. Electrochem. Soc., 147, 2000, 665.

167. H. Varela, M. Malta, R. M. Torresi, Química Nova, 23 (5), 2000, 664.

168. D. E. Stilwell, S. M. Park, J. Electrochem. Soc., 136, 1989, 427.

169. S. I. Córdoba de Torresi, A. N. Bassetto, B. C. Trasferetti, J. Solid State Electrochem., 2, 1998, 24.

170. K. Berrada, Tese de Doutorado - “Étude Par Diffusion Raman 'in-situ' De La Polyaniline Et De La Poly(o Toluidine): Effet Du Milieu Électrolytique Sur L'Oxydation Et La. Protonation", Universidade de Nantes, 1995, 137. 